AUTARQUIA ASSOCIADA À UNIVERSIDADE DE SÃO PAULO

ANÁLISE NEUTRÔNICA E ESPECIFICAÇÃO TÉCNICA PARA O COMBUSTÍVEL A DISPERSÃO UMO-AI COM ADIÇÃO DE VENENO QUEIMÁVEL

Rafael Oliveira Rondon Muniz

Tese apresentada como parte dos requisitos para obtenção do Grau de Doutor em Ciências na Área de Tecnologia Nuclear - Reatores

Orientador:

Prof. Dr. Antonio Teixeira e Silva

Coorientador:

Prof. Dr. Adimir dos Santos 



\section{INSTITUTO DE PESQUISAS ENERGÉTICAS E NUCLEARES}

Autarquia associada à Universidade de São Paulo

\section{ANÁLISE NEUTRÔNICA E ESPECIFICAÇÃO TÉCNICA PARA O COMBUSTÍVEL A DISPERSÃO UMO-AI COM ADIÇÃO DE VENENO QUEIMÁVEL}

Rafael Oliveira Rondon Muniz

Tese apresentada como parte dos
requisitos para obtenção do Grau de
$\begin{aligned} & \text { Doutor em Ciências na Área } \\ & \text { de Tecnologia Nuclear - Reatores }\end{aligned}$
Orientador:
Prof. Dr. Antonio Teixeira e Silva
Coorientador:
Prof. Dr. Adimir dos Santos

Versão Corrigida

Versão Original disponível no IPEN

São Paulo

2015 
Em memória de minha avó Palmira Gomes Muniz 


\section{Agradecimentos}

Aos meus pais Wanderley Gomes Muniz e Cecília Rogato Rondon pelo incentivo sem o qual não conseguiria realizar este trabalho;

À minha noiva Aurélia Miranda dos Santos pelo apoio e incentivo;

À minha irmã Rafaela Rogato Rondon Silva pelo apoio;

À minha avó Palmira Gomes Muniz;

Ao meu orientador Dr. Antonio Teixeira e Silva pela ajuda e atenção para a realização deste trabalho;

Ao meu coorientador Dr. Adimir dos Santos por toda dedicação e orientação em todas as etapas deste trabalho, os meus sinceros agradecimentos;

Ao Dr. Douglas Borges Domingos por toda ajuda e apoio nas simulações, revisão do trabalho e utilização do LATEX;

Ao Dr. Pedro Carlos Russo Rossi por toda ajuda nas simulações com os programas SERPENT e MCNP-5;

Ao Dr. Luís Liambos Mura pela ajuda na análise dos resultados da irradiação das miniplacas e revisão do trabalho;

Ao Msc. Mitsuo Yamaguchi pela ajuda com o programa CITATION;

À Dra. Leda Cristina Cabelo Bernardes Fanaro pela ajuda com os dados do programa CITATION;

Ao Hugo Rodrigues Landim pelo projeto do irradiador e ajuda na irradiação das miniplacas;

Ao Rogério Jerez pela ajuda na irradiação das miniplacas;

Ao Msc. Rinaldo Fuga pelas operações do reator IPEN/MB-01 para irradiação das miniplacas; 
A todos os funcionários do reator IPEN/MB-01 que direta ou indiretamente ajudaram na irradiação das miniplcas;

Ao Dr. Michelangelo Durazzo pela ajuda na especificação técnica e fabricação das miniplacas;

A todos os funcionários do Centro do Combustível Nuclear do IPEN/CNEN-SP que direta ou indiretamente ajudaram na fabricação das miniplacas;

Aos colegas: Dr. Gabriel Ângelo, Dr. Felipe Massicano, Msc. Gregório Soares de Souza e Thiago Garcia João;

À CAPES pelo apoio financeiro. 


\title{
ANÁLISE NEUTRÔNICA E ESPECIFICAÇÃO TÉCNICA PARA O COMBUSTÍVEL A DISPERSÃO UMo-Al COM ADIÇÃO DE VENENO QUEIMÁVEL
}

\author{
Rafael Oliveira Rondon Muniz
}

\begin{abstract}
Resumo
Este trabalho apresenta a análise neutrônica do combustível a dispersão de UMo-Al em relação ao aumento da densidade de urânio e faz uma comparação com o combustível de $\mathrm{U}_{3} \mathrm{Si}_{2}$-Al. Neste estudo, a densidade de urânio do $\mathrm{U}_{3} \mathrm{Si}_{2}$ - $\mathrm{Al}$ é variada de 3,0 à $5,5 \mathrm{gU} / \mathrm{cm}^{3}$ e a do UMo-Al entre 4,0 à $7,5 \mathrm{gU} / \mathrm{cm}^{3}$ e com a porcentagem em massa de molibdênio com 7 e $10 \%$. Neste trabalho também é proposta a aplicação de veneno queimável metálico no cerne do combustível de UMo-Al, uma vez que este combustível é metálico e é analisada a utilização de gadolínio $(\mathrm{Gd})$ e európio $(\mathrm{Eu})$ como veneno queimável. A utilização do $\mathrm{Gd}$ como veneno queimável foi analisada com o fator de multiplicação infinito $\left(\mathrm{k}_{\infty}\right)$ através do programa celular HRC desenvolvido pelo IPEN e composto pelos códigos HAMMERTECHNION para a analise de célula, ROLAIDS para o cálculo de auto blindagem dos actinídeos e CINDER-2 empregado para a fissão e transmutação dos actinídeos. O núcleo do reator simulado foi similar ao do RMB (Reator Multipropósito Brasileiro) composto por um arranjo de 5x5 posições com 23 elementos combustíveis e dois blocos de alumínio. Para o európio, foram utilizados os programas SERPENT e CITATION. Os cálculos de queima foram realizados considerando uma potência de $30 \mathrm{MW}$ durante três ciclos do RMB de 97 dias. Os resultados obtidos mostram que a porcentagem em massa do molibdênio têm uma grande influência no comportamento neutrônico devido a seção de choque de absorção do molibdênio ser considerável. Portanto, foi escolhida a porcentagem de $7 \%$ de Mo para os estudos com veneno queimável. Para o núcleo proposto, o európio mostrou-se melhor, pois apresenta uma queima mais gradual que o gadolínio. Foi realizada uma simulação com o programa SERPENT com adição de $6 \%$ de silício, o que mostrou que a adição de Si não causa mudança significativa no ciclo de operação do reator. Para validação da metodologia de cálculo, foi elaborada uma especificação técnica e fabricadas 12 miniplacas combustíveis de UMo-Al sem veneno queimável. As miniplacas foram irradiadas no núcleo do reator IPEN/MB-01, em quatro configurações de núcleo, para obtenção da reatividade inserida.
\end{abstract}


Os resultados simulados obtidos para a inserção de reatividade pelas miniplacas nos diversos núcleos analisados apresentaram alta concordância com os resultados experimentais. 


\title{
NEUTRONIC ANALYSIS AND TECHNICAL SPECIFICATION FOR A UMo-Al DISPERSION FUEL WITH BURNABLE POISON ADDITION
}

\author{
Rafael Oliveira Rondon Muniz
}

\begin{abstract}
This work presents the neutronic analysis of the UMo-Al dispersion fuel concerning uranium density increase and shows comparisons relatively to the $\mathrm{U}_{3} \mathrm{Si}_{2}-\mathrm{Al}$ fuel. The $\mathrm{U}_{3} \mathrm{Si}_{2}-\mathrm{Al}$ uranium density varied from 3.0 to $5.5 \mathrm{gU} / \mathrm{cm}^{3}$ while that of UMo-Al fuel varied from 4.0 to $7.5 \mathrm{gU} / \mathrm{cm}^{3}$. The molybdenum mass content in the former case varies from 7 to $10 \%$ in mass. Here, it is also proposed the utilization of burnable poison nuclides in the UMo-Al fuel meat. Since the fuel is metallic, gadolinium and europium were chosen as candidates to cope with this task. A recently developed cell code at IPEN (HRC) composed of the coupling of the codes HAMMER-TECHNION for the cell analysis, ROLAIDS for the actinide self-shielding calculations and CINDER-2 for the actinide and fission transmutation was employed for the neutronic analyses of UMo-Al. The simulated reactor core was similar to the one of RMB (Brazilian Multipurpose Reactor) composed of an array of $5 \times 5$ positions with 23 fuel elements and 2 aluminum blocks. A second analysis of the europium case employed the SERPENTE and CITATION codes. The burnup calculations were performed considering a power of $30 \mathrm{MW}$ during three cycles of RMB 97 days. The analyses revealed that the molybdenum content has a great impact in the core reactivity due to its high absorption cross section. A value of $7 \%$ was found adequate for the molybdenum mass content. The analyses also reveal that europium is a better burnable poison than gadolinium for the core cycle length and power level under consideration. It was realized a simulation with the computer code SERPENT with addition of $6 \%$ silicon in UMo-Al fuel. The silicon does not change significantly the reactor operation cycle. To validate the calculation methodology it was developed a technical specification and fabricated 12 UMo-Al fuel miniplates without burnable poison. The miniplates were irradiated in the IPEN-MB/01 reactor core for four core configurations, in order to obtain the inserted reactivity. The simulated results for the reactivity insertion by the fuel miniplates in the analyzed cores showed high agreement with the experimental results.
\end{abstract}




\section{Lista de Figuras}

2.1 Densidade de urânio em função da fração volumétrica. . . . . . . . . . . . 18

2.2 Seção de choque de absorção de nêutrons do molibdênio e do silício. . . . . 21

2.3 Seções de choque total e (n, gama) para ${ }^{152} \mathrm{Gd}$. . . . . . . . . . . . . . 26

2.4 Seções de choque total e (n, gama) para ${ }^{153} \mathrm{Gd} \ldots \ldots$. . . . . . . . . . . 26

2.5 Seções de choque total e (n, gama) para ${ }^{154} \mathrm{Gd}$. . . . . . . . . . . . . . 27

2.6 Seções de choque total e (n, gama) para ${ }^{155} \mathrm{Gd}$. . . . . . . . . . . . . . 27

2.7 Seções de choque total e (n, gama) para ${ }^{156} \mathrm{Gd}$. . . . . . . . . . . . . 28

2.8 Seções de choque total e (n, gama) para ${ }^{157} \mathrm{Gd}$. . . . . . . . . . . . . . 28

2.9 Seções de choque total e (n, gama) para ${ }^{158} \mathrm{Gd}$. . . . . . . . . . . . . . . 29

2.10 Seções de choque total e (n, gama) para ${ }^{160} \mathrm{Gd}$. . . . . . . . . . . . . . . 29

2.11 Seções de choque total e (n, gama) para ${ }^{151} \mathrm{Eu}$. . . . . . . . . . . . . . 31

2.12 Seções de choque total e (n, gama) para ${ }^{152} \mathrm{Eu}$. . . . . . . . . . . . . . . 31

2.13 Seções de choque total e (n, gama) para ${ }^{153} \mathrm{Eu}$. . . . . . . . . . . . . . . 32

2.14 Seções de choque total e (n, gama) para ${ }^{154} \mathrm{Eu}$. . . . . . . . . . . . . . . . 32

2.15 Seções de choque total e (n, gama) para ${ }^{155} \mathrm{Eu}$. . . . . . . . . . . . . 33

2.16 Seções de choque total e (n, gama) para ${ }^{156} \mathrm{Eu}$. . . . . . . . . . . . . 33

2.17 Seções de choque total e (n, gama) para ${ }^{157} \mathrm{Eu}$. . . . . . . . . . . . . . . 34

3.1 Núcleo do reator (vista superior) . . . . . . . . . . . . . . . 35

3.2 Elemento Combustível (plano XY), visão da parte superior do elemento combustível. . . . . . . . . . . . . . . . . . . 36

3.3 Elemento combustível composto por quatro regiões ao longo do eixo axial - z. 37

3.4 Dimensões das miniplacas combustíveis. . . . . . . . . . . . . . . . . . 40 
3.5 Doze miniplacas combustíveis fabricadas. . . . . . . . . . . . . . . 41

3.6 Projeto do irradiador de acrílico. . . . . . . . . . . . . . . . . . 43

3.7 Irradiador de acrílico para as miniplacas combustíveis. . . . . . . . . . . . 44

3.8 Núcleo padrão $(28 \times 26)$ sem 16 varetas central. . . . . . . . . . . . . . . 45

3.9 Núcleo do reator com o irradiador de acrílico (visão radial). . . . . . . . . . 46

3.10 Núcleo do reator com o irradiador de acrílico (visão axial) . . . . . . . . . . 47

3.11 Núcleo do reator com o irradiador de acrílico e miniplacas combustíveis. . 48

3.12 Núcleo do reator modificado com o irradiador de acrílico e miniplacas combustíveis. . . . . . . . . . . . . . . . . . . . . . . . 49

4.1 Comparação entre o $\mathrm{U}_{3} \mathrm{Si}_{2}-\mathrm{Al}$ e UMo-Al com a variação da densidade de urânio. . . . . . . . . . . . . . . . . . . 50 50

4.2 Fator $\eta$ da fórmula dos quatro fatores. . . . . . . . . . . . . . . 52

4.3 Fator $\varepsilon$ da fórmula dos quatro fatores. . . . . . . . . . . . . . . 52

4.4 Fator $p$ da fórmula dos quatro fatores. . . . . . . . . . . . . . . 53

4.5 Fator $f$ da fórmula dos quatro fatores. . . . . . . . . . . . . . . 53

4.6 Comparação entre a queima do combustível $\mathrm{U}_{3} \mathrm{Si}_{2}-\mathrm{Al}$ e do U7wt\%Mo-Al. . 54

4.7 Comparação entre a queima do combustível $\mathrm{U}_{3} \mathrm{Si}_{2}-\mathrm{Al}$ e do U10wt\%Mo-Al. 55

4.8 Comparação entre a conversão do ${ }^{239} \mathrm{Pu}$ no combustível $\mathrm{U}_{3} \mathrm{Si}_{2}$-Al e no U7wt\%Mo-

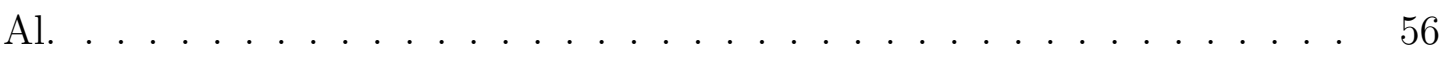

4.9 Simulações com o programa HRC com a variação Gd entre 0 (sem Gd) a $0,10 \%$ em massa. . . . . . . . . . . . . . . . . . . . 57

4.10 Simulações com o CITATION com a variação de Eu entre 0 a 0,30\% em massa. . . . . . . . . . . . . . . . . . 58

4.11 Valores de k para U7wt\%Mo-Al com 3,55 gU/ $\mathrm{cm}^{3}$ e $0,25 \%$ de Eu. . . . . . 60

4.12 Reatividade para U7wt\%Mo-Al com 3,55 gU/ $\mathrm{cm}^{3}$ e $0,25 \%$ de $\mathrm{Eu}$. . . . . 62

4.13 Concentração total em átomo/b.cm para o ${ }^{235} \mathrm{U}$ ao longo da queima. . . . . 63

4.14 Concentração total em átomo/b.cm para o ${ }^{238} \mathrm{U}$ e ${ }^{239} \mathrm{Pu}$ ao longo da queima. 64

4.15 Concentração total em átomo/b.cm para o ${ }^{151} \mathrm{Eu}$ e ${ }^{152} \mathrm{Eu}$ ao longo da queima. 64

4.16 Concentração total em átomo/b.cm para o ${ }^{153} \mathrm{Eu} \mathrm{e}{ }^{154} \mathrm{Eu}$ ao longo da queima. 65

4.17 Concentração total em átomo/b.cm para o ${ }^{155} \mathrm{Eu}$ e ${ }^{156} \mathrm{Eu}$ ao longo da queima. 66

4.18 Comparação do ciclo sem veneno queimável e com európio. . . . . . . . . . 66 
4.19 Comparação da queima com e sem adição de silício . . . . . . . . . . . . . 69

4.20 Detalhe de duas regiões de medida do reatímetro. . . . . . . . . . . 71

4.21 Reatímetro ao londo de toda medida - terceira configuração. . . . . . . . . 72

A.1 Projeto do conjunto inteiro do irradiador de acrílico. . . . . . . . . 78

A.2 Detalhe do suporte das miniplacas, parte superior do irradiador. . . . . . . 79

A.3 Detalhe do suporte do irradiador, parte inferior do irradiador. . . . . . . . 80 


\section{Lista de Tabelas}

2.1 Elementos possíveis para veneno queimável. . . . . . . . . . . . . . . . 24

2.2 Porcentagem isotópica natural do gadolínio. . . . . . . . . . . . . . 25

2.3 Porcentagem isotópica natural európio. . . . . . . . . . . . . . . . 30

3.1 Granulometria das partículas de UMo. . . . . . . . . . . . . . . . 39

3.2 Dimensões da minipla combustível U7wt\%Mo-Al. . . . . . . . . . . . . . . 40

3.3 Massas das miniplacas combustíveis . . . . . . . . . . . . . . . . . 42

4.1 Valores de k para U7wt\%Mo-Al com 3,55 gU/ $\mathrm{cm}^{3}$ e 0,25\% de Eu. . . . . . 59

4.2 Reatividade para U7wt\%Mo-Al com 3,55 gU/ $\mathrm{cm}^{3}$ e 0,25\% de Eu. . . . . 61

4.3 Variação da reatividade com o aumento da temperatura. . . . . . . . . . . 67

4.4 Comparação entre a queima com e sem silício. . . . . . . . . . . . . . . 68

4.5 Simulações das operações de irradiação das miniplacas. . . . . . . . . . . . 70

4.6 Simulação da reatividade inserida pelo irradiador e miniplacas. . . . . . . . 70

4.7 Segunda operação criticalidade inserida pelo irradiador. . . . . . . . . . . . 71

4.8 Retirada da Barra BC\#1 . . . . . . . . . . . . . . . . . . . . 73

4.9 Retirada da Barra BC\#2 . . . . . . . . . . . . . 73

4.10 Quarta configuração núcleo modificado. . . . . . . . . . . . . . . . . 74

4.11 Resultados das simulações e experimentos. . . . . . . . . . . . . . . . 74 


\section{Sumário}

1. Introdução . . . . . . . . . . . . . . . . . . . . . . . . . . . 14

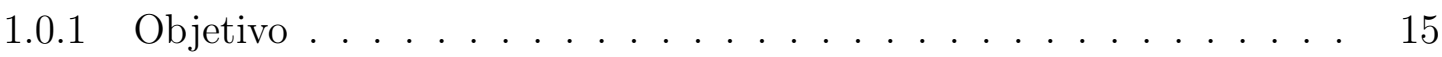

1.0.2 Aspectos Relevantes e Originalidade. . . . . . . . . . . . 15

1.0.3 Organização do Conteúdo . . . . . . . . . . . . . . . . . 16

2. Revisão Bibliográfica . . . . . . . . . . . . . . . . . . . . . . . . 17

2.1 Restrição ao Alto Enriquecimento de Urânio . . . . . . . . . . . . . . . . 17

2.2 A liga Urânio - Molibdênio . . . . . . . . . . . . . . . . . . . 20

2.3 Descrição dos Reatores de Pesquisa Similares ao RMB . . . . . . . . . . . 22

2.4 Veneno Queimável . . . . . . . . . . . . . . . . . . . . . . . 23

2.4 .1 Gadolínio . . . . . . . . . . . . . . . 25

2.4.2 Európio . . . . . . . . . . . . . . . . . . . . . 30

3. Metodologia para Análise Neutrônica do Combustível UMo-Al com Adição de Veneno Queimável . . . . . . . . . . . . . . . . . . . . . . 35

3.1 Descrição Do Reator Para Estudo . . . . . . . . . . . . . . . . . . 35

3.2 Códigos Computacionais . . . . . . . . . . . . . . . . . . 37

3.3 Parâmetros Para a Fabricação das Miniplacas . . . . . . . . . . . . . . . . 38

3.3.1 Conteúdo de Urânio e Molibdênio . . . . . . . . . . . . . . . . . . . 38

3.3 .2 Concentração Isotópica . . . . . . . . . . . . . . . . . . . 38

3.3.3 Diâmetro da Partícula Combustível . . . . . . . . . . . . . . . . . 38

3.3.4 Massa Específica . . . . . . . . . . . . . . . . . . . . . . 39

3.3.5 Dimensões da Miniplaca Combustível . . . . . . . . . . . . . . . . . 39 
3.3.6 Miniplacas Combustíveis Fabricadas . . . . . . . . . . . . 41

3.4 Irradiador de Acrílico . . . . . . . . . . . . . . . . . . . . . 42

3.5 Irradiação das Miniplacas . . . . . . . . . . . . . . . . . . 44

4. Resultados e Análise . . . . . . . . . . . . . . . . . . . . . . . 50

4.0.1 Variação da Densidade de Urânio . . . . . . . . . . . . . . . 50

4.0.2 Veneno Queimável . . . . . . . . . . . . . . . . . 56

4.0.3 Gadolínio . . . . . . . . . . . . . . . . . 56

4.0 .4 Európio . . . . . . . . . . . . . . . . . 57

4.0.5 Ciclo de Operação . . . . . . . . . . . . . . . . . 62

4.0.6 Variação de Temperatura . . . . . . . . . . . . . . . . . . . 67

4.0 .7 Adição de Silício . . . . . . . . . . . . . . . . . . . 67

4.0 .8 Resultados Irradiação das Miniplacas . . . . . . . . . . . . . . 69

4.0.9 Comparação Entre os Resultados Simulados E Experimentais . . . . 74

5. Conclusões. . . . . . . . . . . . . . . . . . . . . . . 75

6. Trabalhos Futuros . . . . . . . . . . . . . . . . 76

$\begin{array}{ll}\text { Apêndice } & 77\end{array}$

A. Irradiador De Acrílico . . . . . . . . . . . . . . . . . . . 78

B. Dados De Entrada Do MCNP-5 Configuração 3 . . . . . . . . . . . . . . . . . . 83

C. Dados De Entrada Do MCNP-5 Configuração 4 . . . . . . . . . . . . . . . . . . 96

D. Dados De Entrada Do CITATION . . . . . . . . . . . . . . . . . . . . 110

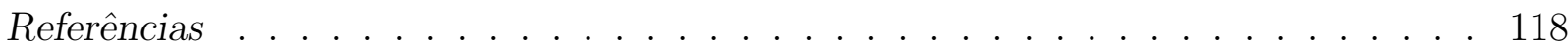


Capítulo 1

\section{Introdução}

Com as restrições impostas ao comércio e utilização de combustíveis nucleares com urânio altamente enriquecido (maior que $20 \%$ de ${ }^{235} \mathrm{U}$ ) os estudos na área de combustíveis nucleares voltaram-se para materiais que permitissem uma maior densidade de urânio no combustível, para compensar o baixo enriquecimento. Esses novos materiais, com isso, permitiriam a conversão dos reatores de pesquisa que utilizam combustíveis com alto enriquecimento (HEU - "High Enriched Uranium") para combustíveis de baixo enriquecimento (LEU - "Low Enriched Uranium"), sem alteração no projeto e finalidade destes reatores.

Em 1987, foram apresentados trabalhos que deram como qualificadas as dispersões $\mathrm{UAl}_{x}-\mathrm{Al}, \mathrm{U}_{3} \mathrm{O}_{8}-\mathrm{Al}$ e o $\mathrm{U}_{3} \mathrm{Si}_{2}-\mathrm{Al}$ com densidades, respectivamente, de $2,3 \mathrm{gU} / \mathrm{cm}^{3}$ (45\% em volume), $3,2 \mathrm{gU} / \mathrm{cm}^{3}$ (45\% em volume) e 4,8 gU/ $\mathrm{cm}^{3}$ (42,5\% em volume).

Destes combustíveis, o que permite maior densidade de urânio é o $\mathrm{U}_{3} \mathrm{Si}_{2}-\mathrm{Al}\left(4,8 \mathrm{gU} / \mathrm{cm}^{3}\right)$. Mesmo com este combustível, não foi possível converter para baixo enriquecimento os combustíveis dos reatores de pesquisa que possuem alta potência.

As pesquisas atualmente apontam que a liga mais promissora, que permite maior densidade de urânio, é a liga de urânio-molibdênio (UMo). Esta liga pode chegar a uma densidade de urânio de $8 \mathrm{gU} / \mathrm{cm}^{3}$ na fase dispersa e $16 \mathrm{gU} / \mathrm{cm}^{3}$ na forma monolítica.

O urânio-molibdênio é uma liga metálica que permite a adição de um elemento diretamente no combustível nuclear com a função de veneno queimável.

A possibilidade do combustível de UMo-Al se tornar um padrão para reatores de pesquisa, como o $\mathrm{U}_{3} \mathrm{Si}_{2}$-Al é hoje, tem motivado os pesquisadores do IPEN/CNEN-SP a desenvolver pesquisas com este combustível.

No Brasil, está em desenvolvimento o Reator Multipropósito Brasileiro (RMB), em fase 
de projeto de detalhamento, que irá utilizar como combustível o $\mathrm{U}_{3} \mathrm{Si}_{2}-\mathrm{Al}$ e como veneno queimável fios de cádmio fixados no elemento combustível.

\subsubsection{Objetivo}

Esta tese tem como objetivo avaliar a aplicação do combustível UMo-Al em um núcleo análogo ao do RMB com a utilização de veneno queimável. Será analisado, através de simulações, o comportamento neutrônico do combustível UMo-Al com o aumento da densidade de urânio e com as porcentagens em massa de 7\% e 10\% de molibdênio e comparado com o comportamento neutrônico do combustível de $\mathrm{U}_{3} \mathrm{Si}_{2}$-Al. Os programas HAMMER, ROLAIDS e CINDER (HRC) serão aplicados nesta analise.

Com relação ao veneno queimável, é avaliada a utilização do gadolínio e do európio no ciclo de operação de um reator análogo ao RMB. A aplicação do gadolínio é analisada com o programa HRC e a do európio com o programa CITATION.

Também, será elaborada uma especificação técnica de fabricação para miniplacas combustíveis de UMo-Al, sem veneno queimável, com a densidade de $4 \mathrm{gU} / \mathrm{cm}^{3}$. As miniplacas fabricadas a partir dessa especificação serão irradiadas no núcleo do reator IPEN/MB-01 e permitirão verificar a inserção de reatividade inserida no núcleo do reator e a sua comparação com simulações computacionais efetuadas para as mesmas configurações utilizadas no núcleo.

\subsubsection{Aspectos Relevantes e Originalidade}

A metodologia utilizada neste trabalho mostra que, do ponto de vista neutrônico, será possível utilizar veneno queimável aplicado diretamente no cerne do combustível de UMoAl para o RMB. A utilização de veneno queimável distribuído homogeneamente no interior do combustível poderá facilitar a fabricação do elemento combustível do RMB.

A irradiação de miniplacas combustíveis do tipo UMo-Al nunca foi realizada no Brasil. A qualificação da metodologia de cálculo para o combustível UMo-Al com adição de veneno queimável dará aval para a fabricação futura de miniplacas com veneno queimável para testes e utilização em reatores de pesquisa. 


\subsubsection{Organização do Conteúdo}

O capítulo 2 apresenta a revisão bibliográfica relativa ao desenvolvimento de combustíveis nucleares devido as restrições ao alto enriquecimento de urânio e uma breve descrição da liga de urânio-molibdênio, de reatores de pesquisa similares à proposta do RMB, dos venenos queimáveis que podem ser adicionados à liga e as seções de choque total e de captura radiativa do gadolínio e európio. O capítulo 3 apresenta a metodologia utilizada com a descrição do reator simulado, os códigos computacionais utilizados, os parâmetros mais importantes para a fabricação das miniplacas utilizadas para irradiação no reator IPEN-MB/01 e o projeto do irradiador. Também, neste capítulo, são apresentadas as configurações utilizadas no núcleo do reator IPEN/MB-01 para a irradiação das miniplacas. No capítulo 4, são apresentados os resultados obtidos das simulações e das irradiações das miniplacas. O capítulo 5 apresenta as conclusões do trabalho. O capítulo 6 apresenta sugestões de trabalhos futuros baseados nos resultados encontrados nesta tese. 
Capítulo 2

\section{Revisão Bibliográfica}

\subsection{Restrição ao Alto Enriquecimento de Urânio}

Em meados dos anos cinquenta, com as restrições impostas ao comércio e utilização de combustíveis com urânio altamente enriquecido, a "Atomic Energy Commission" dos Estados Unidos requisitou ao "Oak Ridge National Laboratory" (ORNL) a construção de um reator tipo piscina utilizando elementos combustíveis tipo placa com baixo enriquecimento em ${ }^{235} \mathrm{U}$ (menor que $20 \%$ em peso de ${ }^{235} \mathrm{U}$ - "Low Enriched Uranium - LEU"). Este reator deveria ser apresentado na Conferência de Genebra em agosto de 1955. Devido ao pouco tempo disponível, tornou-se impossível realizar grandes modificações no projeto do combustível, uma vez que a tecnologia existente estava voltada para a fabricação de combustíveis com alto enriquecimento. Sendo assim, o ORNL optou simplesmente por aumentar por um fator de 5 a quantidade de urânio em cada placa (conservando as demais variáveis de projeto). Desta forma, ele garantia que a reatividade do núcleo do reator não se alteraria devido à redução do enriquecimento.

As ligas de Urânio - Alumínio (UAl), que vinham sendo utilizadas em reatores de teste de materiais com 10 a $20 \%$ em peso de urânio, passaram a ter entre 45 e $50 \%$ em peso deste material. Entretanto, já nas etapas de fabricação, as placas combustíveis fabricadas com altas concentrações de urânio apresentaram problemas de fragilidade e de falta de homogeneidade da composição, tornando inviável a sua utilização /1/.

Para contornar este problema, os pesquisadores da época iniciaram a busca de materiais com maiores massas específicas de urânio, de forma a reduzir a concentração em peso (e ou volume) das placas fabricadas. Dentre os materiais pesquisados, o $\mathrm{UAl}_{x}$, o $\mathrm{U}_{3} \mathrm{O}_{8}, \mathrm{o}_{3} \mathrm{Si}_{2}$ e o $\mathrm{U}_{6} \mathrm{Fe}$ apresentaram-se como os mais promissores a possíveis utilizações. $\mathrm{O}_{3} \mathrm{Si}_{2}$ era o 
mais viável, devido a sua maior massa específica e o $\mathrm{U}_{6} \mathrm{Fe}$ não se mostrou adequado.

Além de novos materiais, novas técnicas de fabricação tiveram que ser desenvolvidas, surgindo os combustíveis a dispersão, onde um composto de urânio é disperso homogeneamente em alumínio, fabricados pela técnica da metalurgia do pó, uma vez que era impossível combinar os novos materiais em uma liga. Através desta técnica de fabricação pode-se obter, além de uma distribuição homogênea da fase físsil, concentrações que não comprometessem as etapas de fabricação subsequentes. Entretanto, para garantir a integridade mecânica das placas, a concentração em volume da fase dispersa deveria ser limitada em $45 \%$ em volume $/ 2 /$.

A Figura 2.1 mostra a relação da densidade de urânio com a fração volumétrica, para os principais compostos de urânio usados como combustível. A linha tracejada na vertical mostra a fração volumétrica máxima para combustíveis a dispersão.

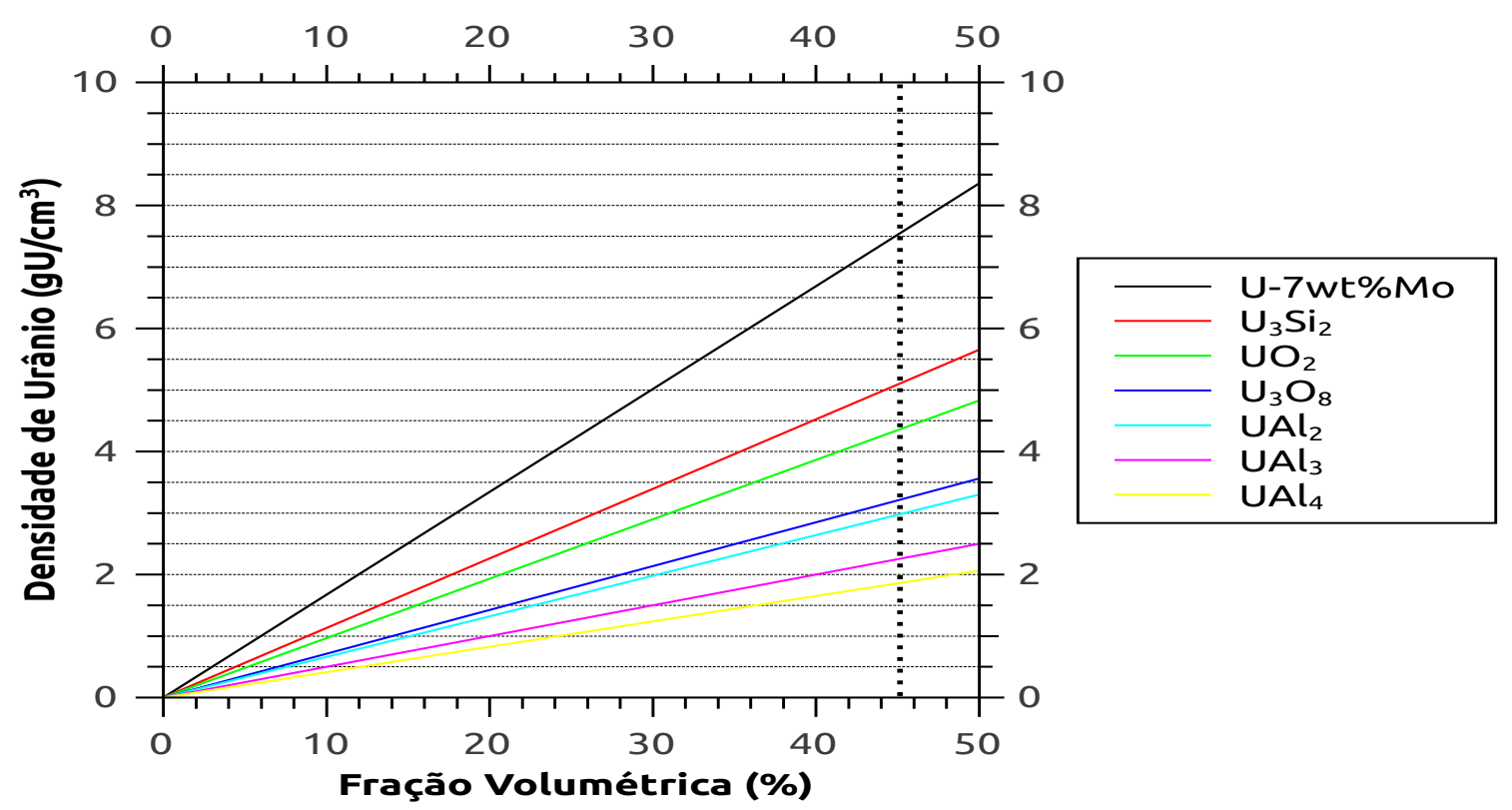

Figura 2.1: Densidade de urânio em função da fração volumétrica.

No final dos anos setenta, um grupo de trabalho selecionado pelo International Atomic Energy Agency (IAEA) dentro da estrutura do International Nuclear Fuel Cycle Evaluation (INFCE) começou a investigar a possibilidade de utilização da energia nuclear para fins pacíficos com a simultânea minimização do risco de proliferação de armas nucleares. A partir destas investigações, concluiu-se que o risco de proliferação de armas nucleares 
poderia ser minimizado com a conversão dos núcleos de Material Test Reactor (MTR) de High Enriched Uranium (HEU - 93\% em peso de ${ }^{235} \mathrm{U}$ ) para Low Enriched Uranium (LEU - $20 \%$ em peso de ${ }^{235} \mathrm{U}$ ). Sendo assim, países detentores da tecnologia nuclear (em particular, Estados Unidos, Canadá, Alemanha, França e Argentina) iniciaram programas de desenvolvimento de combustíveis com baixo enriquecimento em ${ }^{235} \mathrm{U}$ com o intuito de realizar posteriormente a conversão de seus reatores (Programa RERTR - Reduced Enrichment Research and Test Reactor) /3/.

Em 1987, no congresso intitulado "International Meeting on Reduced Enrichment for Research and Test Reactor" realizado em Buenos Aires, Argentina, foram apresentados trabalhos que deram como qualificadas as dispersões $\mathrm{UAl}_{x}-\mathrm{Al}, \mathrm{U}_{3} \mathrm{O}_{8}-\mathrm{Al}$ e o $\mathrm{U}_{3} \mathrm{Si}_{2}-\mathrm{Al}$ com densidades, respectivamente, de $2,3 \mathrm{gU} / \mathrm{cm}^{3}$ (45\% em volume), $3,2 \mathrm{gU} / \mathrm{cm}^{3}$ (45\% em volume) e $4,8 \mathrm{gU} / \mathrm{cm}^{3}$ (42,5\% em volume), devido ao bom desempenho apresentado pelas mesmas nos testes realizados $/ 4 /$.

O combustível usado no Reator IEA-R1, o reator de pesquisa de maior potência do país, é formado por placas combustíveis com núcleos de dispersão e revestidas com alumínio.

Até 1981, os elementos combustíveis do Reator IEA-R1 eram do tipo MTR consistindo de ligas de $\mathrm{UAl}$ enriquecidas a $93,15 \%$ em peso de ${ }^{235} \mathrm{U}$ e, atualmente, é composto por combustível do tipo $\mathrm{LEU}$ de $\mathrm{U}_{3} \mathrm{Si}_{2}-\mathrm{Al}$ com baixo enriquecimento e pode operar a uma potência de até 5MW /5/. Tal combustível é hoje produzido no Brasil com tecnologia totalmente nacional, resultado de um esforço conjunto do Centro de Engenharia Nuclear e do Centro do Combustível Nuclear ambos do IPEN/CNEN-SP em resposta à dificuldade de adquirir esse combustível no mercado internacional na primeira metade da década de 80 e à decisão de aumentar a potência e o regime de operação do reator IEA-R1 para fazer frente à necessidade de aumentar a produção de radioisótopos.

Um novo reator produtor de radioisótopos, o Reator Multipropósito Brasileiro (RMB) com potência e fluxo neutrônico compatíveis com as necessidades brasileiras, já vem a algum tempo sendo discutido pela comunidade médica e científica e pela Comissão Nacional de Energia Nuclear - CNEN, sendo considerada prioritária e inadiável a sua conclusão. Para este projeto, um novo tipo de combustível que permita uma flexibilização no ciclo do combustível e no veneno queimável utilizado é de grande interesse.

Um combustível que possa permitir uma maior densidade de urânio é importante para 
a vida útil do combustível. Quanto maior for a concentração de urânio no mesmo, maior será seu ciclo de queima, ou seja, sua vida útil operando no núcleo do reator, diminuindo o consumo de elementos combustíveis e resultando na geração de uma menor quantidade de combustível exaurido, ou queimado, além de simplificar o projeto como um todo, sob o ponto de vista de fabricação do combustível e de impacto ambiental.

As pesquisas mundiais apontam para a substituição da tecnologia do siliceto de urânio pela tecnologia da liga Urânio - Molibdênio (considerado o combustível do futuro), tanto pela dificuldade observada no reprocessamento do combustível queimado de siliceto de urânio, quanto pela alta concentração de urânio que pode ser atingida com o uso do combustível urânio-molibdênio.

\subsection{A liga Urânio - Molibdênio}

As ligas de urânio que se mostraram promissoras, em termos de comportamento sob irradiação, são as que podem ser mantidas na sua estrutura cristalina cúbica (fase $\gamma$ ). Ligas com tendência de formar esta fase gama são: UCr, UMo, UNb, URe, URu, UTi, UV, UZr, etc. Entre estas, a liga que apresenta uma ampla extensão de fase gama é a liga UMo. Além disso, o Mo tem uma seção de choque de absorção relativamente baixa /6/. A liga UMo é atualmente a liga estudada para ser o combustível dos reatores nucleares de pesquisa no futuro.

A liga de UMo é obtida pela fusão do urânio com o molibdênio, obtendo-se um lingote de U-Mo. As ligas de urânio-molibdênio geralmente estudadas utilizam uma porcentagem em peso de molibdênio de $7 \%$ (U7wt\%Mo) ou 10\% (U10wt\%Mo).

Das técnicas para se obter o pó de UMo, o Brasil possui a técnica de hidretaçãodehidretação $/ 7 /$.

Entre as vantagens de se utilizar esta liga como combustível nuclear destacam-se: permitir utilizar maior densidade de urânio em relação aos combustíveis atuais $\left(\mathrm{U}_{3} \mathrm{O}_{8}-\mathrm{Al}\right.$ e $\mathrm{U}_{3} \mathrm{Si}_{2}-\mathrm{Al}$ ), possuir melhor eficiência no reprocessamento do combustível e poder ser fabricado tanto como combustível a dispersão (utilizando pó de UMo-Al) como no formato de uma lâmina de UMo (conhecido como Monolítico) /8/.

A variação da porcentagem do molibdênio (Mo) muda o comportamento neutrônico do combustível, uma vez que a absorção de nêutrons pelo Mo é considerável. A Figura 2.2 
mostra a comparação entre a seção de choque de absorção do Mo e do silício ( $\mathrm{Si}$ ) /9/. O silício é a base do combustível nuclear $\left(\mathrm{U}_{3} \mathrm{Si}_{2}-\mathrm{Al}\right)$ mais utilizado para reatores de pesquisa.

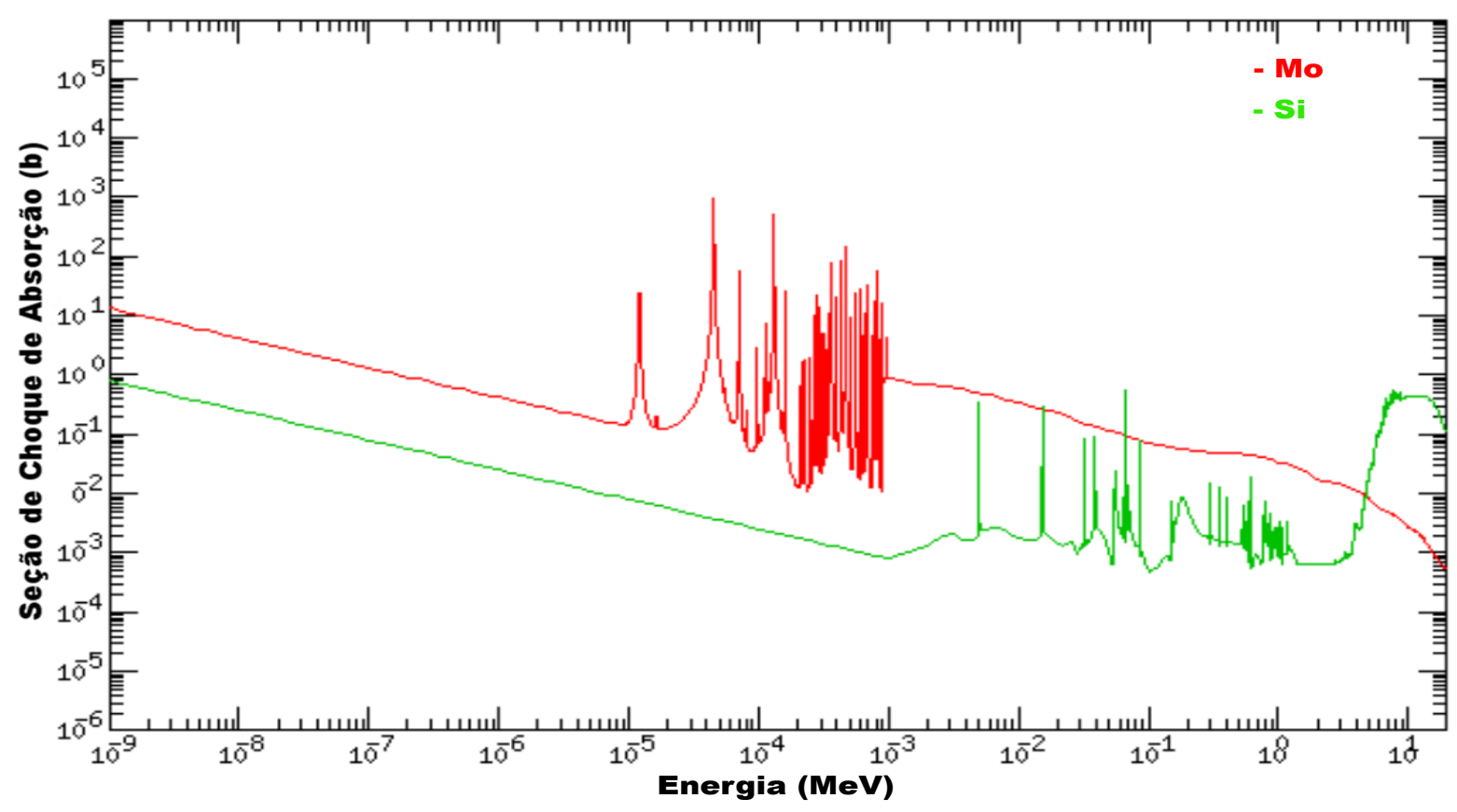

Figura 2.2: Seção de choque de absorção de nêutrons do molibdênio e do silício.

Em meados dos anos oitenta, o programa RERTR iniciou o estudo das ligas de urâniomolibdênio. Este tipo de liga permite uma densidade de urânio em torno de $8 \mathrm{gU} / \mathrm{cm}^{3}$ na fase dispersa. Porém, nos teste de irradiação com queimas acima de $65 \%$ do combustível, foi detectado o surgimento de uma camada de interação entre o urânio e o alumínio, devido a difusão do alumínio nas partículas de UMo, causando inchamento e perda da condutividade térmica no combustível /10/.

Os estudos atuais buscam solucionar o problema da difusão do alumínio no núcleo do combustível. Os resultados encontrados até o momento indicam como uma das soluções a adição de silício na matriz, estabilizando e reduzindo as propriedades de interação. Porém, ainda não se tem um limite claro para a porcentagem de Si na matriz. As pesquisas têm sido realizadas com adição de valores entre 3 a $7 \%$ de Si. O fenômeno que dificulta a obtenção e uma porcentagem mais precisa de Si é o aumento da camada de interação sobre irradiação, o que faz com que o Si se "dilua" na região e cause a perda de eficiência. Embora essa dificuldade possa ser contornada com o aumento de Si na matriz, este aumento dificulta o reprocessamento do combustível /11/. 
Além da adição de Si, outro parâmetro importante para reduzir a camada de interação é o tamanho das partículas de UMo usadas na dispersão /12/.

Outra possibilidade de utilização do combustível UMo é a possibilidade de ser fabricado na forma monolítica (núcleo do combustível na forma metálica continuo de UMo). A espessura desta placa esta entre 0,254 a 0,381 mm, sendo possível obtenção de densidades em torno de $16 \mathrm{gU} / \mathrm{cm}^{3}$. O interesse no estudo deste tipo de material é para a conversão de reatores de pesquisa de alto desempenho como, por exemplo, o Reator de Testes Avançados ("Advanced Test Reactor" - ATR) do Laboratório Nacional de Idaho. Este reator pode operar a uma potência de 250 MW /13/.

O Brasil não dispõe de reatores de pesquisa que possibilitem testes de queima do combustível com miniplacas combustíveis de UMo-Al em intervalos razoáveis de tempo e nem células quentes que permitam testes destrutivos. O avanço na pesquisa com este tipo de combustível no país tem sido feito através de estudos bibliográficos e simulações computacionais.

\subsection{Descrição dos Reatores de Pesquisa Similares ao RMB}

Para o fornecimento de radioisótopos e pesquisas em geral, os reatores de teste de materiais são de vital importância. Em relação ao fornecimento de radioisótopos, o mundo enfrenta grandes dificuldades de produção e fornecimento, principalmente para o molibdênio para obtenção do Tecnécio-99 $\left({ }^{99} \mathrm{Tc}\right)$. Neste cenário, ao redor do mundo, têm-se projetos de reatores multipropósito (fornecimento de radioisótopos, teste de materiais, pesquisas neutrônicas etc...) em desenvolvimento.

Nesta linha de reatores, pode-se dar como exemplo dois reatores, um em operação e o outro em fase de construção, respectivamente, o reator Open Pool Australian Lightwater (OPAL) e o Jules Horowitz Reactor (JHR).

O reator OPAL entrou em operação em agosto de 2006. Ele tem uma potência de 20 Megawatt e utiliza combustível $\mathrm{U}_{3} \mathrm{Si}_{2}-\mathrm{Al}$ de baixo enriquecimento (LEU), como moderador a água leve $\left(\mathrm{H}_{2} \mathrm{O}\right)$ e como refletor a água pesada $\left(\mathrm{D}_{2} \mathrm{O}\right)$ e tem um ciclo de operação entre 30 e 35 dias. O reator Opal tem como objetivos a produção de radiofármacos, pesquisas cientificas e industrial /14/.

Uma colaboração internacional está desenvolvendo o JHR que está sendo construído 
em Cadarache na França. A potência térmica do JHR será de 100 MW com moderação e refrigeração a água. O futuro combustível do JHR será de UMo com densidade de urânio de $8 \mathrm{gU} / \mathrm{cm}^{3}$. O combustivel uranio - molibdênio tanto à dispersão quanto monolítico ainda está em fase de desenvolvimento e não estará em produção antes do inicio da operação do JHR. A solução para o inicio das atividades do reator será utilizar o combustível $\mathrm{U}_{3} \mathrm{Si}_{2}-\mathrm{Al}$ com alto enriquecimento $\left(27 \%\right.$ de $\left.{ }^{235} \mathrm{U}\right) / 15 /$.

No Brasil, está em fase de detalhamento o projeto do Reator Multipropósito Brasileiro (RMB) que tem a finalidade dos reatores citados anteriormente. O RMB usará como moderador a água leve $\left(\mathrm{H}_{2} \mathrm{O}\right)$ e como refletor a água pesada $\left(\mathrm{D}_{2} \mathrm{O}\right)$ e terá uma potência de 30 MW, um ciclo de operação aproximadamente de 30 dias e usará como combustível o $\mathrm{U}_{3} \mathrm{Si}_{2}-\mathrm{Al}$.

Nesses reatores, é necessário o uso de veneno queimável. O OPAL usa fios de cádmio junto ao elemento combustível e o RMB também usará este tipo de veneno queimável.

\subsection{Veneno Queimável}

Em física de reatores, materiais que são adicionados ao núcleo do reator e têm alta seção de choque de absorção de nêutrons e durante a reação de absorção geram produtos com baixa seção de choque de absorção de nêutrons são chamados de veneno queimável, uma vez que o elemento absorvedor de nêutrons desaparece na reação.

A aplicação de veneno queimável no núcleo do reator é de vital importância para reatores de potência para assegurar a reatividade inicial do núcleo necessária e, portanto, permitir um ciclo de operação adequado para a finalidade do reator. Exemplos de materiais utilizados como veneno queimável são:

- Óxido de gadolínio - $\mathrm{Gd}_{2} \mathrm{O}_{3}$ (usado na usina Angra 2);

- Compostos borados tais como: $\mathrm{B}_{4} \mathrm{C}, \mathrm{ZrB}_{2}$ e ligas de $\mathrm{Al}-\mathrm{B} / 13 /$;

- Fios de cádmio junto ao elemento combustível (Reator OPAL e RMB).

Os materiais citados acima como venenos queimáveis estão posicionados fora do combustível nuclear e ficam em posições especificas no núcleo do reator e não estão distribuídos homogeneamente. A aplicação do veneno queimável diretamente no cerne do combustível 
("meat") e distribuído homogeneamente é importante, pois trás uma segurança maior, uma vez que, não existe a possibilidade dele ser removido do núcleo, pois está contido dentro no próprio combustível. Em relação ao fio de cádmio, os venenos inseridos homogeneamente no cerne do combustível possibilitam a simplificação na construção do elemento combustível (EC), evitando a dificuldade de fixação dos fios de cádmio no EC.

A liga metálica UMo possibilita o estudo da adição de um elemento metálico, com as propriedades de veneno queimável, que seja aplicado diretamente na liga. Como o veneno estará no cerne do combustível, a reação desejada para a absorção é a captura radiativa $(\mathrm{n}, \gamma)$, para não adicionar danos ao combustível devida a emissão de partículas carregadas, como por exemplo em reações $(n, \alpha)$. A Tabela 2.1 apresenta os principais elementos com esta característica para utilização como veneno.

Tabela 2.1 - Elementos possíveis para veneno queimável.

\begin{tabular}{|c|c|}
\hline \hline Elemento & Seção de Choque de Absorção $\left(\sigma_{a}(\mathrm{~b})\right)$ \\
\hline \hline Disprósio & 930 \\
Érbio & 162 \\
Európio & 4600 \\
Gadolínio & 49000 \\
Háfnio & 102 \\
\hline
\end{tabular}

O veneno queimável a ser utilizado deve ser ponderado com o fluxo de nêutrons que o reator apresenta, pois se o fluxo de nêutrons for alto e o elemento utilizado também tiver uma seção de choque alta, o veneno será consumido rapidamente. No caso de uma seção de choque baixa e fluxo baixo, o veneno não atuara da forma adequada no controle da reatividade.

O cádmio também possui seção de choque de absorção alta (2450b) e será o veneno queimável utilizado no RMB. Portanto, será avaliada a utilização de outros materiais como veneno queimável.

A Tabela 2.1 mostra que os elementos com seção de choque mais altas são o gadolínio (Gd) e o európio (Eu). Devido a este fato, os dois elementos serão analisados como possíveis candidatos a venenos queimáveis aplicados ao combustível para o reator proposto. 


\subsubsection{Gadolínio}

A Tabela 2.2 apresenta a porcentagem isotópica natural do gadolínio com as respectivas seções de choque para a captura radiativa.

Tabela 2.2 - Porcentagem isotópica natural do gadolínio.

\begin{tabular}{|c|c|c|}
\hline \hline Isótopo & Porcentagem $(\%)$ & $\sigma_{(n, \gamma)}$ para $0,0253 \mathrm{eV}(\mathrm{b})$ \\
\hline \hline 152 & 0,20 & 1056 \\
154 & 2,18 & 85 \\
155 & 14,80 & 60889 \\
156 & 20,47 & 2,188 \\
157 & 15,65 & 254078 \\
158 & 24,84 & 2,4966 \\
160 & 21,86 & $796.10^{-3}$ \\
\hline
\end{tabular}

Como a reação nuclear é a captura radiativa, ocorre uma "cadeia de absorção" na qual, o ${ }^{152} \mathrm{Gd}$ absorve um nêutron e emite uma gama e se transforma em ${ }^{153} \mathrm{Gd}$ que por sua vez absorve um nêutron e se transforma em ${ }^{154} \mathrm{Gd}$ e, assim, sucessivamente: ${ }^{152} \mathrm{Gd} \rightarrow{ }^{153} \mathrm{Gd}$ $\rightarrow{ }^{154} \mathrm{Gd} \rightarrow{ }^{155} \mathrm{Gd} \rightarrow{ }^{156} \mathrm{Gd} \rightarrow{ }^{157} \mathrm{Gd} \rightarrow{ }^{158} \mathrm{Gd} \rightarrow{ }^{159} \mathrm{Gd}$. O ${ }^{159} \mathrm{Gd}$ decai por emissão beta com uma meia vida de 18,479 horas e o ${ }^{160} \mathrm{Gd} \rightarrow{ }^{161} \mathrm{Gd}$. O ${ }^{161} \mathrm{Gd}$ decai por emissão beta com uma meia vida de 3,646 minutos.

As Figuras de 2.3 a 2.10 mostram a comparação entre a seção de choque total e a seção de choque de captura radiativa $(\mathrm{n}, \gamma)$ dos isótopos naturais do gadolínio. 


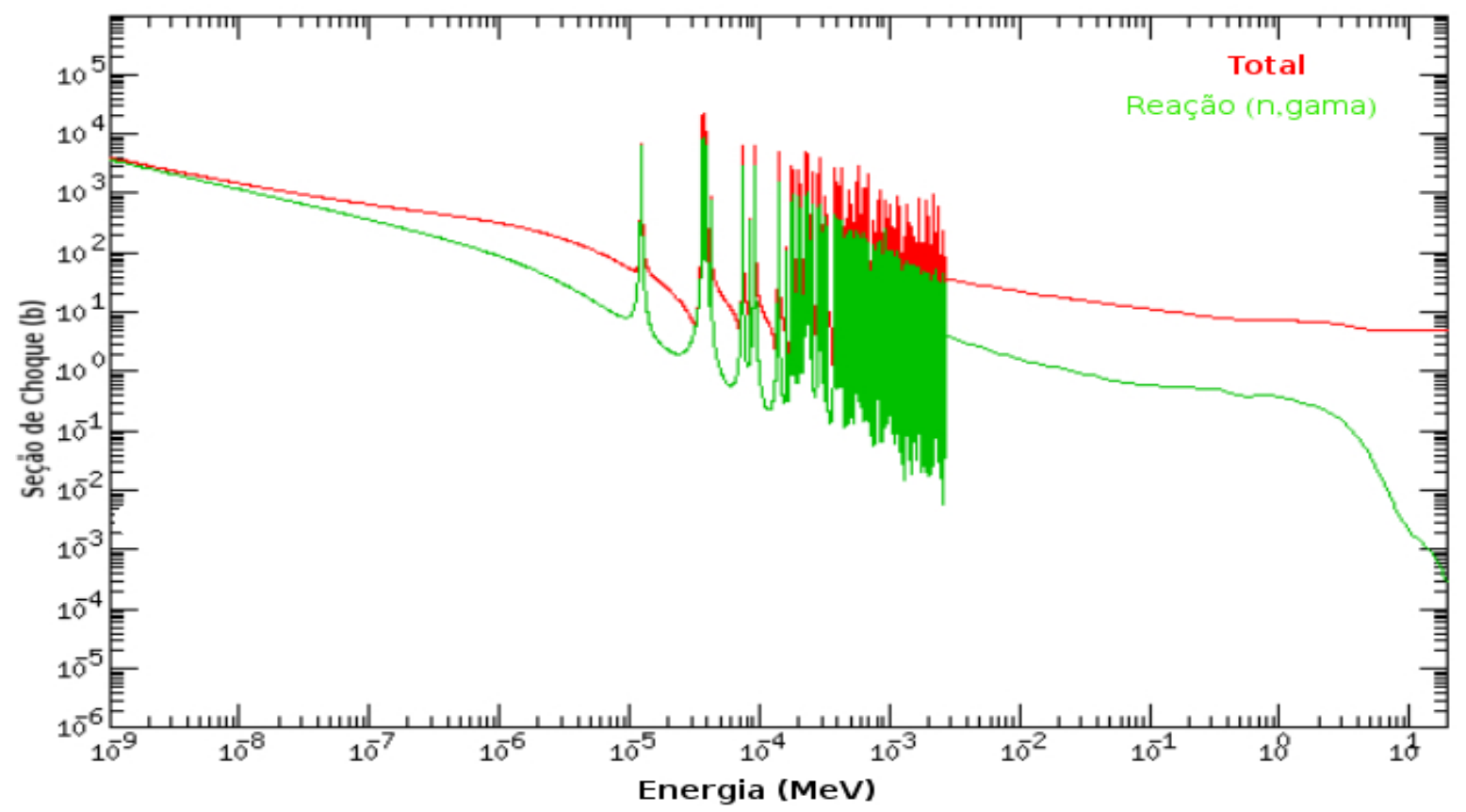

Figura 2.3: Seções de choque total e (n, gama) para ${ }^{152} \mathrm{Gd}$.

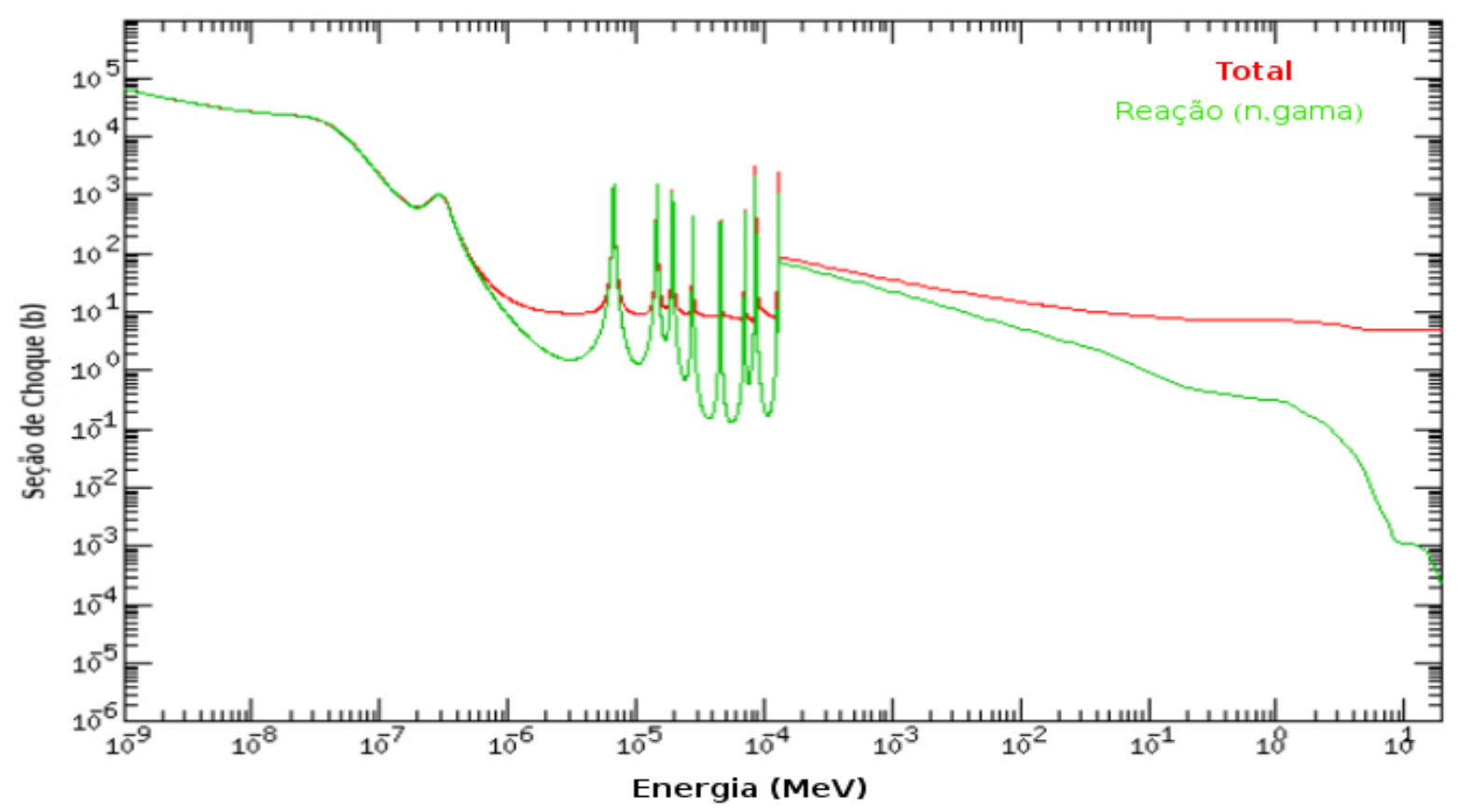

Figura 2.4: Seções de choque total e (n, gama) para ${ }^{153} \mathrm{Gd}$. 


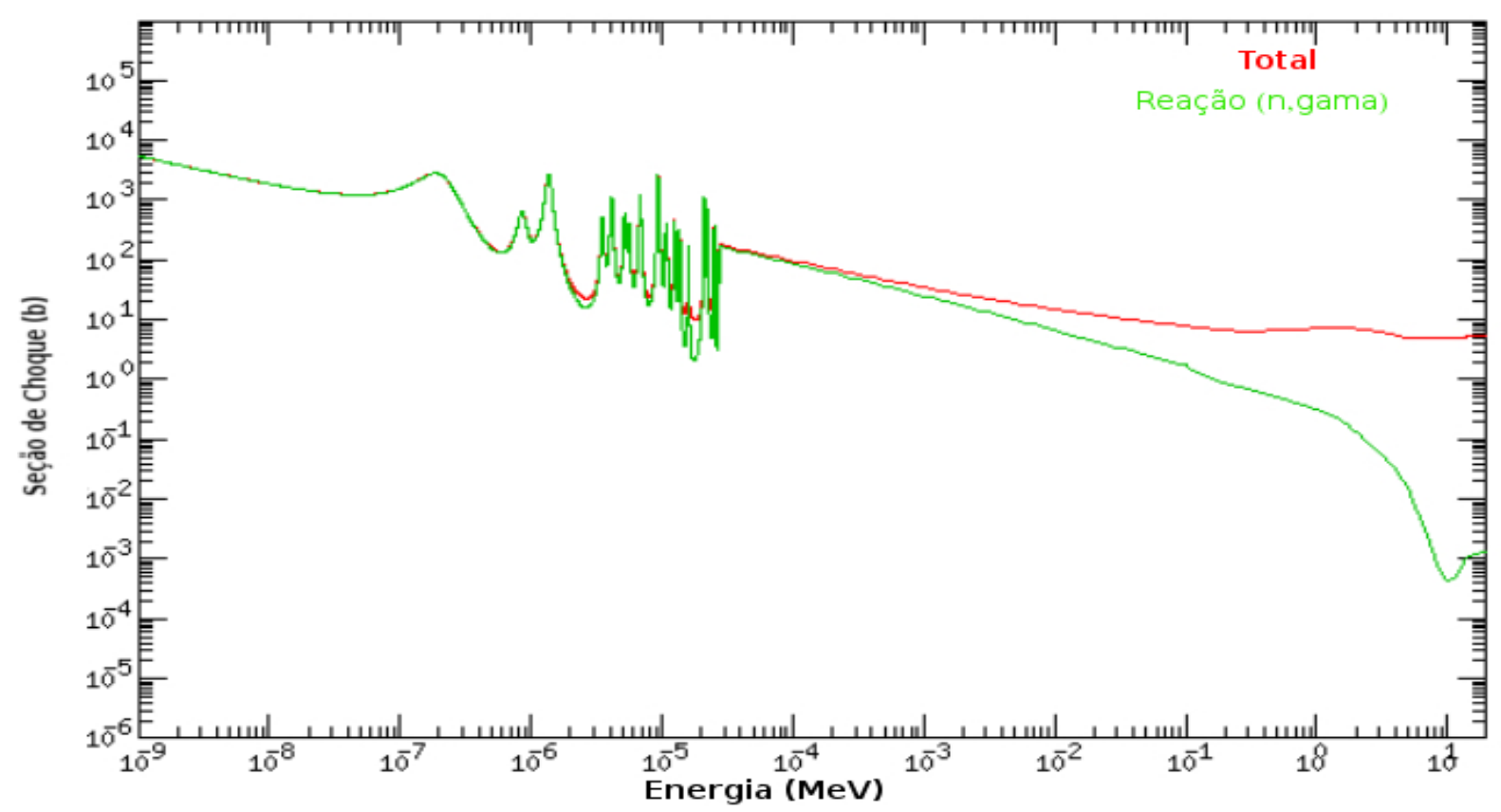

Figura 2.5: Seções de choque total e (n, gama) para ${ }^{154} \mathrm{Gd}$.

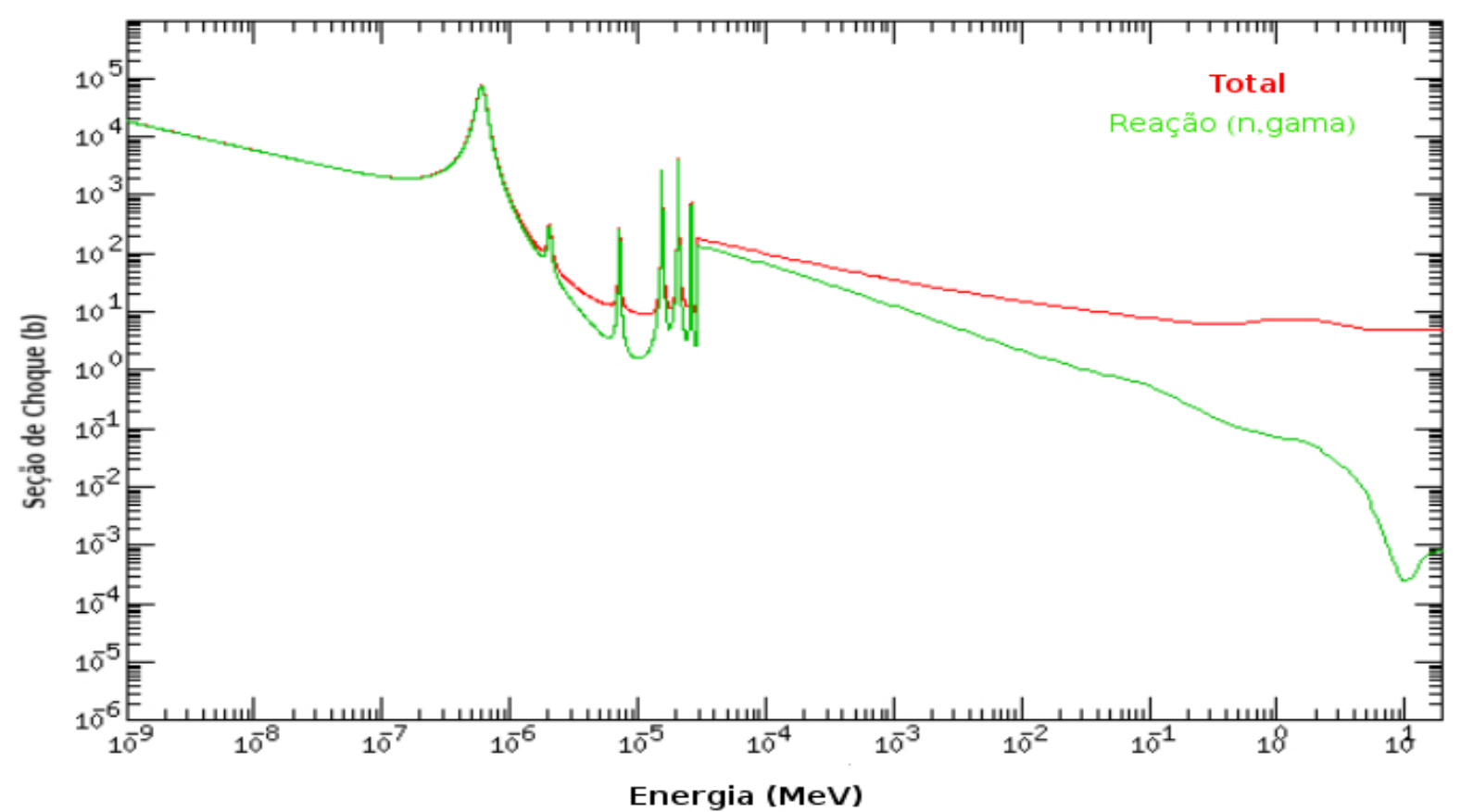

Figura 2.6: Seções de choque total e (n, gama) para ${ }^{155} \mathrm{Gd}$. 


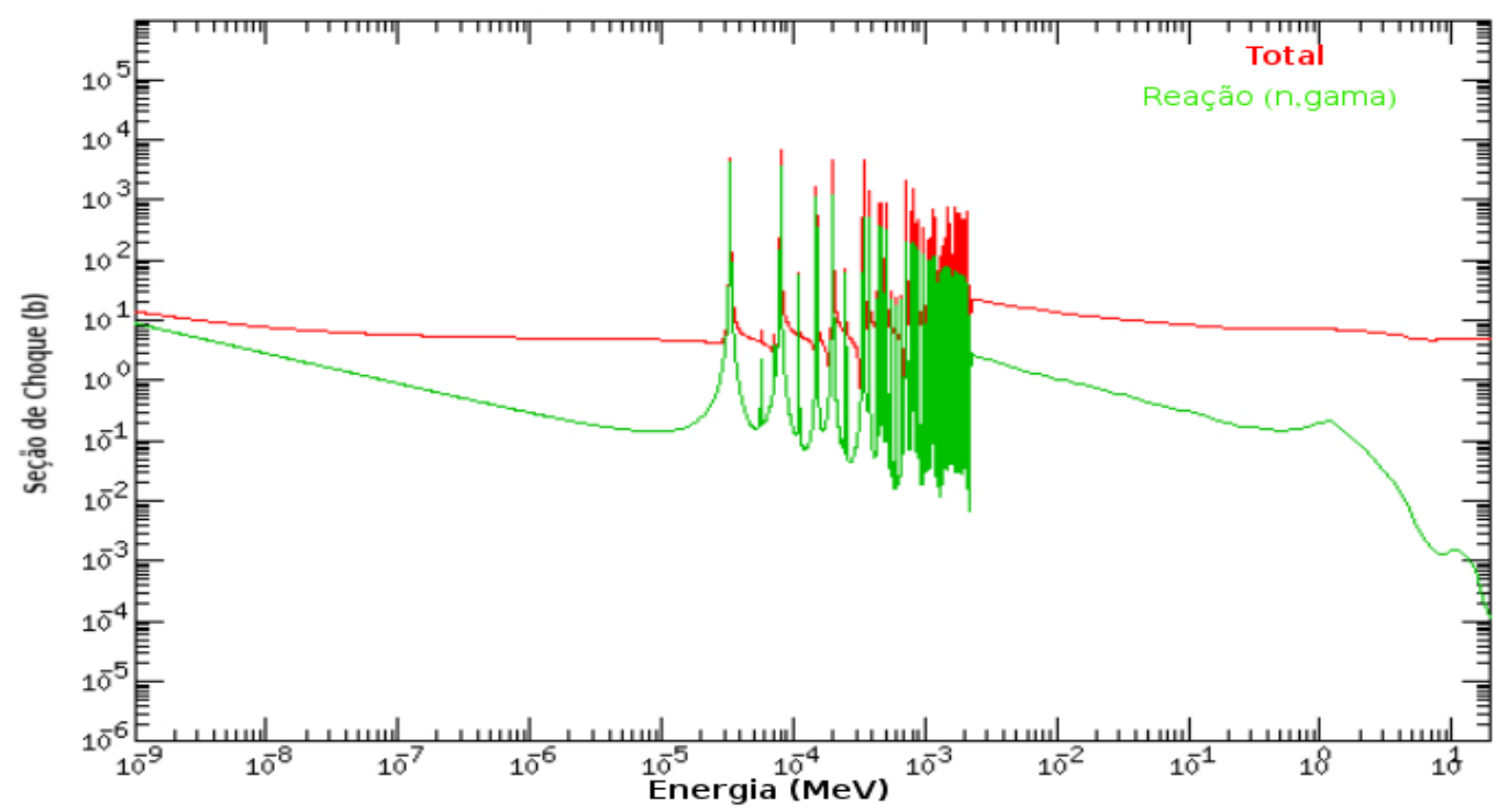

Figura 2.7: Seções de choque total e (n, gama) para ${ }^{156} \mathrm{Gd}$.

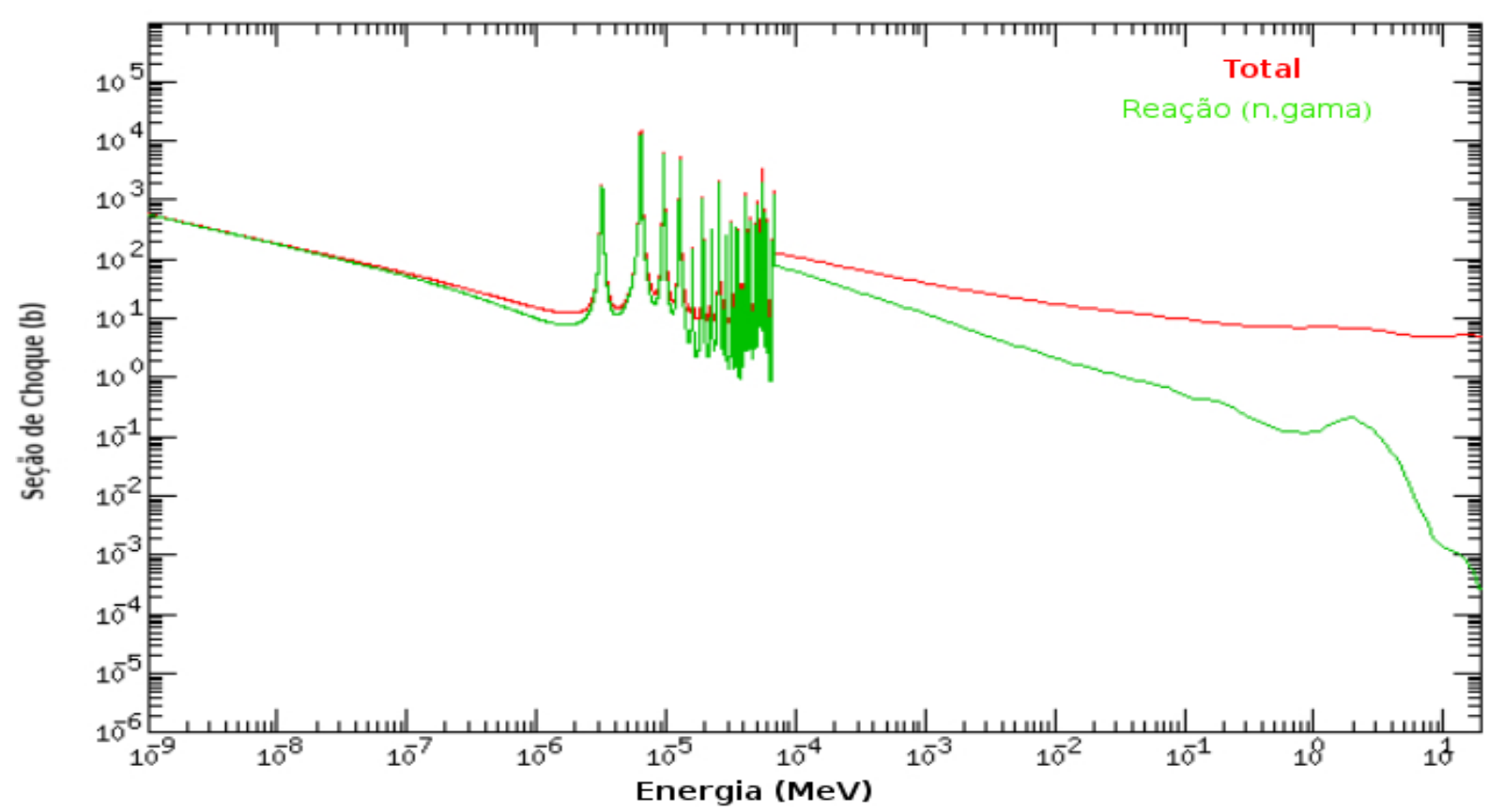

Figura 2.8: Seções de choque total e (n, gama) para ${ }^{157} \mathrm{Gd}$. 


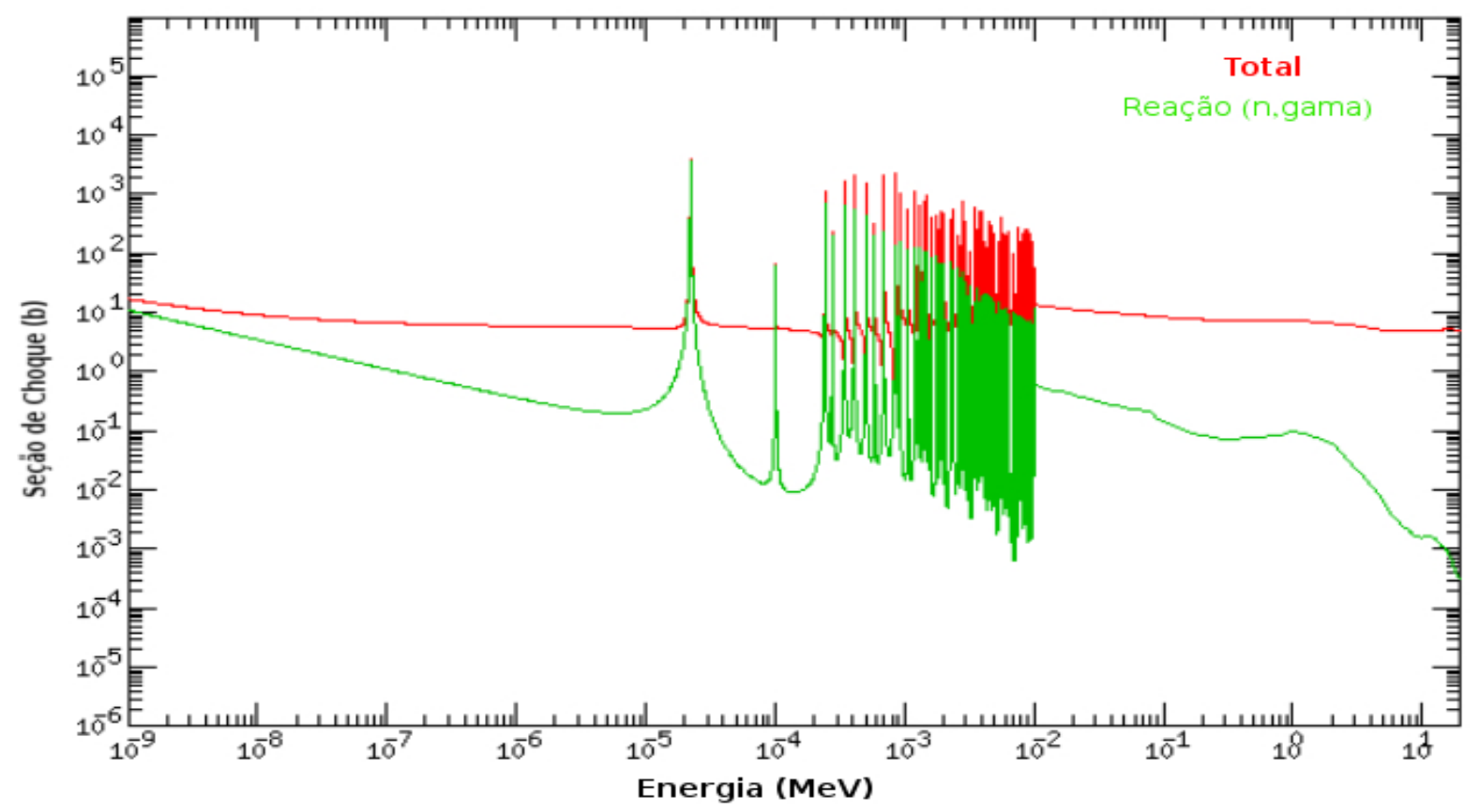

Figura 2.9: Seções de choque total e (n, gama) para ${ }^{158} \mathrm{Gd}$.

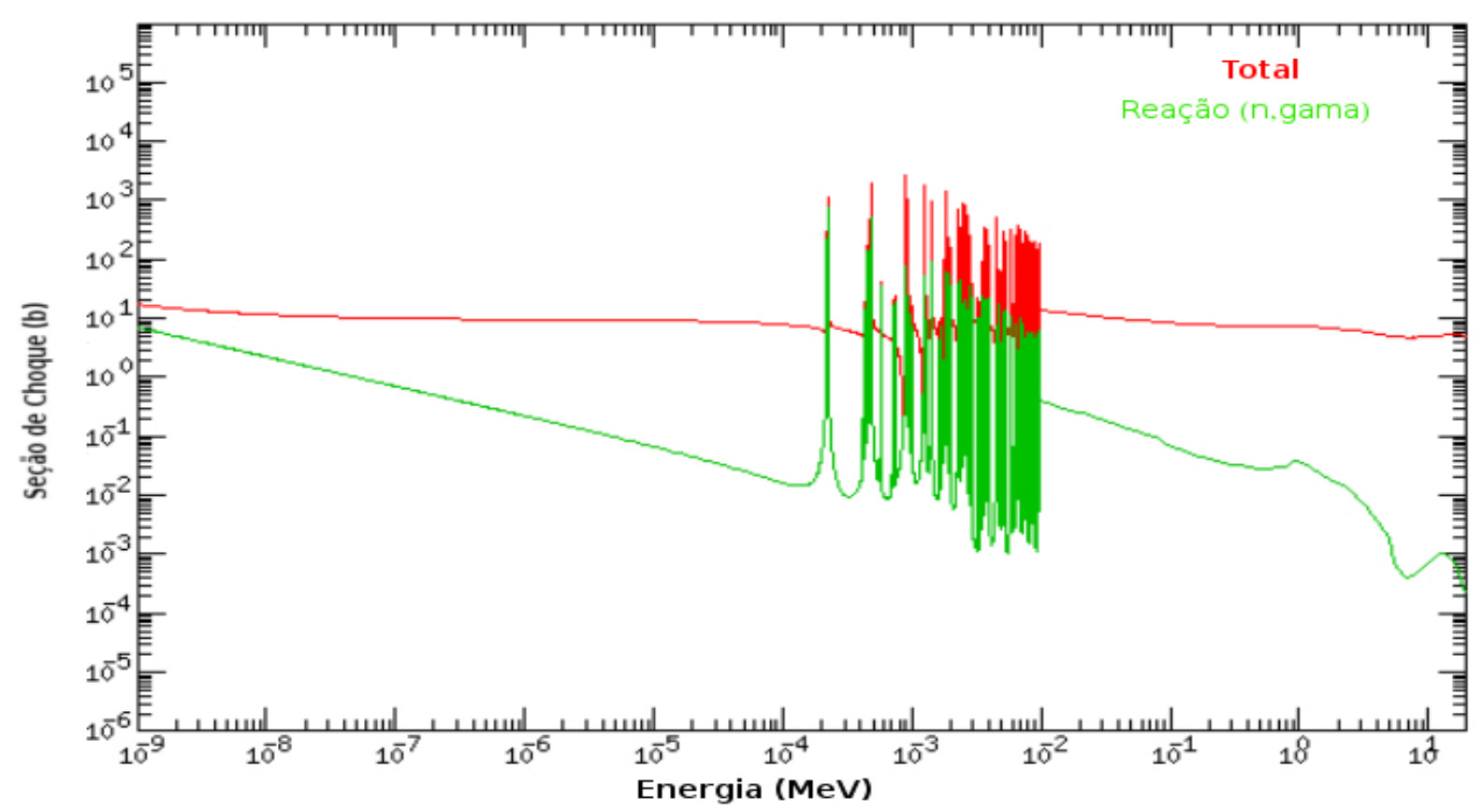

Figura 2.10: Seções de choque total e (n, gama) para ${ }^{160} \mathrm{Gd}$.

Através das Figuras, nota-se que grande parte das seções de choque dos isótopos naturais do gadolínio na região térmica e epitérmica é devido à captura radiativa. 


\subsubsection{Európio}

O európio possui uma seção de choque de captura radiativa aproximadamente 10 vezes (Tabela 2.1) menor que o gadolínio e tem dois isótopos naturais como mostra a Tabela 2.3.

Tabela 2.3 - Porcentagem isotópica natural európio.

\begin{tabular}{|c|c|c|}
\hline \hline Isótopo & Porcentagem (\%) & $\sigma_{(n, \gamma)}$ para $0,0253 \mathrm{eV}(\mathrm{b})$ \\
\hline \hline 151 & 47,8 & 9198 \\
152 & & 12774 \\
153 & 52,2 & 312.7 \\
154 & & 1842 \\
155 & & 3758 \\
156 & & 100 \\
\hline
\end{tabular}

Assim como no caso do gadolínio, também ocorre uma cadeia de captura radiativa: ${ }^{151} \mathrm{Eu} \rightarrow{ }^{152} \mathrm{Eu} \rightarrow{ }^{153} \mathrm{Eu} \rightarrow{ }^{154} \mathrm{Eu} \rightarrow{ }^{155} \mathrm{Eu} \rightarrow{ }^{156} \mathrm{Eu} \rightarrow{ }^{157} \mathrm{Eu}$. Porém, no caso do európio, apenas os isótopos ${ }^{151} \mathrm{Eu}$ e ${ }^{153} \mathrm{Eu}$ são naturais. Do ${ }^{153} \mathrm{Eu}$ em diante, para o surgimento do isótopo seguinte, é necessária a reação de captura pelo isótopo anterior. As Figuras de 2.11 a 2.17 mostram a comparação entre a seções de choque total e de captura radiativa. Pode-se notar pelas figuras que nas regiões das energias térmica e epitérmica praticamente só ocorre a reação de captura radiativa. 


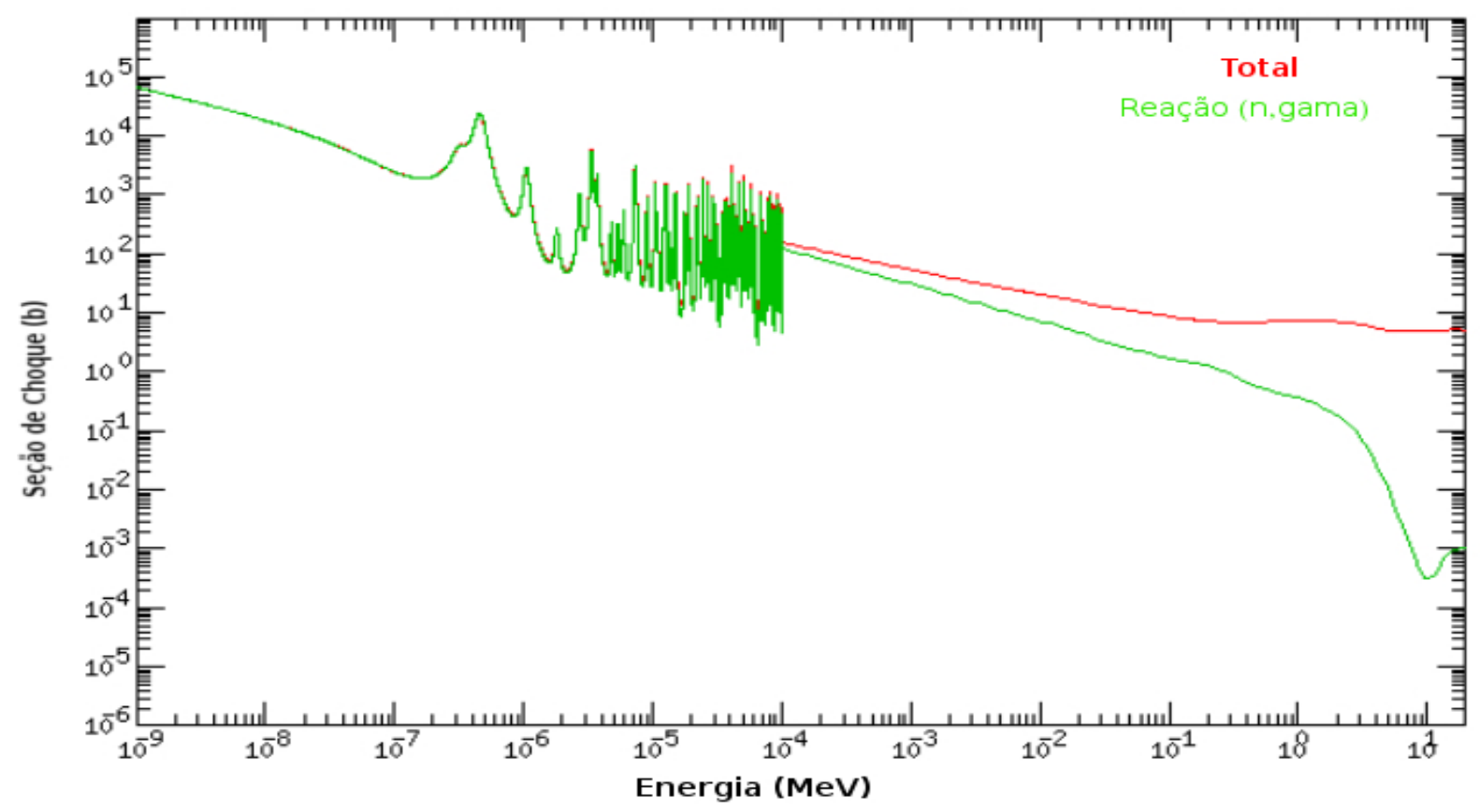

Figura 2.11: Seções de choque total e (n, gama) para ${ }^{151} \mathrm{Eu}$.

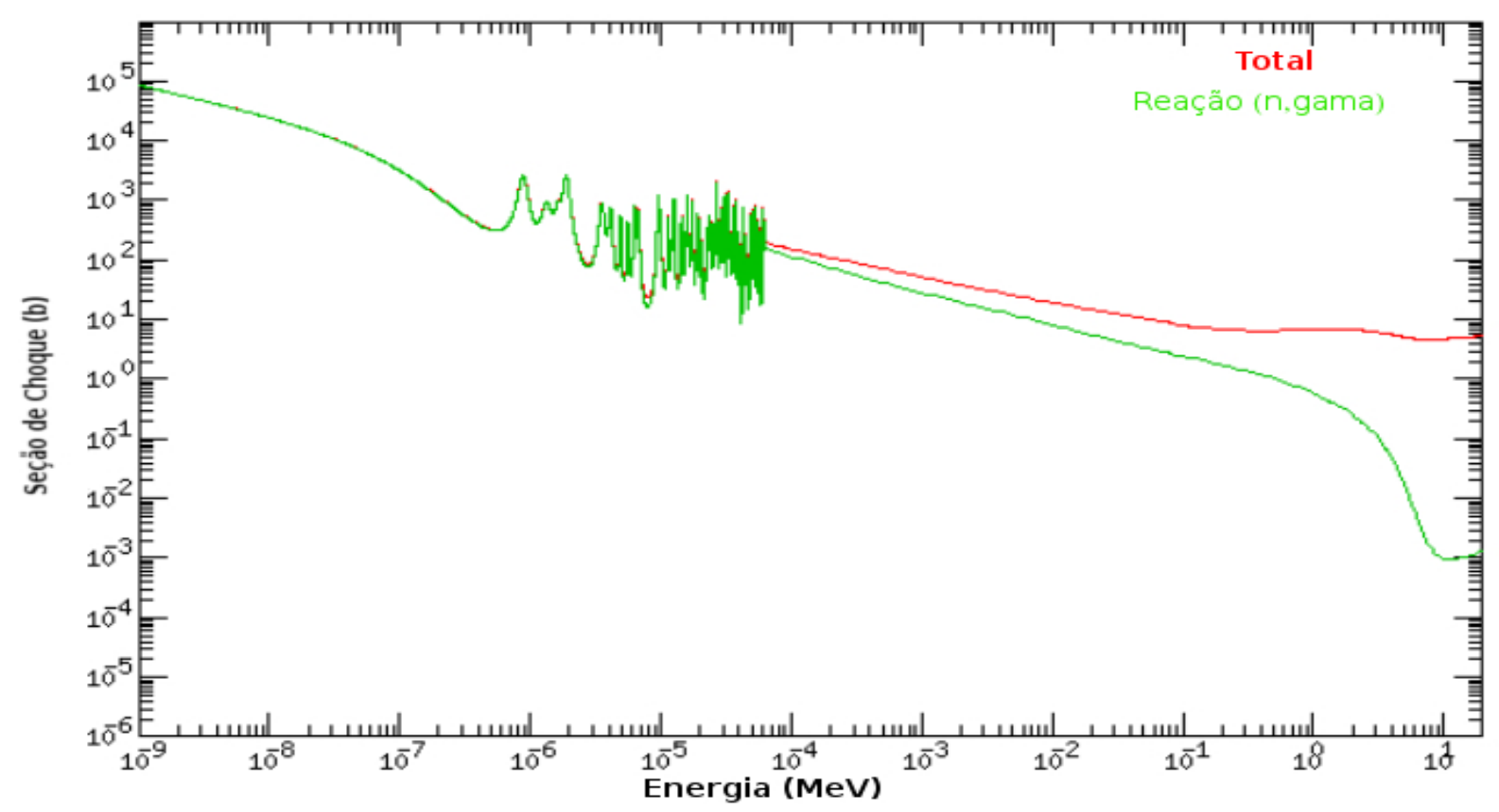

Figura 2.12: Seções de choque total e (n, gama) para ${ }^{152} \mathrm{Eu}$. 


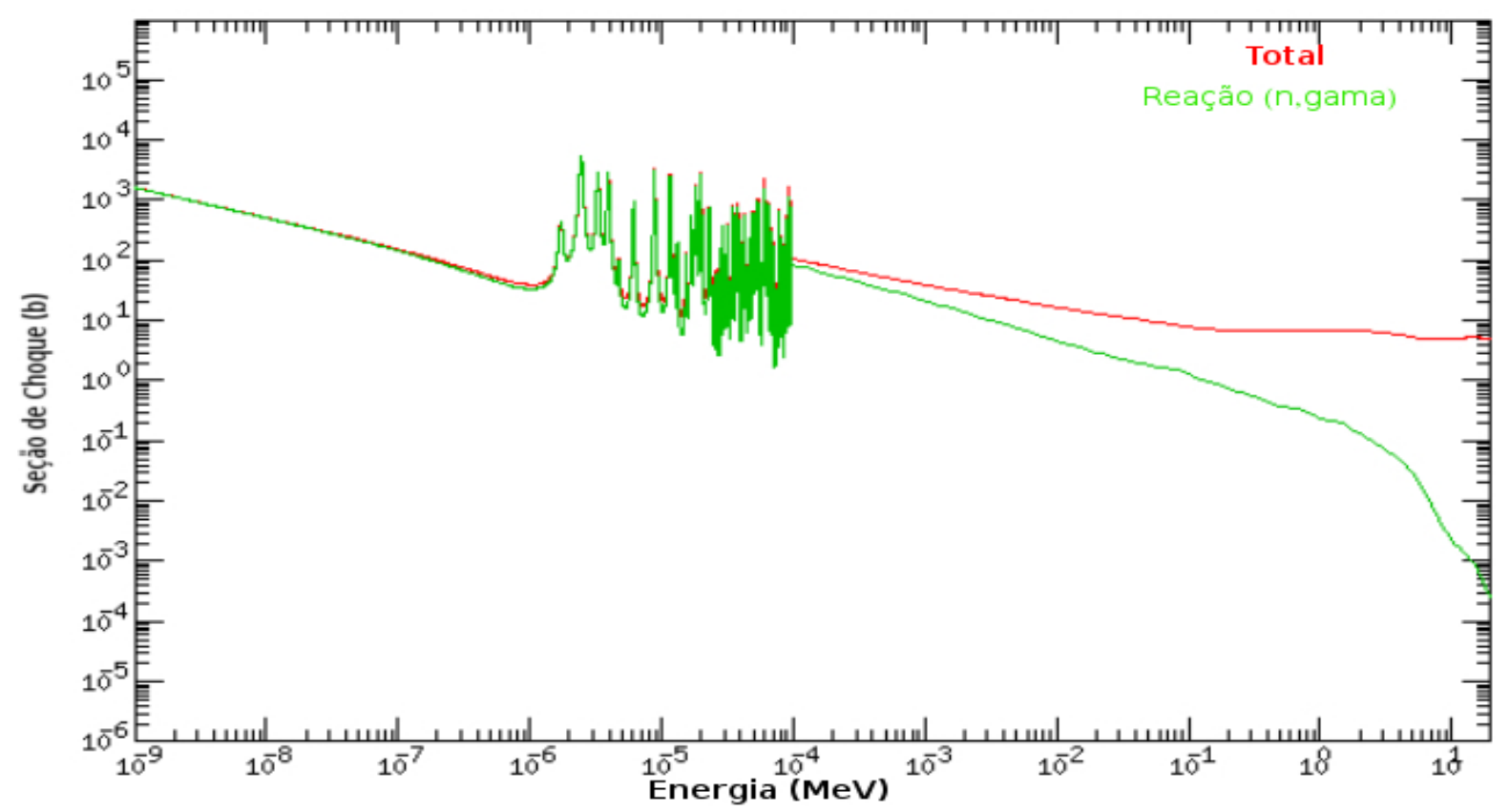

Figura 2.13: Seções de choque total e (n, gama) para ${ }^{153} \mathrm{Eu}$.

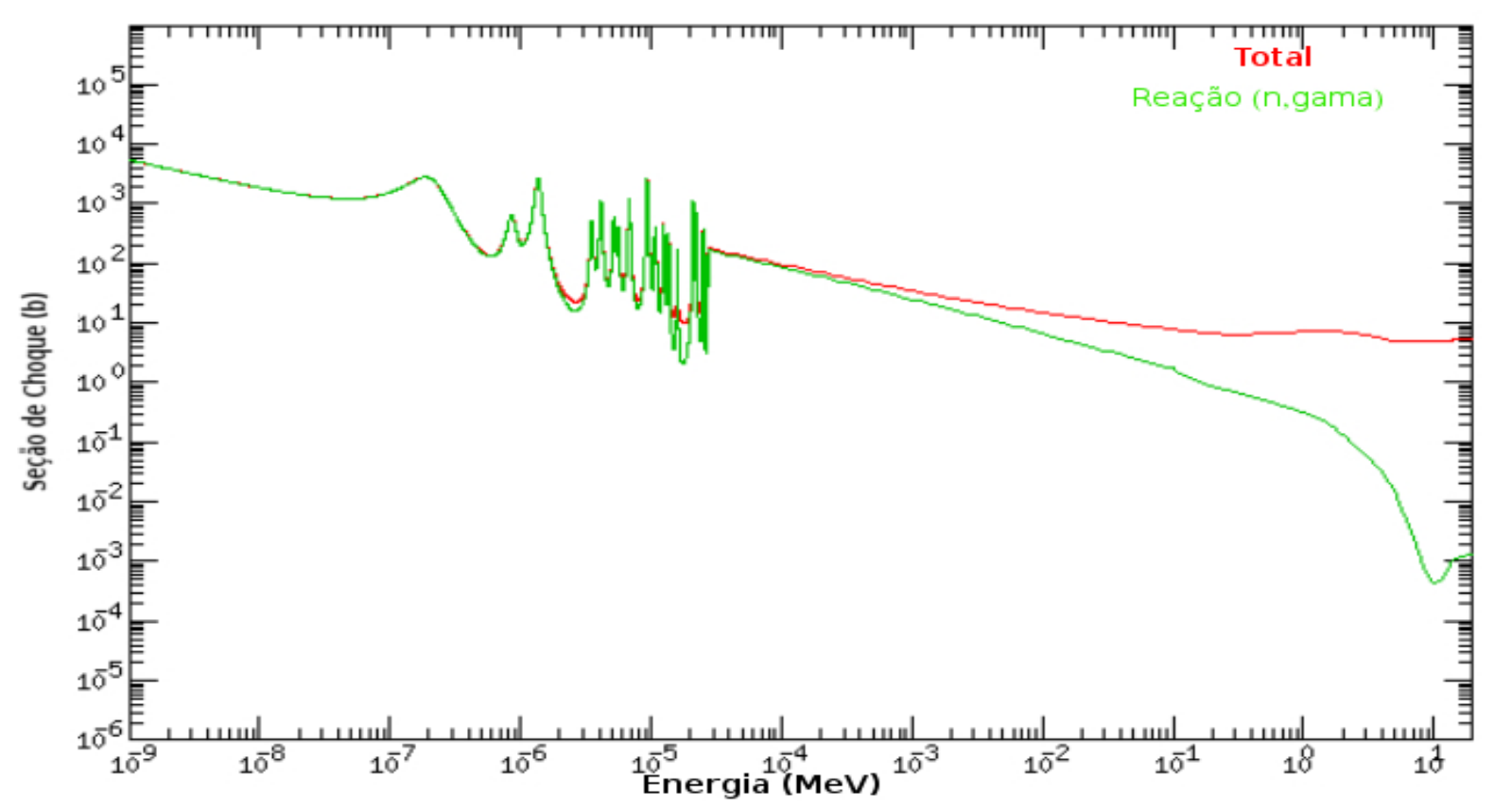

Figura 2.14: Seções de choque total e (n, gama) para ${ }^{154} \mathrm{Eu}$. 


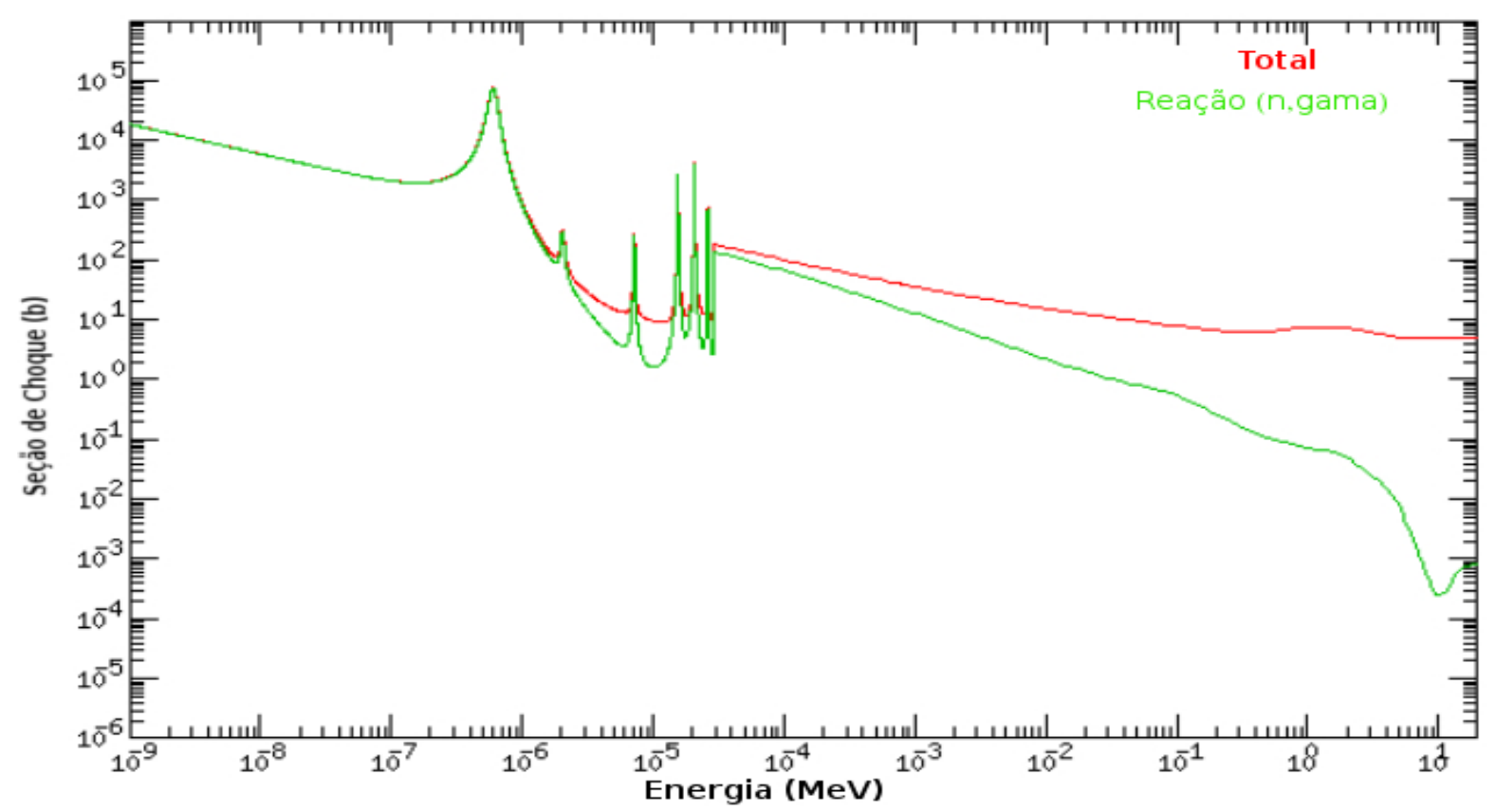

Figura 2.15: Seções de choque total e (n, gama) para ${ }^{155} \mathrm{Eu}$.

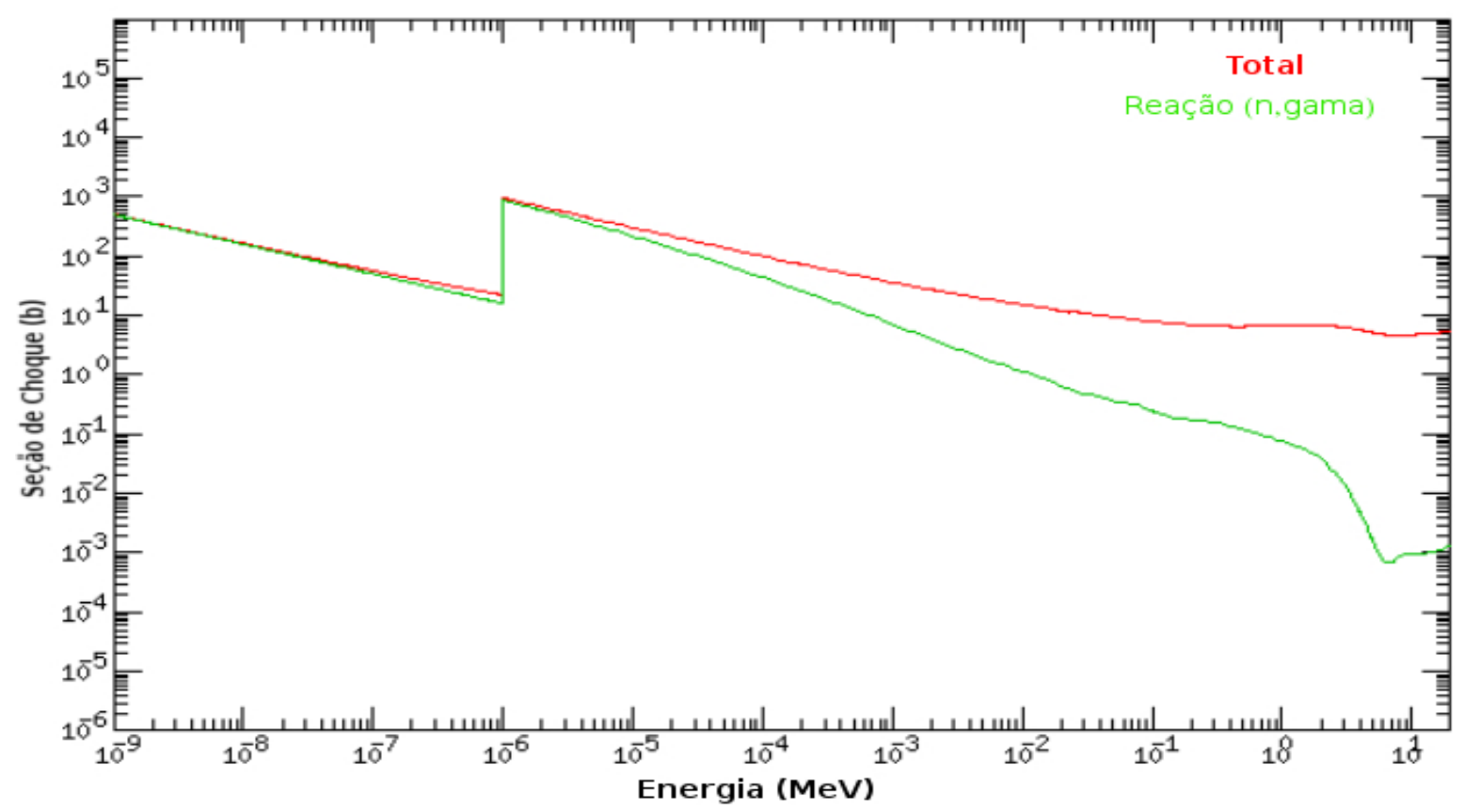

Figura 2.16: Seções de choque total e (n, gama) para ${ }^{156} \mathrm{Eu}$. 


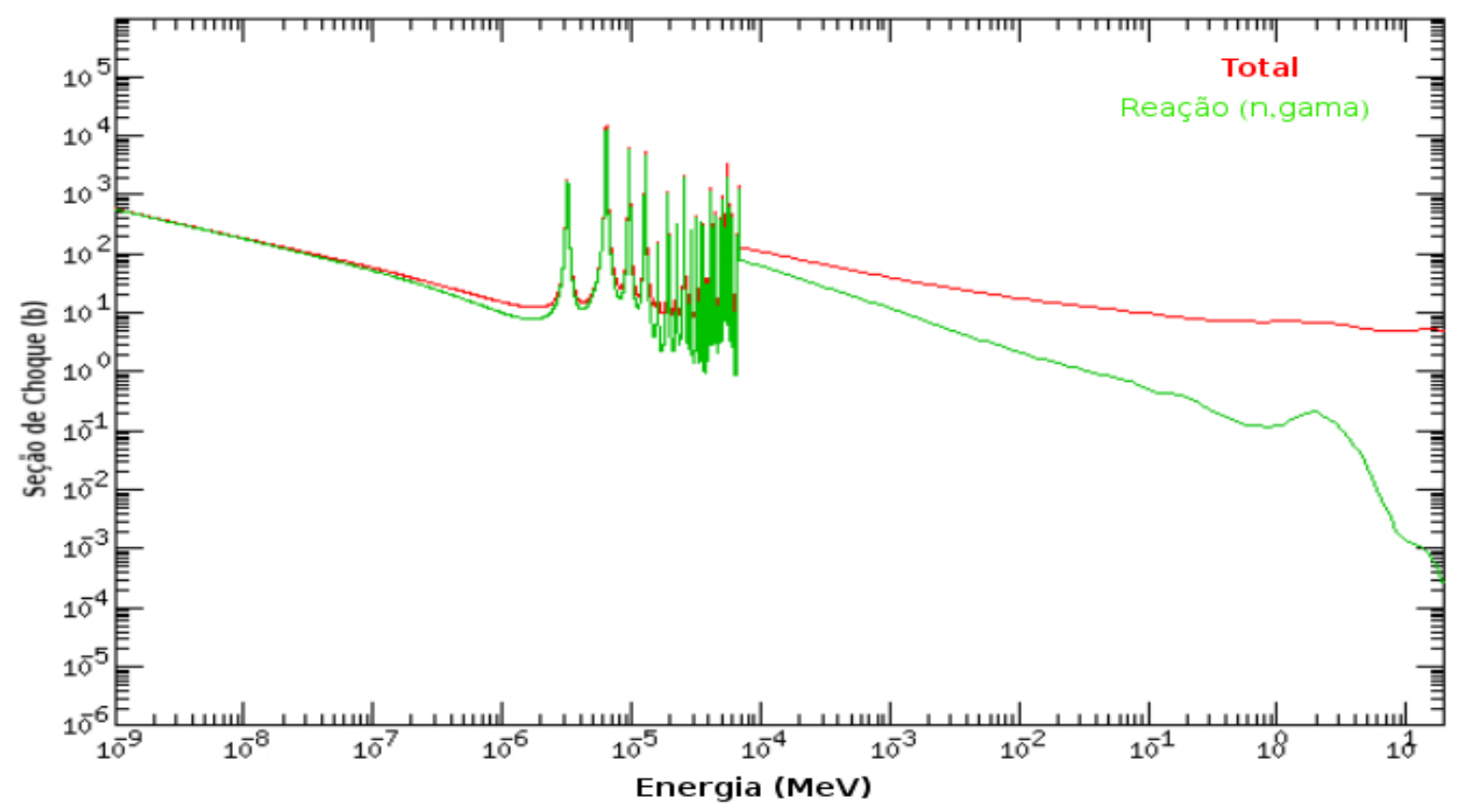

Figura 2.17: Seções de choque total e (n, gama) para ${ }^{157} \mathrm{Eu}$.

Uma diferença importante entre as seções de choque do gadolínio e do európio é que, para o gadolínio, os isótopos 158 e 160 possuem valores de seção de choque de captura radiativa reduzida (final da cadeia de absorção). Já os isótopos 154, 155 e 156 (seguintes ao $\left.{ }^{153} \mathrm{Eu}\right)$ tem seção de choque elevada. 
Capítulo 3

\section{Metodologia para Análise Neutrônica do Combustível}

\section{UMo-Al com Adição de Veneno Queimável}

\subsection{Descrição Do Reator Para Estudo}

Baseado nos reatores descritos anteriormente, foi simulado um núcleo com 23 elementos combustíveis, em um arranjo com 5 por 5 posições $(5 \times 5)$ e dois blocos de alumínio (posições de irradiação) envolto por $50 \mathrm{~cm}$ de água pesada $\left(\mathrm{D}_{2} \mathrm{O}\right)$ e $40 \mathrm{~cm}$ de água leve, como mostra a Figura 3.1.
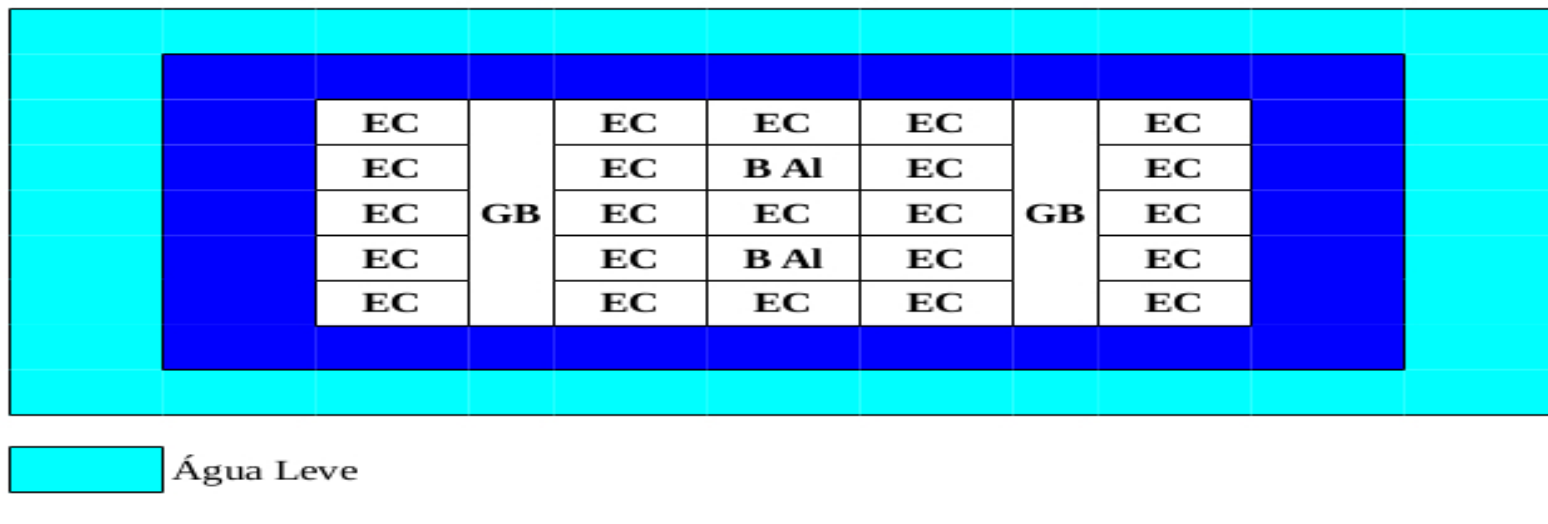

$\square$ Água Pesada

EC Elemento Combustível

GB Guia da Barra de Controle

B Al Bloco de Alumínio

Figura 3.1: Núcleo do reator (vista superior).

O elemento combustível é constituído por 21 placas combustíveis revestidas de alumínio 
e sua estrutura é um suporte lateral de alumínio onde as placas combustíveis são encaixadas. Cada placa possui um cerne do combustível com $6,5 \mathrm{~cm}$ de largura, $61,5 \mathrm{~cm}$ de comprimento e 0,061 cm de espessura. As placas combustíveis exteriores que "fecham" (bordas) o elemento tem uma espessura de 0,150 cm. O espaço entre as placas formam o canal de refrigeração com uma espessura de $0,245 \mathrm{~cm}$. Na simulação, a região do canal de refrigeração é preenchida com água assim como em volta do elemento combustível, que tem uma camada de $0,05 \mathrm{~cm}$ de água. A Figura 3.2 mostra o elemento combustível com as 21 placas.

\section{Cerne do Combustível}

Moldura

Canal de Refrigeração

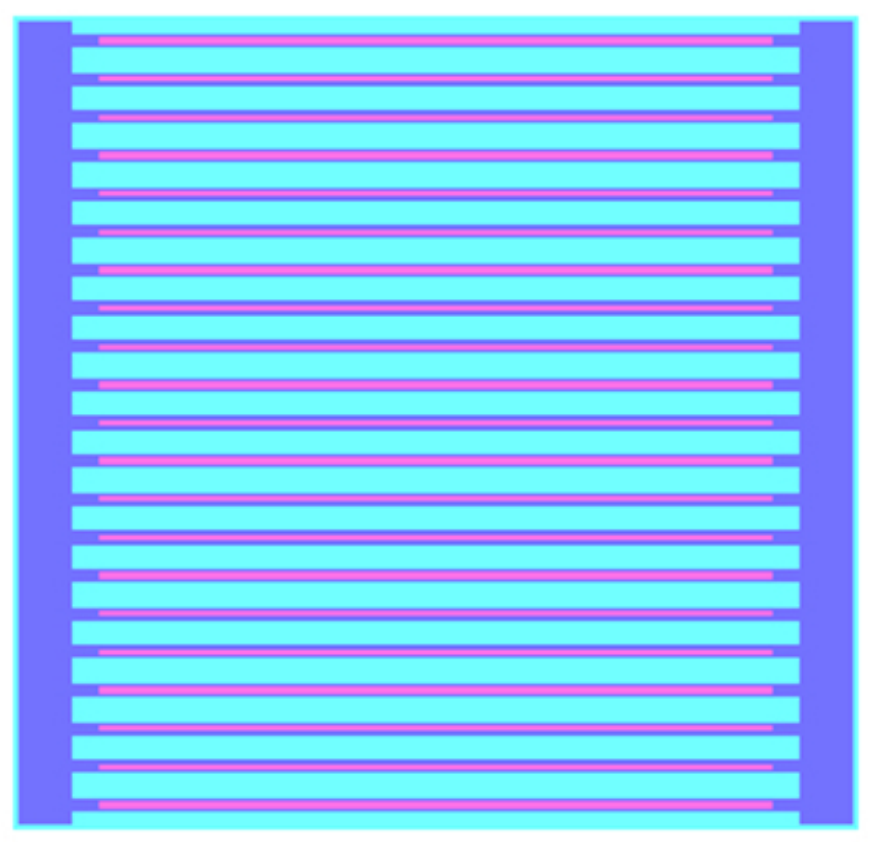

Figura 3.2: Elemento Combustível (plano XY), visão da parte superior do elemento combustível.

Nas simulações, os elementos combustíveis foram modelados como compostos por quatro regiões ao longo do comprimento (eixo axial - z), como mostra a Figura 3.3. Estas divisões são necessárias para levar em consideração a variação do fluxo de nêutrons ao longo do eixo axial ("buckling") em cada passo de queima.

A potência utilizada nas simulações foi de $30 \mathrm{MW}$ e o ciclo de operação que o reator tem que atingir é de 30 dias.

Nas simulações, não foram modeladas as partes estruturais do núcleo, como por exemplo, os canais de irradiação devido ao objetivo ser uma análise do combustível do núcleo. 


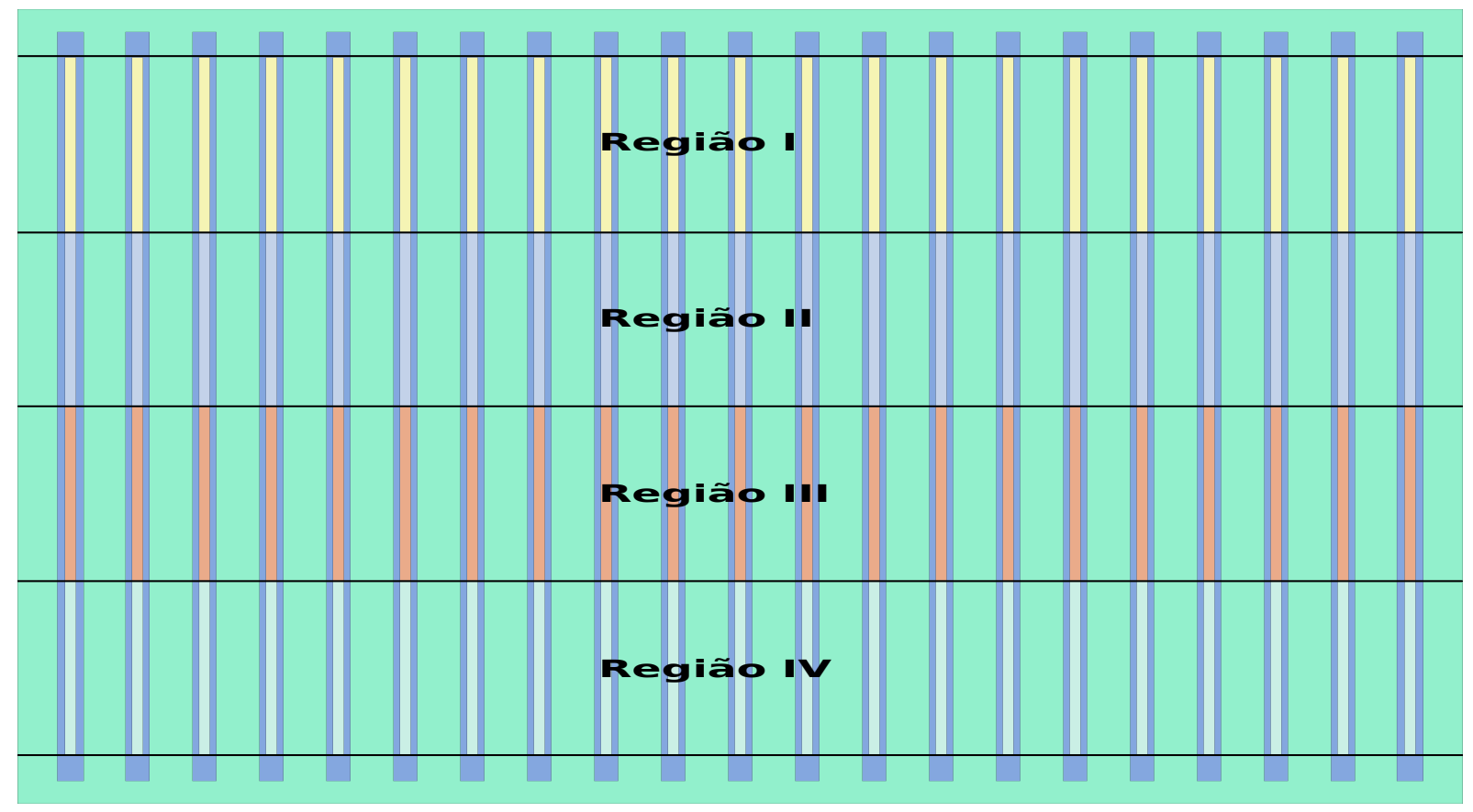

Figura 3.3: Elemento combustível composto por quatro regiões ao longo do eixo axial - z.

\subsection{Códigos Computacionais}

Neste trabalho, os dados nucleares para o combustível foram gerados pelo programa HRC, que consiste do acoplamento dos programas HAMMER /16/, ROLAIDS /17/ e CINDER /18/. O HAMMER utiliza a equação de transporte para gerar a seção de choque de uma célula unitária homogênea. O ROLAIDS faz o tratamento da autoblindagem na forma pontual e o CINDER é o módulo responsável pela queima /19/.

A simulação tridimensional do núcleo proposto foi realizada utilizando o código computacional CITATION /20/ que utiliza o método das diferenças finitas e aplica a teoria da difusão para resolver problemas de difusão de nêutrons. Os dados nucleares para o elemento combustível em cada etapa de queima foram fornecidos pelo programa $\mathrm{HRC}$, ou seja, o elemento combustível considerado é uma região homogeneizada, exceto o suporte lateral que é colocada explicitamente. Os dados nucleares para os componentes, tais como o suporte lateral do elemento combustível, água leve, água pesada, bloco de alumínio etc... foram obtidos através do sistema modular AMPX-II /17/.

Outro código utilizado para a simulação foi o SERPENT /21/, que foi desenvolvido pelo VTT Centro de Pesquisa Tecnológico da Finlândia em 2004. Ele utiliza o método de Monte 
Carlo de energia continua e realiza o cálculo de queima do combustível ao longo do ciclo. No SERPENT, toda a simulação do reator é realizada de forma explicita, diferentemente do HRC - CITATION (região do combustível homogenizada), porém o tempo necessário de cálculo é muito maior do que o HRC - CITATION necessita. Por essa razão, a simulação com o SERPENT será utilizada apenas no combustível selecionado.

Para as simulações das miniplacas combustíveis no núcleo do reator IPEN/MB-01 foi utilizado o código "Monte Carlo $N$ - Particle Transporte Code" (MCNP) versão MCNP$5 / 22 /$. Este código foi utilizado pois os dados de entrada para as simulações foram os utilizados pela física de reatores do Centro de Engenharia Nuclear (CEN) modelado em MCNP. O MCNP, assim como o SERPENT, utilizam método Monte Carlo, que é um método estatístico utilizado para obter aproximações numéricas de sistemas complexos.

\subsection{Parâmetros Para a Fabricação das Miniplacas}

Os parâmetros mais importantes para a fabricação do combustível de UMo-Al estão apresentados a seguir.

\subsubsection{Conteúdo de Urânio e Molibdênio}

A proporção a ser utilizado é de $93 \%$ em massa de urânio e $7 \%$ em massa de molibdênio (U7wt\%Mo).

A densidade de urânio em cada placa será de $4 \mathrm{gU} / \mathrm{cm}^{3}$.

O lingote de urânio-molibdênio será produzido pela fusão do urânio e do molibdênio.

O pó de urânio-molibdênio é obtido através do processo de Hidretação - Dehidretação, realizado pelo Centro do Combustível Nuclear do IPEN/CNEN-SP.

\subsubsection{Concentração Isotópica}

A concentração isotópica do ${ }^{235} \mathrm{U}$ é de $19,755_{-}^{+} 0,20 \%$ em peso.

\subsubsection{Diâmetro da Partícula Combustível}

O diâmetro da partícula combustível é um parâmetro importante que está relacionado com a acomodação dos produtos de fissão no cerne do combustível. 
A distância média entre as partículas varia de acordo com a fração em volume de combustível existente na placa. Dada a impossibilidade de se obter um único diâmetro de partícula, especifica-se normalmente uma faixa granulométrica na qual as partículas combustíveis devam estar inseridas.

É comum a utilização de partículas combustíveis na faixa de 44 a $150 \mu \mathrm{m}$ (75 a $85 \%$ em peso) com apenas uma quantidade limitada (15 a 25\% em peso) de pó mais fino (menor que $44 \mu \mathrm{m})$.

A partícula de UMo apresenta um comportamento dúctil, ou seja, uma resistência a se fragmentar nas etapas de laminação. Devido a este comportamento a granulometria usualmente utilizada pelos demais combustíveis não apresenta resultados satisfatórios quando aplicados no UMo-Al /23/.

Baseado na pesquisa bibliográfica, foi estabelecida uma granulometria que será testada na fabricação das miniplacas, Tabela ?? /24/ /25/. Como pode ser observado na tabela 3.1, o tamanho máximo permitido das partículas foi reduzido do usual $150 \mu \mathrm{m}$ para 125 $\mu \mathrm{m}$.

Tabela 3.1 - Granulometria das partículas de UMo.

\begin{tabular}{|c|c|}
\hline \hline Tamanho da Partícula $(\mu \mathrm{m})$ & Quantidade de Partículas Abaixo do Tamanho (\%) \\
\hline \hline 125 & 100,00 \\
90 & 78,41 \\
63 & 55,56 \\
45 & 19,92 \\
\hline
\end{tabular}

\subsubsection{Massa Específica}

A massa específica do pó de U7wt\%Mo é $16,47 \mathrm{gU} / \mathrm{cm}^{3}$.

\subsubsection{Dimensões da Miniplaca Combustível}

As dimensões, tolerâncias e acabamentos superficiais especificados para a miniplaca combustível acabada são relacionados na Tabela 3.2 e indicadas na Figura 3.4. 
Tabela 3.2 - Dimensões da minipla combustível U7wt\%Mo-Al.

\begin{tabular}{|c|c|}
\hline Discriminação & Especificação \\
\hline \multicolumn{2}{|r|}{ Dimensões da miniplaca } \\
\hline Comprimento (mm) & $1700_{-}^{+} 1$ \\
\hline Largura (mm) & $46,5_{-}^{+} 0,5$ \\
\hline Espessura (mm) & $1,52_{-}^{+} 0,05$ \\
\hline \multicolumn{2}{|r|}{ Dimensões do cerne } \\
\hline Comprimento (mm) & $118 \pm 3$ \\
\hline Largura (mm) & $40 \pm 3$ \\
\hline Espessura (mm) & $0,76_{-}^{+} 0,05$ \\
\hline Acabamento superficial & $\begin{array}{l}\text { Livre de riscos, ranhuras e pites. } \\
\text { Máxima profundidade de defeito na área do cerne }=0,1 \mathrm{~mm} \\
\text { Máxima profundidade de defeito na área restante }=0,127 \mathrm{~mm}\end{array}$ \\
\hline $\begin{array}{l}\text { Espessura mínima } \\
\text { do revestimento }\end{array}$ & $\begin{array}{l}\text { Zona } 1: 0,30 \mathrm{~mm} \\
\text { Zona } 2: 0,25 \mathrm{~mm}\end{array}$ \\
\hline
\end{tabular}

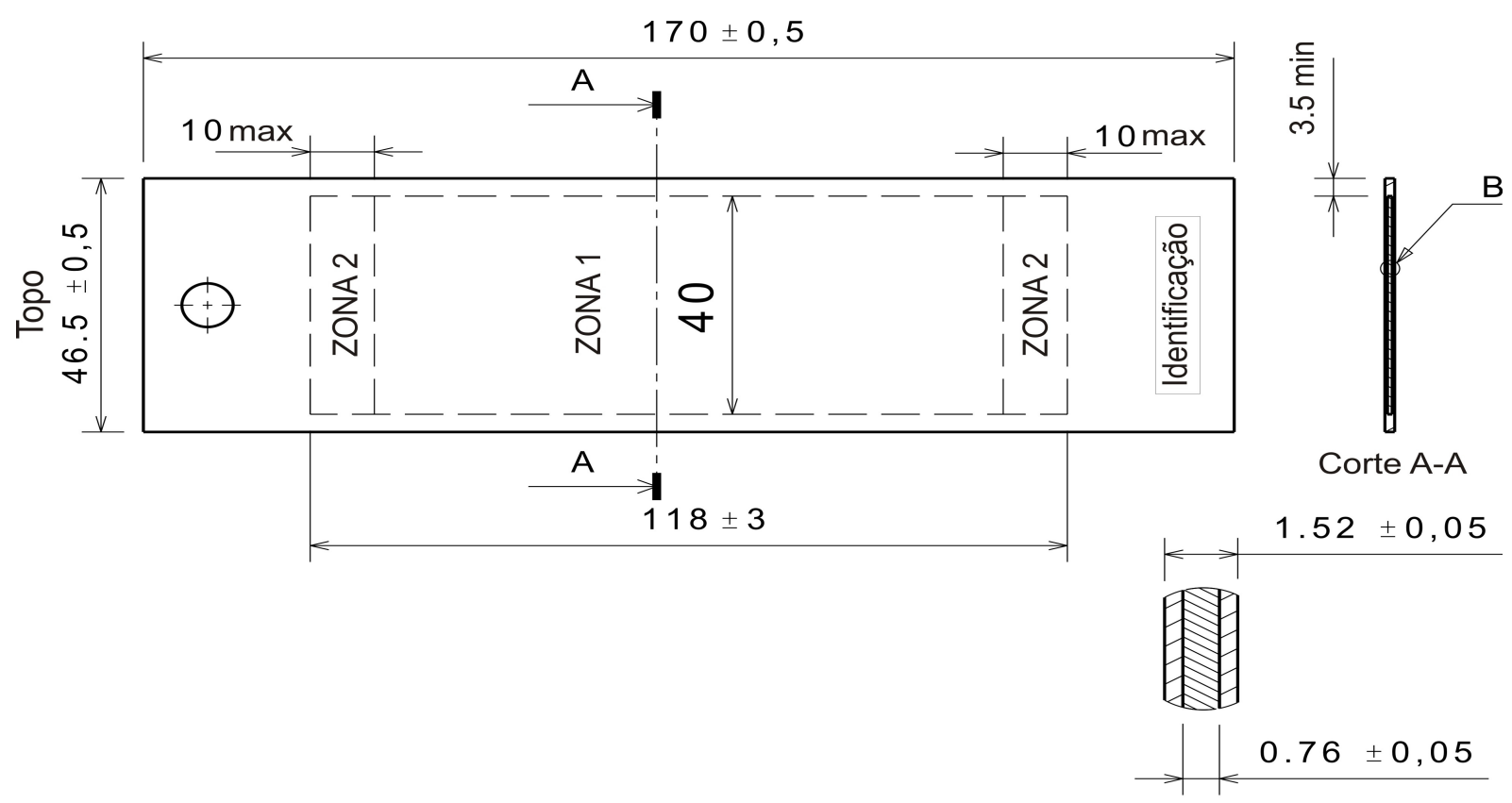

Detalhe B

Figura 3.4: Dimensões das miniplacas combustíveis. 


\subsubsection{Miniplacas Combustíveis Fabricadas}

Através da especificação técnica, 12 miniplacas foram fabricas com a densidade de 4 $\mathrm{gU} / \mathrm{cm}^{3}$ de urânio. Esta densidade foi escolhida devido estar próxima a que será usada no núcleo de equilíbrio do RMB com o combustível de $\mathrm{U}_{3} \mathrm{Si}_{2}$-Al.

A Figura 3.5 mostra as miniplacas fabricadas. A identificação delas foi gravada como U7MoE4-XX, onde:

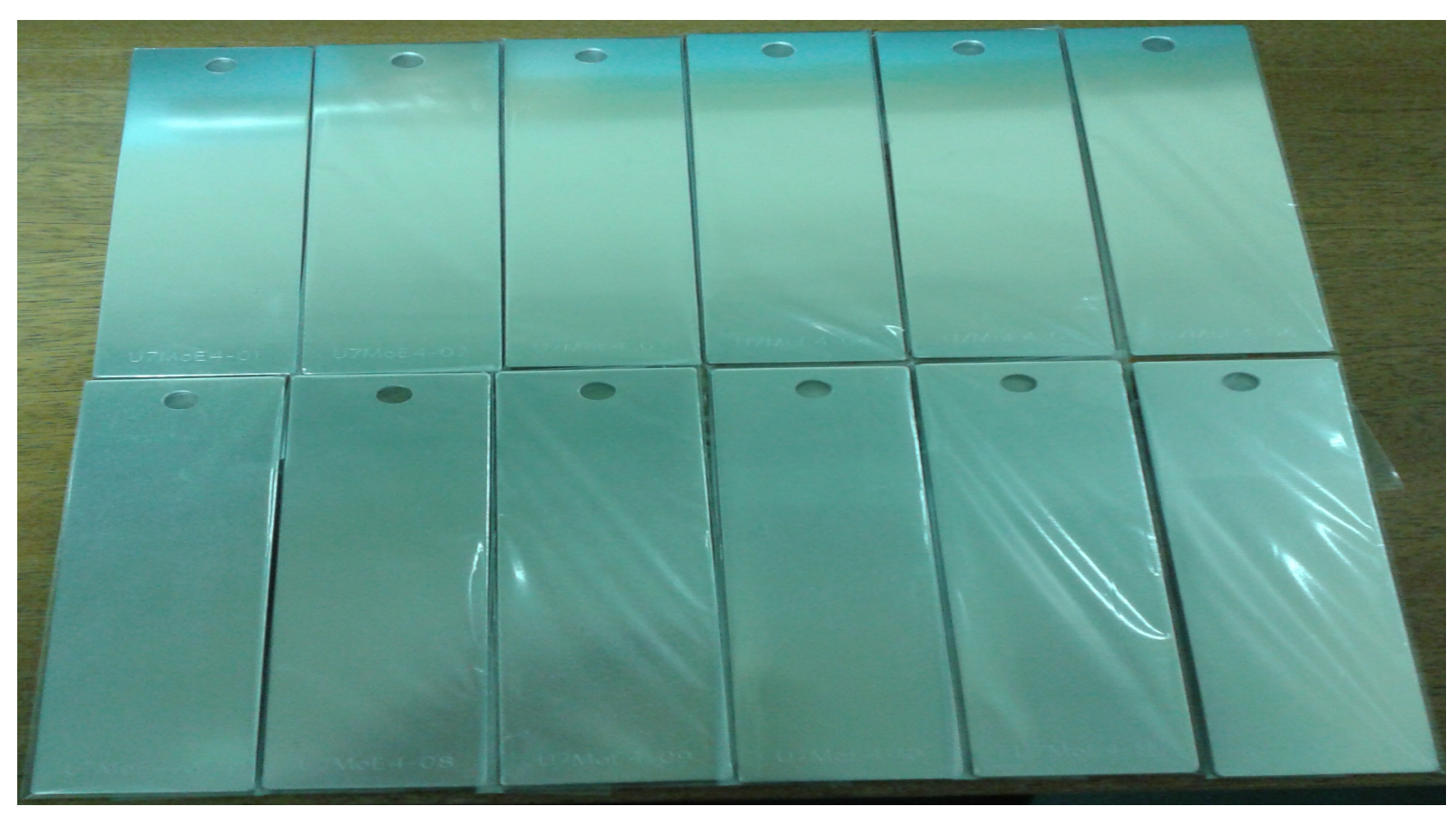

Figura 3.5: Doze miniplacas combustíveis fabricadas.

- U7Mo refere-se ao combustível ser de Urânio - Molibdênio com o molibdênio na quantidade de $7 \%$ em massa;

- E indica que o combustível é enriquecido de ${ }^{235} \mathrm{U}$;

- 4 representa a densidade de urânio, que é de $4 \mathrm{gU} / \mathrm{cm}^{3}$ e

- XX é a numeração de cada placa, que vai de 01 à 12.

A informação da massa do combustível de cada miniplaca é apresentada na Tabela 3.3. 
Tabela 3.3 - Massas das miniplacas combustíveis

\begin{tabular}{|c|c|c|c|c|c|}
\hline \hline Identificação & Massa de UMo $(\mathrm{g})$ & Massa U $(\mathrm{g})$ & Massa de Mo $(\mathrm{g})$ & Enriquecimento (\%) & Massa de ${ }^{235} \mathrm{U}(\mathrm{g})$ \\
\hline \hline U7MoE4-01 & 14,29 & 13,15 & 1,14 & & 2,604 \\
U7MoE4-02 & 14,37 & 13,22 & 1,15 & & 2,618 \\
U7MoE4-03 & 14,29 & 13,22 & 1,07 & & 2,618 \\
U7MoE4-04 & 14,30 & 13,16 & 1,14 & & 2,606 \\
U7MoE4-05 & 14,32 & 13,18 & 1,14 & & 2,610 \\
U7MoE4-06 & 14,25 & 13,11 & 1,14 & \multirow{2}{*}{19,804} & 2,596 \\
U7MoE4-07 & 14,32 & 13,18 & 1,14 & & 2,610 \\
U7MoE4-08 & 14,27 & 13,13 & 1,14 & & 2,600 \\
U7MoE4-09 & 14,29 & 13,22 & 1,07 & & 2,618 \\
U7MoE4-10 & 14,28 & 13,14 & 1,14 & & 2,602 \\
U7MoE4-11 & 14,29 & 13,22 & 1,07 & & 2,618 \\
U7MoE4-12 & 14,30 & 13,16 & 1,14 & & 2,606 \\
\hline
\end{tabular}

Das 12 miniplacas fabricadas apenas as placas de 1 à 10 foram usadas na irradiação no núcleo do reator IPEN/MB-01. As placas 11 e 12 ficaram como referência de miniplacas não irradiadas.

\subsection{Irradiador de Acrílico}

Para a irradiação das miniplacas combustíveis no reator IPEN/MB-01, foi projetado um irradiador de acrílico como mostram as Figuras 3.6 e 3.7.

O irradiador foi projetado para que o centro das miniplacas fiquem na metade da parte ativa das varetas combustíveis do reator, altura de $364 \mathrm{~mm}$ Figura 3.6. O projeto completo do irradiador encontra-se no apêndice A.

A Figura 3.7 mostra o irradiador fabricado. 

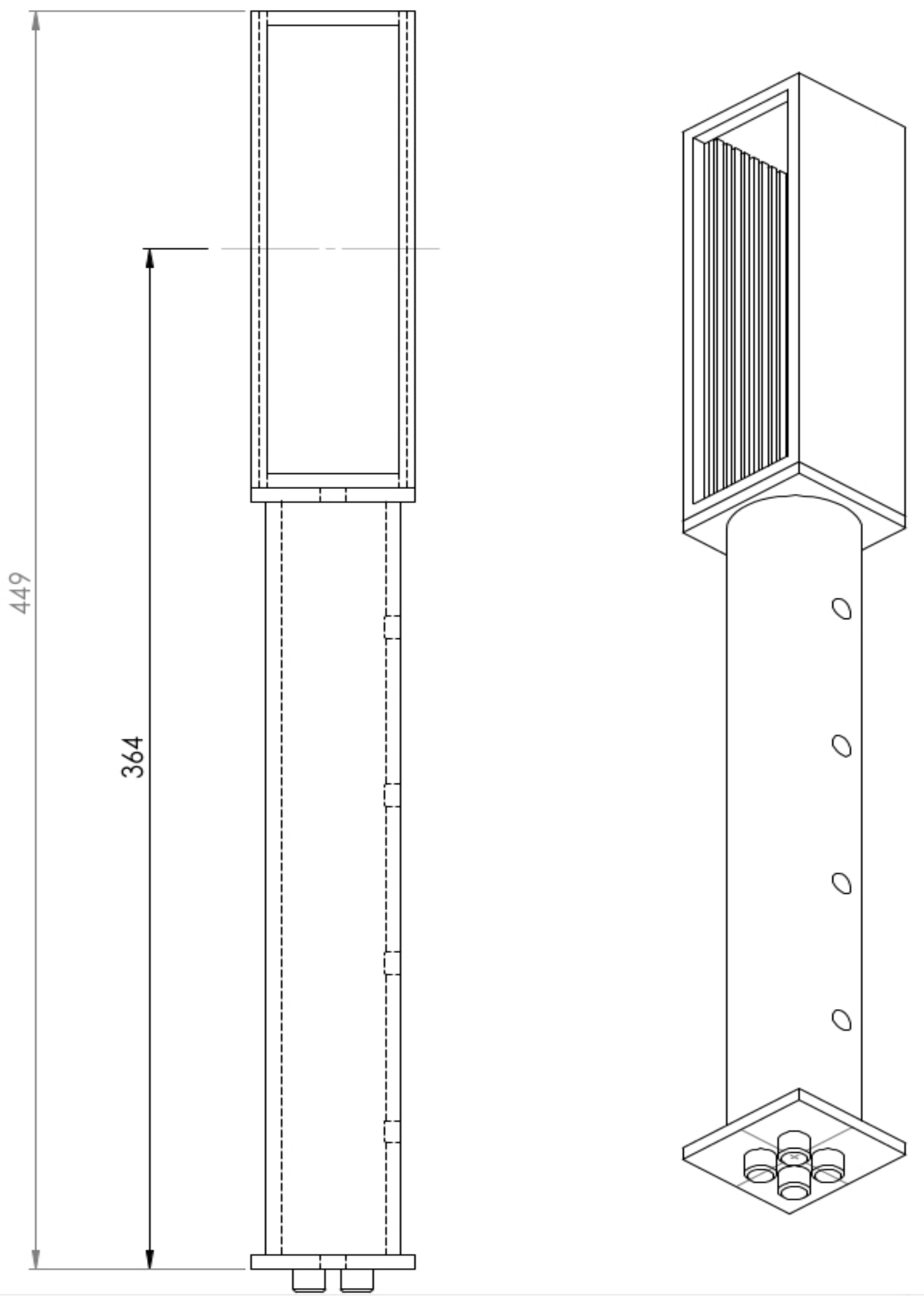

Figura 3.6: Projeto do irradiador de acrílico. 


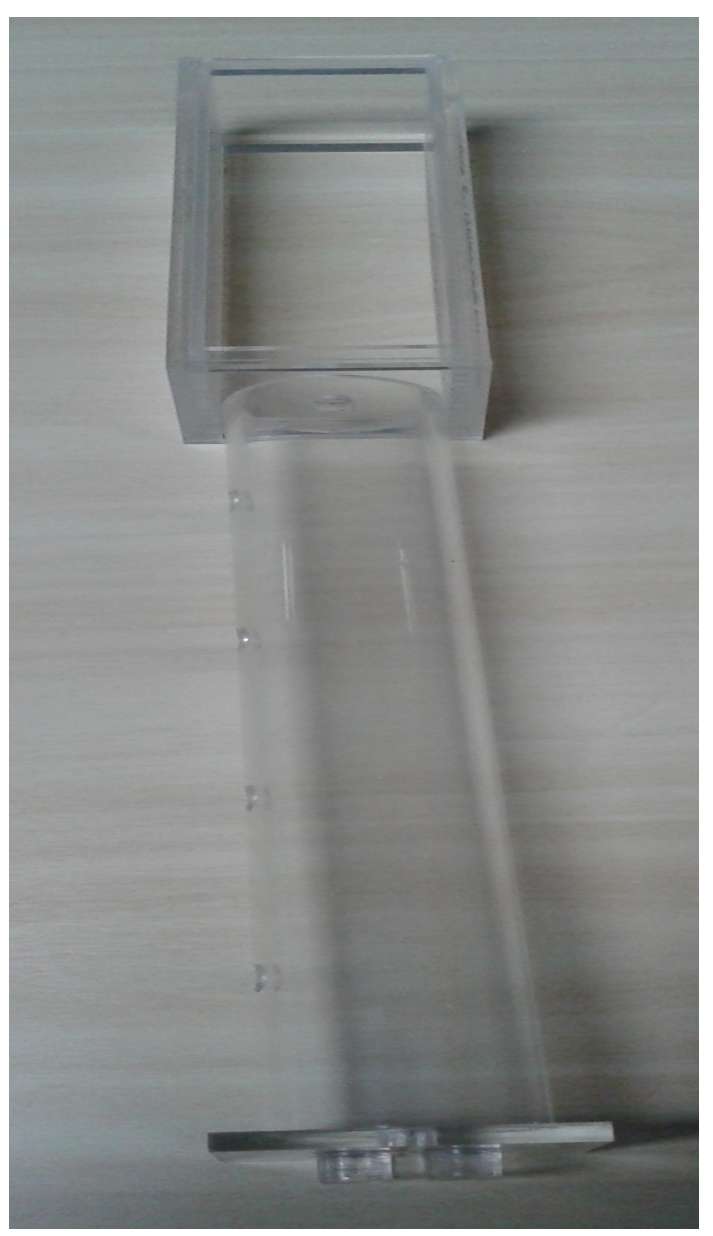

Figura 3.7: Irradiador de acrílico para as miniplacas combustíveis.

\subsection{Irradiação das Miniplacas}

Para determinar a reatividade inserida pelas miniplacas de U7wt\%Mo-AL com $4 \mathrm{gU} / \mathrm{cm}^{3}$, no núcleo do reator IPEN/MB-01, são realizadas quatro configurações do núcleo do reator. As simulações foram realizadas usando o código MCNP-5 e os dados de entrada utilizados foram os modificados da referência /27/, com a temperatura de $20{ }^{\circ} \mathrm{C}$. A descrição de cada configuração será dada a seguir.

\section{1) Primeira Configuração}

A primeira configuração é realizada com a configuração padrão 28 x 26 varetas com a retirada das seguintes varetas: colunas $\mathrm{L}$ a $\mathrm{O}$ e das linhas 13 a 16, totalizando 16 varetas retiradas do centro do núcleo, Figura 3.8. A potência de operação é de $1 \mathrm{~W}$ e após a 
determinação da reatividade através do reatímetro o reator é desligado (scram).

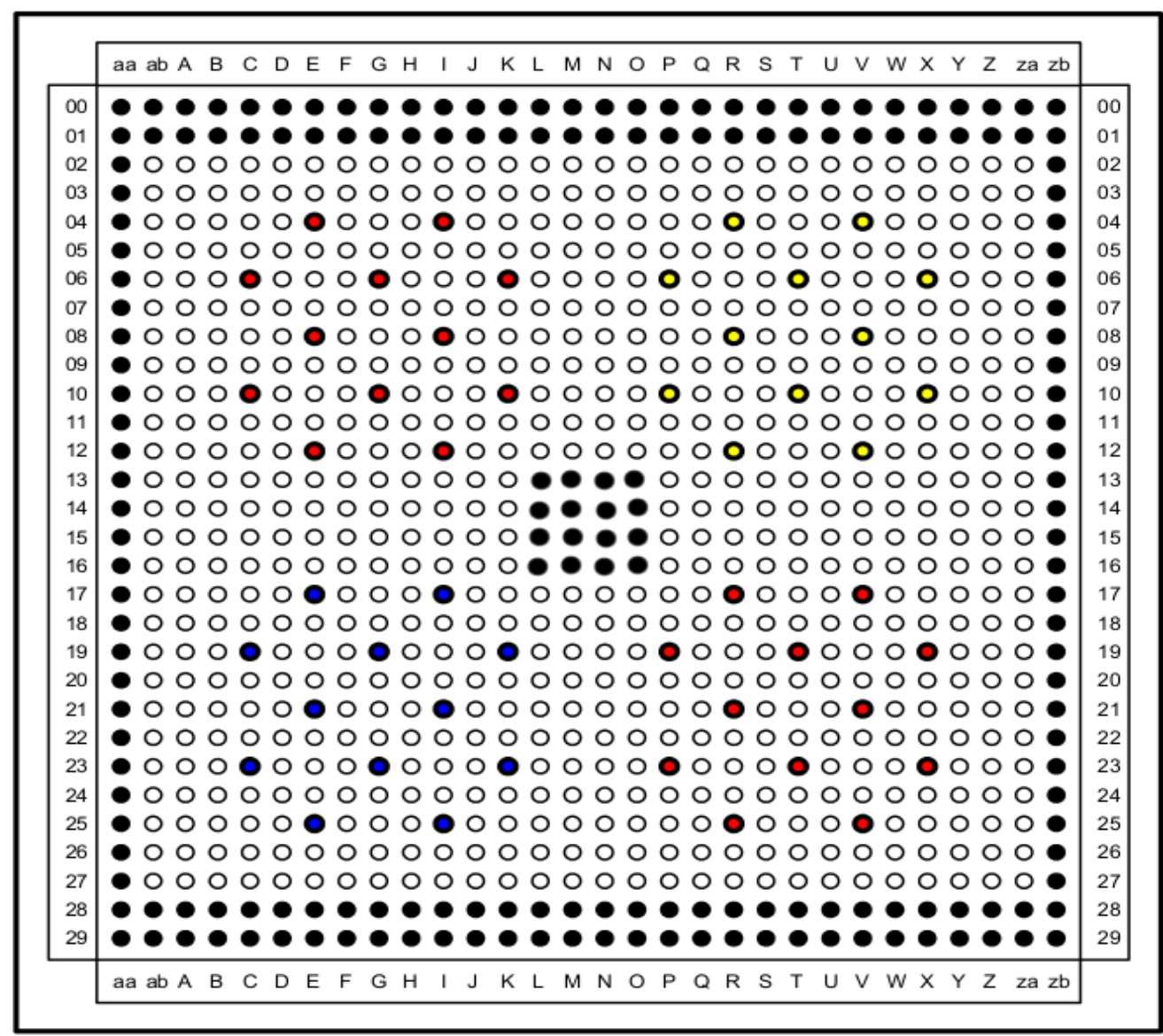

O Vareta Combustível

- Barra de Controle BC 1

- Barra de Controle BC 2

- Barra de Segurança

- Água Leve

Figura 3.8: Núcleo padrão (28 x 26) sem 16 varetas central.

\section{2) Segunda Configuração}

A segunda configuração é a do núcleo padrão retangular (28 x 26), com o irradiador (Figura 3.7) inserido na posição das varetas retiradas, como mostra a Figuras 3.9. 


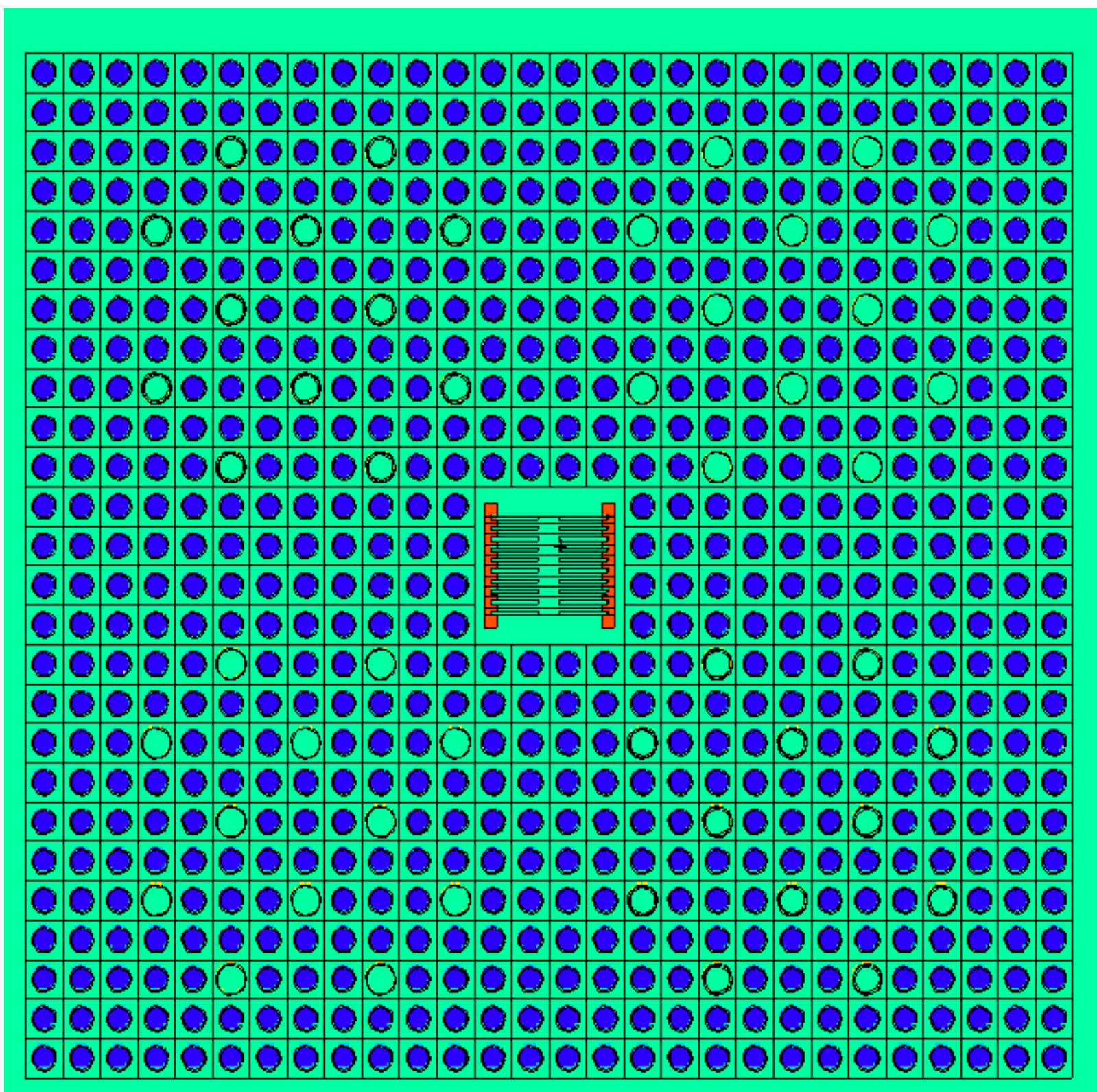

Figura 3.9: Núcleo do reator com o irradiador de acrílico (visão radial).

A Figura 3.10, mostra o eixo axial (altura) em que o ponto central das miniplacas fica na metade da parte ativa do núcleo do reator. A potência de operação é de $1 \mathrm{~W}$ e após a determinação da reatividade através do reatímetro o reator é desligado (scram). 


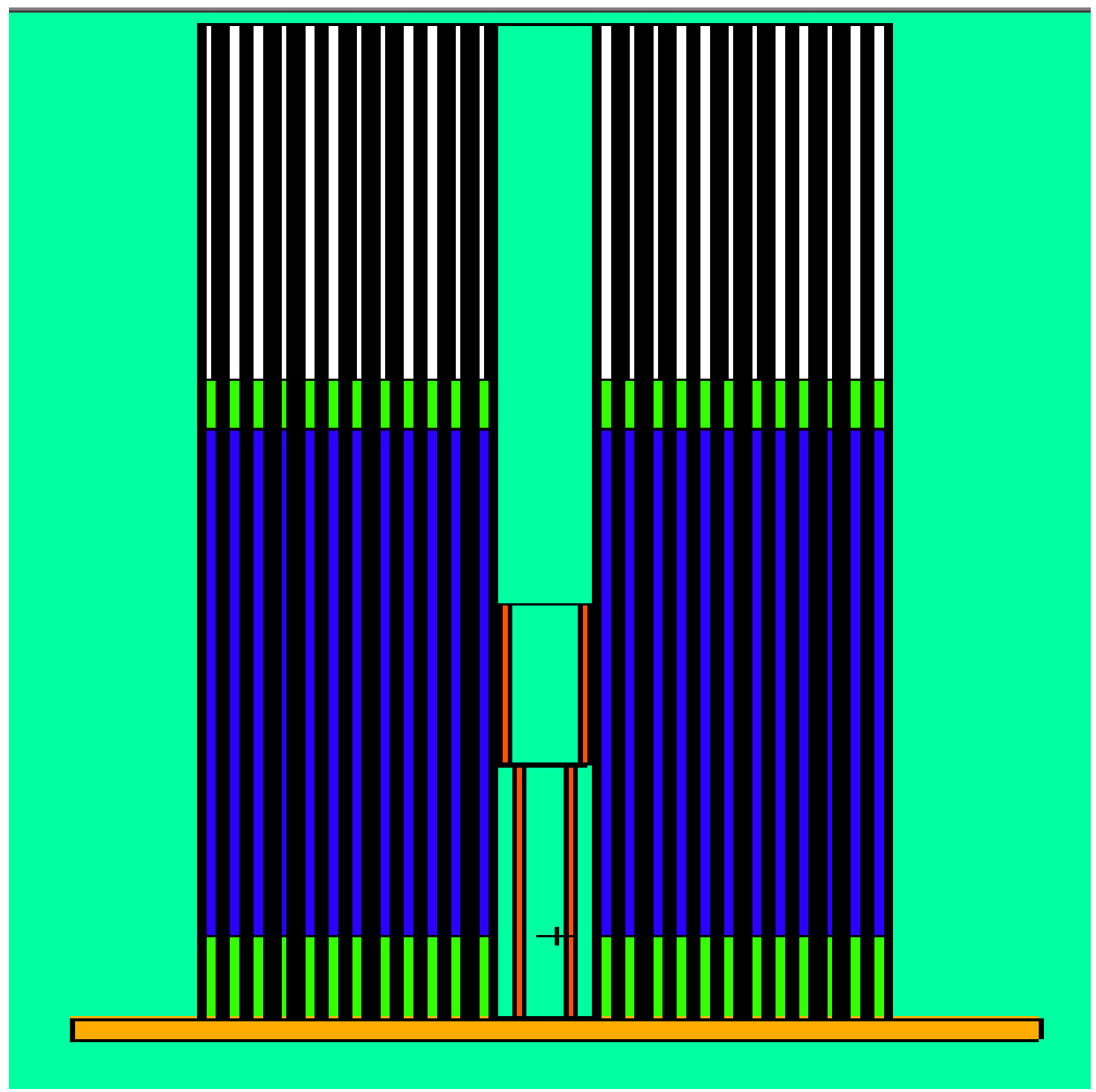

Figura 3.10: Núcleo do reator com o irradiador de acrílico (visão axial).

\section{3) Terceira Configuração}

Na terceira configuração, as 10 miniplacas combustíveis foram colocadas no irradiador como mostra a Figura 3.11. A operação foi realizada a uma potência de $1 \mathrm{~W}$ e após a determinação da reatividade através do reatímetro, o reator foi desligado (scram). Os dados de entrada utilizados na simulação desta configuração estão no apêndice B. 


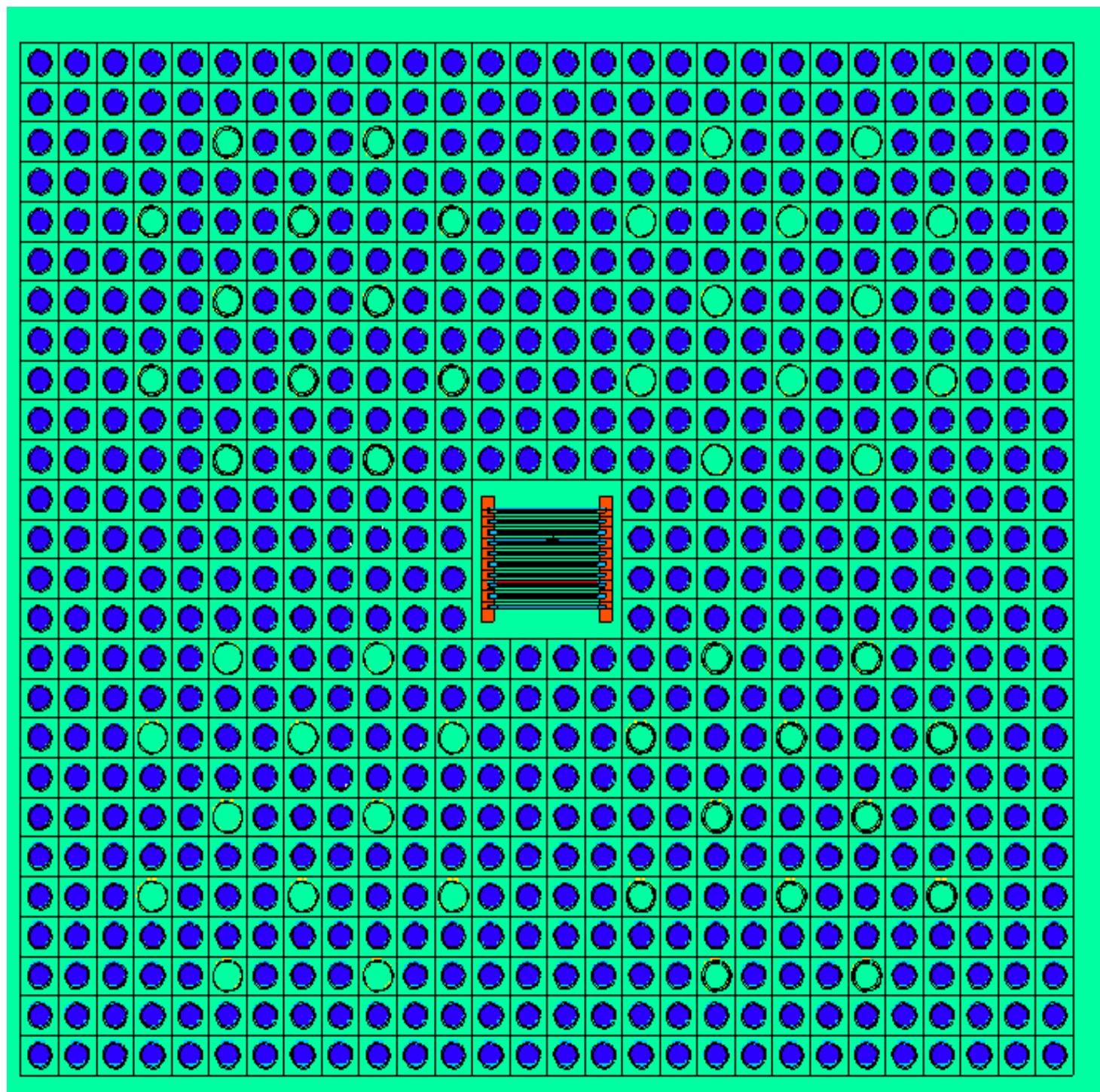

Figura 3.11: Núcleo do reator com o irradiador de acrílico e miniplacas combustíveis.

\section{4) Quarta Configuração}

Na quarta configuração, o núcleo padrão é modificado com a retirada de varetas combustíveis. Foram retiradas 102 varetas combustíveis, como mostra a Figura 3.12, para obter uma "leve" supercríticalidade com as barras de controle totalmente retiradas e com o irradiador inserido no centro do núcleo com as 10 miniplacas combustíveis. A reatividade é obtida com o reatímetro com o reator supercrítico. Os dados de entrada utilizados na simulação desta configuração estão no apêndice C. 


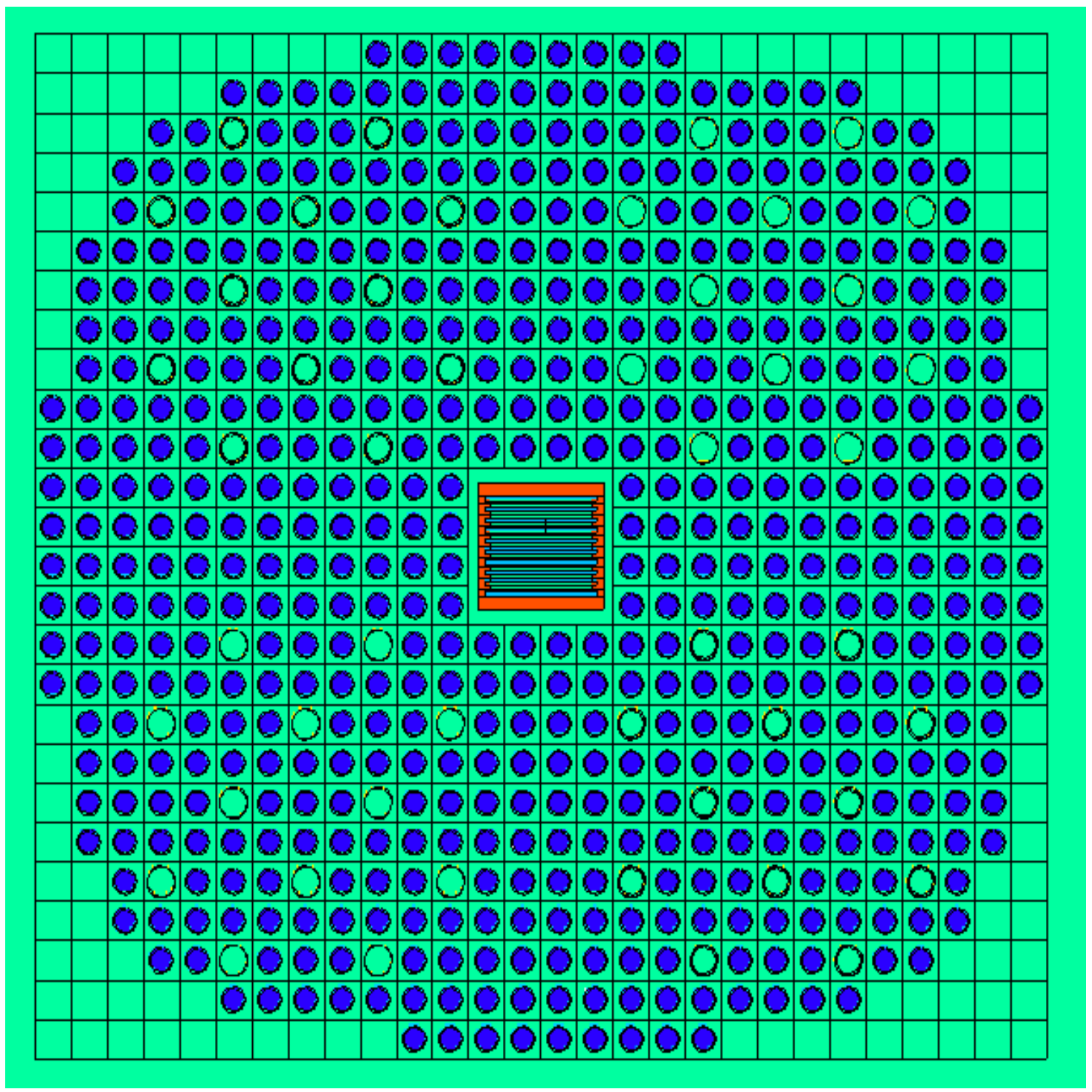

Figura 3.12: Núcleo do reator modificado com o irradiador de acrílico e miniplacas combustíveis. 
Capítulo 4

\section{Resultados e Análise}

\subsubsection{Variação da Densidade de Urânio}

A primeira comparação realizada foi entre o comportamento dos combustíveis $\mathrm{U}_{3} \mathrm{Si}_{2}-\mathrm{Al}$ e UMo-Al (com 7 e 10\% em massa de Mo) com a variação da densidade de urânio. Os resultados obtidos são apresentados na Figura 4.1.

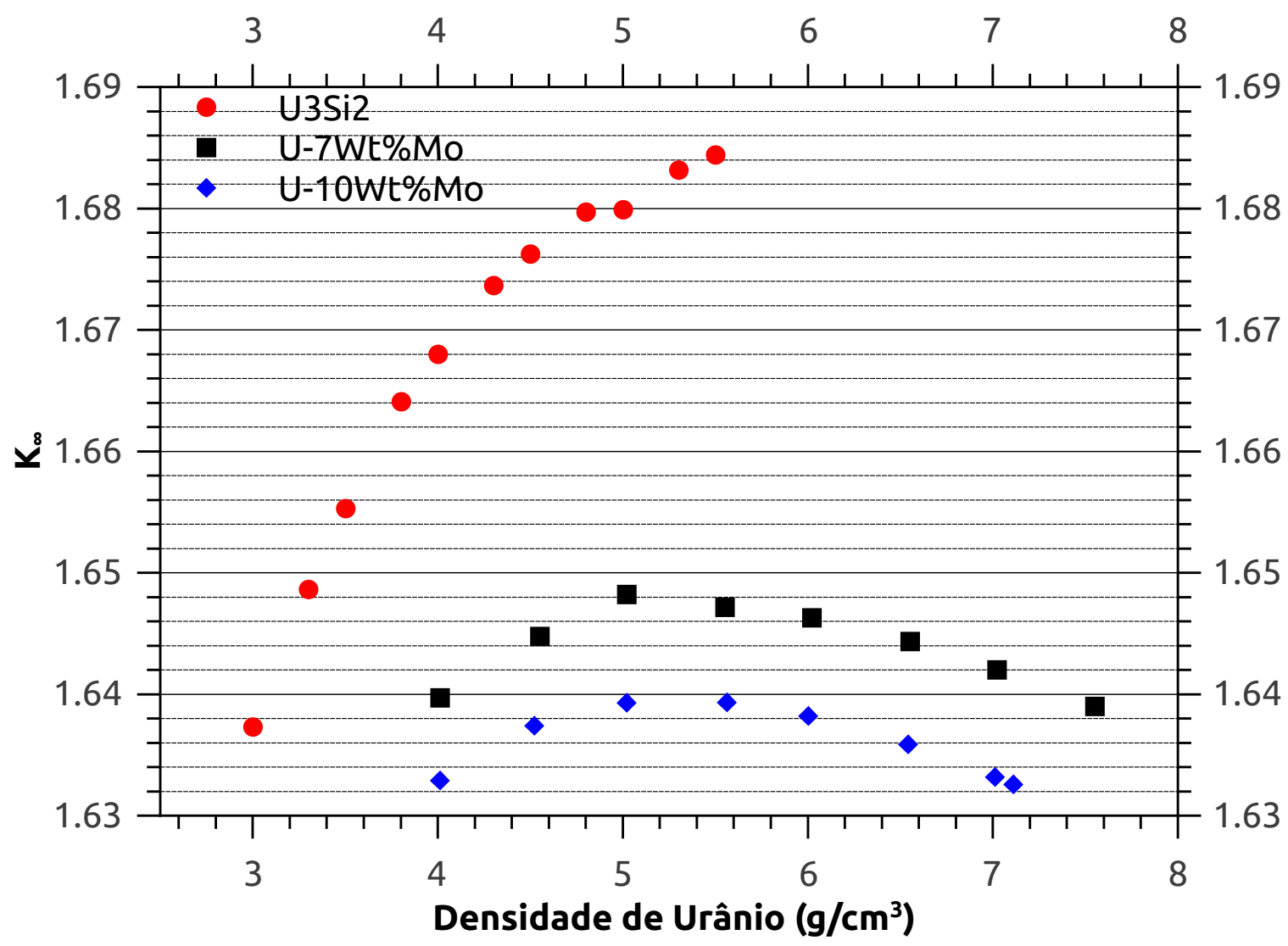

Figura 4.1: Comparação entre o $\mathrm{U}_{3} \mathrm{Si}_{2}-\mathrm{Al}$ e UMo-Al com a variação da densidade de urânio. 
Esta comparação foi obtida utilizando-se apenas o HRC, devido ao objetivo aqui ser a comparação entre os dois tipos de combustível.

O $\mathrm{U}_{3} \mathrm{Si}_{2}$ está qualificado para a densidade de até $4,8 \mathrm{gU} / \mathrm{cm}^{3}$ e os demais pontos simulados foram apenas para comparação. O HRC calcula o valor do fator de multiplicação infinito $\left(\mathrm{k}_{\infty}\right)$.

$\mathrm{O}\left(\mathrm{k}_{\infty}\right)$ não leva em consideração a fuga de nêutrons do sistema (sistema infinito) e é formado por quatro fatores como mostra a equação 1 :

$$
\mathrm{k}_{\infty}=\eta \cdot \varepsilon \cdot p \cdot f(1)
$$

Onde:

$\eta$ é o número de nêutrons produzidos por fissão por nêutrons térmico absorvido;

$\varepsilon$ é o fator de fissão rápido;

$p$ é a probabilidade de escape da ressonância;

$f$ é o fator de utilização térmica.

Como mostra a Figura 4.1, o comportamento dos combustíveis é bem diferente com a variação da densidade de urânio.

Esta diferença esta relacionada com a diferença na seção de choque de absorção entre o Si e o Mo como mostra a Figura 2.2.

As Figuras 4.2, 4.3, 4.4 e 4.5 mostram a comparação entre o combustível $\mathrm{U}_{3} \mathrm{Si}_{2}-\mathrm{Al}$ e o U7wt\%Mo-Al para cada fator da fórmula dos quatro fatores que compõem a equação do $\mathrm{K}_{\infty}$ 


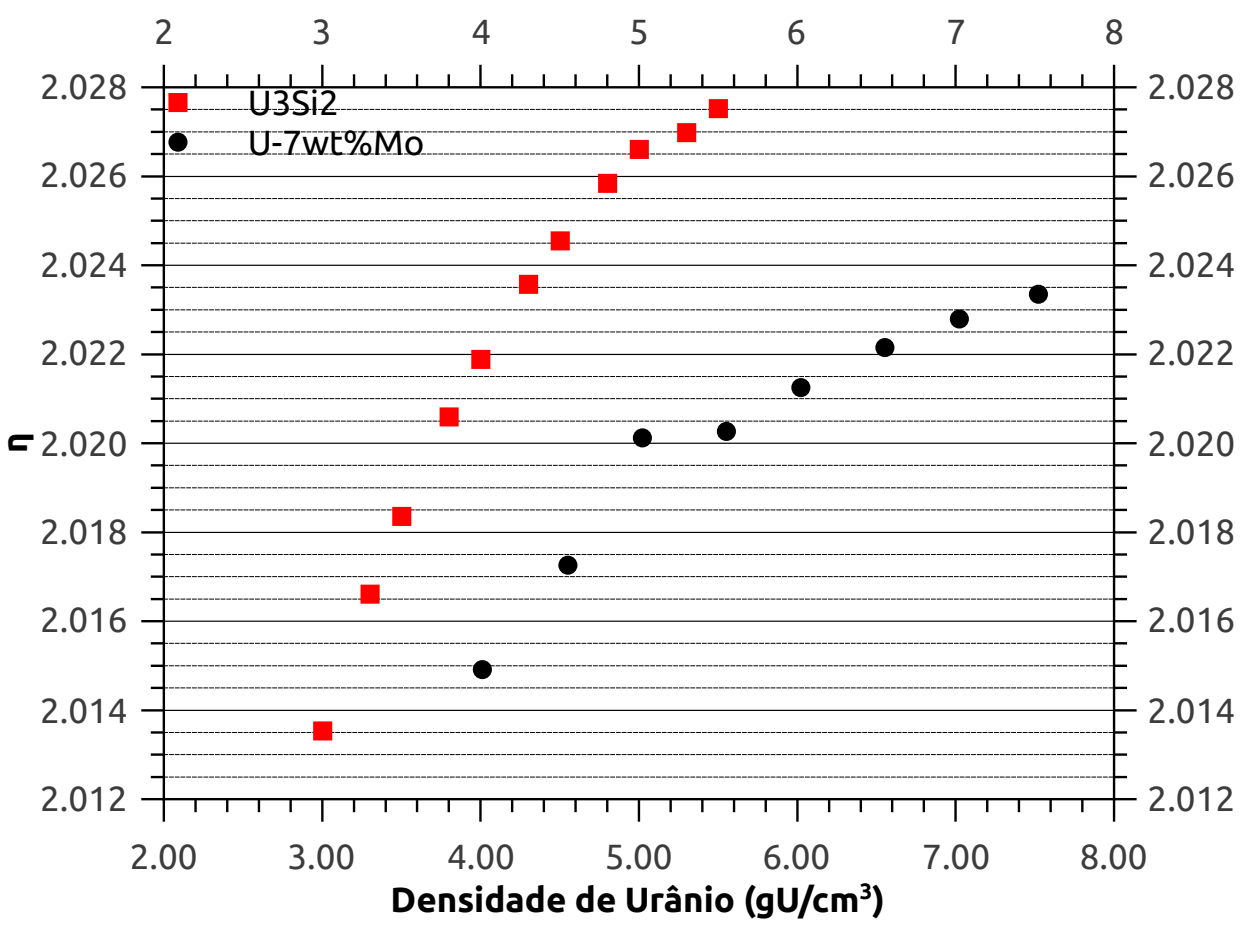

Figura 4.2: Fator $\eta$ da fórmula dos quatro fatores.

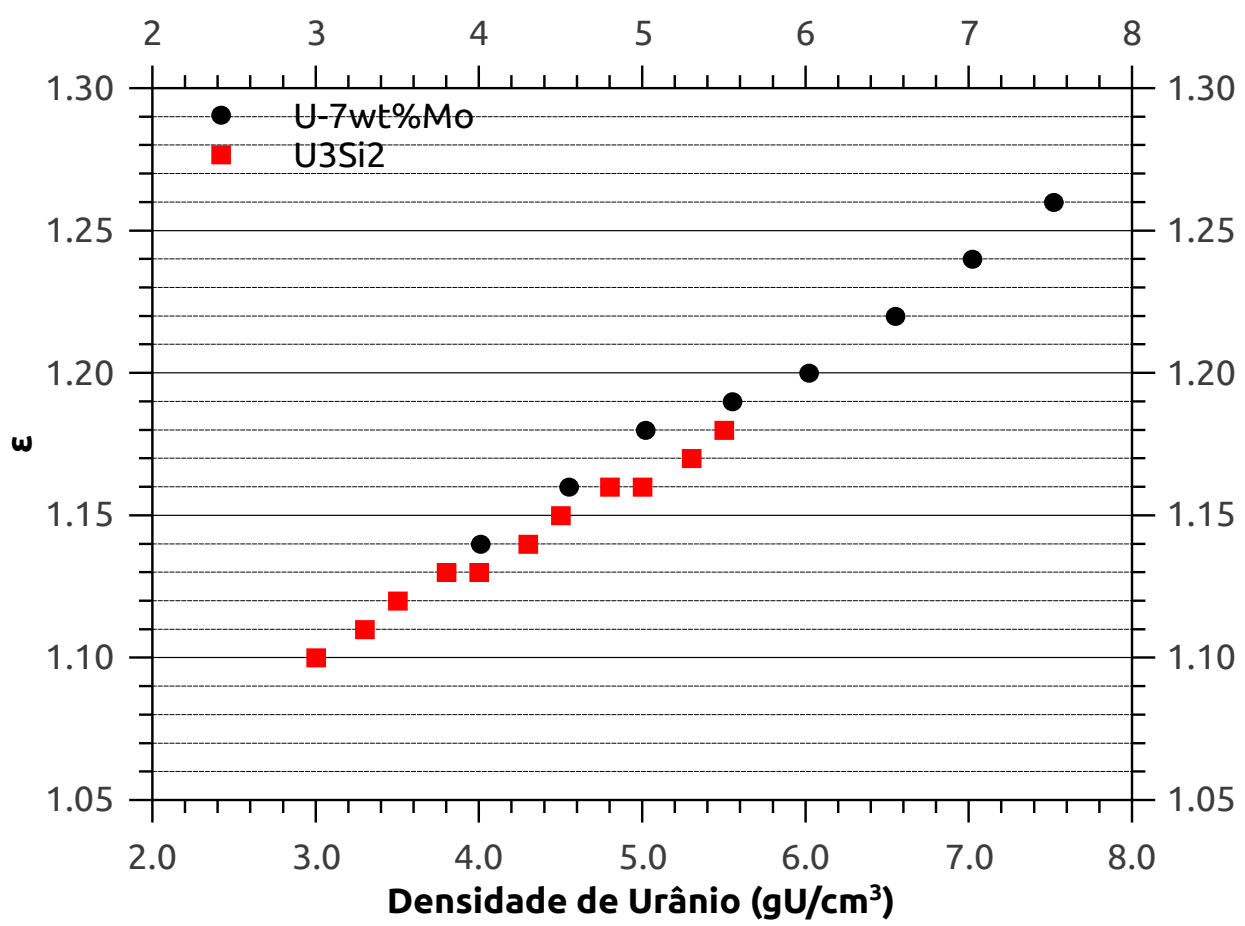

Figura 4.3: Fator $\varepsilon$ da fórmula dos quatro fatores. 


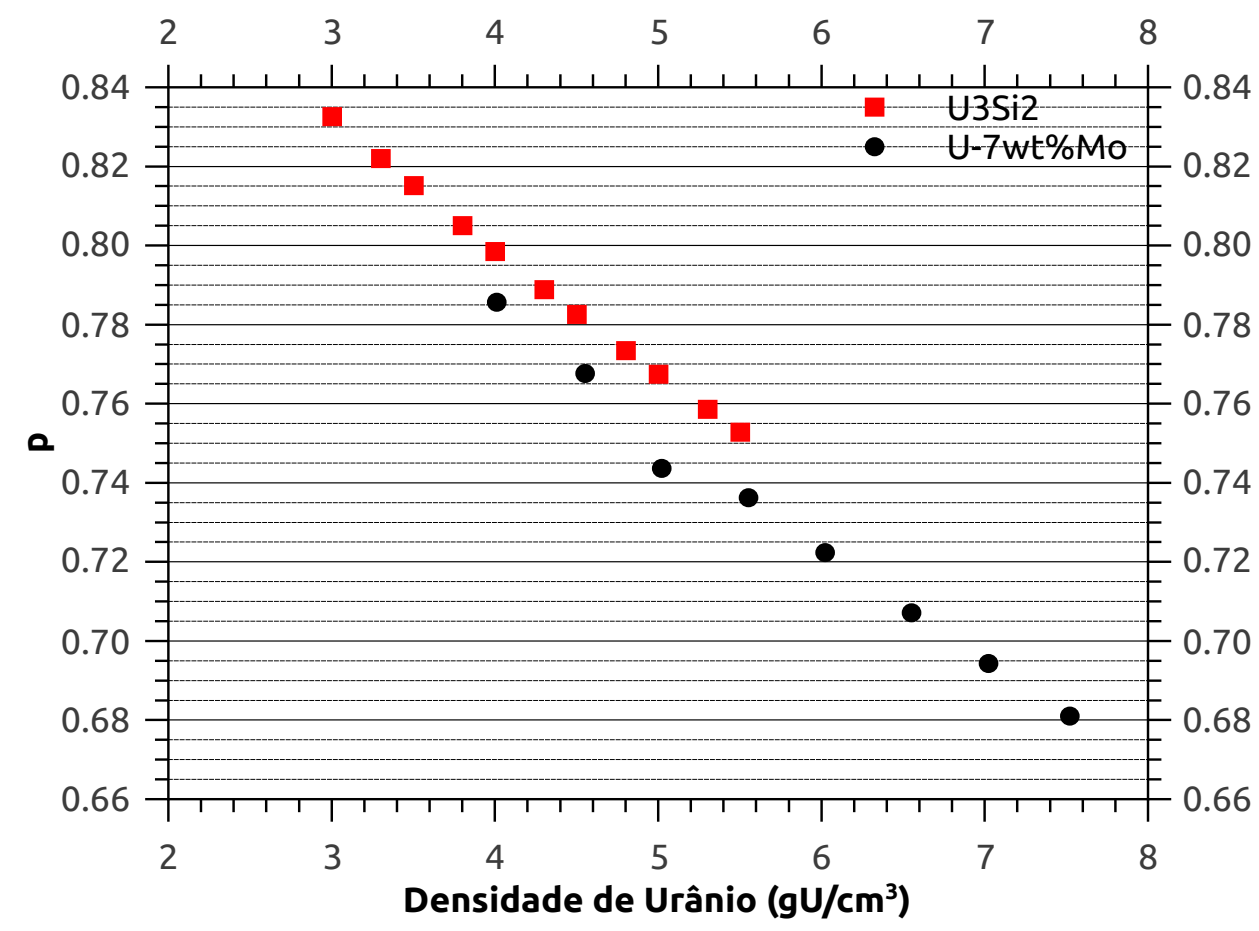

Figura 4.4: Fator $p$ da fórmula dos quatro fatores.

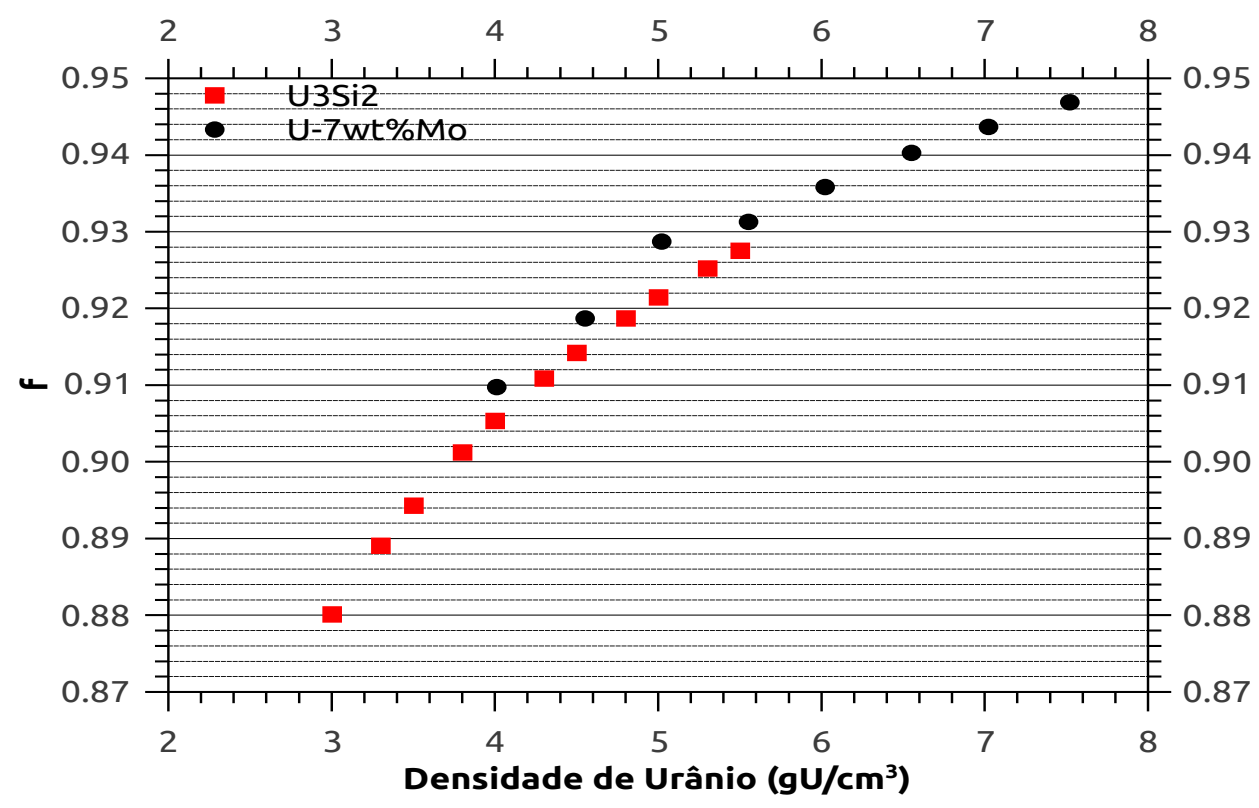

Figura 4.5: Fator $f$ da fórmula dos quatro fatores.

Com os resultados apresentados é possível observar que o fator $p$, que é a probabilidade 
de escape da ressonância, diminui mais acentuadamente no UMo-Al do que no $\mathrm{U}_{3} \mathrm{Si}_{2}-\mathrm{Al}$, isto quer dizer que mais nêutrons estão sendo absorvidos na liga de UMo. Uma parte dos nêutrons que são absorvidos são capturados pelo ${ }^{238} \mathrm{U}$ que forma o núcleo composto de ${ }^{239} \mathrm{U}$, que decai para o ${ }^{239} \mathrm{~Np}$ e depois para o ${ }^{239} \mathrm{Pu}$. A conversão para ${ }^{239} \mathrm{Pu}$ é de extrema importância na queima do combustível pois, assim como o ${ }^{235} \mathrm{U}$ é um material físsil.

O comportamento durante a queima do combustível $\mathrm{U}_{3} \mathrm{Si}_{2}-\mathrm{Al}$ com a densidade de 4 $\mathrm{gU} / \mathrm{cm}^{3}$ e do combustível de UMo-Al com a densidade de urânio entre 5 e $7 \mathrm{gU} / \mathrm{cm}^{3}$ é apresentado nas Figuras 4.6 e 4.7. Estes resultados foram obtidos com o programa HRC.

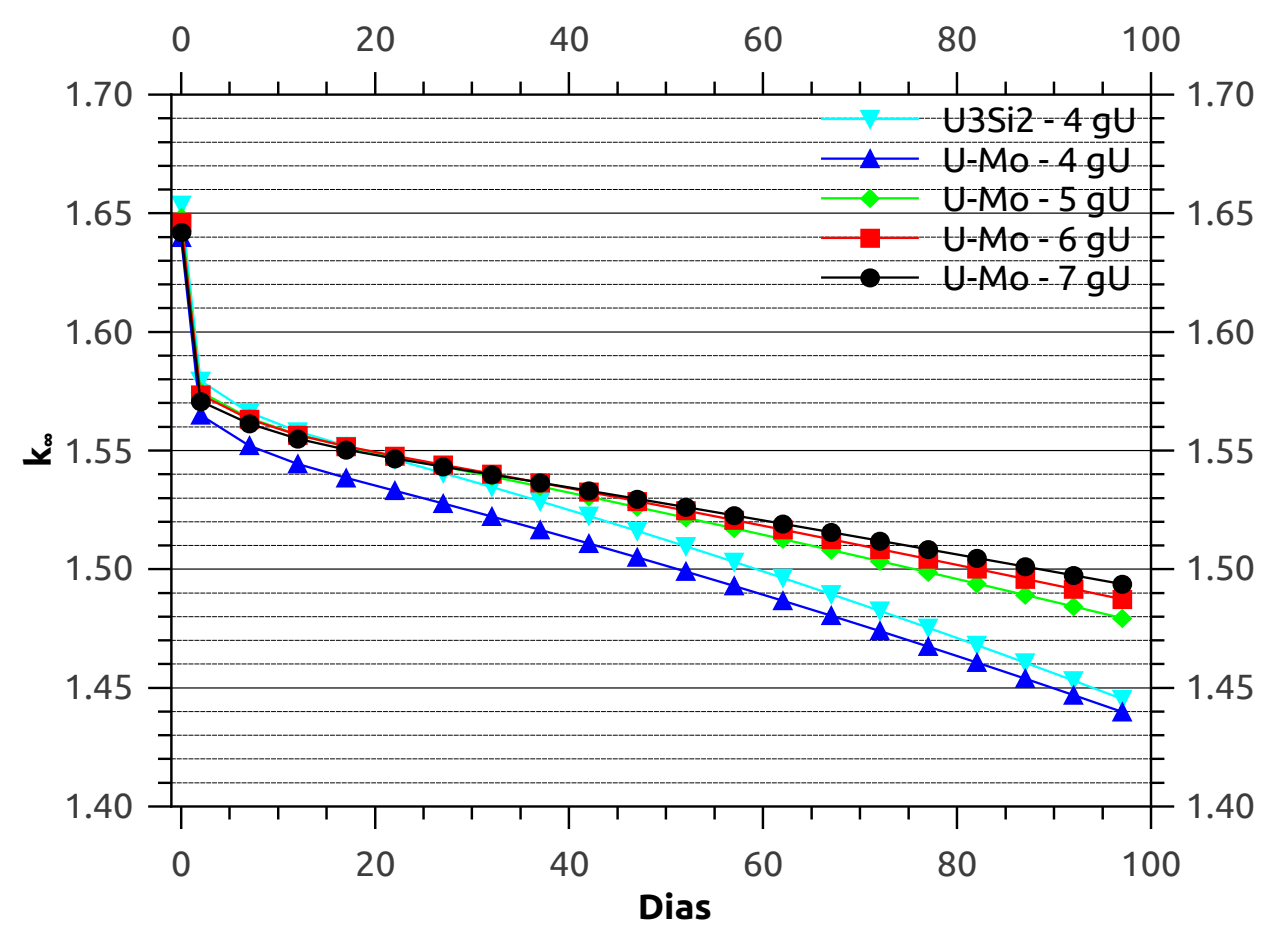

Figura 4.6: Comparação entre a queima do combustível $\mathrm{U}_{3} \mathrm{Si}_{2}$-Al e do U7wt\%Mo-Al. 


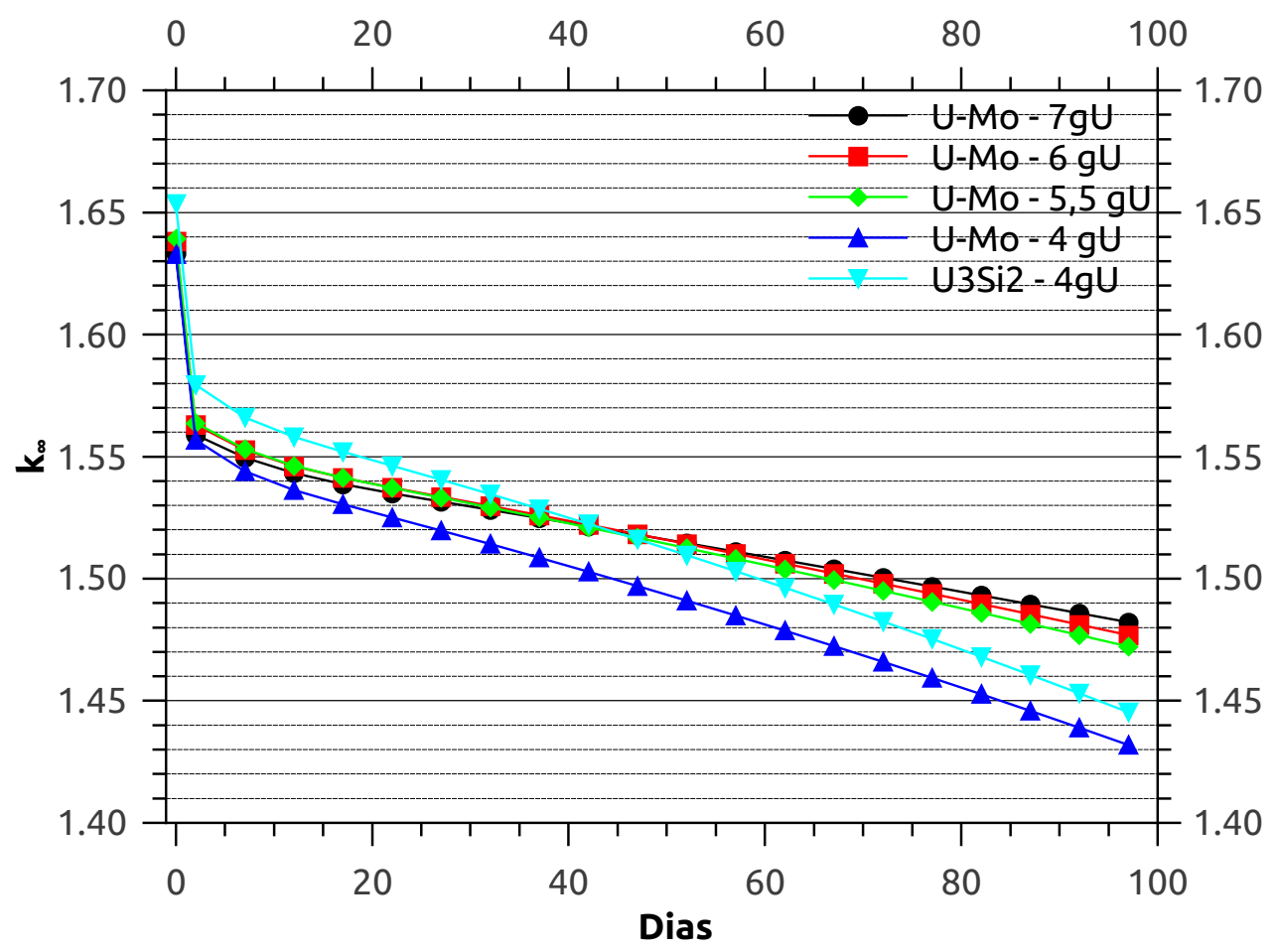

Figura 4.7: Comparação entre a queima do combustível $\mathrm{U}_{3} \mathrm{Si}_{2}$-Al e do U10wt\%Mo-Al.

Os resultados mostram que há uma inversão, para as densidades acima de $4 \mathrm{gU} / \mathrm{cm}^{3}$ do combustível UMo-Al, durante a queima e que no final do período analisado (em torno de 100 dias) o combustível UMo-Al apresenta valores do $\mathrm{K}_{\infty}$ maiores que o $\mathrm{U}_{3} \mathrm{Si}_{2}-\mathrm{Al}$.

Os resultados mostram que é possível obter um ciclo de queima maior com o UMo-Al, com maior densidade de urânio, do que com o combustível $\mathrm{U}_{3} \mathrm{Si}_{2}$-Al com $4 \mathrm{gU} / \mathrm{cm}^{3}$. O ciclo de queima é maior no combustível UMo-Al devido a conversão em ${ }_{94}^{239} \mathrm{Pu}$ ser maior no UMo-Al do que no combustível de $\mathrm{U}_{3} \mathrm{Si}_{2}-\mathrm{Al}$, como exemplifica a Figura 4.8 com a comparação entre a produção de plutonio 239 no $\mathrm{U}_{3} \mathrm{Si}_{2}-\mathrm{Al}$ com a densidade de urânio de $4 \mathrm{gU} / \mathrm{cm}^{3}$ e no UMo-Al com a densidade de $5 \mathrm{gU} / \mathrm{cm}^{3}$. 


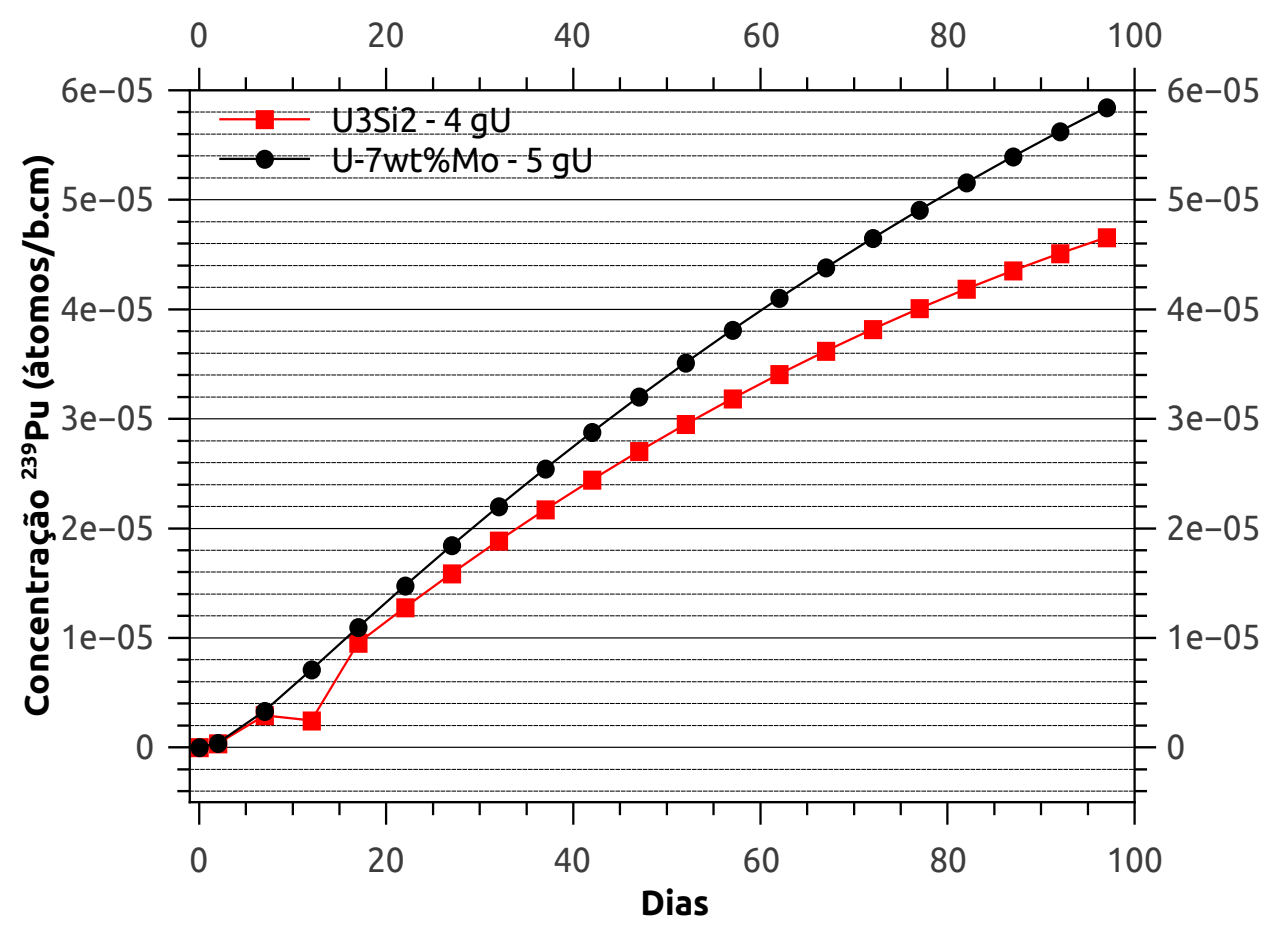

Figura 4.8: Comparação entre a conversão do ${ }^{239} \mathrm{Pu}$ no combustível $\mathrm{U}_{3} \mathrm{Si}_{2}-\mathrm{Al}$ e no U7wt\%Mo-Al.

Devido a absorção de nêutrons no molibdênio ser considerável, a porcentagem de molibdênio escolhida para as demais análises foi de $7 \%$ em massa (U7wt\%Mo).

\subsubsection{Veneno Queimável}

Este trabalho tem como objetivo analisar a utilização de um elemento adicionado ao combustível que funcione como veneno queimável.

O método utilizado para adicionar a quantidade de veneno queimável no combustível foi adicionar uma porcentagem em massa do material (veneno) em relação a massa do combustível, por exemplo, se a massa do UMo for de $100 \mathrm{~g}$ e o veneno estiver em uma porcentagem de $0,25 \%$ a quantidade em massa de veneno adicionada é de 0,25 g.

\subsubsection{Gadolínio}

O primeiro material analisado foi o gadolínio (Gd), que possui alta seção de choque de absorção de 49000 b /26/. Foram realizadas simulações com o programa HRC onde a porcentagem em massa de Gd variou de 0 (sem Gd) a 0,10 \%, com densidade de urânio 
$5,55 \mathrm{gU} / \mathrm{cm}^{3}$ no combustível de U7wt\%Mo-Al. A densidade de $5,55 \mathrm{gU} / \mathrm{cm}^{3}$ foi escolhida para esta análise por permitir um maior ciclo de queima, como as densidades de 6 e 7 $\mathrm{gU} / \mathrm{cm}^{3}$, como mostram os resultados da Figura 4.6. Os resultados são apresentados na Figura 4.9 .

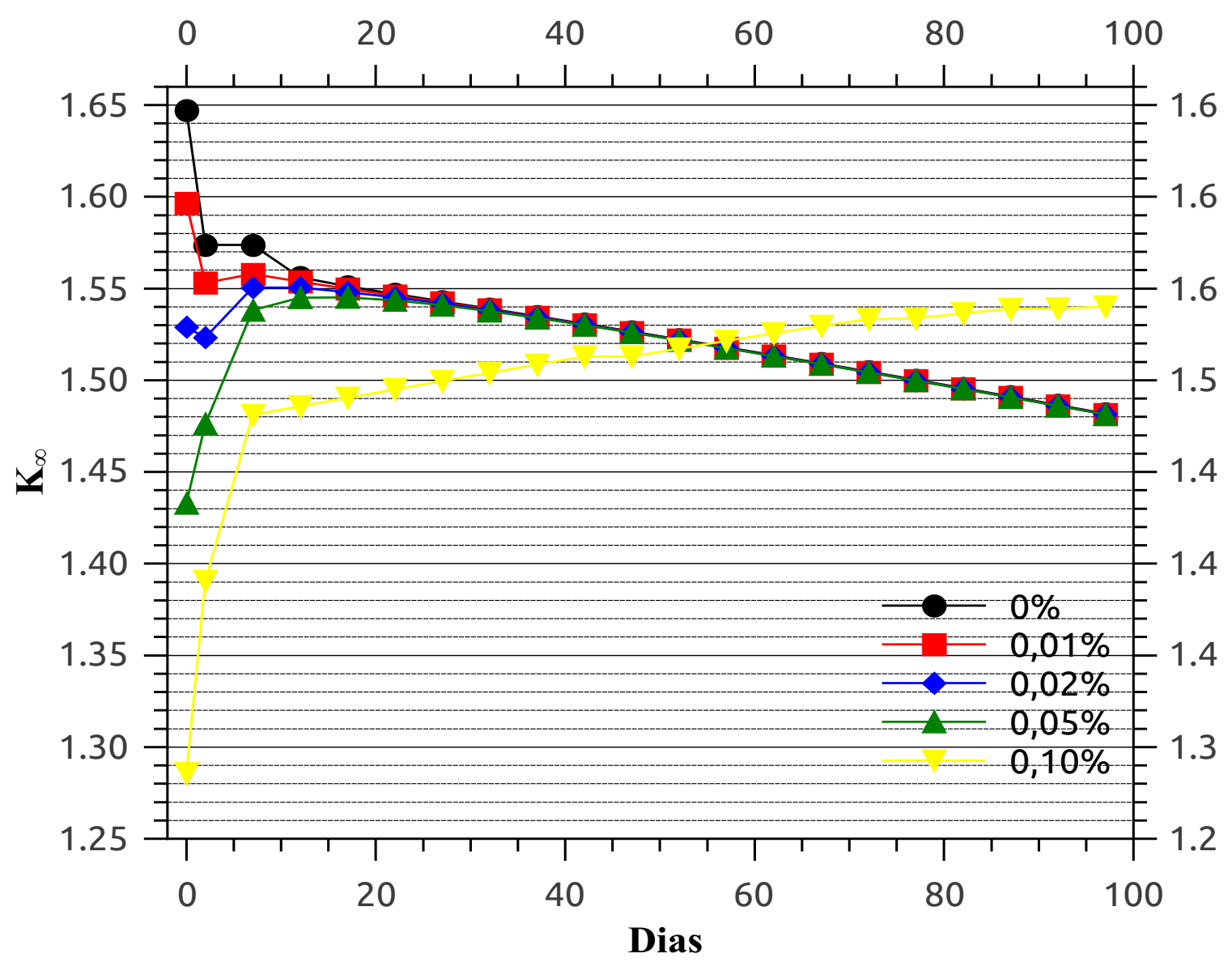

Figura 4.9: Simulações com o programa HRC com a variação Gd entre 0 (sem Gd) a 0,10\% em massa.

Pela Figura 4.9 observa-se que o gadolínio causa uma grande perturbação na reatividade inicial do ciclo e que apenas quantidades entre 0,020 e 0,010 \% permitem minimizar esta perturbação. Outro problema causado é a rápida "queima" do gadolínio que não permite um ciclo de operação do reator plano (reatividade constante) ao longo do tempo.

\subsubsection{Európio}

O európio possui uma seção de choque de absorção de 4600 b, menor que a do gadolínio, mas ainda assim alta /26/. Foram realizadas simulações com o programa CITATION onde 
a porcentagem em massa de Eu variou de 0 (sem Eu) a 0,30\%, com densidade de urânio 3,55 gU/ $\mathrm{cm}^{3}$ no combustível de U7wt\%Mo-Al. Esta densidade de urânio foi escolhida para a análise por estar próxima a densidade que será usada no RMB com o combustível de $\mathrm{U}_{3} \mathrm{Si}_{2}$-Al. Os resultados são apresentados na Figura 4.10. Os dados de entrada para a simulação com 0,25 \% de Eu estão no apêndice D.

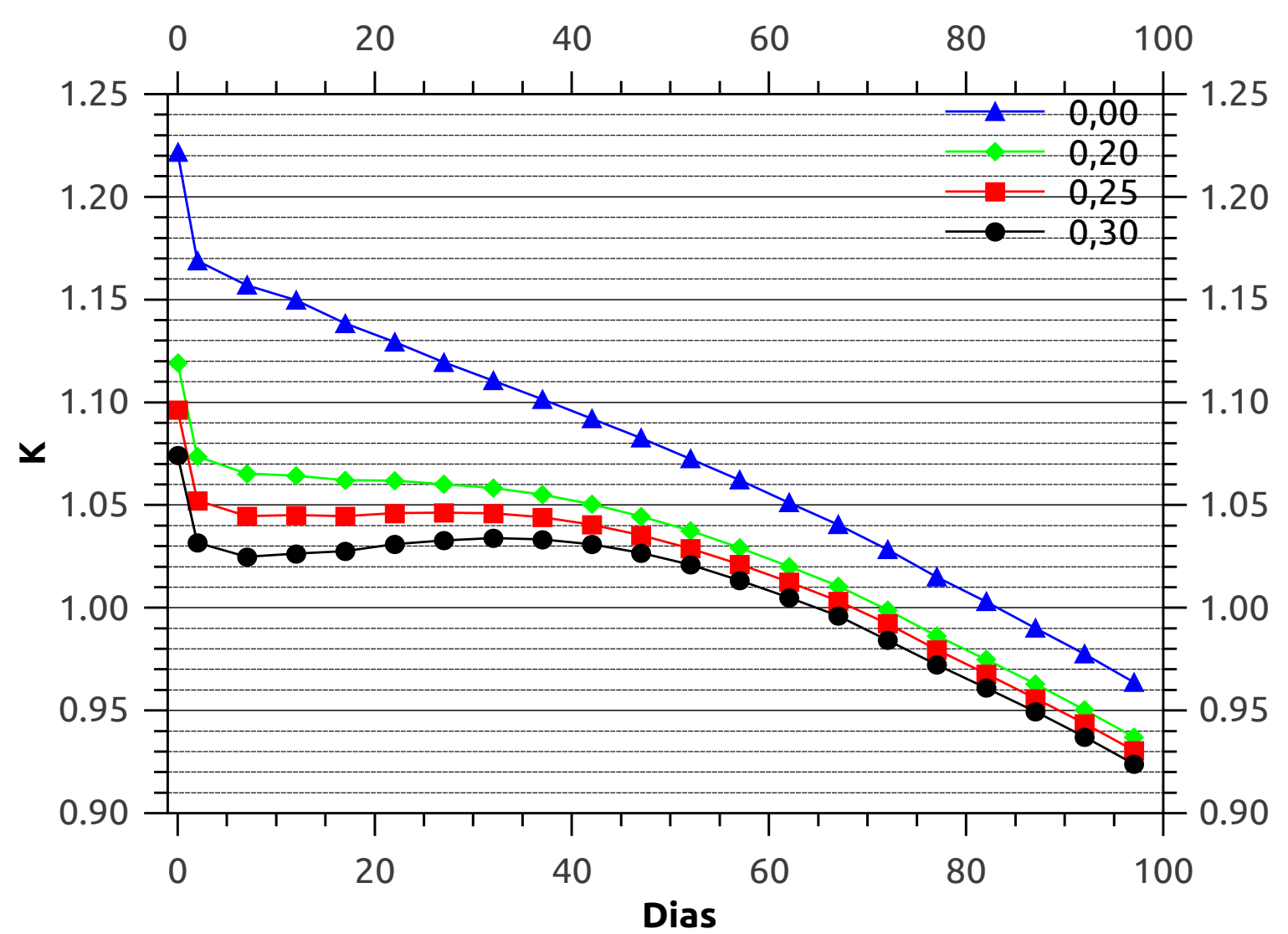

Figura 4.10: Simulações com o CITATION com a variação de Eu entre 0 a 0,30\% em massa.

É possível notar pela Figura 4.10 que o európio permite um controle inicial melhor da reatividade do reator e ao longo do ciclo de operação, permitindo uma menor variação da reatividade ao longo do ciclo de 30 dias de operação. Estes resultados mostram que do ponto de vista neutrônico, o európio pode ser usado como veneno queimável para um reator com as características consideradas.

Destes resultados, considerou-se que a quantidade de európio que melhor atende ao ciclo do reator é a de 0,25\%. Para este caso, também utilizou-se o programa SERPENT. 
Os resultados obtidos com o CITATION e o SERPENT estão nas Tabelas 3.4 e Figura 4.11 .

Com os resultados obtidos é possível verificar que os dois programas tem uma boa concordância entre si, ou seja, representam da mesma forma a geração do Xenônio (2 dias), o consumo do veneno ( $\approx 32$ dias) e a depleção do combustível.

Tabela 4.1 - Valores de k para U7wt\%Mo-Al com 3,55 gU/ $\mathrm{cm}^{3}$ e 0,25\% de Eu.

\begin{tabular}{|c|c|c|c|}
\hline \hline Dias & SERPENT $(\mathrm{k})$ & $\sigma_{\text {SERPENT }}$ & CITATION \\
\hline \hline 0 & 1,10444 & 0,00012 & 1,09633 \\
2 & 1,05857 & 0,00012 & 1,04969 \\
7 & 1,05015 & 0,00012 & 1,04101 \\
12 & 1,05117 & 0,00012 & 1,04085 \\
17 & 1,05470 & 0,00012 & 1,04371 \\
22 & 1,05879 & 0,00012 & 1,04673 \\
27 & 1,06213 & 0,00012 & 1,04942 \\
32 & 1,06362 & 0,00012 & 1,05056 \\
37 & 1,06331 & 0,00012 & 1,05001 \\
42 & 1,06140 & 0,00012 & 1,04817 \\
47 & 1,05776 & 0,00012 & 1,04415 \\
52 & 1,05277 & 0,00012 & 1,03937 \\
57 & 1,04622 & 0,00012 & 1,03367 \\
62 & 1,03899 & 0,00013 & 1,02613 \\
67 & 1,03003 & 0,00012 & 1,01781 \\
72 & 1,02124 & 0,00012 & 1,00925 \\
77 & 1,01136 & 0,00013 & 0,99995 \\
82 & 1,00104 & 0,00012 & 0,99015 \\
87 & 0,99039 & 0,00013 & 0,97947 \\
92 & 0,97882 & 0,00012 & 0,96827 \\
97 & 0,96737 & 0,00013 & 0,95692 \\
\hline
\end{tabular}




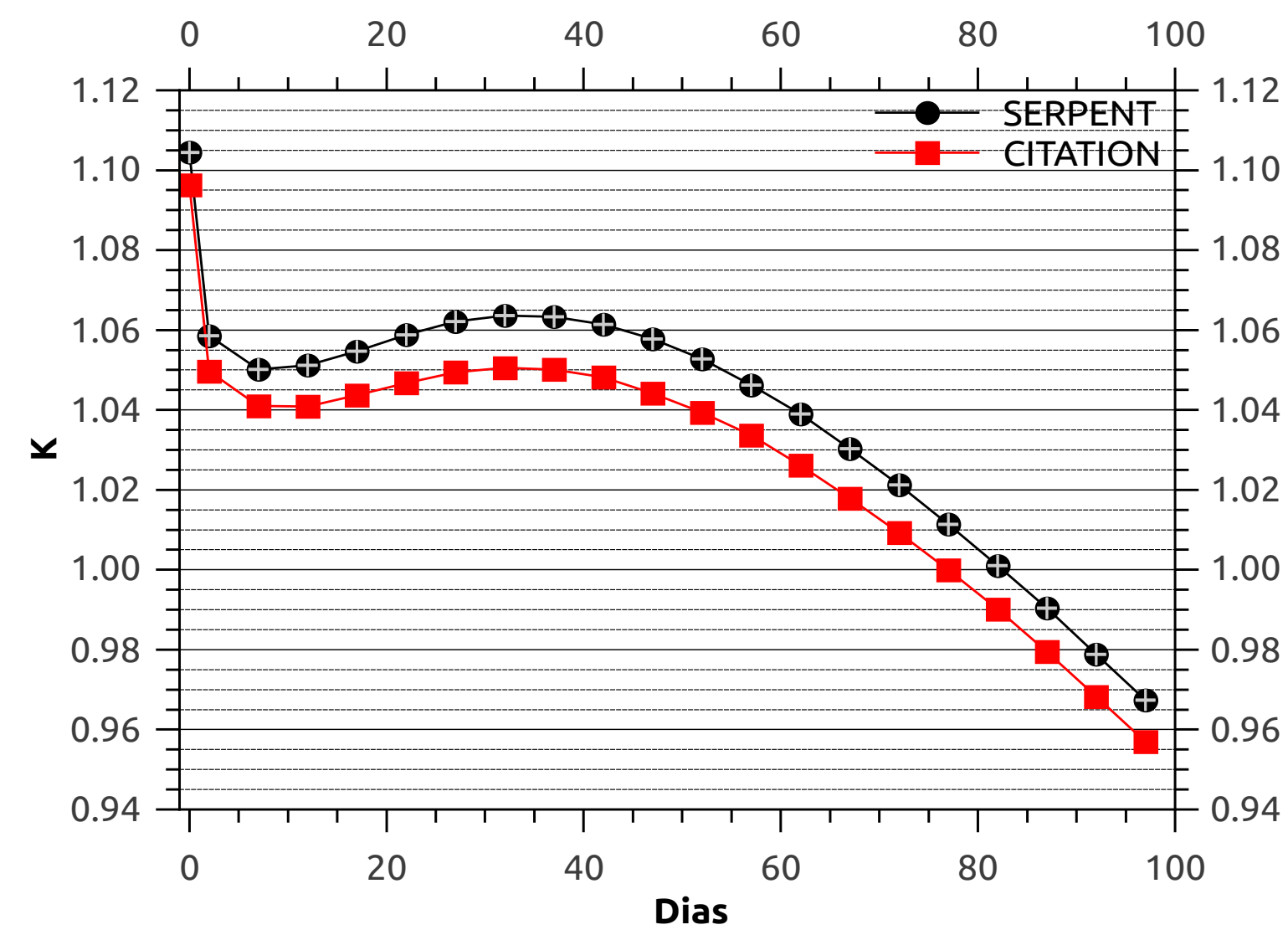

Figura 4.11: Valores de k para U7wt\%Mo-Al com 3,55 gU/ $\mathrm{cm}^{3}$ e 0,25\% de Eu.

A diferença encontrada esta relacionada a diferença da metodologia de cálculo utilizada em cada código. A metodologia que o SERPENT utiliza representa "melhor" a realidade física do problema, pois não se baseia em aproximações da metodologia de difusão utilizada.

As simulações não levam em consideração as demais partes do reator tais como: locais de irradiação, canais de irradiação ("beam hole") e fonte de nêutrons frio. Estas partes absorvem nêutrons e diminuem a reatividade. A seção de física de reatores do Centro de Engenharia Nuclear (CEN) estima que estas partes consomem cerca de 3500 pcm de reatividade. Este valor serve apenas para de uma forma muito simplificada aproximar estas simulações para o caso real de funcionamento do RMB.

Os valores de reatividade calculadas com o SERPENT e com o CITATION, descontados 3500 pcm, são apresentados na Tabela 4.1 e na Figura 4.12. 
Tabela 4.2 - Reatividade para U7wt\%Mo-Al com 3,55 gU/ $\mathrm{cm}^{3}$ e 0,25\% de Eu.

\begin{tabular}{|c|c|c|}
\hline \hline Dias & SERPENT $(\mathrm{pcm})$ & CITATION $(\mathrm{pcm})$ \\
\hline \hline 0 & 5956 & 5287 \\
2 & 2033 & 1234 \\
7 & 1276 & 439 \\
12 & 1368 & 425 \\
17 & 1686 & 688 \\
22 & 2053 & 964 \\
27 & 2350 & 1209 \\
32 & 2481 & 1313 \\
37 & 2454 & 1270 \\
42 & 2285 & 1096 \\
47 & 1961 & 728 \\
52 & 1512 & 288 \\
57 & 918 & -243 \\
62 & 253 & -954 \\
\hline
\end{tabular}

Através da Tabela 4.1 e da Figura 4.12, é possível notar que a reatividade ao longo do ciclo permite uma operação do reator além de 30 dias. Os valores obtidos pelo SERPENT mostram que a principio poderia se operar por aproximadamente 60 dias.

Estes resultados são qualitativos, pois esta análise foi realizada com apenas uma densidade de urânio no núcleo. Na realidade, o núcleo do reator possui elementos combustíveis com densidades de urânio diferentes, com elementos combustíveis com densidade menor no centro de reator (maior fluxo de nêutrons) e elementos com densidades maiores nas extremidades do núcleo (menor fluxo de nêutrons). 


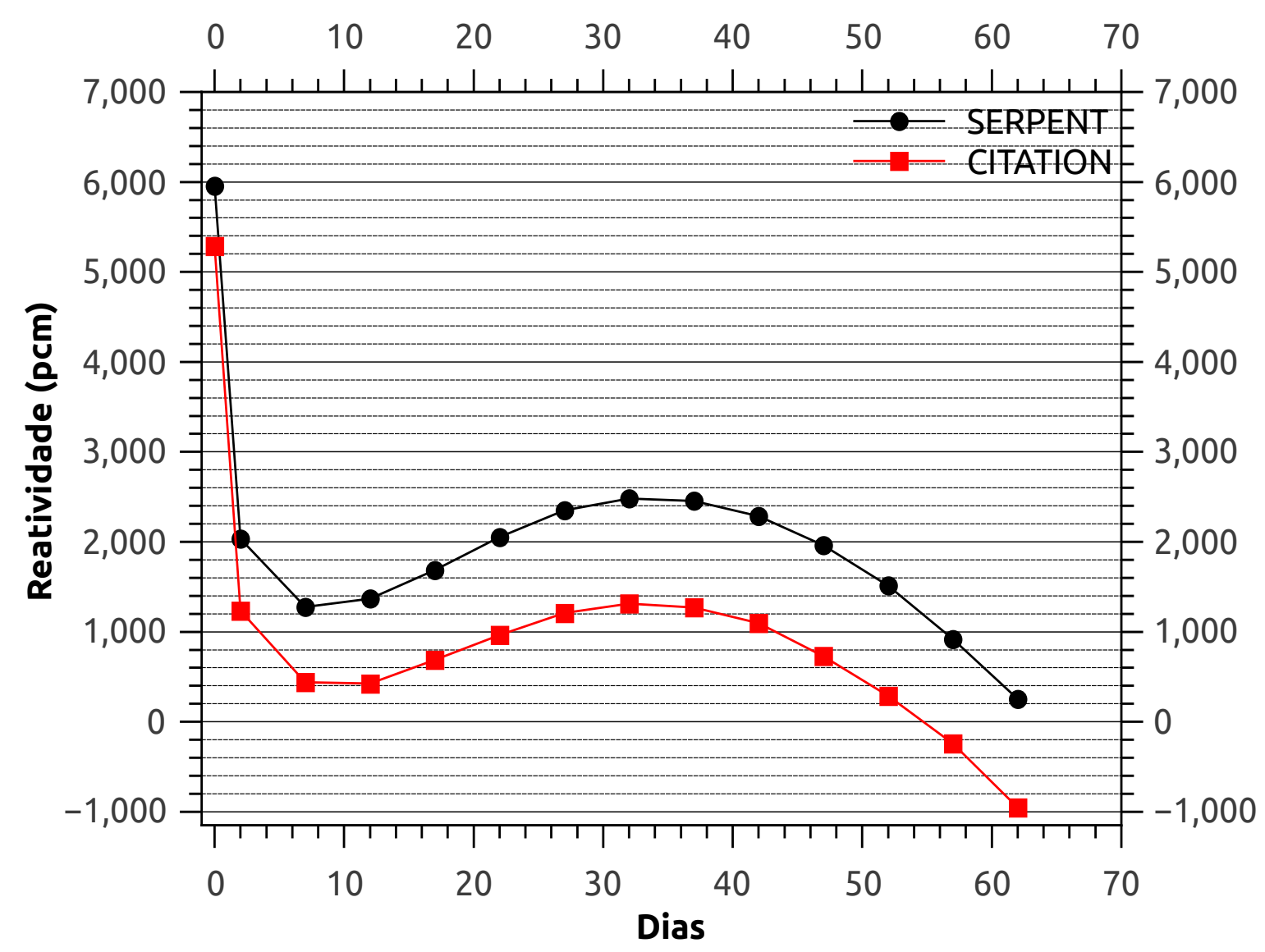

Figura 4.12: Reatividade para U7wt\%Mo-Al com 3,55 gU/ $\mathrm{cm}^{3}$ e 0,25\% de Eu.

\subsubsection{Ciclo de Operação}

Através da função "inventory" do SERPENT, as concentrações dos nuclídeos mais importantes para o ciclo de operação do reator foram geradas.

A razão entre a concentração final e inicial, Figura 4.13, mostra que no final de 100 dias de operação a quantidade de ${ }^{235} \mathrm{U}$ utilizada foi de aproximadamente $43 \%$. 


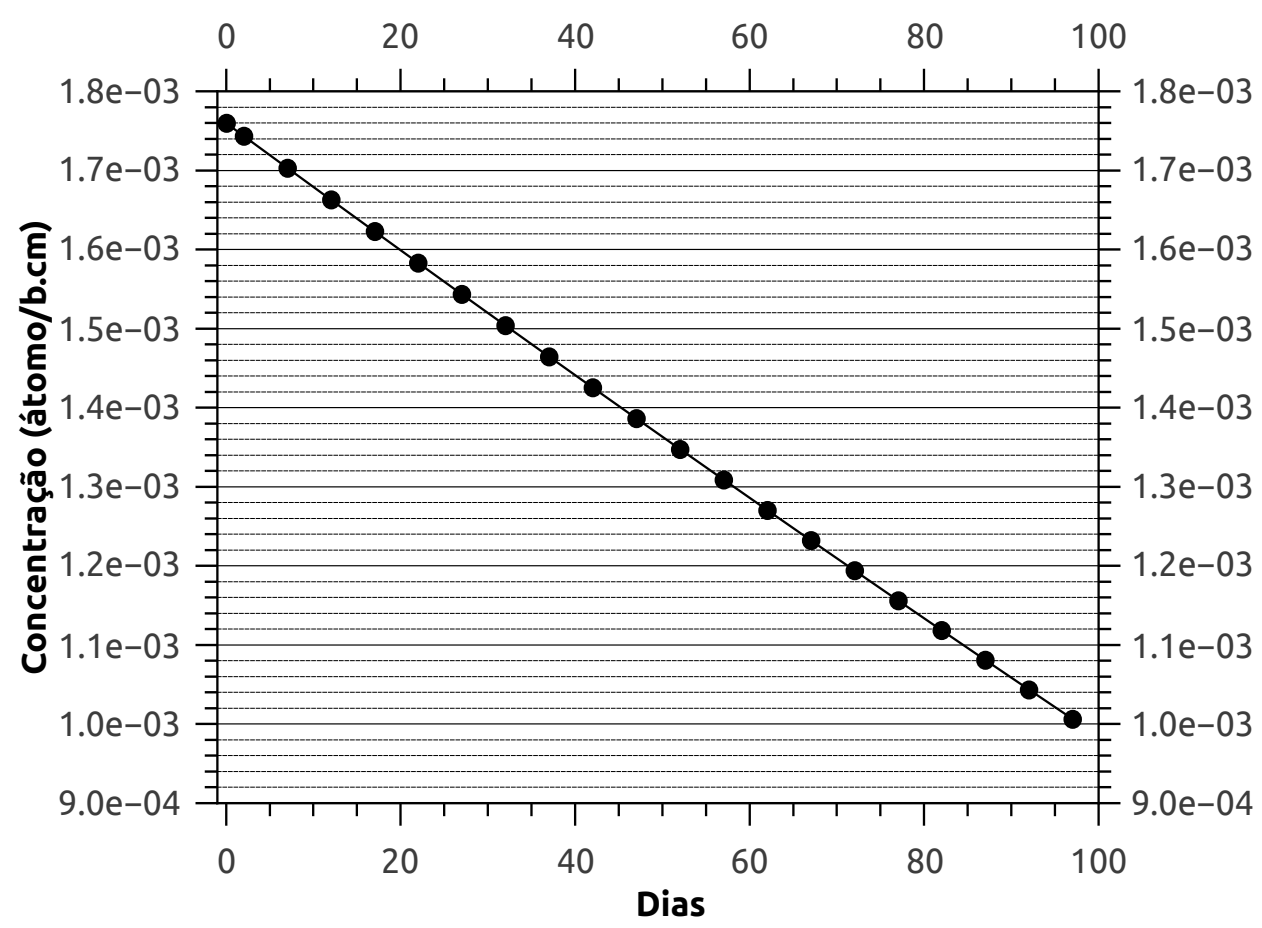

Figura 4.13: Concentração total em átomo/b.cm para o ${ }^{235} \mathrm{U}$ ao longo da queima.

Como o ciclo desejado para o reator é de 30 dias e o período considerado foi de 97 dias, o que corresponde a aproximadamente 3 ciclos de operação do reator (90 dias), a porcentagem de consumo do combustível esta abaixo da porcentagem que causa problemas de inchamento no combustível de UMo-Al, acima de $65 \%$ de queima de urânio.

Este resultado mostra que a principio o reator não teria problema em utilizar o combustível de UMo-Al sem adição de elementos de liga para evitar o inchamento.

A conversão do ${ }^{238} \mathrm{U}$ em ${ }^{239} \mathrm{Pu}$ (que é um material físsil) é mostrado na Figura 4.14. Como apresentado anteriormente, esta conversão é importante para o combustível de UMo$\mathrm{Al}$ quando comparado com o $\mathrm{U}_{3} \mathrm{Si}_{2}-\mathrm{Al}$.

A Figura 4.15 mostra que conforme o ${ }^{151} \mathrm{Eu}$ sofre a reação de captura radiativa, ele se transforma em ${ }^{152} \mathrm{Eu}$, que por sua vez também é consumido e a partir de 60 dias a quantidade de ambos é praticamente nula. 


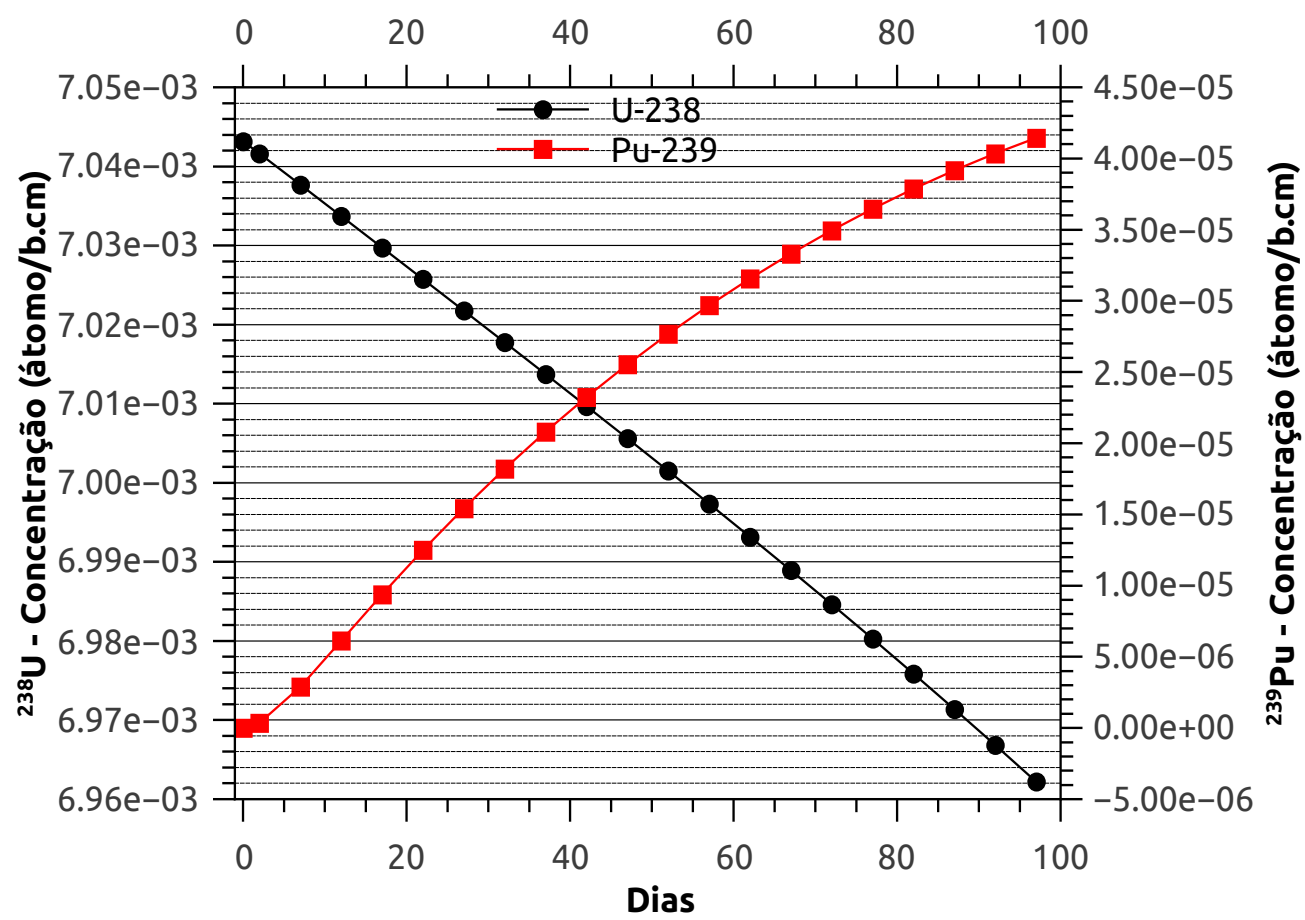

Figura 4.14: Concentração total em átomo/b.cm para o ${ }^{238} \mathrm{U}$ e ${ }^{239} \mathrm{Pu}$ ao longo da queima.

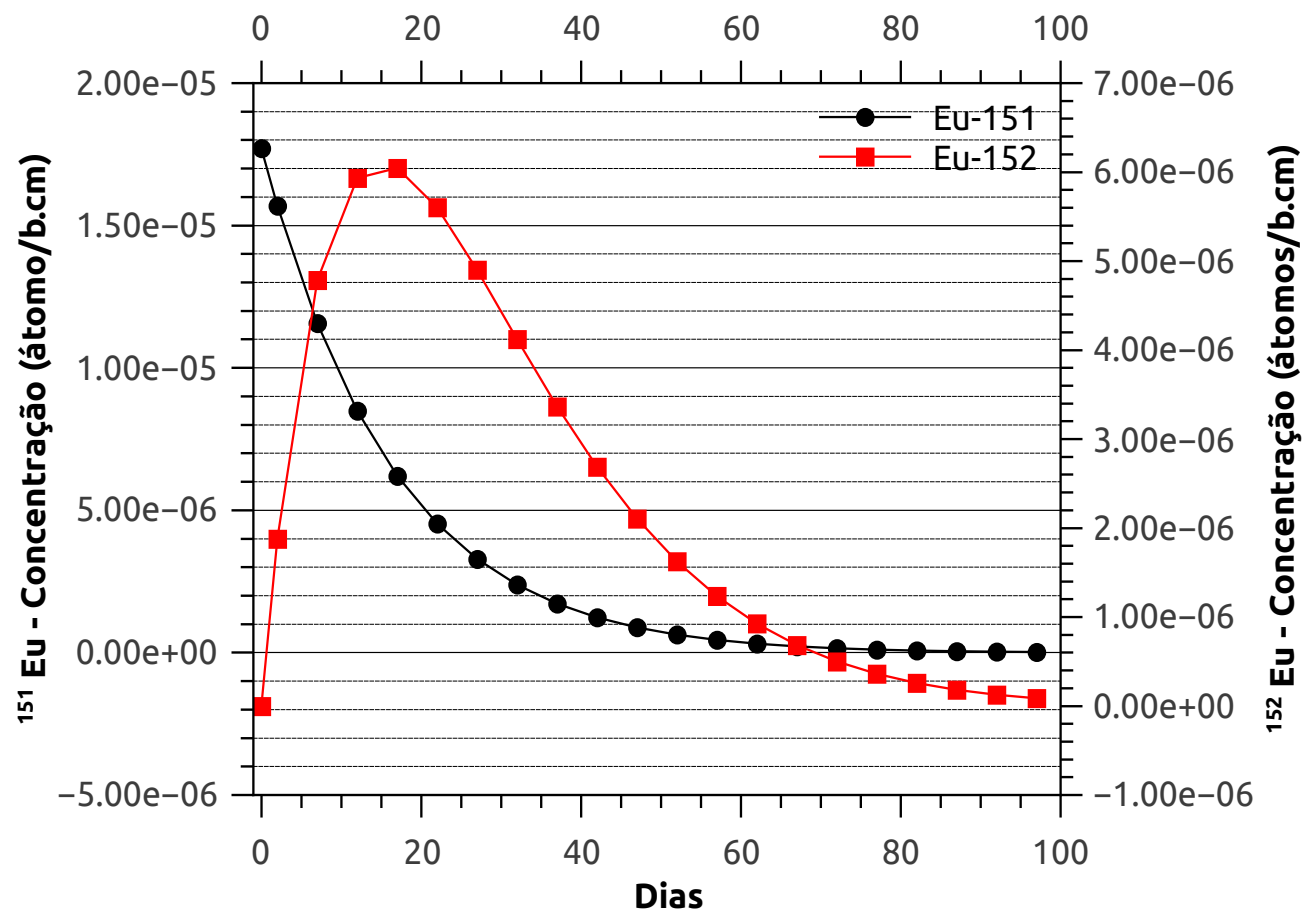

Figura 4.15: Concentração total em átomo/b.cm para o ${ }^{151} \mathrm{Eu}$ e ${ }^{152} \mathrm{Eu}$ ao longo da queima. 
A Figura 4.16 mostra que concentração do ${ }^{153} \mathrm{Eu}$ aumenta até aproximadamente 45 dias e então começa a cair, mas ainda é considerável no final do ciclo e que a concentração do ${ }^{154} \mathrm{Eu}$ aumenta ao longo de todo o ciclo de operação.

A Figura 4.17 mostra que assim como o ${ }^{154} \mathrm{Eu}$, a concentração do ${ }^{155} \mathrm{Eu}$ e do ${ }^{156} \mathrm{Eu}$ aumenta ao longo do ciclo como apresentado. Então, os resultados mostram que com a utilização do európio como veneno irá ocorrer uma concentração residual dos isótopos ${ }^{154} \mathrm{Eu},{ }^{155} \mathrm{Eu}$ e ${ }^{156} \mathrm{Eu}$ no final do ciclo.

Devido ao acúmulo dos isótopos do Eu citados, ao se comparar o ciclo do reator sem e com európio, nota-se que há uma diferença no final do ciclo, devido ao acumulo dos isótopos de európio, Figura 4.18.

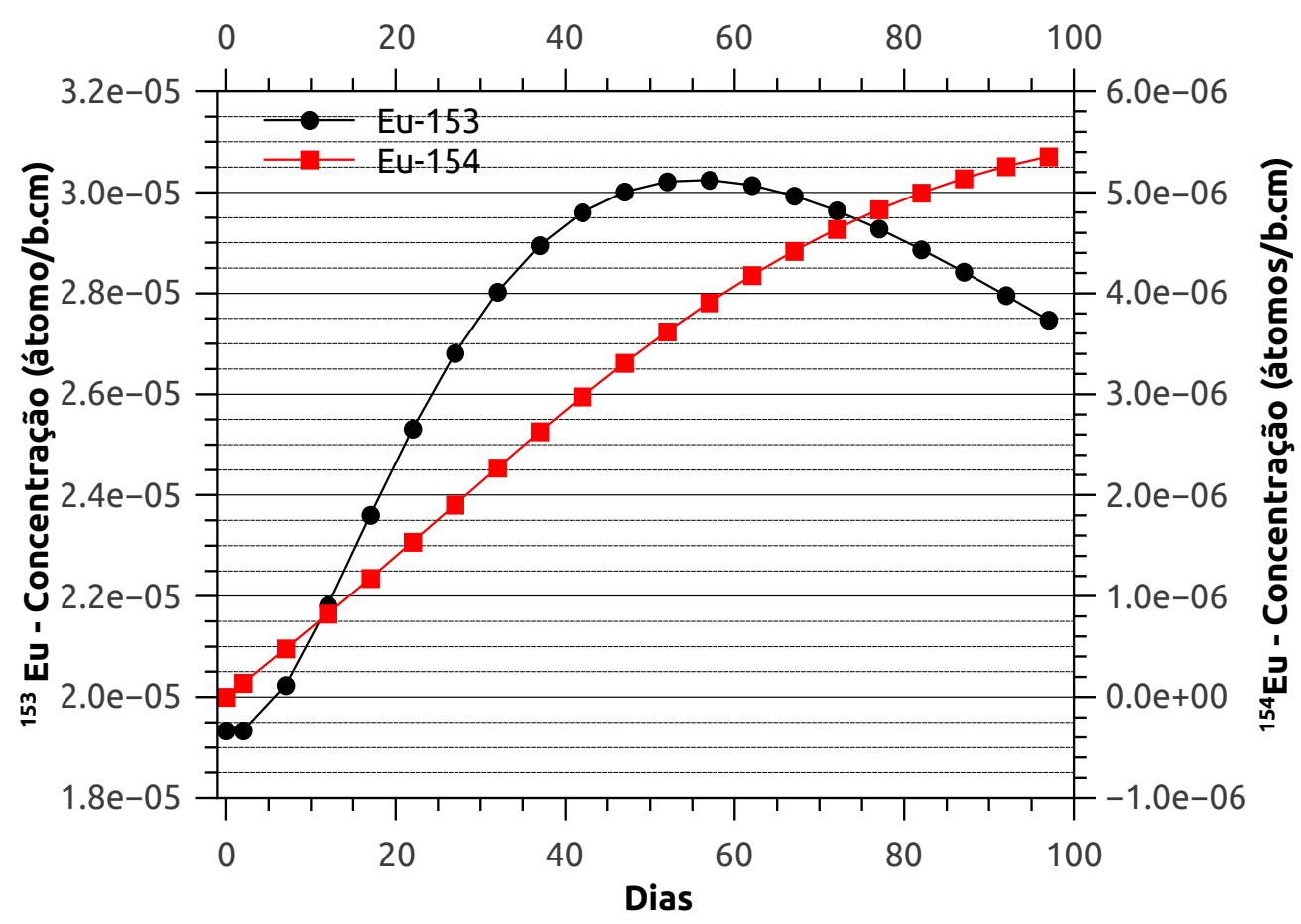

Figura 4.16: Concentração total em átomo/b.cm para o ${ }^{153} \mathrm{Eu} \mathrm{e}{ }^{154} \mathrm{Eu}$ ao longo da queima. 


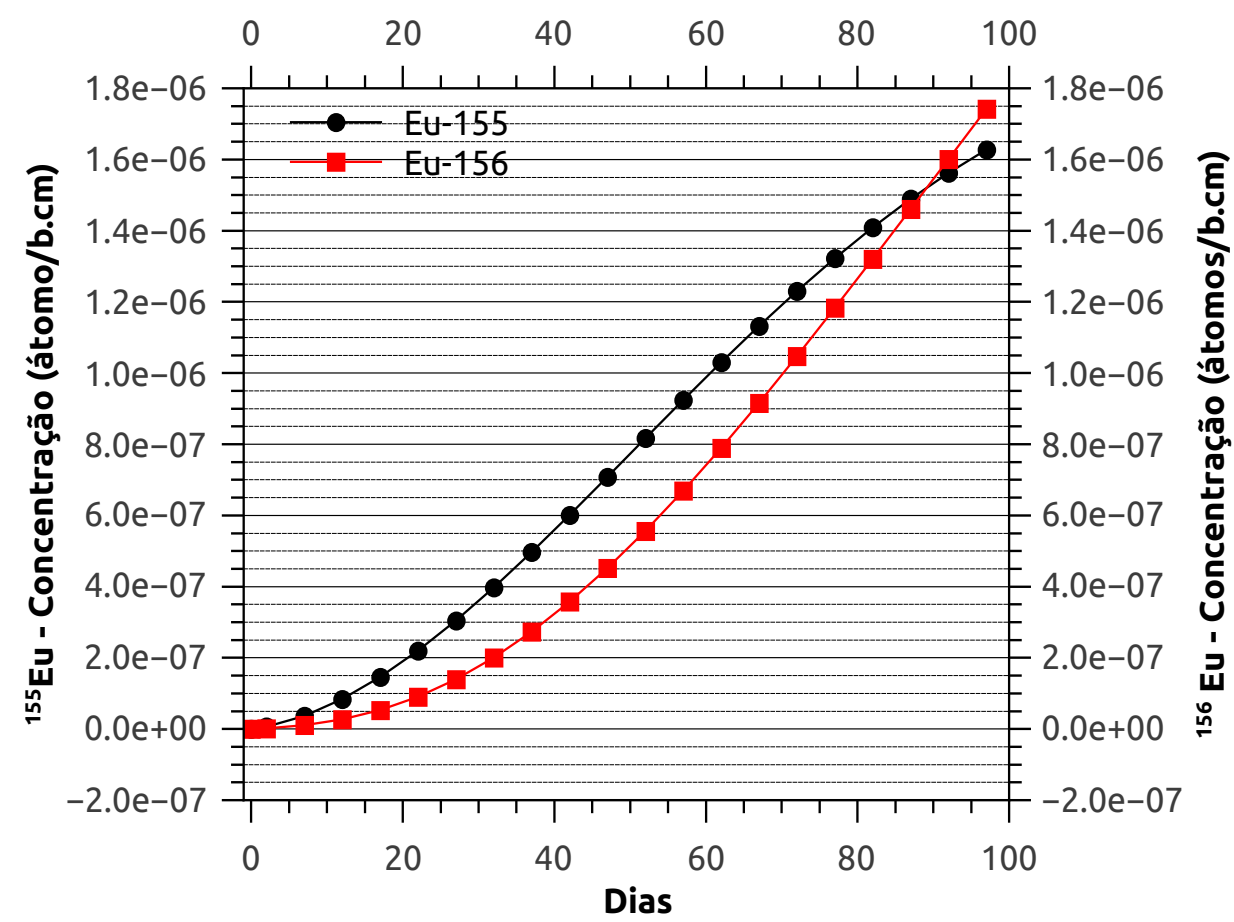

Figura 4.17: Concentração total em átomo/b.cm para o ${ }^{155} \mathrm{Eu}$ e ${ }^{156} \mathrm{Eu}$ ao longo da queima.

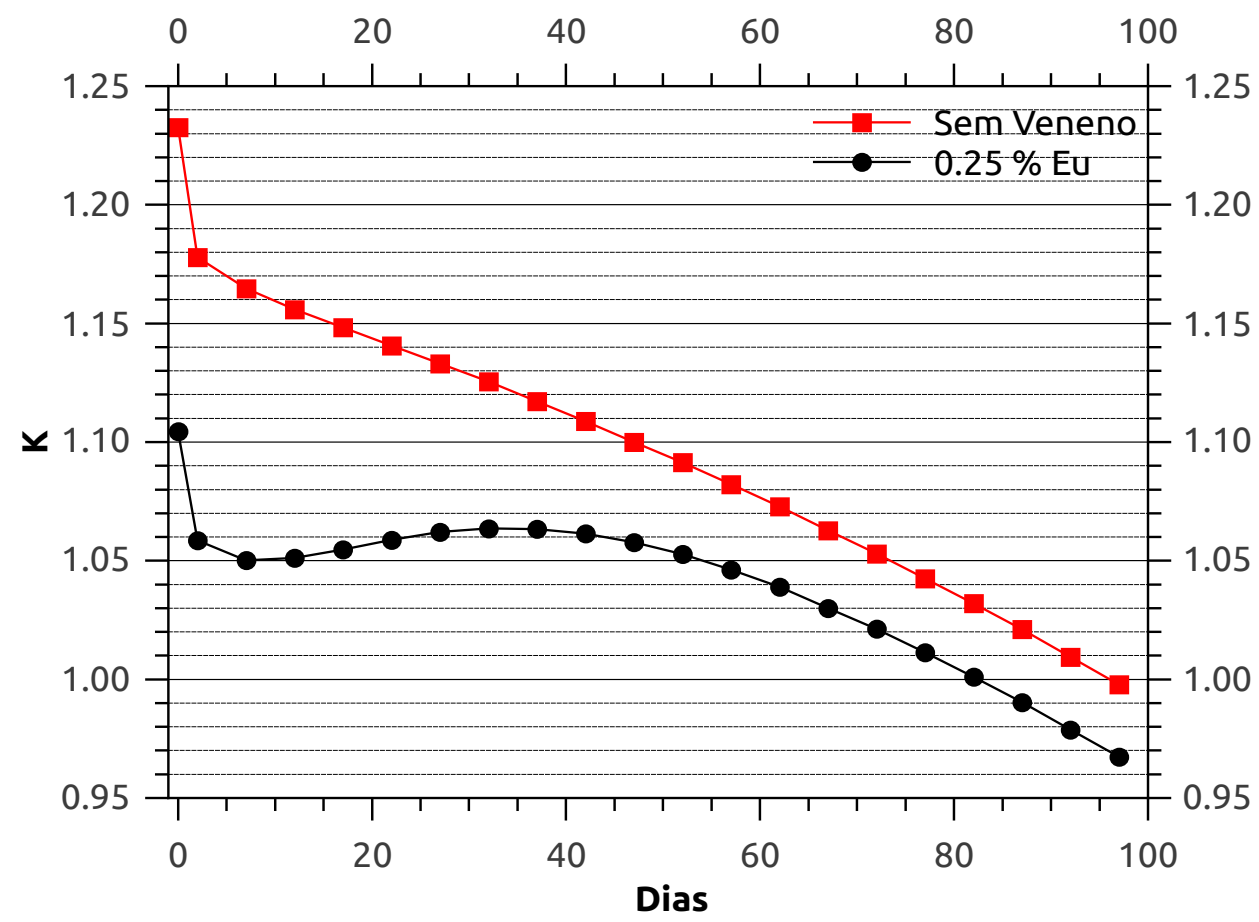

Figura 4.18: Comparação do ciclo sem veneno queimável e com európio. 


\subsubsection{Variação de Temperatura}

Um fator importante de segurança relacionado a temperatura é a diminuição da reatividade com o aumento da temperatura (alpha iso). Para verificar a reatividade com o aumento da temperatura, foi simulado no CITATION e no SERPENT um aumento de temperatura de $30{ }^{\circ} \mathrm{C}$ para o núcleo selecionado (U7wt\%Mo-Al com 3,55 gU/ $\mathrm{cm}^{3}$ e 0,25\% de $\mathrm{Eu})$.

O HRC e o sistema modular AMPX-II foram utilizados para gerar os dados, com o aumento da temperatura do combustível e dos elementos estruturais do reator para o CITATION.

No SERPENT foi utilizado a função "tmp". Devido a variação de temperatura ser baixa, o manual recomenda não utilizar esta função com grandes variações de temperatura em relação as temperaturas de sua biblioteca: 300, 600 e $1200 \mathrm{~K}$.

Os valores de reatividade para $20{ }^{\circ} \mathrm{C}$ e $50{ }^{\circ} \mathrm{C}$ estão na tabela 4.3.

Tabela 4.3 - Variação da reatividade com o aumento da temperatura.

\begin{tabular}{|c|c|c|c|c|}
\hline \hline Código & $20{ }^{\circ} \mathrm{C}$ & $50{ }^{\circ} \mathrm{C}$ & Diferença & $\mathrm{pcm} /{ }^{\circ} \mathrm{C}$ \\
\hline \hline CITATION & $5287(\mathrm{pcm})$ & $4996(\mathrm{pcm})$ & $-291(\mathrm{pcm})$ & 9,7 \\
SERPENT & $5956_{-}^{+11(\mathrm{pcm})}$ & $5700_{-}^{+} 11(\mathrm{pcm})$ & $-256_{-}^{+} 16(\mathrm{pcm})$ & $8,5_{-}^{+} 0,5$ \\
\hline
\end{tabular}

Os resultados obtidos com os dois programas mostram que a reatividade diminui com o aumento da temperatura, mostrando que é viável a utilização deste combustível proposto.

\subsubsection{Adição de Silício}

Embora não fosse o objetivo deste trabalho, estudar o comportamento do combustível com adição de elementos que possam evitar o seu inchamento acima de $65 \%$ de queima. Foi realizada uma simulação com o SERPENT com a adição de $6 \%$ em massa de silício, em relação ao combustível.

A Tabela 4.4 e a Figura 4.19 mostram que não há nenhuma alteação no ciclo de operação do reator devido a adição do silício. 
Tabela 4.4 - Comparação entre a queima com e sem silício.

\begin{tabular}{|c|c|c|c|c|c|}
\hline \hline Dias & Sem Si & $\sigma_{\text {sem Si }}$ & Com Si & $\sigma_{\text {com Si }}$ & Razão Sem/Com Si \\
\hline \hline 0 & 1,10444 & 0,00012 & 1,10487 & 0,00012 & 99,96 \\
2 & 1,05857 & 0,00012 & 1,05867 & 0,00012 & 99,99 \\
7 & 1,05015 & 0,00012 & 1,05068 & 0,00013 & 99,95 \\
12 & 1,05117 & 0,00012 & 1,05096 & 0,00012 & 100,02 \\
17 & 1,05470 & 0,00012 & 1,05502 & 0,00012 & 99,97 \\
22 & 1,05879 & 0,00012 & 1,05890 & 0,00012 & 99,99 \\
27 & 1,06213 & 0,00012 & 1,06206 & 0,00012 & 100,01 \\
32 & 1,06362 & 0,00012 & 1,06379 & 0,00012 & 99,98 \\
37 & 1,06331 & 0,00012 & 1,06362 & 0,00011 & 99,97 \\
42 & 1,06140 & 0,00012 & 1,06156 & 0,00012 & 99,98 \\
47 & 1,05776 & 0,00012 & 1,05788 & 0,00012 & 99,99 \\
52 & 1,05277 & 0,00012 & 1,05289 & 0,00012 & 99,99 \\
57 & 1,04622 & 0,00012 & 1,04639 & 0,00012 & 99,98 \\
62 & 1,03899 & 0,00013 & 1,03942 & 0,00012 & 99,96 \\
67 & 1,03003 & 0,00012 & 1,03063 & 0,00012 & 99,94 \\
72 & 1,02124 & 0,00012 & 1,02143 & 0,00012 & 99,98 \\
77 & 1,01136 & 0,00013 & 1,01168 & 0,00013 & 99,97 \\
82 & 1,00104 & 0,00012 & 1,00143 & 0,00013 & 99,96 \\
87 & 0,99039 & 0,00013 & 0,99059 & 0,00013 & 99,98 \\
92 & 0,97882 & 0,00012 & 0,97908 & 0,00013 & 99,97 \\
97 & 0,96737 & 0,00013 & 0,96774 & 0,00013 & 99,96 \\
\hline
\end{tabular}

Pela Tabela 4.4 é possível notar que há uma tendência dos valores com adição de silício serem maiores que os sem silício.

Esta variação ocorre, pois o silício tem uma seção de choque de espalhamento um pouco maior que o alumínio, porém como dito anteriormente está variação é desprezível como mostra a Figura 4.19. 


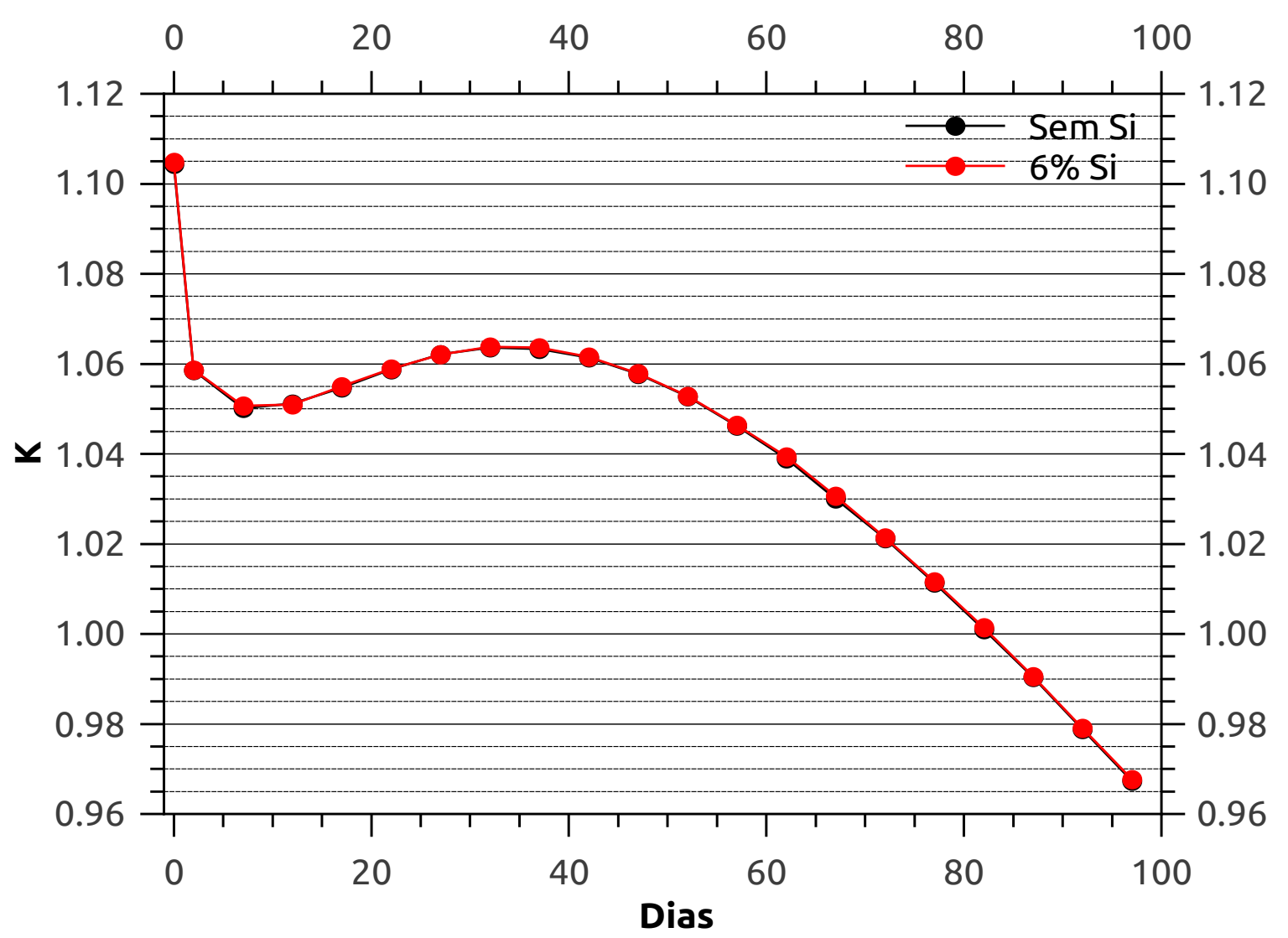

Figura 4.19: Comparação da queima com e sem adição de silício

\subsubsection{Resultados Irradiação das Miniplacas}

As operações do reator IPEN/MB-01 sem as barras de controle foram simuladas através do código MCNP-5 utilizando a biblioteca de dados ENDF/B-VII.0 com 2.10 histórias.

A simulação não leva em consideração a absorção de nêutrons pelos tubos guias dos detetores e pelos termopares que retiram do sistema 33,5 pcm /27/. Portanto, dos valores de reatividade obtidos na simulação foram subtraídos estes 33,5 pcm.

Os resultados das quatro configurações analisadas são apresentados na Tabela 4.5. 
Tabela 4.5 - Simulações das operações de irradiação das miniplacas.

\begin{tabular}{|c|c|c|c|c|}
\hline \hline Configuração & $\mathrm{K}$ & $\sigma_{K}$ & $\begin{array}{c}\text { Reatividade } \\
(\mathrm{pcm})\end{array}$ & $\begin{array}{c}\sigma_{\text {Reatividade }} \\
(\mathrm{pcm})\end{array}$ \\
\hline \hline 1 - 16 varetas centrais removidas & 1.01128 & 0.00005 & 1082 & 5 \\
2 - Irradiador inserido no centro do núcleo & 1.01170 & 0.00005 & 1123 & 5 \\
3 - Irradiador com as 10 miniplacas & 1.01966 & 0.00005 & 1895 & 5 \\
4 - Núcleo modificado com irradiador e 10 miniplacas & 1.00128 & 0.00005 & 95 & 5 \\
\hline
\end{tabular}

Para se obter o valor de reatividade inserida no núcleo do reator pelo irradiador de acrílico é necessário subtrair o valor de reatividade da configuração 1 da configuração 2 .

Da mesma forma, para se obter o valor de reatividade inserida pelas miniplacas é necessário subtrair o valor de reatividade da configuração 2 da configuração 3 .

A Tabela 4.6 apresenta os valores de reatividade devido a inserção do irradiador e miniplacas.

Tabela 4.6 - Simulação da reatividade inserida pelo irradiador e miniplacas.

\begin{tabular}{|c|c|c|}
\hline \hline Material & Reatividade Inserida $(\mathrm{pcm})$ & $\sigma_{\text {Reatividade }}(\mathrm{pcm})$ \\
\hline \hline Irradiador & 41 & 7 \\
Miniplacas & 772 & 7 \\
\hline
\end{tabular}

Os resultados experimentais para as quatro configurações analisadas foram obtidos através do reatímetro. Para cada valor de reatividade é realizada uma média em um intervalo mínimo de 60 segundos.

Um exemplo de dois intervalos de medida na região crítica e supercrítica é apresentado na Figura 4.20. 


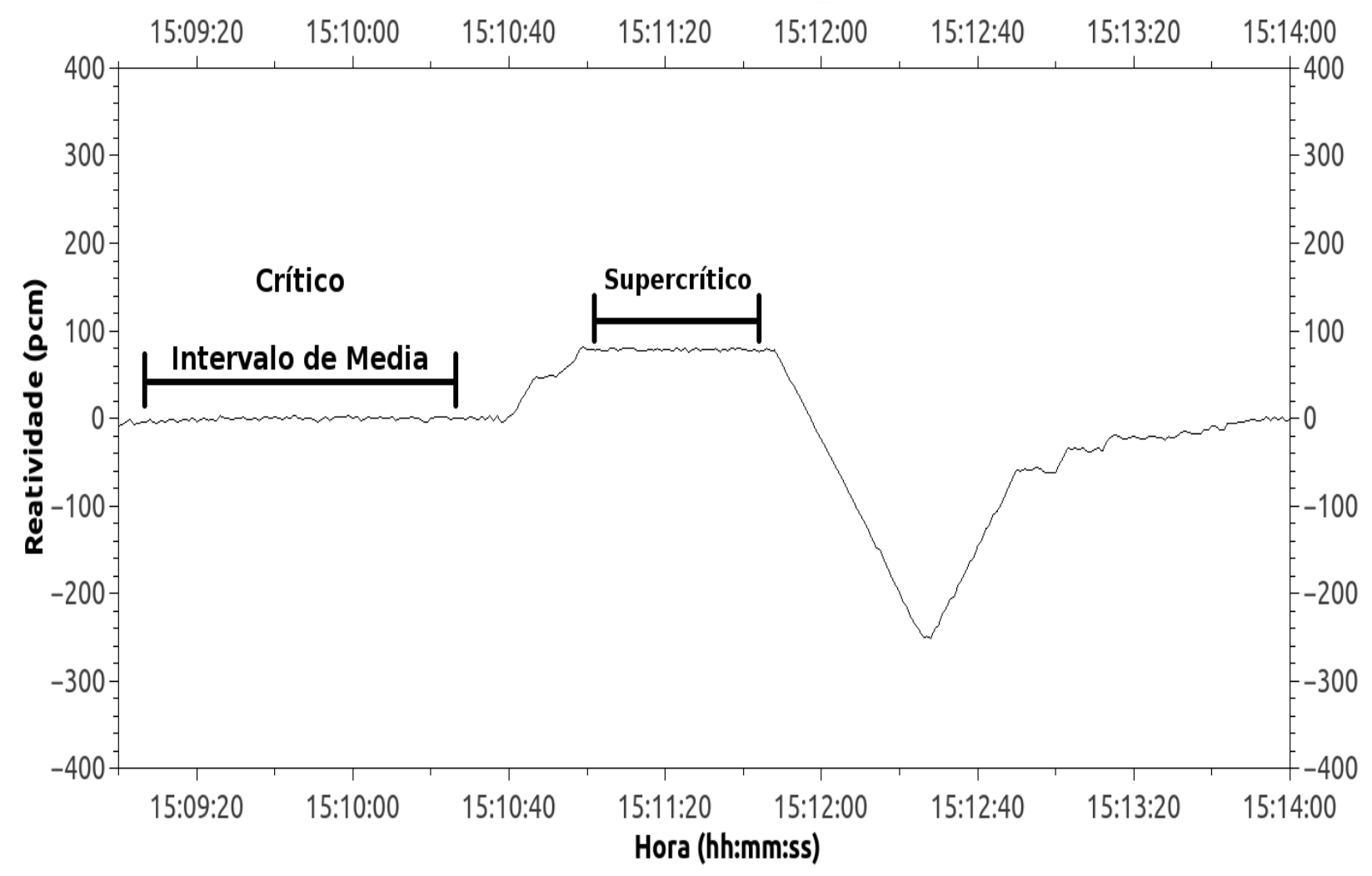

Figura 4.20: Detalhe de duas regiões de medida do reatímetro.

Na configuração dois, após a criticalidade, as barras de controle foram colocadas na posição crítica da configuração 1. Assim sendo, a reatividade inserida pelo irradiador foi determinada. O valor de reatividade obtida com este procedimento, juntamente com as informações sobre a operação, é apresentado na Tabela 4.7.

Tabela 4.7 - Segunda operação criticalidade inserida pelo irradiador.

\begin{tabular}{|c|c|c|c|}
\hline \hline Posição das Barras de Controle & Temperatura Média $\left({ }^{\circ} \mathrm{C}\right)$ & Reatividade Inserida $(\mathrm{pcm})$ & $\sigma_{\text {Reatividade }}(\mathrm{pcm})$ \\
\hline \hline $\mathrm{BC} 1$ e $\mathrm{BC} 2-73,31 \%$ & $20,19_{-}^{+} 0.02$ & 2 & 1 \\
\hline
\end{tabular}

O valor de reatividade das miniplacas é inferido a partir da diferença da posição crítica de barras de controle nas configurações 2 e 3 . A medida foi iniciada a partir do ponto de criticalidade com a configuração 3 . A barra de controle $1(\mathrm{BC} \# 1)$ é retirada de modo a deixar o reator supercrítico. Neste momento, a reatividade é medida e em seguida compensada com a inserção da barra de controle 2 (BC\#2). Este procedimento é repetido 
até que a BC\#1 fique na posição crítica da configuração 2. A Figura 4.21 mostra os vários passos de reatividade ao longo de toda a medida. O procedimento é repetido para a $\mathrm{BC} \# 2$, ou seja, retirada da BC\#2 e inserção da BC\#1 de modo a inferir a reatividade total.

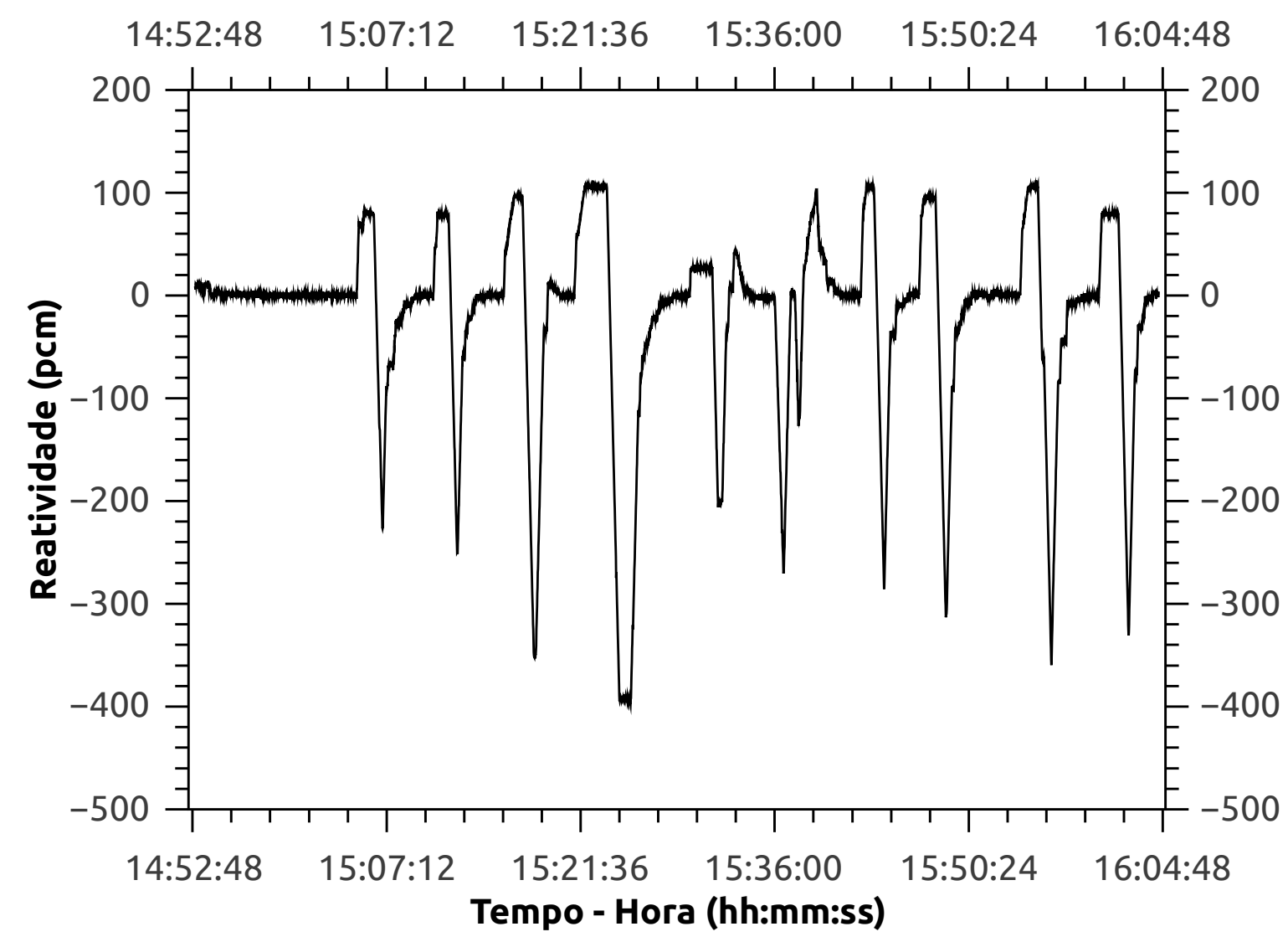

Figura 4.21: Reatímetro ao londo de toda medida - terceira configuração.

As Tabelas 4.8 e 4.9 mostram a reatividade obtida em cada região (crítica e supercrítica) e a soma total da reatividade, sendo que a Tabela 4.8 é com a retirada da $\mathrm{BC} \# 1$ e inserção da $\mathrm{BC} \# 2$ e a Tabela 4.9 com a inserção da $\mathrm{BC} \# 1$ e retirada da $\mathrm{BC} \# 2$. A temperatura média do núcleo do reator durante a operação foi de $20,42{ }_{-}^{+} 0,02{ }^{\circ} \mathrm{C}$. 
Tabela 4.8 - Retirada da Barra BC\#1

\begin{tabular}{|c|c|c|c|c|c|c|}
\hline \hline Posição BC\#1 / BC\#2 & Detetor 1 & $\sigma_{1}$ & Detetor 2 & $\sigma_{2}$ & Média & $\sigma_{\text {Média }}$ \\
\hline \hline $63.48 / 63.48$ & 0.2 & 1.7 & 0.2 & 1.6 & 0.2 & 1.2 \\
$65.32 / 63.48$ & 80 & 1 & 81 & 1 & 80.5 & 0.7 \\
$65.32 / 61.69$ & -1.5 & 3 & -1.5 & 3 & -1.5 & 2.1 \\
$67.20 / 61.69$ & 78 & 1 & 79 & 1 & 78.5 & 0.7 \\
$67.20 / 60.02$ & 0.8 & 1.7 & 0.8 & 1.7 & 0.8 & 1.2 \\
$69.62 / 60.02$ & 96.1 & 0.6 & 96.3 & 0.7 & 96.2 & 0.5 \\
$69.62 / 58.00$ & -0.4 & 1.7 & -0.5 & 2 & -0.5 & 1.3 \\
$72.51 / 58.00$ & 106 & 1 & 106 & 2 & 106.0 & 1.1 \\
$72.51 / 55.83$ & -0.5 & 1.8 & -0.6 & 1.5 & -0.6 & 1.2 \\
$73.28 / 55.83$ & 27 & 2 & 27 & 1 & 27.0 & 1.1 \\
$73.28 / 55.25$ & 0.3 & 1.8 & 0.4 & 1.7 & 0.3 & 1.2 \\
\hline \hline
\end{tabular}

Tabela 4.9 - Retirada da Barra BC\#2

\begin{tabular}{|c|c|c|c|c|c|c|}
\hline \hline Posição BC\#1 / BC\#2 & Detetor 1 & $\sigma_{1}$ & Detetor 2 & $\sigma_{2}$ & Média & $\sigma_{\text {Média }}$ \\
\hline \hline $63.48 / 65.94$ & 105 & 1 & 105 & 1 & 105.0 & 0.7 \\
\hline $61.16 / 65.94$ & -1 & 3 & -0.9 & 3 & -0.9 & 2.1 \\
$61.16 / 68.27$ & 95 & 1 & 95 & 1 & 95.0 & 0.7 \\
$59.16 / 68.27$ & 0.8 & 2.1 & 0.9 & 2.1 & 0.8 & 1.5 \\
$59.16 / 71.01$ & 105.3 & 0.7 & 105.2 & 0.9 & 105.2 & 0.6 \\
$56.97 / 71.01$ & -1 & 2 & -1 & 2 & -1.0 & 1.4 \\
$56.97 / 73.27$ & 79 & 1 & 79 & 1 & 79.0 & 0.7 \\
$55.37 / 73.27$ & 0.3 & 1.6 & 0.4 & 1.9 & 0.3 & 1.2 \\
$55.25 / 73.27$ & -6 & 2 & -6 & 2 & -6.0 & 1.4 \\
\hline \hline
\end{tabular}

Pela soma da reatividade inserida por todas as regiões é obtida a reatividade inserida pelas miniplacas que foi de $767_{-}^{+} 6 \mathrm{pcm}$.

Na quarta configuração, o reator foi modificado com a retirada das varetas combustíveis. O reator foi colocado crítico com as barras de controle nas posições $\mathrm{BC} \# 1=99,62 \%$ retirada e a $\mathrm{BC} \# 2=98,95 \%$. Após o pontos de criticalidade, as barras de controle 
foram retiradas e o reator ficou "levemente" supercrítico. O valor de reatividade obtido é apresentado na Tabela 4.10.

Tabela 4.10 - Quarta configuração núcleo modificado.

\begin{tabular}{|c|c|c|c|}
\hline \hline Posição das Barras de Controle & Temperatura Média $\left({ }^{\circ} \mathrm{C}\right)$ & Reatividade Inserida $(\mathrm{pcm})$ & $\sigma_{\text {Reatividade }}(\mathrm{pcm})$ \\
\hline \hline BC\#1 e BC\#2 - retiradas & $20,15_{-}^{+} 0,02$ & 5 & 8 \\
\hline
\end{tabular}

\subsubsection{Comparação Entre os Resultados Simulados E Experimentais}

Os resultados das simulações e experimentais estão na Tabela 4.11.

Tabela 4.11 - Resultados das simulações e experimentos.

\begin{tabular}{|c|c|c|}
\hline \hline Descrição & Simulação $(\mathrm{pcm})$ & Experimental $(\mathrm{pcm})$ \\
\hline \hline Irradiador & $41_{-}^{+} 7$ & $2_{-}^{+1}$ \\
Miniplacas & $772_{-}^{+} 7$ & $767_{-}^{+} 6$ \\
Núcleo Modificado & $95_{-}^{+} 5$ & $5_{-}^{+8}$ \\
\hline
\end{tabular}

Como mostra a Tabela 4.11, para o irradiador de acrílico o valor experimental obtido de inserção de reatividade é pequeno sendo praticamente desprezível. Já na simulação, o valor obtido ficou 39 pcm acima do experimental.

Analisando a inserção de reatividade das miniplacas os valores possuem baixa incerteza tanto nos valores simulados quanto experimentais. Através da metodologia utilizada foi possível observar que os dados simulados apresentaram alta concordância com os resultados experimentais, ou seja, esta metodologia representou adequadamente a realidade física do sistema das miniplacas combustíveis.

Dos valores obtidos, o de maior diferença entre simulado e medido foi com o núcleo modificado, porém, assim como no caso do irradiador, os valores de reatividade obtidos, tanto na simulação quanto no experimental, representam valores pequenos de reatividade. 


\section{Capítulo 5}

\section{Conclusões}

Através da análise neutrônica, optou-se por estudar a aplicação do combustível UMo-Al com 7\% em massa de Mo (U7wt\%Mo), ao invés de usar $10 \%$, uma vez que a absorção de nêutrons pelo molibdênio é considerável.

Neste trabalho foi proposto que o veneno queimável seja aplicado diretamente na liga de UMo. Foram estudados dois elementos como veneno queimável: gadolínio e európio. Pelos resultados obtidos escolheu-se o Eu, pois este tem uma queima mais gradual do que o Gd e não causa uma grande variação da reatividade no inicio do ciclo de operação do reator.

Os resultados mostraram que com o combustível e o veneno queimável propostos, o ciclo de operação pode ultrapassar os 30 dias estipulados, o que contribui para otimização do reator e economia de combustível.

A análise dos resultados simulados para o aumento da temperatura mostrou que a reatividade diminui, sendo este um importante fator para a segurança do reator e mostrando viabilidade da utilização do combustível.

Com a simulação da adição de silício no combustível, foi observado que não há nenhuma mudança no ciclo de operação do reator devido a esta adição.

A partir da especificação técnica elaborada neste trabalho, foram fabricadas as 12 miniplacas combustíveis. As miniplacas foram irradiadas no centro do núcleo do reator IPEN/MB-01. O resultado obtido na simulação, para a reatividade inserida pelas miniplacas, teve uma alta concordância com os resultados experimentais. Portanto, a metodologia utilizada pode ser aplicada em futuros trabalhos com o combustível de UMo-Al que utilize európio como veneno queimável. 
Capítulo 6

\section{Trabalhos Futuros}

Elaboração de uma especificação técnica de fabricação, em conjunto com o Centro do Combustível Nuclear (CCN), para a fabricação de miniplacas combustíveis de U7wt\%Mo$\mathrm{Al}$ com $4 \mathrm{gU} / \mathrm{cm}^{3}$ e 0,25 \% em massa de Eu e adição de silício.

Irradiação das miniplacas combustíveis com Eu e Si no reator IPEN/MB-01 baseado na metodologia apresentada neste trabalho. 
Apêndice 
A

\section{Irradiador De Acrílico}
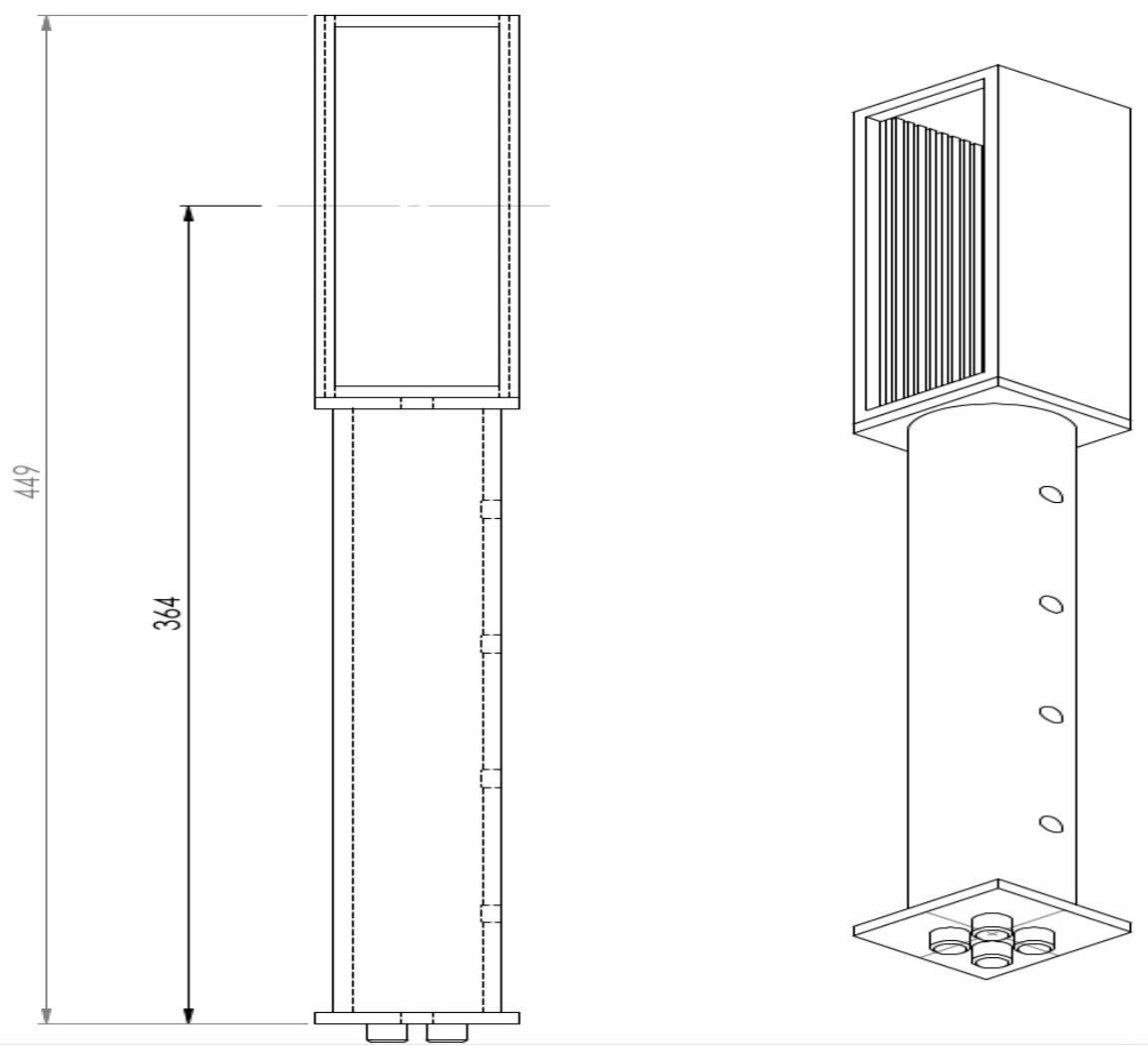

Figura A.1: Projeto do conjunto inteiro do irradiador de acrílico. 

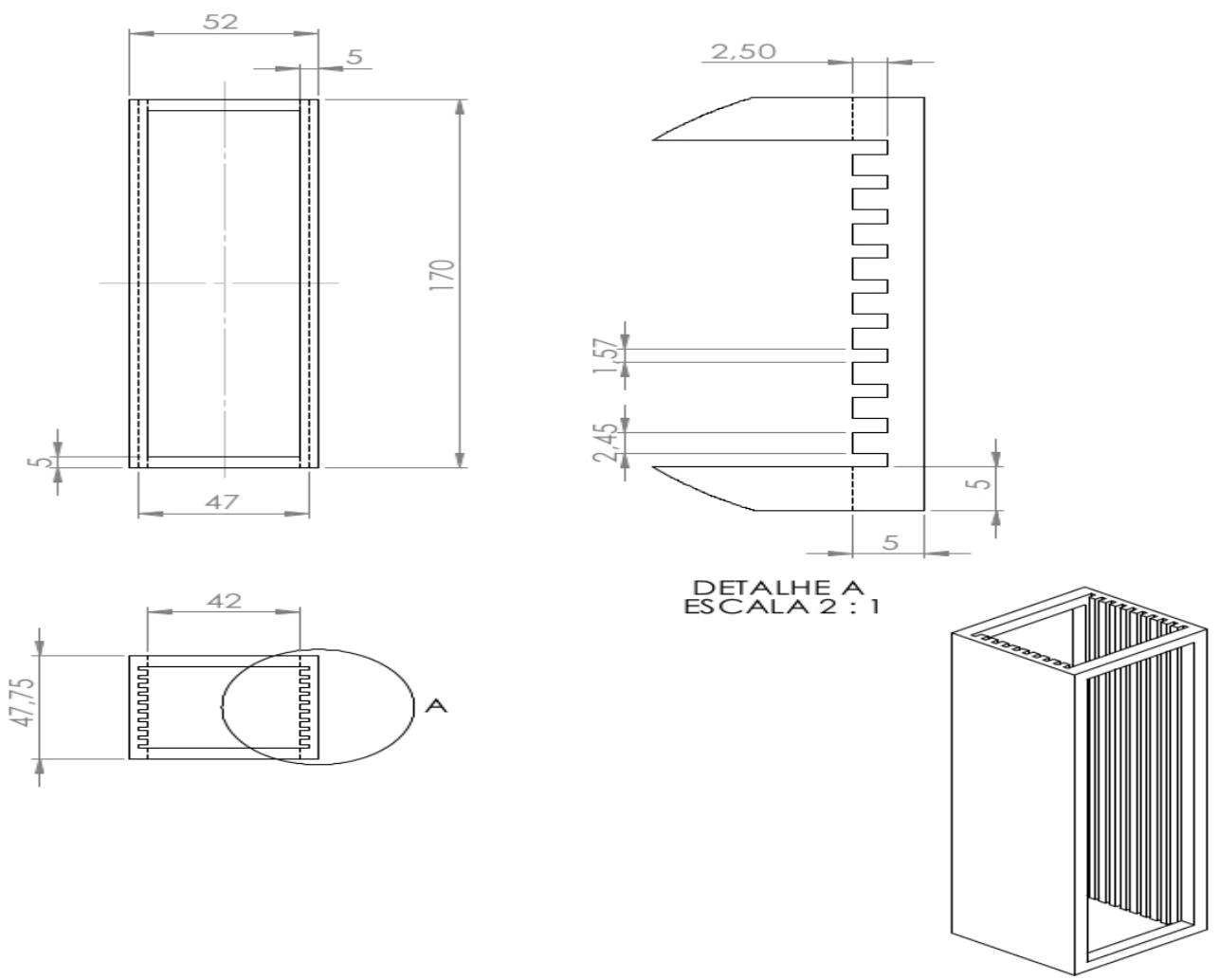

Figura A.2: Detalhe do suporte das miniplacas, parte superior do irradiador. 

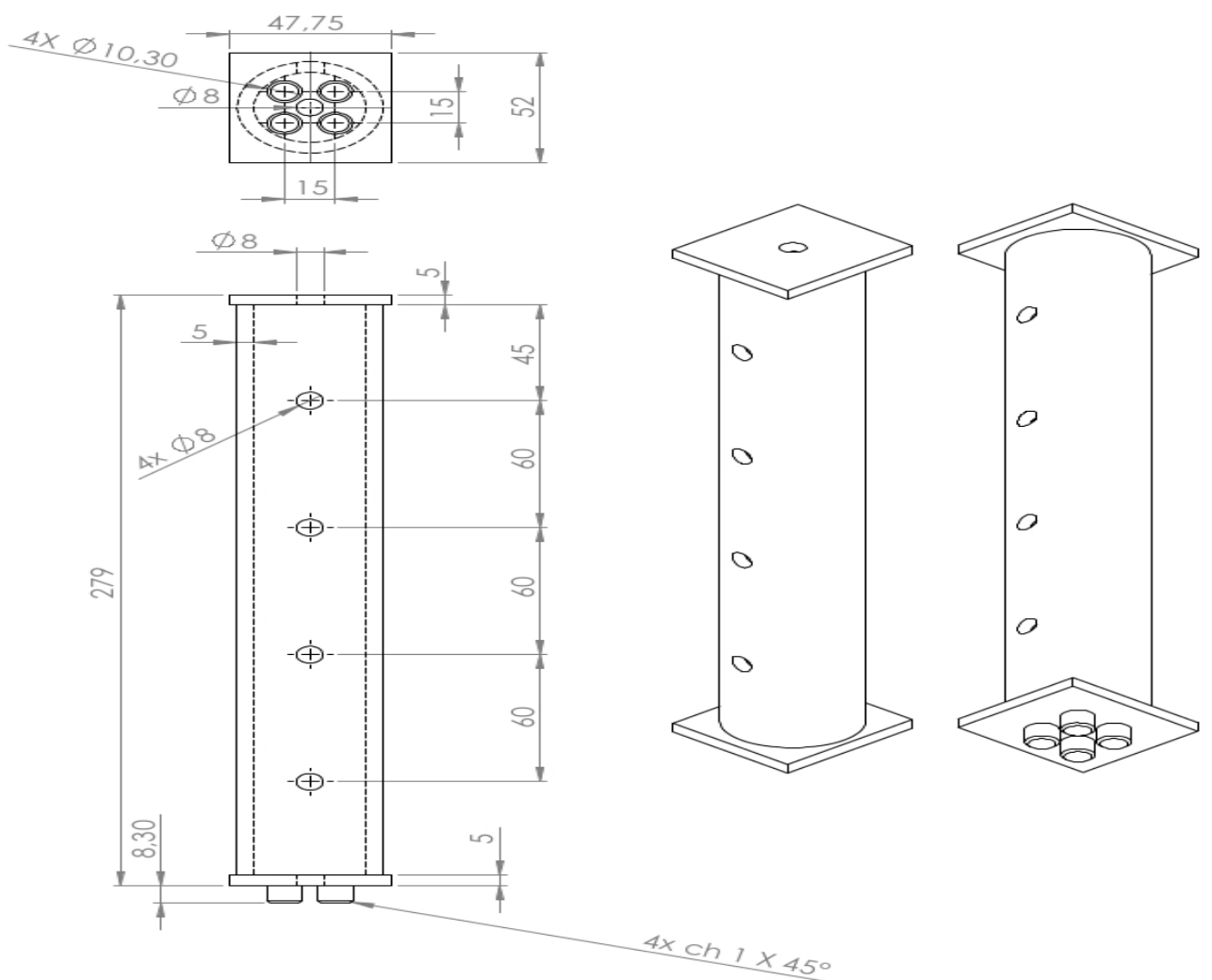

Figura A.3: Detalhe do suporte do irradiador, parte inferior do irradiador.

A seguir as informações do fabricante para o acrílico usado na fabricação do suporte das miniplacas, parte superior (primeira tabela) e inferior (segunda tabela - tubo) do irradiador. 


\section{¿Acrigel ${ }_{c T}^{\oplus}$}

Ficha Técnica - Acrigel $^{\circledR}$ CT

Descrição

Acrigel ${ }^{\circledR}$ CT - Chapa acrílica feita pelo processo cell cast com excelente qualidade ótica, alta resistência em longo prazo, facilidade de moldagem, facilidade de desenvolvimento de cores e alta resistência química.

\begin{tabular}{|l|c|c|c|}
\hline Propriedades & Método & Valores & Unidades \\
\hline Propriedades físicas & ISO 1183 & 1,19 & $\mathrm{~g} / \mathrm{cm}^{3}$ \\
\hline Densidade & ISO 62, método 1 & 0,3 & $\%$ \\
\hline Absorção de água (em água por 24 horas a 230 ${ }^{\circ}$ ) & ISO 489 - método A & 1,49 & - \\
\hline Propriedades óticas & ISO 13468-1 & 92 & $\%$ \\
\hline Índice de refração & ISO 527-2/1B/5 & 72 & $\mathrm{MPa}$ \\
\hline Transmitância total & ISO 527-2/18/5 & 4,5 & $\%$ \\
\hline Propriedades mecânicas & ISO 527-2/18/1 & 3300 & $\mathrm{MPa}$ \\
\hline \hline Resistência à tração (na ruptura) & ISO 178 & 110 & $\mathrm{MPa}$ \\
\hline Alongamento (na ruptura) & ISO 179 & 14,5 & $\mathrm{~kJ} / \mathrm{m}^{2}$ \\
\hline Módulo de Elasticidade & ISO 306/B/50 & 111 & ${ }^{\circ} \mathrm{C}$ \\
\hline Resistência à flexão & ISO 75 & 97 & ${ }^{\circ} \mathrm{C}$ \\
\hline Resistência ao impacto Charpy (entalhado) & - & 80 & ${ }^{\circ} \mathrm{C}$ \\
\hline Propriedades térmicas & ASTM E-831 & 70 & $\mu \mathrm{m} / \mathrm{m} /{ }^{\circ} \mathrm{C}$ \\
\hline \hline Temperatura de amolecimento Vicat & ISO 3795 & 38 & $\mathrm{~mm} / \mathrm{min}$ \\
\hline Temperatura de deflexão térmica
\end{tabular}

Disponibilidade

Espessura - De 2 a $24 \mathrm{~mm}^{*}$

Cores - Cristal / Branco / Diversas cores (consulte o departamento de vendas)

Tipos - Sanitárias / Texturizadas / Fosforescente / Metalizadas

* Tolerância da espessura conforme ISO 7823-1.

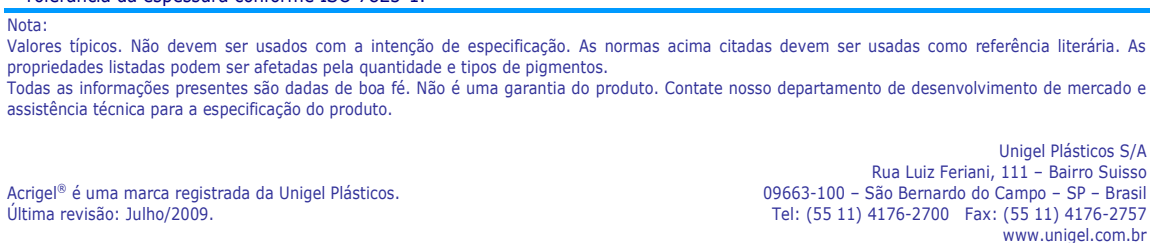




\section{Acrigel ${ }_{x T}^{\otimes}$}

Ficha Técnica - Acrigel $^{\circledR}$ XT

Descrição

Acrige ${ }^{\circledR}$ XT - Chapa acrílica extrudada com boa estabilidade de espessura, transparência, qualidade ótica e resistência à raios ultravioletas.

\begin{tabular}{|c|c|c|c|}
\hline Propriedades & Método & Valores & Unidade \\
\hline \multicolumn{4}{|l|}{ Propriedades físicas } \\
\hline Densidade & ISO 1183 & 1,19 & $\mathrm{~g} / \mathrm{cm}^{3}$ \\
\hline Absorção de água (em água por 24 horas a $23^{\circ} \mathrm{C}$ ) & ISO 62 , método 1 & 0,3 & $\%$ \\
\hline \multicolumn{4}{|l|}{ Propriedades óticas } \\
\hline Índice de refração & ISO 489 - método $\mathrm{A}$ & 1,49 & - \\
\hline Transmitância total & ISO $13468-1$ & 92 & $\%$ \\
\hline \multicolumn{4}{|l|}{ Propriedades mecânicas } \\
\hline Resistência à tração (na ruptura) & ISO $527-2 / 1 \mathrm{~B} / 5$ & 61 & $\mathrm{MPa}$ \\
\hline Alongamento (na ruptura) & ISO $527-2 / 1 \mathrm{~B} / 5$ & 2,7 & $\%$ \\
\hline Módulo de Elasticidade & ISO $527-2 / 1 B / 1$ & 3090 & $\mathrm{MPa}$ \\
\hline Resistência à flexão & ISO 178 & 103 & $\mathrm{MPa}$ \\
\hline Resistência ao impacto Charpy (entalhado) & ISO 179 & 10,6 & $\mathrm{~kJ} / \mathrm{m}^{2}$ \\
\hline \multicolumn{4}{|l|}{ Propriedades térmicas } \\
\hline Temperatura de amolecimento Vicat & ISO $306 / \mathrm{B} / 50$ & 108 & ${ }^{\circ} \mathrm{C}$ \\
\hline Temperatura de deflexão térmica & ISO 75 & 92 & ${ }^{\circ} \mathrm{C}$ \\
\hline Máxima temperatura de uso contínuo & - & 70 & ${ }^{\circ} \mathrm{C}$ \\
\hline Coeficiente de dilatação térmico linear (CLTE) & ASTM E-831 & 70 & $\mu \mathrm{m} / \mathrm{m} /{ }^{\circ} \mathrm{C}$ \\
\hline \multicolumn{4}{|l|}{ Flamabilidade } \\
\hline Taxa de queima & ISO 3795 & 38 & $\mathrm{~mm} / \mathrm{min}$ \\
\hline
\end{tabular}

Disponibilidade

Espessura - De 2 a $20 \mathrm{~mm} *$

Cores - Cristal / Branco (Para outras cores consulte nosso departamento comercial)

* Tolerância da espessura conforme ISO 7823-2.

Valores típicos. Não devem ser usados com a intenção de especificação. As normas acima citadas devem ser usadas como referência literária. As propriedades listadas podem ser afetadas pela quantidade e tipos de pigmentos.

Todas as informações presentes são dadas de boa fé. Não é uma garantia do produto. Contate nosso departamento de desenvolvimento de mercado e assistência técnica para a especificação do produto. 
B

\section{Dados De Entrada Do MCNP-5 Configuração 3}

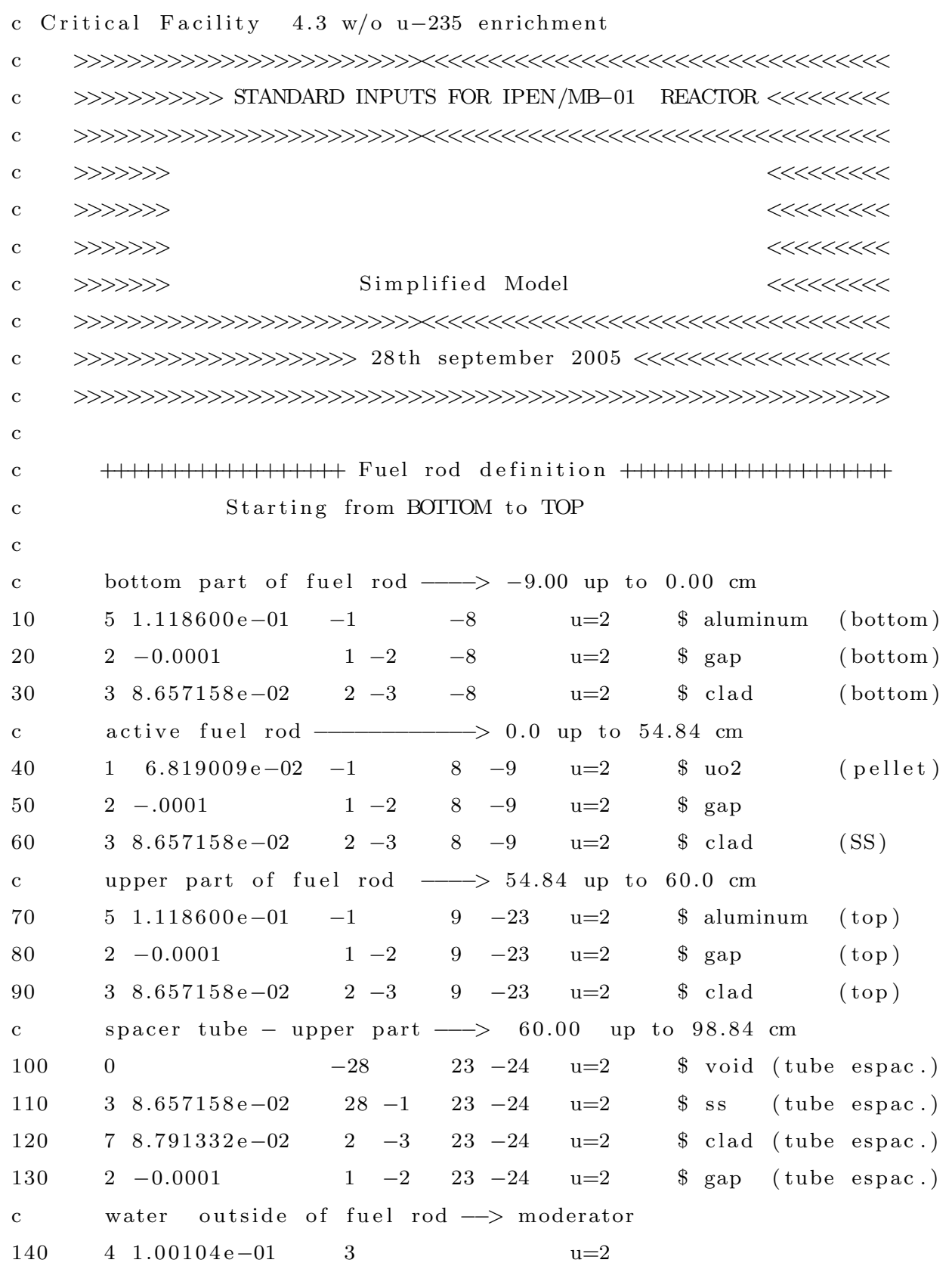


$+H+H+H+H+H+H+$ guide tube definition $+H+H+H+H+H+H+$

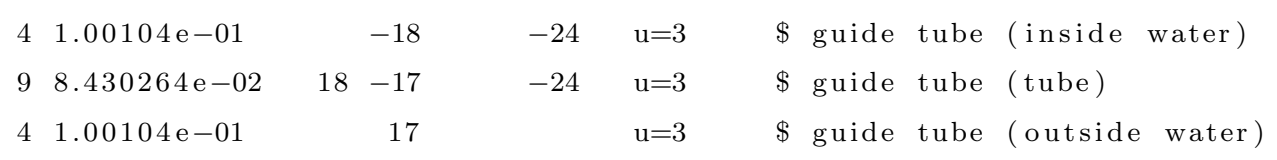

ATTEMPT TO THE :

surface 31 which defines CONTROL ROD INSERTION POSITION
6
$5.8233510 \mathrm{e}-02 \quad-29$
$31-24 \quad \mathrm{u}=5$
$\$$ control rod $B C \# 1$
$2-0.0001$
$\begin{array}{lllll}29 & -2 & 31 & -24 & \mathrm{u}=5\end{array}$
$\$$ gap
$\begin{array}{lllllll}3 & 8.657158 \mathrm{e}-02 & 2 & -3 & 31 & -24 & \mathrm{u}=5\end{array}$
$\$$ clad
$4 \quad 1.00104 \mathrm{e}-01 \quad 3 \quad-18$
$-24 \quad u=5$
$\$$ water inside
$98.430264 \mathrm{e}-02 \quad 18-17$
$-24 \quad \mathrm{u}=5$
$\$$ guide tube (SS)
$41.00104 \mathrm{e}-01 \quad 17$
$\mathrm{u}=5$
$\$$ water outside
plug of control rod\#1
$38.657158 \mathrm{e}-02 \quad-3$
$\begin{array}{lll}30 & -31 \quad \mathrm{u}=5\end{array}$
$\$$ control rod plug
$41.00104 \mathrm{e}-01 \quad-3$
$-30 \quad u=5$
$\$$ water below control rod

$+H+H+H+H+$ Control rod BC\#2 definition $+H+H+H+H+H+H$

ATTEMPT TO THE :

surface 41 which defines CONTROL ROD INSERTION POSITION

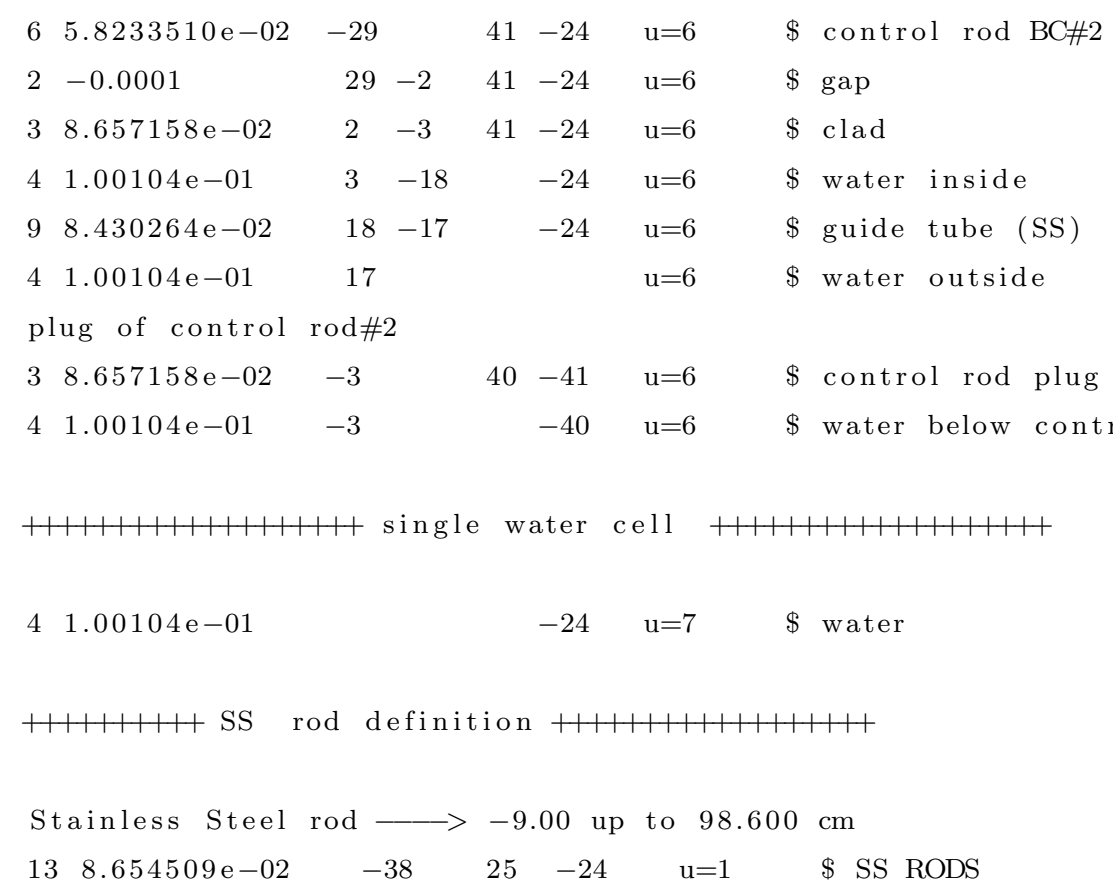




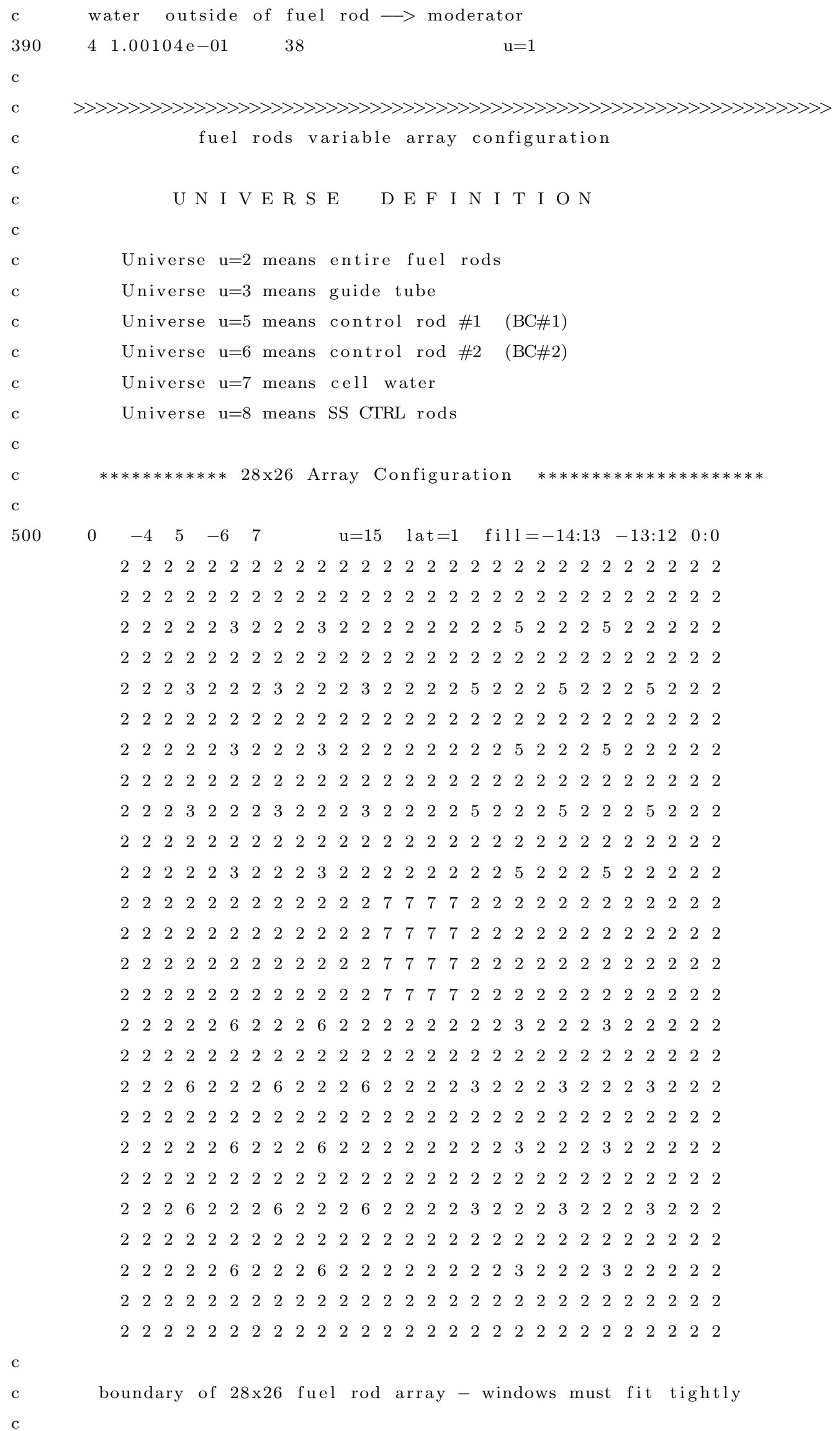




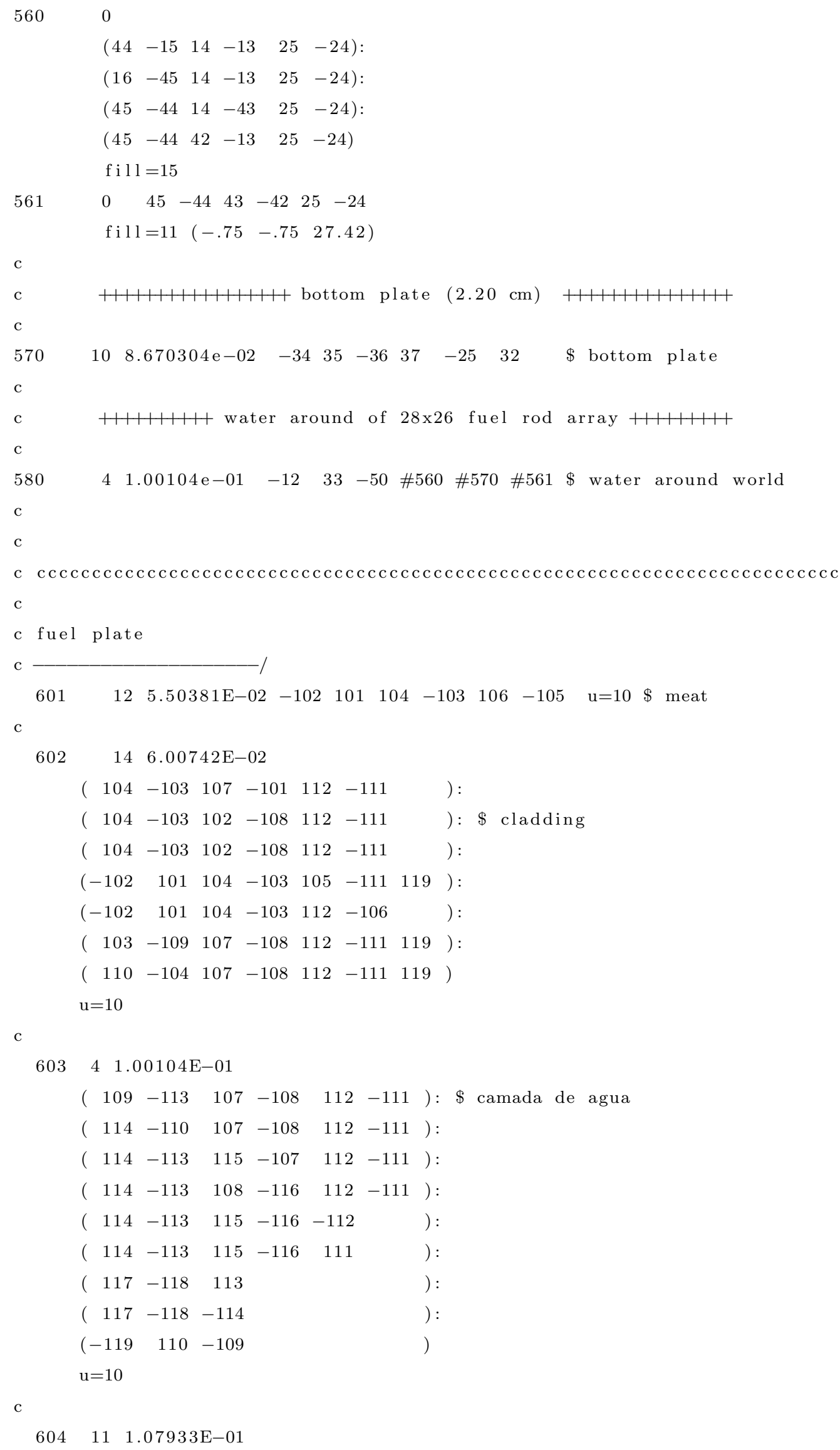




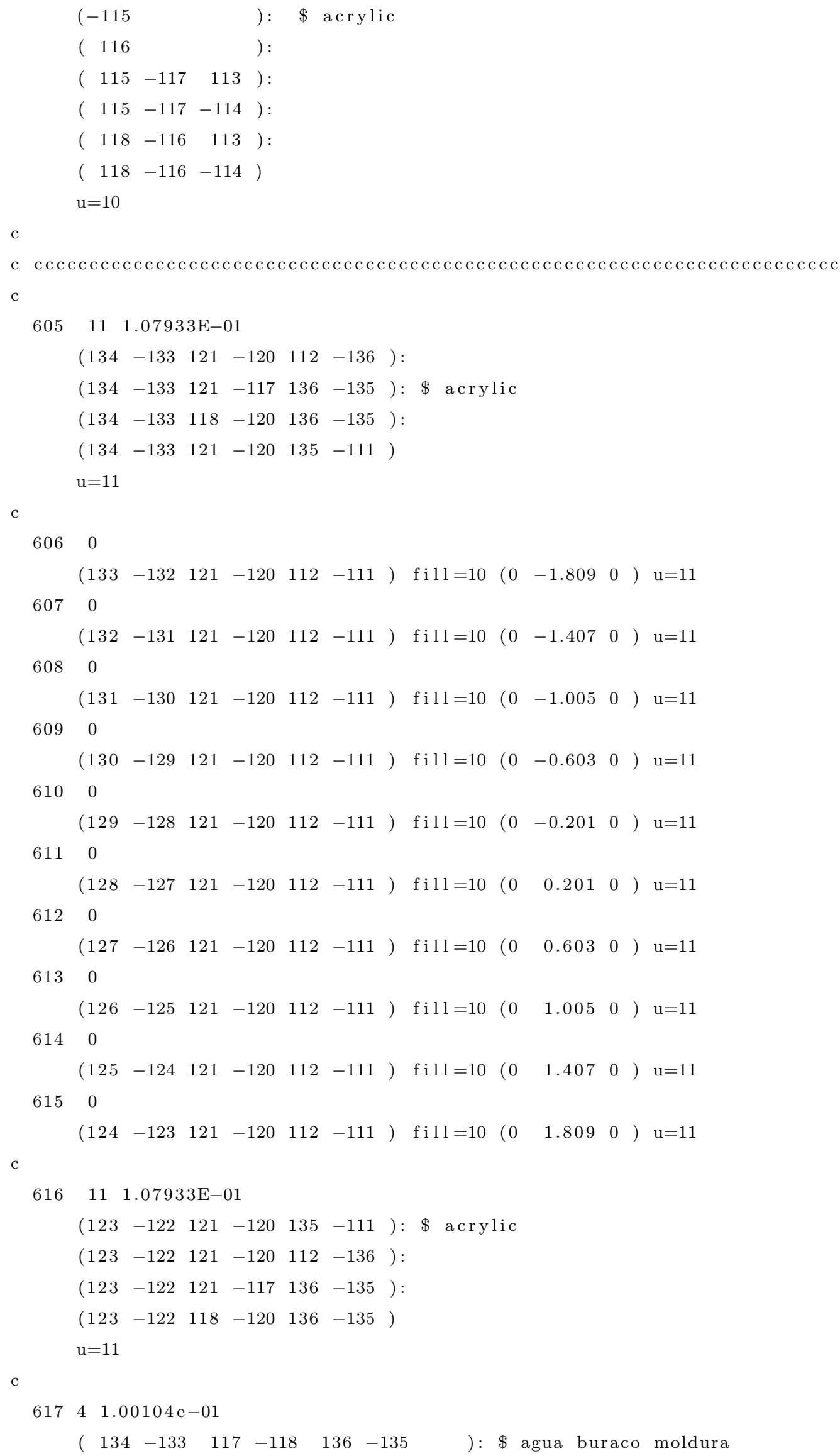




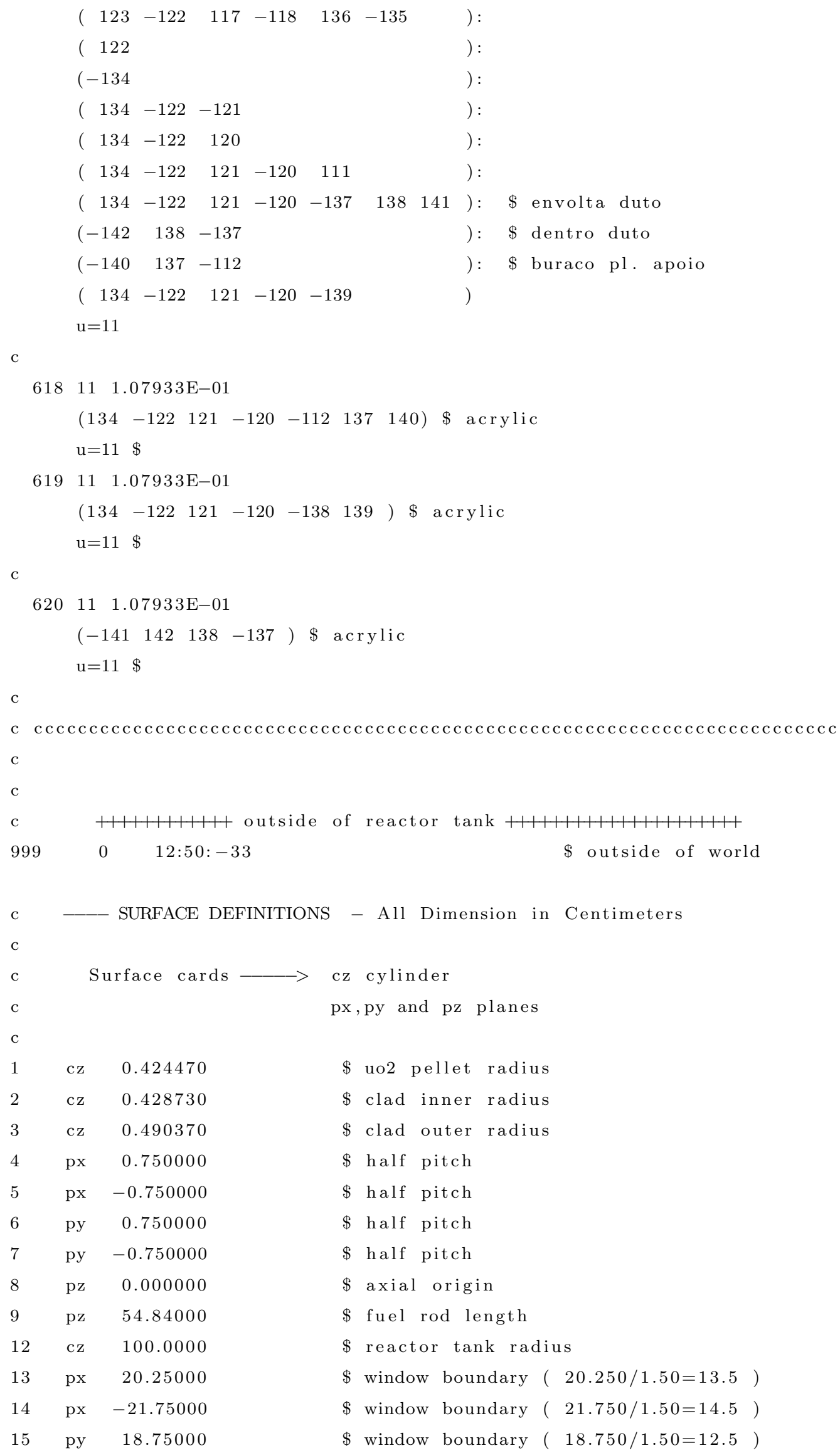




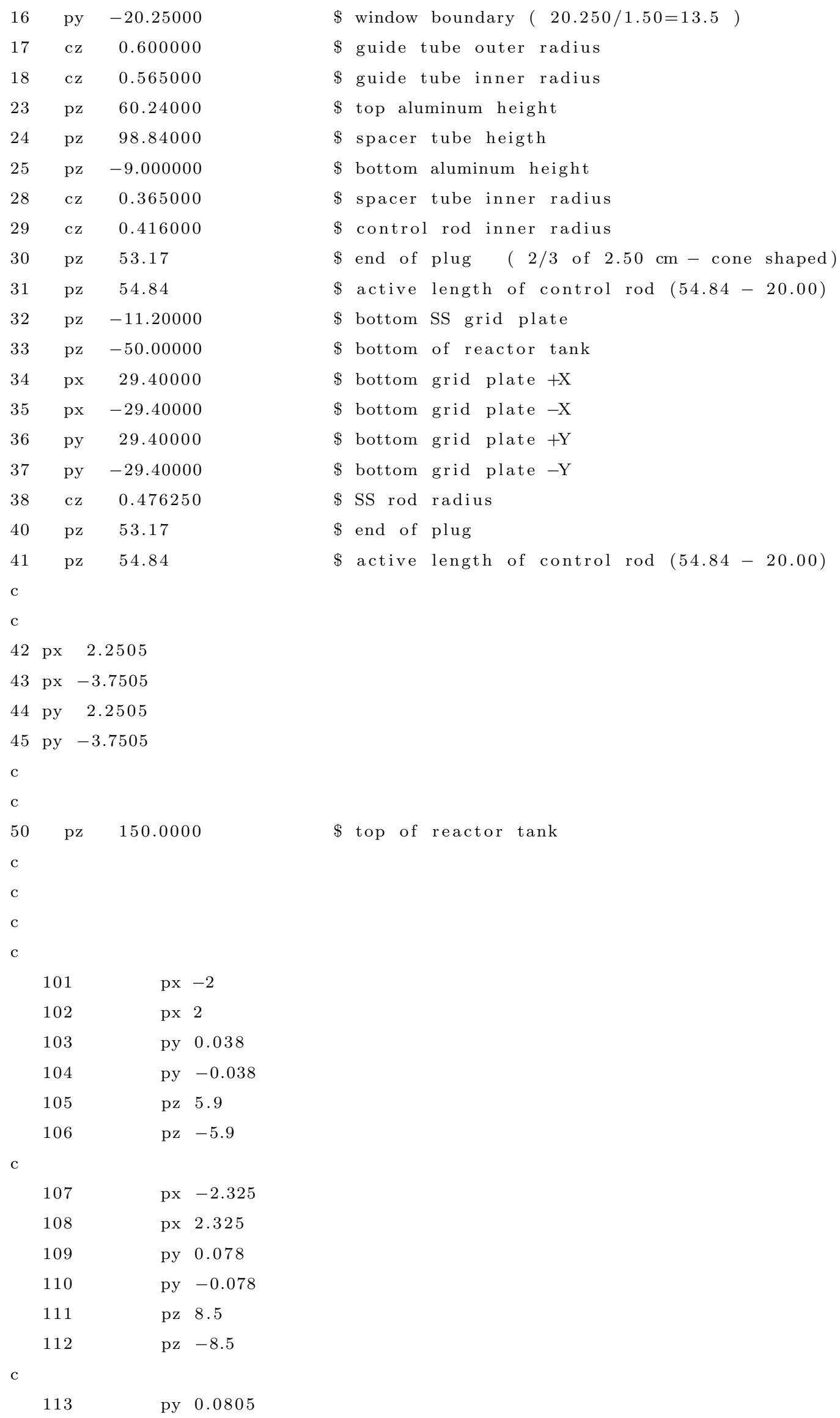




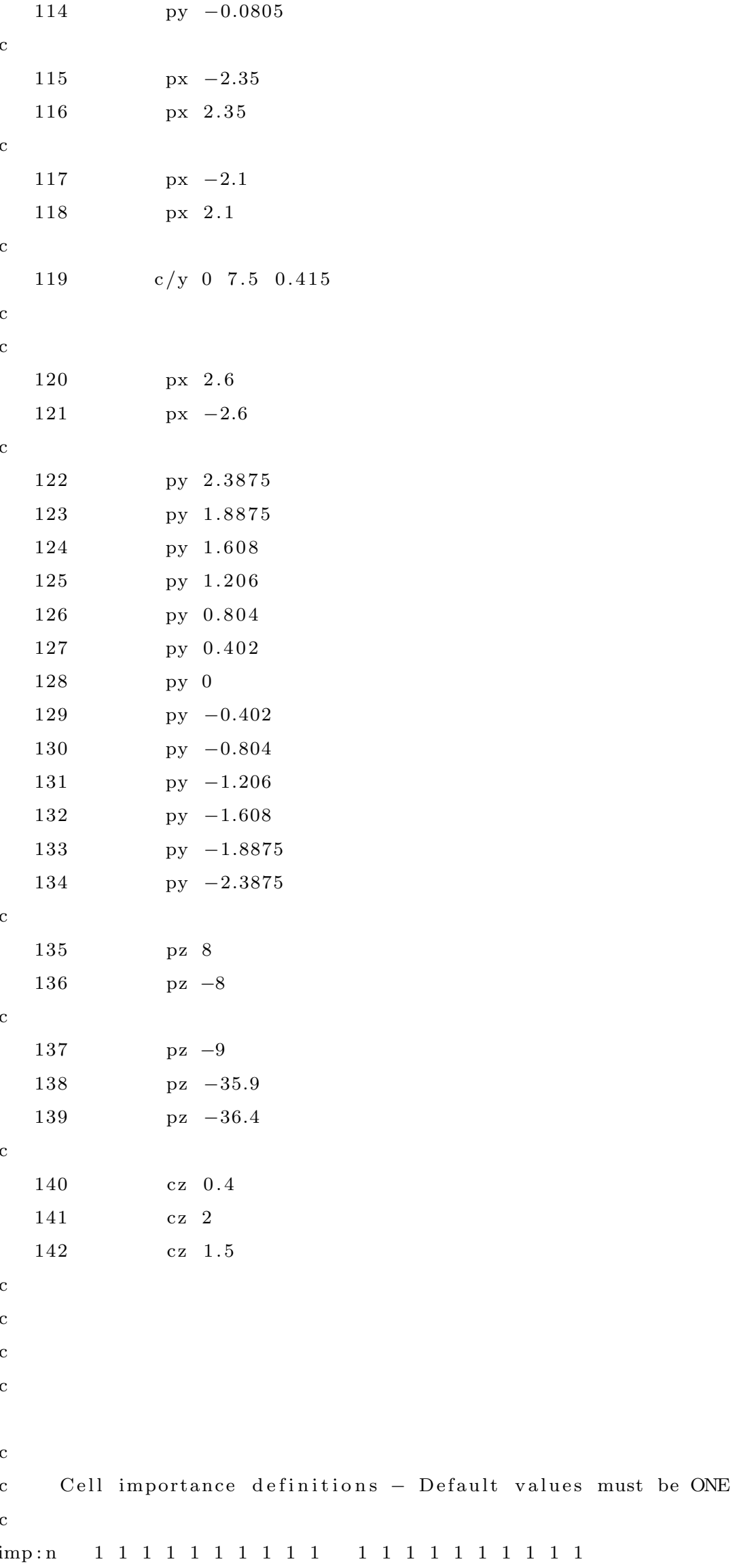




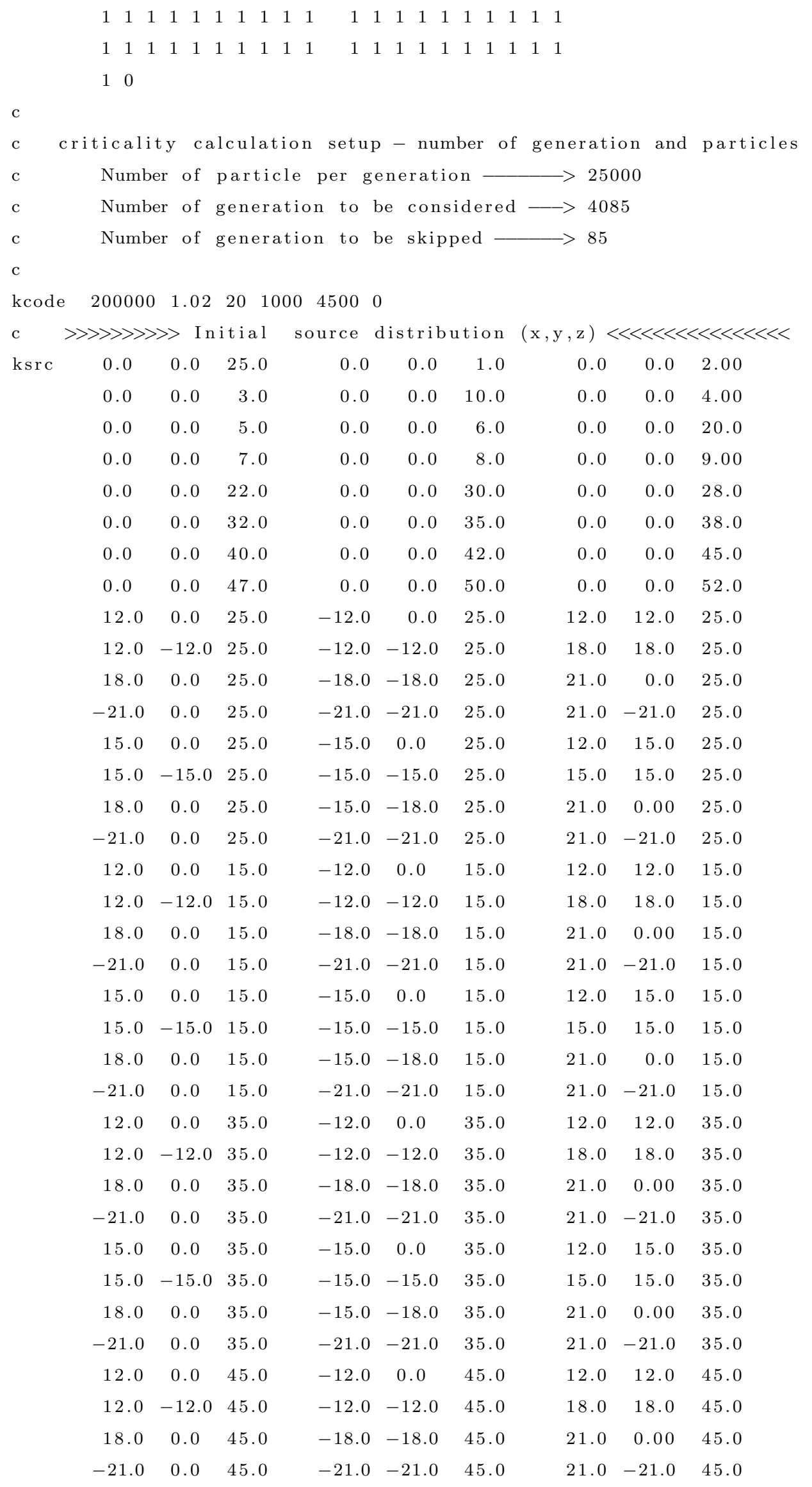




$\begin{array}{rcccccccc}15.0 & 0.0 & 45.0 & -15.0 & 0.0 & 45.0 & 12.0 & 15.0 & 45.0 \\ 15.0 & -15.0 & 45.0 & -15.0 & -15.0 & 45.0 & 15.0 & 15.0 & 45.0 \\ 18.0 & 0.0 & 45.0 & -15.0 & -18.0 & 45.0 & 21.0 & 0.00 & 45.0 \\ -21.0 & 0.0 & 45.0 & -21.0 & -21.0 & 45.0 & 21.0 & -21.0 & 45.0 \\ 12.0 & 0.0 & 51.0 & -12.0 & 0.0 & 51.0 & 12.0 & 12.0 & 51.0 \\ 12.0 & -12.0 & 51.0 & -12.0 & -12.0 & 51.0 & 18.0 & 18.0 & 51.0 \\ 18.0 & 0.0 & 51.0 & -18.0 & -18.0 & 51.0 & 21.0 & 0.00 & 51.0 \\ -21.0 & 0.0 & 51.0 & -21.0 & -21.0 & 51.0 & 21.0 & -21.0 & 51.0 \\ 15.0 & 0.0 & 51.0 & -15.0 & 0.0 & 51.0 & 12.0 & 15.0 & 51.0 \\ 15.0 & -15.0 & 51.0 & -15.0 & -15.0 & 51.0 & 15.0 & 15.0 & 51.0 \\ 18.0 & 0.0 & 51.0 & -15.0 & -18.0 & 51.0 & 21.0 & 0.00 & 51.0 \\ -21.0 & 0.0 & 51.0 & -21.0 & -21.0 & 51.0 & 21.0 & -21.0 & 51.0\end{array}$

material definitions

$\longrightarrow$ NNNNN.60c nuclide NNNNN from ENDF/B-VI cross section library

$\longrightarrow$ NNNNN.50c nuclide NNNNN from ENDF/B-V cross section library

$\longrightarrow$ nuclide concentration in atom/barn.cm

$\mathrm{m} 1 \Rightarrow \mathrm{UO} 2$ pellet $(\mathrm{U} 235, \mathrm{U} 238$ and $\mathrm{O} 16)$

$\mathrm{m} 2 \Rightarrow \operatorname{gap}(\mathrm{O} 16)$

$\mathrm{m} 3 \Rightarrow \mathrm{SS} 304 \operatorname{clad}(\mathrm{Fe}, \mathrm{Ni}, \mathrm{Cr}, \mathrm{Mn}, \mathrm{Si}, \mathrm{P}, \mathrm{C}, \mathrm{S}, \mathrm{Co}$ and Mo)

$\mathrm{m} 4 \Rightarrow \mathrm{H} 2 \mathrm{O}(\mathrm{H}$ and $\mathrm{O})$

$\mathrm{m} 5 \Rightarrow$ Alumina $(\mathrm{Al} \mathrm{O})$

$\mathrm{m} 6 \Rightarrow \mathrm{AG}-\mathrm{IN}-\mathrm{CD}$ Control ROD ( $\mathrm{Ag}$, In and $\mathrm{Cd}$ )

$\mathrm{m} 7 \Rightarrow$ SS304 Spacer Tube ( $\mathrm{Mn}, \mathrm{Si}, \mathrm{Ni}, \mathrm{Cr}, \mathrm{Fe}, \mathrm{C}, \mathrm{P}$ and $\mathrm{Co}$ )

$\mathrm{m} 8 \Rightarrow$ baffle (not used)

$\mathrm{m} 9 \Rightarrow \mathrm{SS} 304$ Guide Tube ( $\mathrm{Fe}, \mathrm{Ni}, \mathrm{Cr}, \mathrm{Mn}, \mathrm{Si}, \mathrm{P}, \mathrm{C}, \mathrm{S}, \mathrm{Co}$ and Mo)

$\mathrm{m} 10 \Rightarrow \mathrm{SS} 304$ Bottom Grid Plate ( Fe, Ni, Cr, Mn, Si, P, C and S)

m11 $\Rightarrow$ SS control Rods

$\mathrm{UO} 2$ - pellet region

m1 $\quad 92235.70 \mathrm{c} \quad 9.99240 \mathrm{e}-04 \quad 92238.70 \mathrm{c} \quad 2.1694 \mathrm{e}-02 \quad 8016.70 \mathrm{c} \quad 4.5489 \mathrm{e}-02$

92234.70 c $7.84620 \mathrm{e}-06$

Void (gap)

$8016.70 \mathrm{c} \quad 0.0001$

$\mathrm{SS} 304-\mathrm{clad}$

m3 $26054.70 \mathrm{c} \quad 3.57366 \mathrm{e}-03 \quad 26056.70 \mathrm{c} \quad 5.40491 \mathrm{e}-02 \quad 26057.70 \mathrm{c} \quad 1.22693 \mathrm{e}-03$

$26058.70 \mathrm{c} \quad 1.59256 \mathrm{e}-04$

24050.70 c $\quad 7.61902 \mathrm{e}-04 \quad 24052.70 \mathrm{c} \quad 1.41123 \mathrm{e}-02 \quad 24053.70 \mathrm{c} \quad 1.56980 \mathrm{e}-03$

$24054.70 \mathrm{c} \quad 3.82755 \mathrm{e}-04$

$28058.70 \mathrm{c} \quad 5.62942 \mathrm{e}-03 \quad 28060.70 \mathrm{c} \quad 2.09590 \mathrm{e}-03 \quad 28061.70 \mathrm{c} \quad 8.96301 \mathrm{e}-05$

$28062.70 \mathrm{c} \quad 2.80805 \mathrm{e}-04 \quad 28064.70 \mathrm{c} \quad 6.96915 \mathrm{e}-05$

$25055.70 \mathrm{c} \quad 1.46450 \mathrm{e}-03 \quad 14028.70 \mathrm{c} \quad 6.26555 \mathrm{e}-04 \quad 14029.70 \mathrm{c} \quad 3.17252 \mathrm{e}-05$

$14030.70 \mathrm{c} \quad 2.10595 \mathrm{e}-05 \quad 15031.70 \mathrm{c} \quad 4.00400 \mathrm{e}-05 \quad 6000.70 \mathrm{c} \quad 1.12390 \mathrm{e}-04$

$16032.70 \mathrm{c} \quad 1.48393 \mathrm{e}-05 \quad 16033.70 \mathrm{c} \quad 1.17128 \mathrm{e}-07 \quad 16034.70 \mathrm{c} \quad 6.57476 \mathrm{e}-07$

$16036.70 \mathrm{c} \quad 3.12340 \mathrm{E}-09 \quad 27059.70 \mathrm{c} \quad 1.74020 \mathrm{e}-04 \quad 42092.70 \mathrm{c} \quad 1.25428 \mathrm{e}-05$

$42094.70 \mathrm{c} \quad 7.81810 \mathrm{e}-06 \quad 42095.70 \mathrm{c} \quad 1.34556 \mathrm{e}-05 \quad 42096.70 \mathrm{c} \quad 1.40979 \mathrm{e}-05$ 
$42097.70 \mathrm{c} \quad 8.07166 \mathrm{e}-06 \quad 42098.70 \mathrm{c} \quad 2.03947 \mathrm{e}-05 \quad 42100.70 \mathrm{c} \quad 8.13928 \mathrm{e}-06$

$\mathrm{c}$

$\mathrm{H} 2 \mathrm{O}$ - water

$\mathrm{m} 4 \quad 1001.70 \mathrm{c} \quad 6.67360 \mathrm{e}-02 \quad 8016.70 \mathrm{c} \quad 3.33680 \mathrm{e}-02$

$\mathrm{mt} 4 \quad \mathrm{wtr} .01 \mathrm{t}$

c $\quad \mathrm{Al} 2 \mathrm{O} 3$ - Alumina

m5 $\quad 8016.70$ c $\quad 6.71160 \mathrm{e}-02 \quad 13027.70 \mathrm{c} \quad 4.47440 \mathrm{e}-02$

c AG-IN-CD Control rods

m6

$47107.70 \mathrm{c} \quad 2.31847 \mathrm{e}-02 \quad 47109.70 \mathrm{c} \quad 2.11443 \mathrm{e}-02$

$49113.70 \mathrm{c} \quad 3.36838 \mathrm{e}-04 \quad 49115.70 \mathrm{c} \quad 7.51486 \mathrm{e}-03$

$48106.70 \mathrm{c} \quad 3.23675 \mathrm{e}-05 \quad 48108.70 \mathrm{c} \quad 2.30457 \mathrm{e}-05 \quad 48110.70 \mathrm{c} \quad 3.23416 \mathrm{e}-04$

$48111.70 \mathrm{c} \quad 3.31443 \mathrm{e}-04 \quad 48112.70 \mathrm{c} \quad 6.24822 \mathrm{e}-04 \quad 48113.70 \mathrm{c} \quad 3.16425 \mathrm{e}-04$

48114.70 c $\quad 7.43935 \mathrm{e}-04 \quad 48116.70 \mathrm{c} \quad 1.93946 \mathrm{e}-04$

$6000.70 \mathrm{c} \quad 1.50520 \mathrm{e}-03 \quad 16032.70 \mathrm{c} \quad 1.78552 \mathrm{e}-04 \quad 16033.70 \mathrm{c} \quad 1.40933 \mathrm{e}-06$

$16034.70 \mathrm{c} \quad 7.91101 \mathrm{e}-06 \quad 16036.70 \mathrm{c} \quad 3.75820 \mathrm{e}-08$

$8016.70 \mathrm{c} \quad 1.77030 \mathrm{e}-03$

c SS304 - Spacer tube

$\mathrm{m} 7 \quad 26054.70 \mathrm{c} \quad 3.74872 \mathrm{e}-03 \quad 26056.70 \mathrm{c} \quad 5.66967 \mathrm{e}-02 \quad 26057.70 \mathrm{c} \quad 1.28703 \mathrm{e}-03$ $26058.70 \mathrm{c} \quad 1.67057 \mathrm{e}-04$

$24050.70 \mathrm{c} \quad 7.59839 \mathrm{e}-04 \quad 24052.70 \mathrm{c} \quad 1.40741 \mathrm{e}-02 \quad 24053.70 \mathrm{c} \quad 1.56555 \mathrm{e}-03$

$24054.70 \mathrm{c} \quad 3.81719 \mathrm{e}-04$

$28058.70 \mathrm{c} \quad 4.53128 \mathrm{e}-03 \quad 28060.70 \mathrm{c} \quad 1.68705 \mathrm{e}-03 \quad 28061.70 \mathrm{c} \quad 7.21458 \mathrm{e}-05$

$28062.70 \mathrm{c} \quad 2.26028 \mathrm{e}-04 \quad 28064.70 \mathrm{c} \quad 5.60967 \mathrm{e}-05$

$25055.70 \mathrm{c} \quad 1.15810 \mathrm{e}-03 \quad 14028.70 \mathrm{c} \quad 1.02883 \mathrm{e}-03 \quad 14029.70 \mathrm{c} \quad 5.20939 \mathrm{e}-05$

$14030.70 \mathrm{c} \quad 3.45805 \mathrm{e}-05 \quad 15031.70 \mathrm{c} \quad 3.11240 \mathrm{e}-05 \quad 6000.70 \mathrm{c} \quad 2.40780 \mathrm{e}-04$

$27059.70 \mathrm{c} \quad 1.14500 \mathrm{e}-04$

c SS304 - Guide tube

m9 $\quad 26054.70 \mathrm{c} \quad 3.44894 \mathrm{e}-03 \quad 26056.70 \mathrm{c} \quad 5.21628 \mathrm{e}-02 \quad 26057.70 \mathrm{c} \quad 1.18411 \mathrm{e}-03$

$26058.70 \mathrm{c} \quad 1.53698 \mathrm{e}-04$

$24050.70 \mathrm{c} \quad 7.38069 \mathrm{e}-04 \quad 24052.70 \mathrm{c} \quad 1.36708 \mathrm{e}-02 \quad 24053.70 \mathrm{c} \quad 1.52070 \mathrm{e}-03$

$24054.70 \mathrm{c} \quad 3.70782 \mathrm{e}-04$

$28058.70 \mathrm{c} \quad 6.27853 \mathrm{e}-03 \quad 28060.70 \mathrm{c} \quad 2.33757 \mathrm{e}-03 \quad 28061.70 \mathrm{c} \quad 9.99650 \mathrm{e}-05$

28062.70 c 3.13183 e-04 28064.70 c 7.77273 e-05

$25055.70 \mathrm{c} \quad 1.15010 \mathrm{e}-03 \quad 14028.70 \mathrm{c} \quad 6.10286 \mathrm{e}-04 \quad 14029.70 \mathrm{c} \quad 3.09014 \mathrm{e}-05$ $14030.70 \mathrm{c} \quad 2.05127 \mathrm{e}-05 \quad 15031.70 \mathrm{c} \quad 4.50000 \mathrm{e}-05 \quad 6000.70 \mathrm{c} \quad 8.89680 \mathrm{e}-05$ SS304 - Bottom grid plate

m10 26054.70c $3.63630 \mathrm{e}-03 \quad 26056.70 \mathrm{c} \quad 5.49964 \mathrm{e}-02 \quad 26057.70 \mathrm{c} \quad 1.24843 \mathrm{e}-03$ $26058.70 \mathrm{c} \quad 1.62047 \mathrm{e}-04$

$24050.70 \mathrm{c} \quad 7.56501 \mathrm{e}-04 \quad 24052.70 \mathrm{c} \quad 1.40122 \mathrm{e}-02 \quad 24053.70 \mathrm{c} \quad 1.55868 \mathrm{e}-03$

$24054.70 \mathrm{c} \quad 3.80042 \mathrm{e}-04$

$28058.70 \mathrm{c} \quad 5.28566 \mathrm{e}-03 \quad 28060.70 \mathrm{c} \quad 1.96791 \mathrm{e}-03 \quad 28061.70 \mathrm{c} \quad 8.41568 \mathrm{e}-05$

$28062.70 \mathrm{c} \quad 2.63658 \mathrm{e}-04 \quad 28064.70 \mathrm{c} \quad 6.54358 \mathrm{e}-05$

$25055.70 \mathrm{c} \quad 1.25030 \mathrm{e}-03 \quad 14028.70 \mathrm{c} \quad 7.98859 \mathrm{e}-04 \quad 14029.70 \mathrm{c} \quad 4.04497 \mathrm{e}-05$

$14030.70 \mathrm{c} \quad 2.68510 \mathrm{e}-05 \quad 42092.70 \mathrm{c} \quad 4.42692 \mathrm{e}-06 \quad 42094.70 \mathrm{c} \quad 2.75937 \mathrm{e}-06$

$42095.70 \mathrm{c} \quad 4.74910 \mathrm{e}-06 \quad 42096.70 \mathrm{c} \quad 4.97581 \mathrm{e}-06 \quad 42097.70 \mathrm{c} \quad 2.84886 \mathrm{e}-06$

$42098.70 \mathrm{c} \quad 7.19822 \mathrm{e}-06 \quad 42100.70 \mathrm{c} \quad 2.87273 \mathrm{e}-06$

$15031.70 \mathrm{c} \quad 5.54400 \mathrm{e}-05 \quad 6000.70 \mathrm{c} \quad 7.94260 \mathrm{e}-05 \quad 16032.70 \mathrm{c} \quad 4.23979 \mathrm{e}-06$

$16033.70 \mathrm{c} \quad 3.34650 \mathrm{e}-08 \quad 16034.70 \mathrm{c} \quad 1.87850 \mathrm{e}-07 \quad 16036.70 \mathrm{c} \quad 8.92400 \mathrm{e}-10$ 
c

c $\operatorname{coccccccccccccccccccc}$

c acrylic c

c ecceccecceccecceccec

$\mathrm{c}$

m11 $1001.70 \mathrm{c} \quad 5.79452 \mathrm{E}-02$

$6000.70 \mathrm{c} \quad 3.54893 \mathrm{E}-02$

$8016.70 \mathrm{c} \quad 1.44989 \mathrm{E}-02$

c

c

c $\operatorname{ccccccccccccccccccc}$

c Comb. Miniplacas c

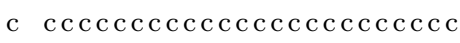

$\mathrm{c}$

m12 $92234.70 \mathrm{c} \quad 2.05212 \mathrm{E}-05 \quad 92235.70 \mathrm{c} \quad 2.04339 \mathrm{E}-03 \quad 92238.70 \mathrm{c} \quad 8.25424 \mathrm{E}-03$ $42092.70 \mathrm{c} \quad 3.33719 \mathrm{E}-04 \quad 42094.70 \mathrm{c} \quad 2.03586 \mathrm{E}-04 \quad 42095.70 \mathrm{c} \quad 3.46701 \mathrm{E}-04$ $42096.70 \mathrm{c} \quad 3.59468 \mathrm{E}-04 \quad 42097.70 \mathrm{c} \quad 2.03689 \mathrm{E}-04 \quad 42092.70 \mathrm{c} \quad 5.09409 \mathrm{E}-04$ $42100.70 \mathrm{c} \quad 1.99233 \mathrm{E}-04 \quad 13027.70 \mathrm{c} \quad 4.18503 \mathrm{E}-02 \quad 26054.70 \mathrm{c} \quad 6.27084 \mathrm{E}-06$ $26056.70 \mathrm{c} \quad 9.48379 \mathrm{E}-05 \quad 26057.70 \mathrm{c} \quad 2.15291 \mathrm{E}-06 \quad 26058.70 \mathrm{c} \quad 2.79443 \mathrm{E}-07$ $29063.70 \mathrm{c} \quad 3.52628 \mathrm{E}-05 \quad 29065.70 \mathrm{c} \quad 1.57171 \mathrm{E}-05 \quad 24050.70 \mathrm{c} \quad 1.14663 \mathrm{E}-06$ $24052.70 \mathrm{c} \quad 2.20865 \mathrm{E}-05 \quad 24053.70 \mathrm{c} \quad 2.50414 \mathrm{E}-06 \quad 24054.70 \mathrm{c} \quad 6.22081 \mathrm{E}-07$ $12024.70 \mathrm{c} \quad 4.00887 \mathrm{E}-04 \quad 12025.70 \mathrm{c} \quad 5.07516 \mathrm{E}-05 \quad 12026.70 \mathrm{c} \quad 5.58775 \mathrm{E}-05$ $25055.70 \mathrm{c} \quad 2.04121 \mathrm{E}-05 \quad 22046.70 \mathrm{c} \quad 2.14689 \mathrm{E}-07 \quad 22047.70 \mathrm{c} \quad 1.93611 \mathrm{E}-07$ $22048.70 \mathrm{c} \quad 1.91841 \mathrm{E}-06 \quad 22049.70 \mathrm{c} \quad 1.40784 \mathrm{E}-07 \quad 22050.70 \mathrm{c} \quad 1.34799 \mathrm{E}-07$ $5010.70 \mathrm{c} \quad 2.29355 \mathrm{E}-07 \quad 5011.70 \mathrm{c} \quad 9.23167 \mathrm{E}-07 \quad 48106.70 \mathrm{c} \quad 6.92768 \mathrm{E}-10$ $48108.70 \mathrm{c} \quad 4.93251 \mathrm{E}-10 \quad 48110.70 \mathrm{c} \quad 6.92214 \mathrm{E}-09 \quad 48111.70 \mathrm{c} \quad 7.09395 \mathrm{E}-09$ $48112.70 \mathrm{c} \quad 1.33732 \mathrm{E}-08 \quad 48113.70 \mathrm{c} \quad 6.77250 \mathrm{E}-09 \quad 48114.70 \mathrm{c} \quad 1.59226 \mathrm{E}-08$ $48116.70 \mathrm{c} \quad 4.15107 \mathrm{E}-09 \quad 27059.70 \mathrm{c} \quad 1.26854 \mathrm{E}-06$ $\mathrm{m} 13$

encamisamento das barras de controle e de seguranca - SS304

$26054.70 \mathrm{c} \quad 3.50278 \mathrm{e}-03 \quad 26056.70 \mathrm{c} \quad 5.29770 \mathrm{e}-02 \quad 26057.70 \mathrm{c} \quad 1.20259 \mathrm{e}-03$

$26058.70 \mathrm{c} \quad 1.56097 \mathrm{e}-04$

$24050.70 \mathrm{c} \quad 7.62733 \mathrm{e}-04 \quad 24052.70 \mathrm{c} \quad 1.41277 \mathrm{e}-02 \quad 24053.70 \mathrm{c} \quad 1.57152 \mathrm{e}-03$

$24054.70 \mathrm{c} \quad 3.83172 \mathrm{e}-04$

$28058.70 \mathrm{c} \quad 6.54682 \mathrm{e}-03 \quad 28060.70 \mathrm{c} \quad 2.43746 \mathrm{e}-03 \quad 28061.70 \mathrm{c} \quad 1.04236 \mathrm{e}-04$

$28062.70 \mathrm{c} \quad 3.26566 \mathrm{e}-0428064.70 \mathrm{c} \quad 8.10488 \mathrm{e}-05$

$25055.70 \mathrm{c} \quad 1.18080 \mathrm{e}-03 \quad 14028.70 \mathrm{c} \quad 7.04878 \mathrm{e}-04 \quad 14029.70 \mathrm{c} \quad 3.56910 \mathrm{e}-05$

$14030.70 \mathrm{c} \quad 2.36921 \mathrm{e}-05 \quad 15031.70 \mathrm{c} \quad 4.15796 \mathrm{e}-05$

$6000.70 \mathrm{c} \quad 8.33972 \mathrm{e}-05 \quad 16032.70 \mathrm{c} \quad 4.23983 \mathrm{e}-06 \quad 16033.70 \mathrm{c} \quad 3.34653 \mathrm{e}-08$

$16034.70 \mathrm{c} \quad 1.87852 \mathrm{e}-07 \quad 16036.70 \mathrm{c} \quad 8.92408 \mathrm{e}-10 \quad 27059.70 \mathrm{c} \quad 1.37594 \mathrm{e}-04$

$42092.70 \mathrm{c} \quad 2.21343 \mathrm{e}-06 \quad 42094.70 \mathrm{c} \quad 1.37967 \mathrm{e}-06 \quad 42095.70 \mathrm{c} \quad 2.37452 \mathrm{e}-06$

$42096.70 \mathrm{c} \quad 2.48787 \mathrm{e}-06 \quad 42097.70 \mathrm{c} \quad 1.42441 \mathrm{e}-06 \quad 42098.70 \mathrm{c} \quad 3.59906 \mathrm{e}-06$ $42100.70 \mathrm{c} \quad 1.43634 \mathrm{e}-06 \quad 29063.70 \mathrm{c} \quad 9.43728 \mathrm{e}-05 \quad 29065.70 \mathrm{c} \quad 4.07687 \mathrm{e}-05$ $50112.70 \mathrm{c} \quad 3.30769 \mathrm{e}-08 \quad 50114.70 \mathrm{c} \quad 2.17761 \mathrm{e}-08 \quad 50115.70 \mathrm{c} \quad 1.12914 \mathrm{e}-08$ $50116.70 \mathrm{c} \quad 4.78714 \mathrm{e}-07 \quad 50117.70 \mathrm{c} \quad 2.50690 \mathrm{e}-07 \quad 50118.70 \mathrm{c} \quad 7.83891 \mathrm{e}-07$ $50119.70 \mathrm{c} \quad 2.75677 \mathrm{e}-07 \quad 50120.70 \mathrm{c} \quad 1.03719 \mathrm{e}-06 \quad 50122.70 \mathrm{c} \quad 1.44933 \mathrm{e}-07$ $50124.70 \mathrm{c} \quad 1.78316 \mathrm{e}-07$ 
c

c

c $\operatorname{ccccccccccccccccccc}$

c Al6061 c

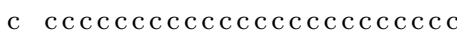

c

c $\quad 12000.70 \mathrm{c} \quad 6.6229 \mathrm{E}-04$

c $\quad 30000.70 \mathrm{c} \quad 0.0000 \mathrm{E}+00$

c $\quad 22000.70 \mathrm{c} \quad 3.3959 \mathrm{E}-06$

m14 $\quad 13027.70 \mathrm{c} \quad 0.058811$

$29063.70 \mathrm{c} \quad 4.6017 \mathrm{e}-005 \quad 29065.70 \mathrm{c} \quad 2.051 \mathrm{e}-005 \quad 24050.70 \mathrm{c} \quad 1.4946 \mathrm{e}-006$

$24052.70 \mathrm{c} \quad 2.8822 \mathrm{e}-005 \quad 24053.70 \mathrm{c} \quad 3.2682 \mathrm{e}-006 \quad 24054.70 \mathrm{c} \quad 8.1352 \mathrm{e}-007$

$12024.70 \mathrm{c} \quad 0.00052314 \quad 12025.70 \mathrm{c} \quad 6.6229 \mathrm{e}-005 \quad 12026.70 \mathrm{c} \quad 7.2918 \mathrm{e}-005$

$14028.70 \mathrm{c} \quad 0.00035775 \quad 14029.70 \mathrm{c} \quad 1.8165 \mathrm{e}-005 \quad 14030.70 \mathrm{c} \quad 1.1974 \mathrm{e}-005$

$26054.70 \mathrm{c} \quad 4.5947 \mathrm{e}-006 \quad 26056.70 \mathrm{c} \quad 7.2127 \mathrm{e}-005 \quad 26057.70 \mathrm{c} \quad 1.6657 \mathrm{e}-006$

$26058.70 \mathrm{c} \quad 2.2168 \mathrm{e}-007 \quad 25055.70 \mathrm{c} \quad 2.6637 \mathrm{e}-005 \quad 22046.70 \mathrm{c} \quad 2.8016 \mathrm{e}-007$

$22047.70 \mathrm{c} \quad 2.5265 \mathrm{e}-007 \quad 22048.70 \mathrm{c} \quad 2.5035 \mathrm{e}-006 \quad 22049.70 \mathrm{c} \quad 1.8372 \mathrm{e}-007$

$22050.70 \mathrm{c} \quad 1.7591 \mathrm{e}-007 \quad 5010.70 \mathrm{c} \quad 2.9779 \mathrm{e}-007 \quad 5011.70 \mathrm{c} \quad 1.2062 \mathrm{e}-006$

$48106.70 \mathrm{c} \quad 9.0404 \mathrm{e}-010 \quad 48108.70 \mathrm{c} \quad 6.4368 \mathrm{e}-010 \quad 48110.70 \mathrm{c} \quad 9.0332 \mathrm{e}-009$

$48111.70 \mathrm{c} \quad 9.2574 \mathrm{e}-009 \quad 48112.70 \mathrm{c} \quad 1.7452 \mathrm{e}-008 \quad 48113.70 \mathrm{c} \quad 8.8379 \mathrm{e}-009$

$48114.70 \mathrm{c} \quad 2.0778 \mathrm{e}-008 \quad 48116.70 \mathrm{c} \quad 5.417 \mathrm{e}-009 \quad 27059.70 \mathrm{c} \quad 1.6554 \mathrm{e}-006$

$3006.70 \mathrm{c} \quad 1.778 \mathrm{e}-008 \quad 3007.70 \mathrm{c} \quad 2.1648 \mathrm{e}-007$

prdmp $1 \mathrm{j} \quad 500 \quad-1$

print 


\section{$\mathrm{C}$}

\section{Dados De Entrada Do MCNP-5 Configuração 4}

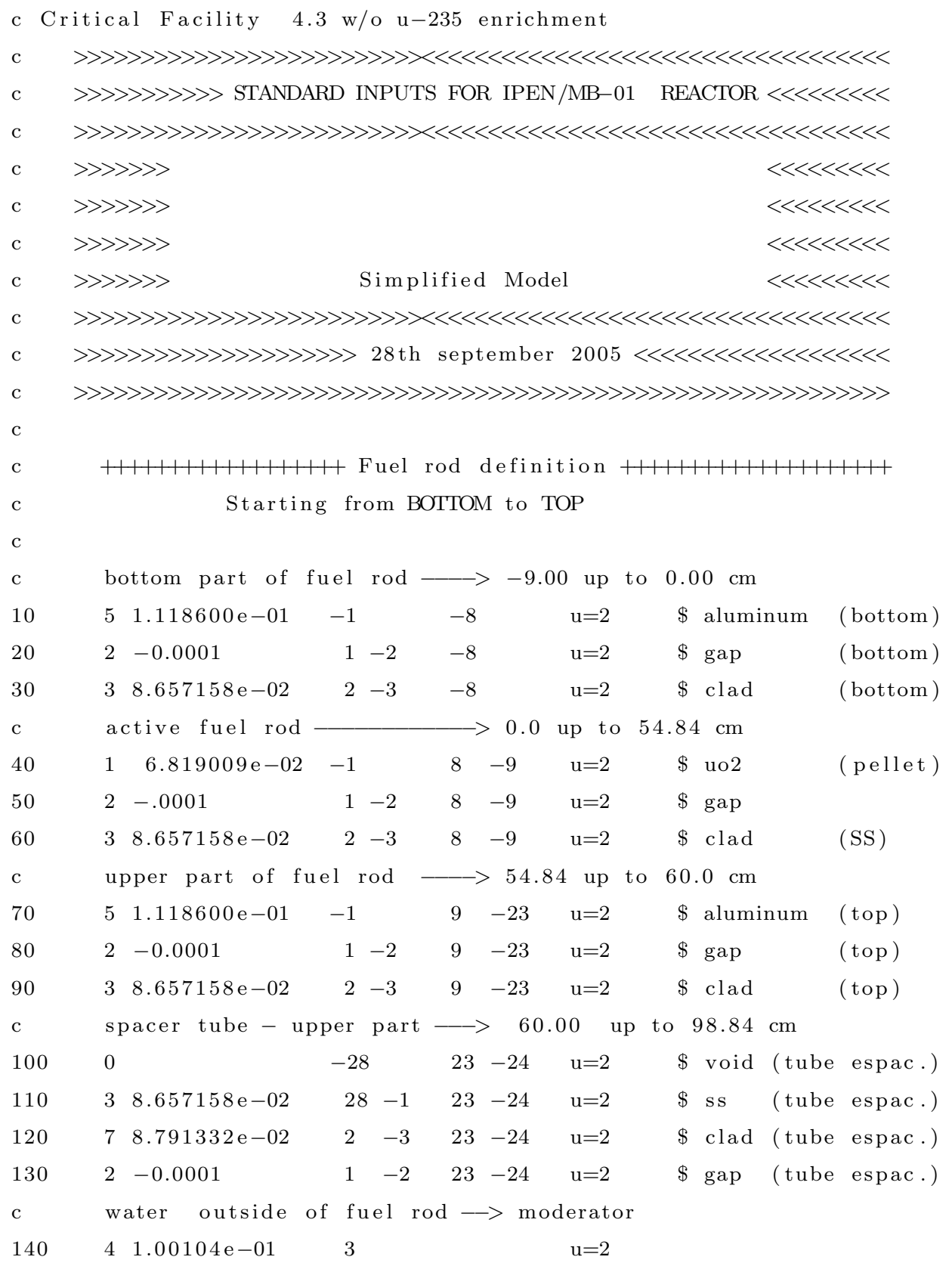


c
$+H+H+H+H+H+H+$ guide tube definition $+H+H+H+H+H+H+$

\begin{tabular}{|c|c|c|c|c|c|c|c|c|}
\hline $41.00104 \mathrm{e}-01$ & & -18 & -24 & $\mathrm{u}=3$ & $\$$ guide & tube & ( inside & water) \\
\hline $8.430264 \mathrm{e}-02$ & 18 & -17 & -24 & $\mathrm{u}=3$ & $\$$ guide & tube & (tube) & \\
\hline $41.00104 \mathrm{e}-01$ & & 17 & & $\mathrm{u}=3$ & $\$$ guide & tube & (outside & water) \\
\hline
\end{tabular}

ATTEMPT TO THE :

surface 31 which defines CONTROL ROD INSERTION POSITION
6
$5.8233510 \mathrm{e}-02 \quad-29$
$31-24 \quad \mathrm{u}=5$
$\$$ control rod $B C \# 1$
$2-0.0001$
$\begin{array}{lllll}29 & -2 & 31 & -24 & \mathrm{u}=5\end{array}$
$\$$ gap
$\begin{array}{lllllll}3 & 8.657158 \mathrm{e}-02 & 2 & -3 & 31 & -24 & \mathrm{u}=5\end{array}$
$\$$ clad
$4 \quad 1.00104 \mathrm{e}-01 \quad 3 \quad-18$
$-24 \quad u=5$
$\$$ water inside
$98.430264 \mathrm{e}-02 \quad 18-17$
$-24 \quad \mathrm{u}=5$
$\$$ guide tube (SS)
$41.00104 \mathrm{e}-01 \quad 17$
$\mathrm{u}=5$
$\$$ water outside
plug of control rod\#1
$38.657158 \mathrm{e}-02 \quad-3$
$\begin{array}{lll}30 & -31 \quad \mathrm{u}=5\end{array}$
$\$$ control rod plug
$4 \quad 1.00104 \mathrm{e}-01 \quad-3$
$-30 \quad u=5$
$\$$ water below control rod

$+H+H+H+H+$ Control rod BC\#2 definition $+H+H+H+H+H+H$

ATTEMPT TO THE :

surface 41 which defines CONTROL ROD INSERTION POSITION

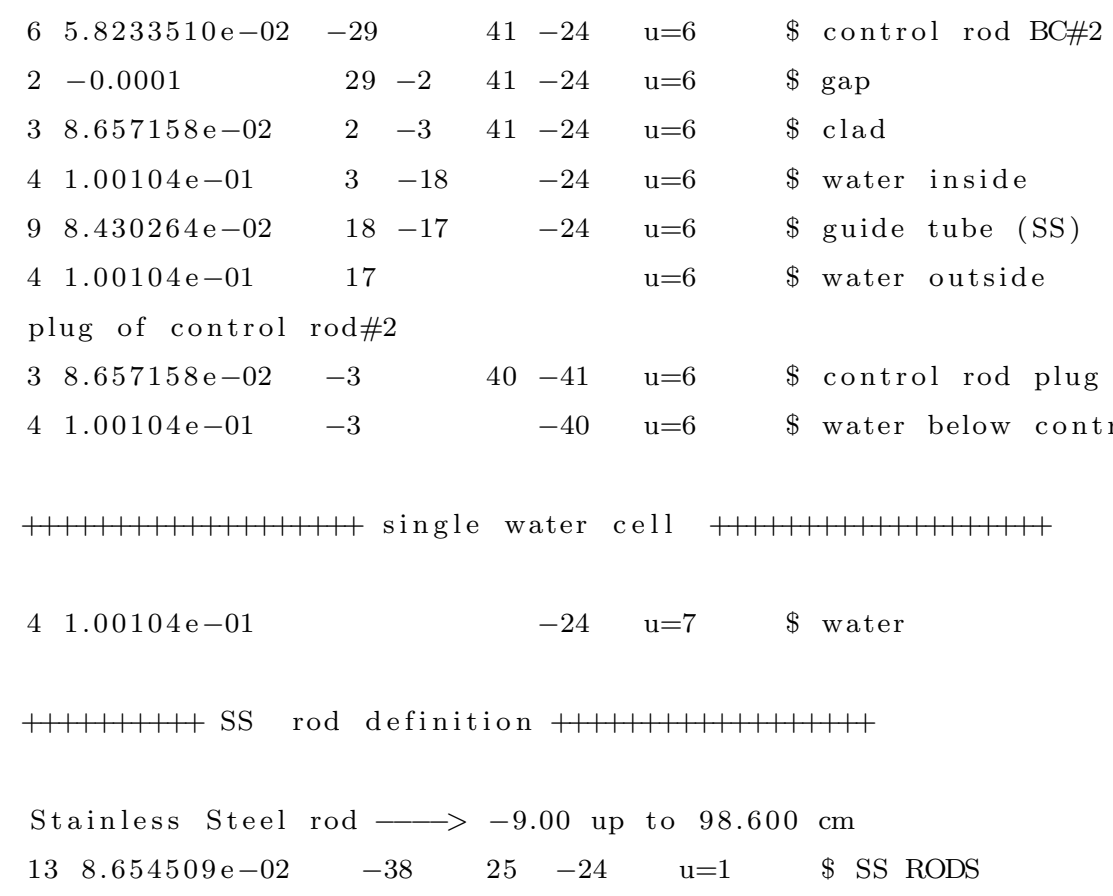




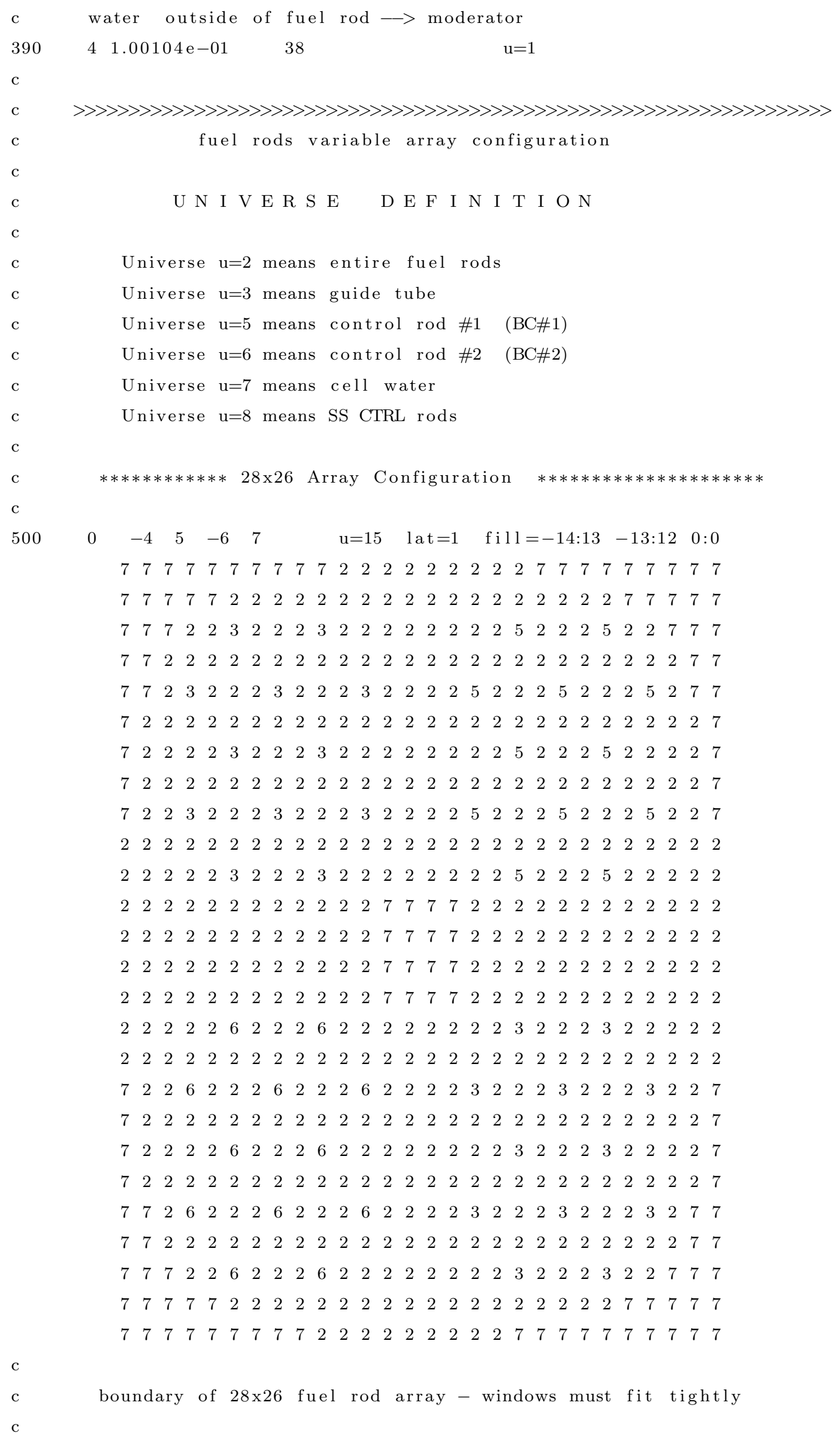




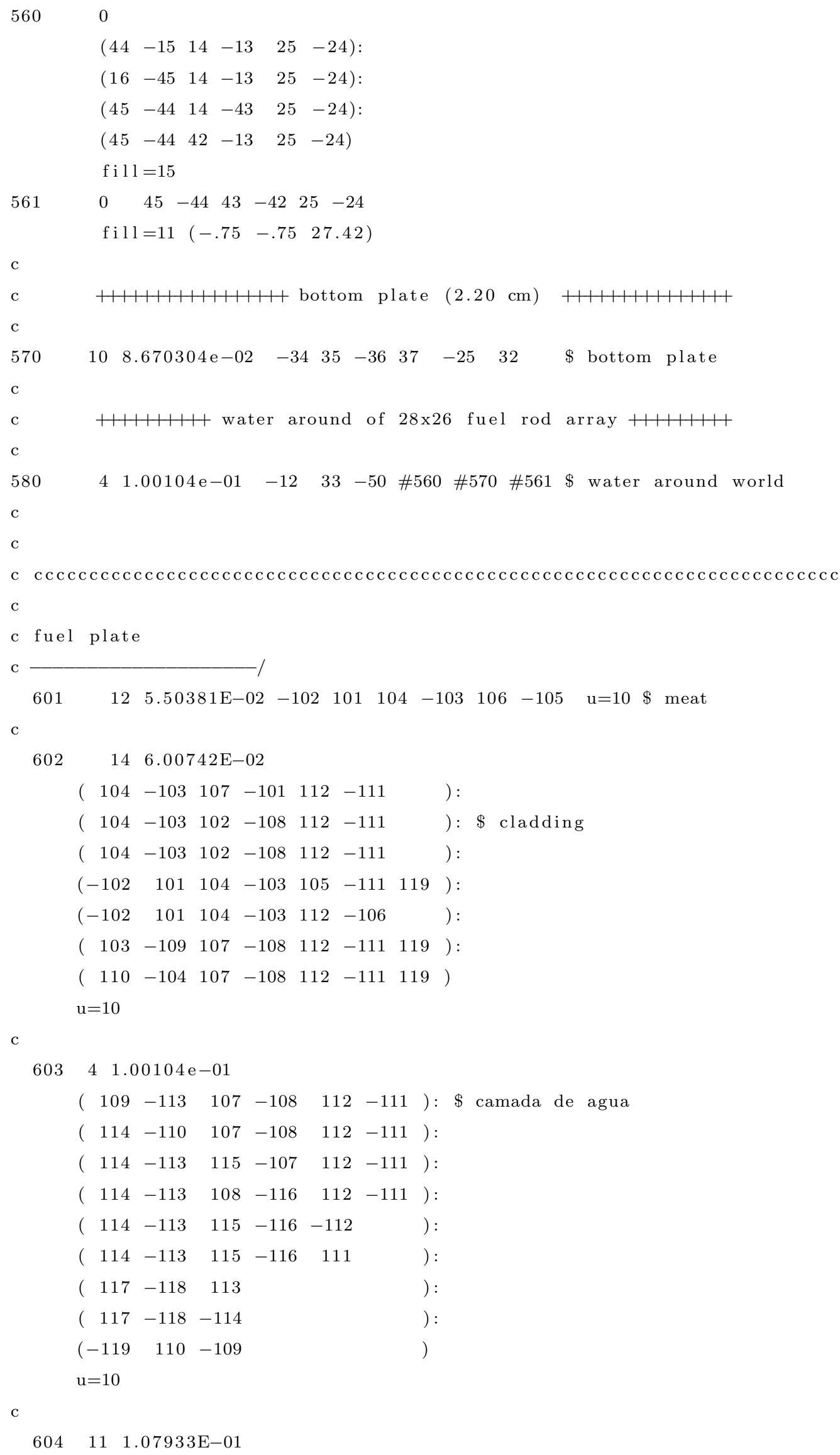




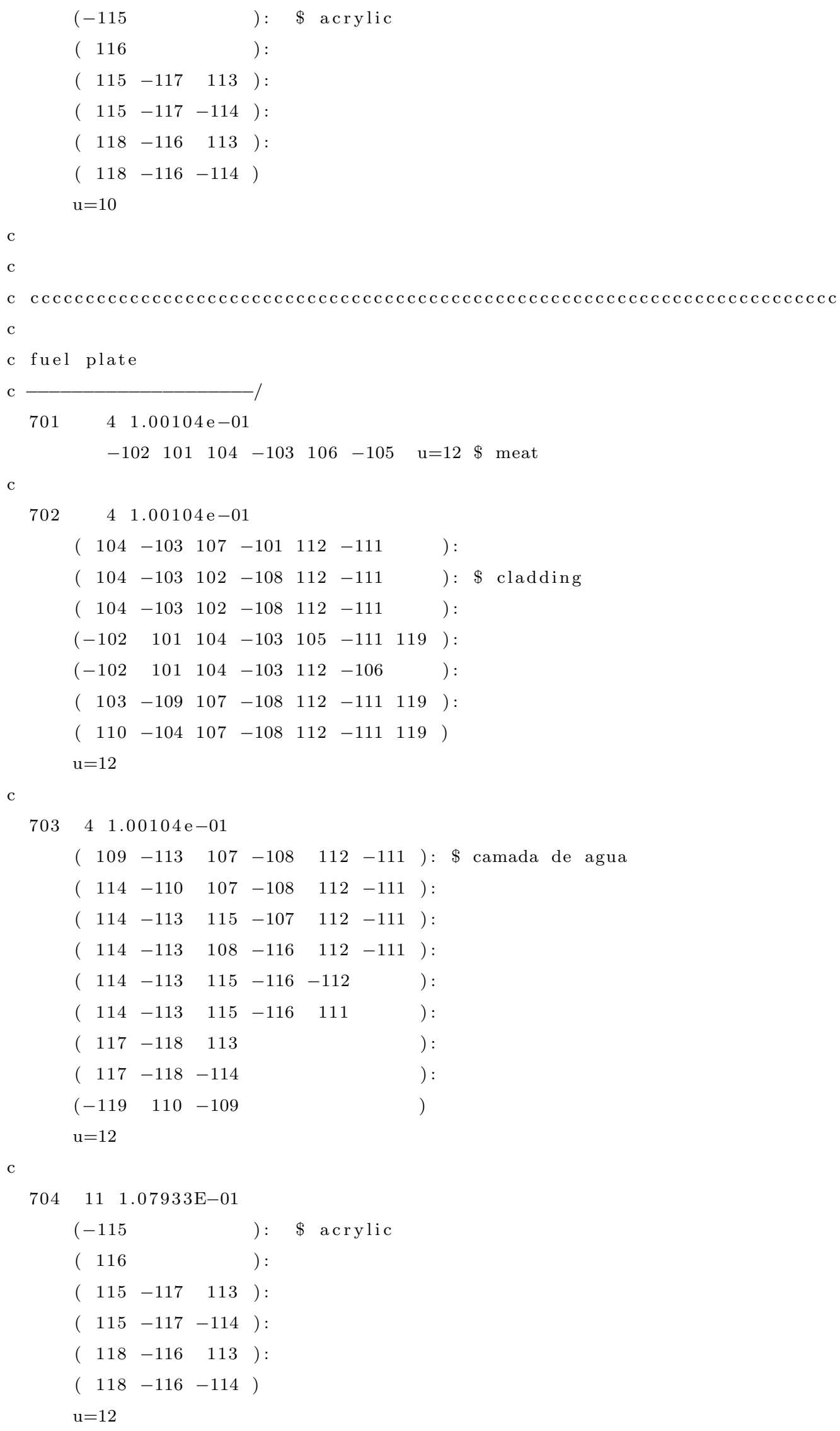




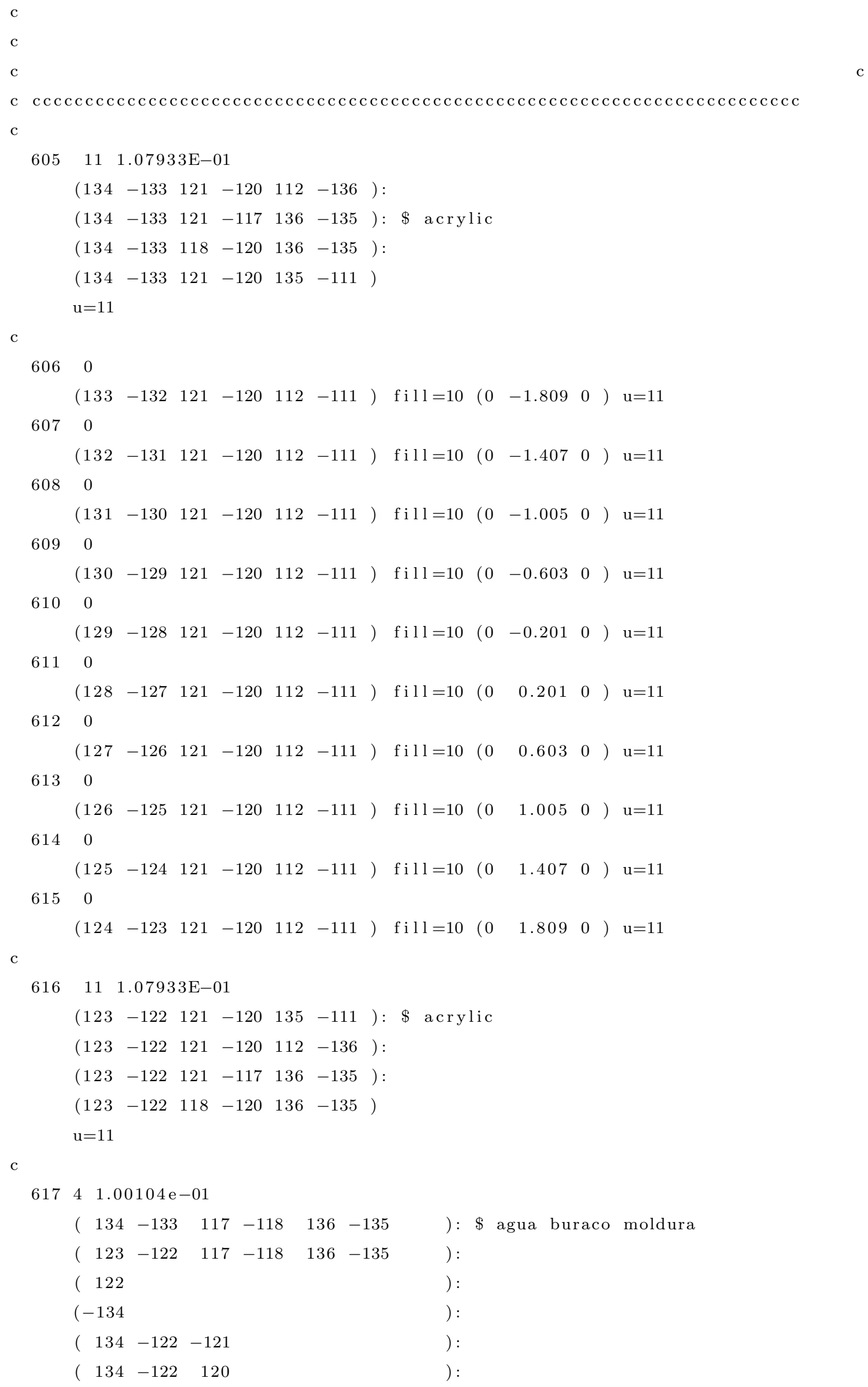




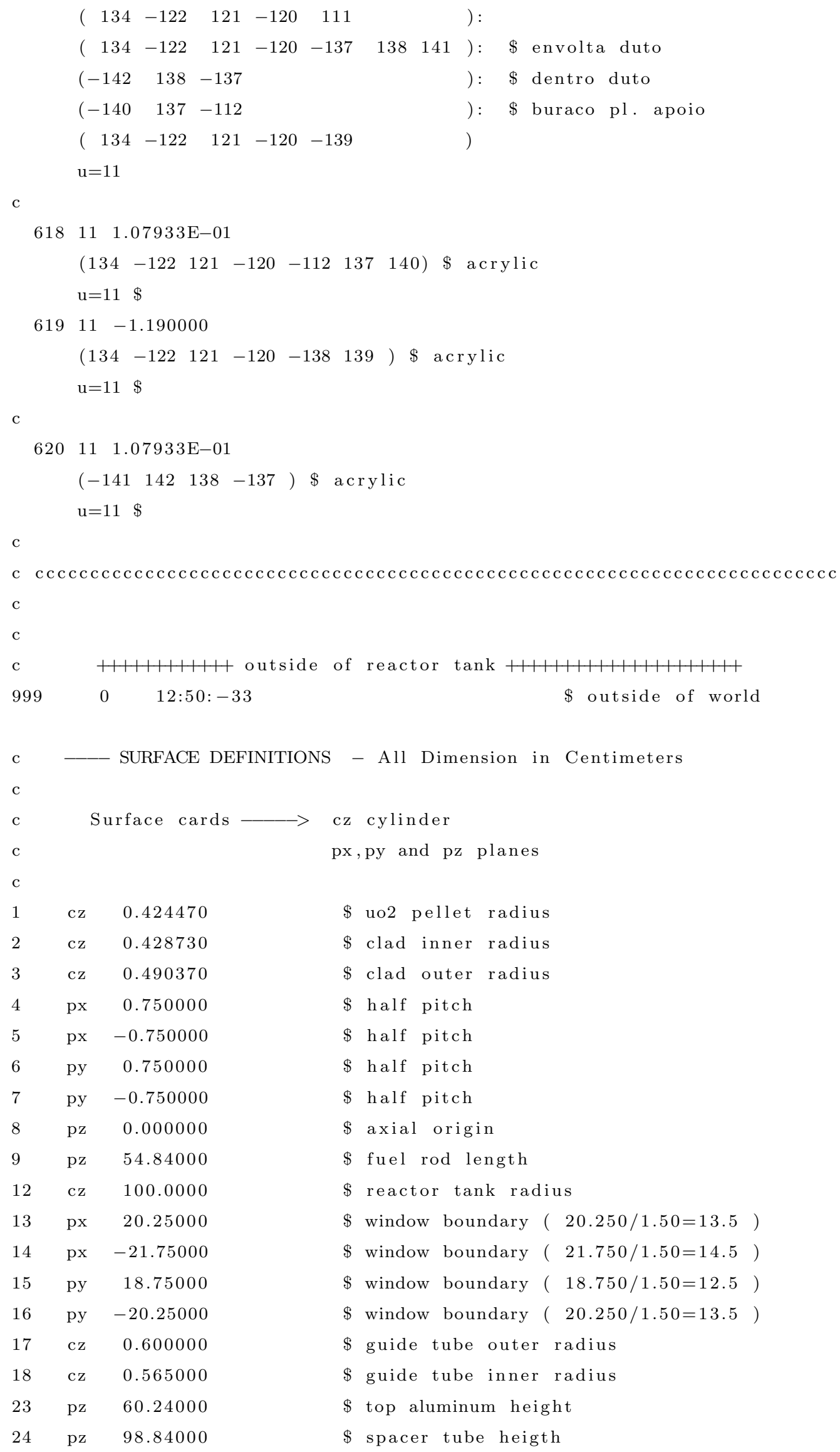




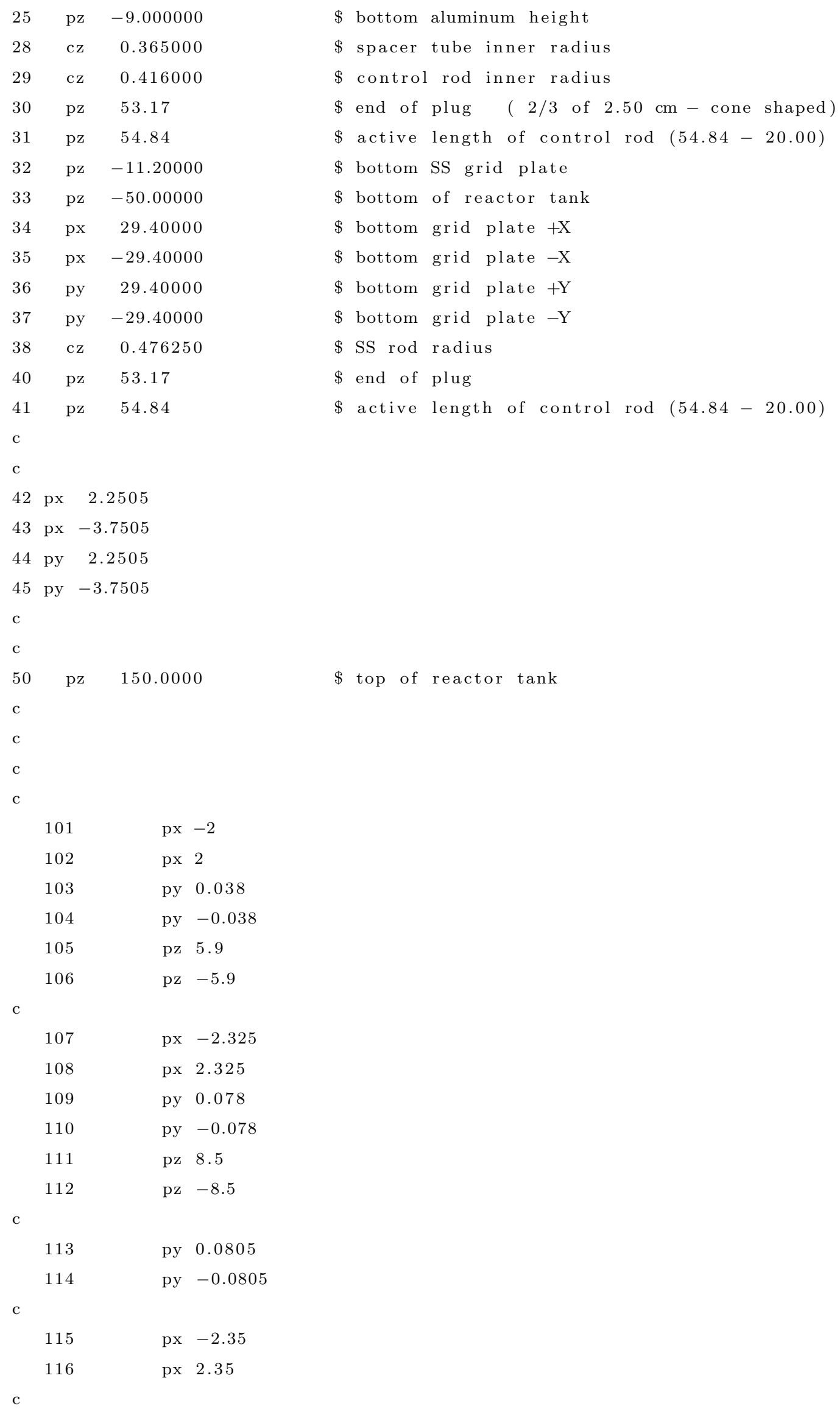




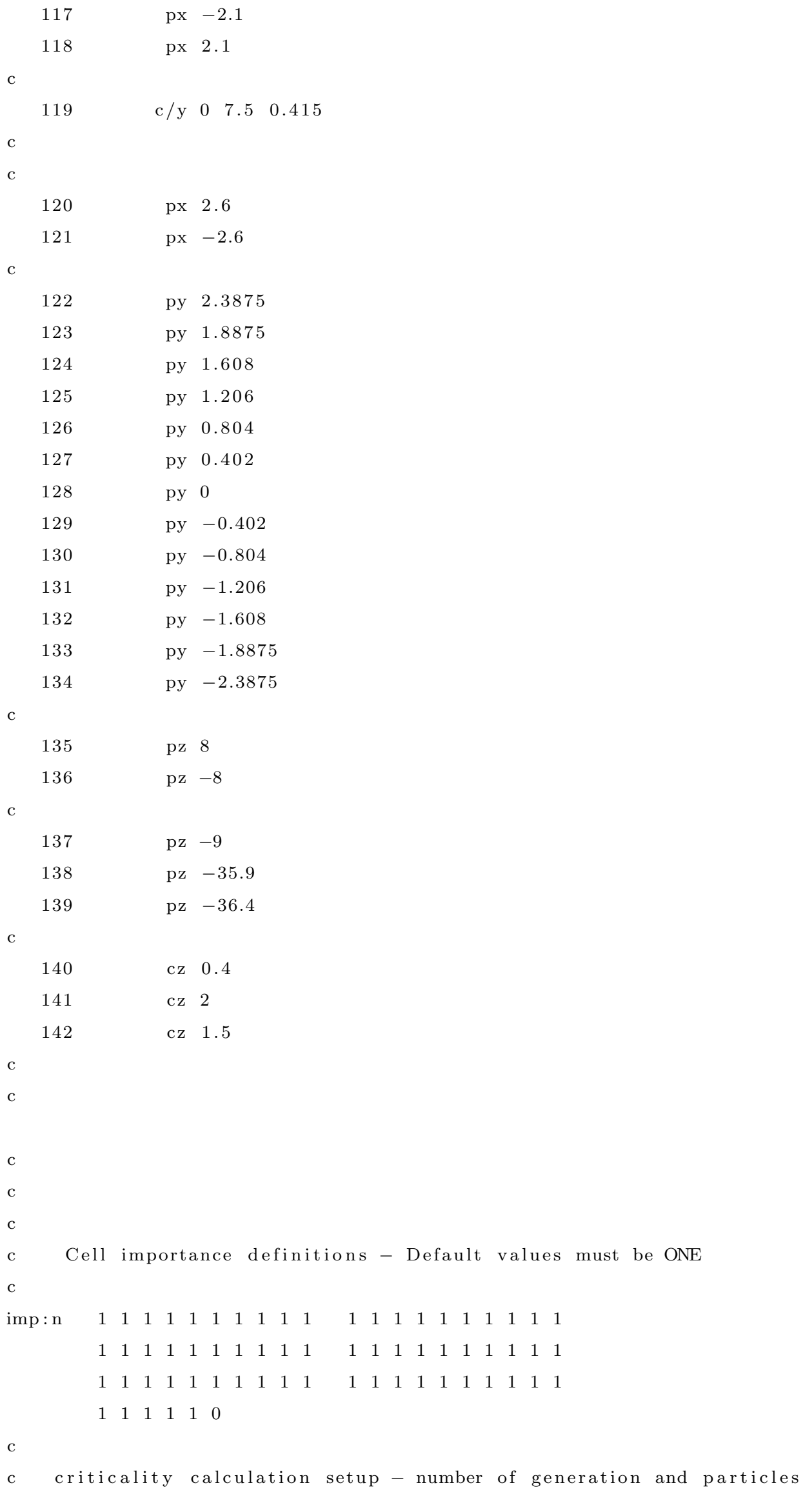




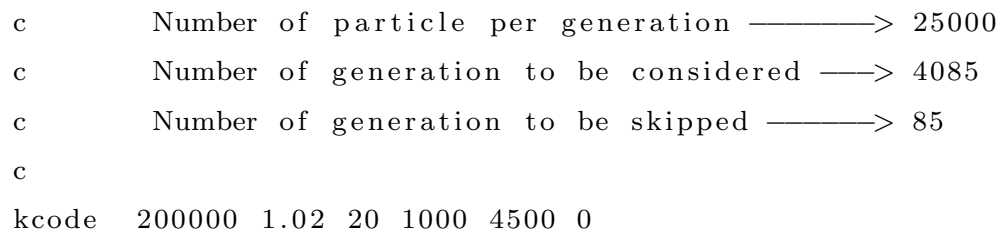

kcode $\quad 200000 \quad 1.02 \quad 20 \quad 1000 \quad 4500 \quad 0$

\begin{tabular}{|c|c|c|c|c|c|c|c|c|c|}
\hline \multirow{2}{*}{$\begin{array}{l}\mathrm{c} \\
\mathrm{ksrc}\end{array}$} & \multicolumn{3}{|c|}{$\gg>>>>>>>>$ Initial } & \multirow{2}{*}{$\begin{array}{r}\text { source } \\
0.0\end{array}$} & \multicolumn{2}{|c|}{ distribution } & $(\mathrm{x}, \mathrm{y}, \mathrm{z})$ & \multicolumn{2}{|c|}{$<<<<<<<<<<<<<<<<~$} \\
\hline & 0.0 & 0.0 & 25.0 & & 0.0 & 1.0 & 0.0 & 0.0 & 2.00 \\
\hline & 0.0 & 0.0 & 3.0 & 0.0 & 0.0 & 10.0 & 0.0 & 0.0 & 4.00 \\
\hline & 0.0 & 0.0 & 5.0 & 0.0 & 0.0 & 6.0 & 0.0 & 0.0 & 20.0 \\
\hline & 0.0 & 0.0 & 7.0 & 0.0 & 0.0 & 8.0 & 0.0 & 0.0 & 9.00 \\
\hline & 0.0 & 0.0 & 22.0 & 0.0 & 0.0 & 30.0 & 0.0 & 0.0 & 28.0 \\
\hline & 0.0 & 0.0 & 32.0 & 0.0 & 0.0 & 35.0 & 0.0 & 0.0 & 38.0 \\
\hline & 0.0 & 0.0 & 40.0 & 0.0 & 0.0 & 42.0 & 0.0 & 0.0 & 45.0 \\
\hline & 0.0 & 0.0 & 47.0 & 0.0 & 0.0 & 50.0 & 0.0 & 0.0 & 52.0 \\
\hline & 12.0 & 0.0 & 25.0 & -12.0 & 0.0 & 25.0 & 12.0 & 12.0 & 25.0 \\
\hline & 12.0 & -12.0 & 25.0 & -12.0 & -12.0 & 25.0 & 18.0 & 18.0 & 25.0 \\
\hline & 18.0 & 0.0 & 25.0 & -18.0 & -18.0 & 25.0 & 21.0 & 0.0 & 25.0 \\
\hline & -21.0 & 0.0 & 25.0 & -21.0 & -21.0 & 25.0 & 21.0 & -21.0 & 25.0 \\
\hline & 15.0 & 0.0 & 25.0 & -15.0 & 0.0 & 25.0 & 12.0 & 15.0 & 25.0 \\
\hline & 15.0 & -15.0 & 25.0 & -15.0 & -15.0 & 25.0 & 15.0 & 15.0 & 25.0 \\
\hline & 18.0 & 0.0 & 25.0 & -15.0 & -18.0 & 25.0 & 21.0 & 0.00 & 25.0 \\
\hline & -21.0 & 0.0 & 25.0 & -21.0 & -21.0 & 25.0 & 21.0 & -21.0 & 25.0 \\
\hline & 12.0 & 0.0 & 15.0 & -12.0 & 0.0 & 15.0 & 12.0 & 12.0 & 15.0 \\
\hline & 12.0 & -12.0 & 15.0 & -12.0 & -12.0 & 15.0 & 18.0 & 18.0 & 15.0 \\
\hline & 18.0 & 0.0 & 15.0 & -18.0 & -18.0 & 15.0 & 21.0 & 0.00 & 15.0 \\
\hline & -21.0 & 0.0 & 15.0 & -21.0 & -21.0 & 15.0 & 21.0 & -21.0 & 15.0 \\
\hline & 15.0 & 0.0 & 15.0 & -15.0 & 0.0 & 15.0 & 12.0 & 15.0 & 15.0 \\
\hline & 15.0 & -15.0 & 15.0 & -15.0 & -15.0 & 15.0 & 15.0 & 15.0 & 15.0 \\
\hline & 18.0 & 0.0 & 15.0 & -15.0 & -18.0 & 15.0 & 21.0 & 0.0 & 15.0 \\
\hline & -21.0 & 0.0 & 15.0 & -21.0 & -21.0 & 15.0 & 21.0 & -21.0 & 15.0 \\
\hline & 12.0 & 0.0 & 35.0 & -12.0 & 0.0 & 35.0 & 12.0 & 12.0 & 35.0 \\
\hline & 12.0 & -12.0 & 35.0 & -12.0 & -12.0 & 35.0 & 18.0 & 18.0 & 35.0 \\
\hline & 18.0 & 0.0 & 35.0 & -18.0 & -18.0 & 35.0 & 21.0 & 0.00 & 35.0 \\
\hline & -21.0 & 0.0 & 35.0 & -21.0 & -21.0 & 35.0 & 21.0 & -21.0 & 35.0 \\
\hline & 15.0 & 0.0 & 35.0 & -15.0 & 0.0 & 35.0 & 12.0 & 15.0 & 35.0 \\
\hline & 15.0 & -15.0 & 35.0 & -15.0 & -15.0 & 35.0 & 15.0 & 15.0 & 35.0 \\
\hline & 18.0 & 0.0 & 35.0 & -15.0 & -18.0 & 35.0 & 21.0 & 0.00 & 35.0 \\
\hline & -21.0 & 0.0 & 35.0 & -21.0 & -21.0 & 35.0 & 21.0 & -21.0 & 35.0 \\
\hline & 12.0 & 0.0 & 45.0 & -12.0 & 0.0 & 45.0 & 12.0 & 12.0 & 45.0 \\
\hline & 12.0 & -12.0 & 45.0 & -12.0 & -12.0 & 45.0 & 18.0 & 18.0 & 45.0 \\
\hline & 18.0 & 0.0 & 45.0 & -18.0 & -18.0 & 45.0 & 21.0 & 0.00 & 45.0 \\
\hline & -21.0 & 0.0 & 45.0 & -21.0 & -21.0 & 45.0 & 21.0 & -21.0 & 45.0 \\
\hline & 15.0 & 0.0 & 45.0 & -15.0 & 0.0 & 45.0 & 12.0 & 15.0 & 45.0 \\
\hline & 15.0 & -15.0 & 45.0 & -15.0 & -15.0 & 45.0 & 15.0 & 15.0 & 45.0 \\
\hline & 18.0 & 0.0 & 45.0 & -15.0 & -18.0 & 45.0 & 21.0 & 0.00 & 45.0 \\
\hline & -21.0 & 0.0 & 45.0 & -21.0 & -21.0 & 45.0 & 21.0 & -21.0 & 45.0 \\
\hline & 12.0 & 0.0 & 51.0 & -12.0 & 0.0 & 51.0 & 12.0 & 12.0 & 51.0 \\
\hline
\end{tabular}




$\begin{array}{rccrrrrrr}12.0 & -12.0 & 51.0 & -12.0 & -12.0 & 51.0 & 18.0 & 18.0 & 51.0 \\ 18.0 & 0.0 & 51.0 & -18.0 & -18.0 & 51.0 & 21.0 & 0.00 & 51.0 \\ -21.0 & 0.0 & 51.0 & -21.0 & -21.0 & 51.0 & 21.0 & -21.0 & 51.0 \\ 15.0 & 0.0 & 51.0 & -15.0 & 0.0 & 51.0 & 12.0 & 15.0 & 51.0 \\ 15.0 & -15.0 & 51.0 & -15.0 & -15.0 & 51.0 & 15.0 & 15.0 & 51.0 \\ 18.0 & 0.0 & 51.0 & -15.0 & -18.0 & 51.0 & 21.0 & 0.00 & 51.0 \\ -21.0 & 0.0 & 51.0 & -21.0 & -21.0 & 51.0 & 21.0 & -21.0 & 51.0\end{array}$

$\mathrm{c}$

material definitions

$\longrightarrow$ NNNNN.60 c nuclide NNNNN from ENDF/B-VI cross section library

$\longrightarrow$ NNNNN.50 c nuclide NNNNN from ENDF/B-V cross section library

$\longrightarrow$ nuclide concentration in atom/barn. $\mathrm{cm}$

$\mathrm{m} 1 \Rightarrow \mathrm{UO} 2$ pellet $(\mathrm{U} 235, \mathrm{U} 238$ and $\mathrm{O} 16)$

$\mathrm{m} 2 \Rightarrow \operatorname{gap} \quad(\mathrm{O} 16)$

$\mathrm{m} 3 \Rightarrow \mathrm{SS} 304$ clad ( Fe, Ni, Cr, Mn, Si, P, C, S, Co and Mo)

$\mathrm{m} 4 \Rightarrow \mathrm{H} 2 \mathrm{O}(\mathrm{H}$ and $\mathrm{O})$

$\mathrm{m} 5 \Rightarrow$ Alumina $(\mathrm{Al} \mathrm{O})$

$\mathrm{m} 6 \Rightarrow \mathrm{AG}-\mathrm{IN}-\mathrm{CD}$ Control ROD ( $\mathrm{Ag}, \mathrm{In}$ and $\mathrm{Cd}$ )

$\mathrm{m} 7 \Rightarrow$ SS304 Spacer Tube ( Mn, Si, Ni, Cr, Fe, C, P and Co)

$\mathrm{m} 8 \Rightarrow$ baffle (not used)

$\mathrm{m} 9 \Rightarrow$ SS304 Guide Tube ( Fe, Ni, Cr, Mn, Si, P, C, S, Co and Mo)

$\mathrm{m} 10 \Rightarrow \mathrm{SS} 304$ Bottom Grid Plate ( Fe, Ni, Cr, Mn, Si, P, C and S)

$\mathrm{m} 11 \Rightarrow \mathrm{SS}$ control Rods

UO2 - pellet region

$92235.70 \mathrm{c} \quad 9.99240 \mathrm{e}-04 \quad 92238.70 \mathrm{c} \quad 2.1694 \mathrm{e}-02 \quad 8016.70 \mathrm{c} \quad 4.5489 \mathrm{e}-02$

$92234.70 \mathrm{c} \quad 7.84620 \mathrm{e}-06$

Void (gap)

$8016.70 \mathrm{c} \quad 0.0001$

$\mathrm{SS} 304-\mathrm{clad}$

$26054.70 \mathrm{c} \quad 3.57366 \mathrm{e}-03 \quad 26056.70 \mathrm{c} \quad 5.40491 \mathrm{e}-02 \quad 26057.70 \mathrm{c} \quad 1.22693 \mathrm{e}-03$

$26058.70 \mathrm{c} \quad 1.59256 \mathrm{e}-04$

$24050.70 \mathrm{c} \quad 7.61902 \mathrm{e}-04 \quad 24052.70 \mathrm{c} \quad 1.41123 \mathrm{e}-02 \quad 24053.70 \mathrm{c} \quad 1.56980 \mathrm{e}-03$

$24054.70 \mathrm{c} \quad 3.82755 \mathrm{e}-04$

$28058.70 \mathrm{c} \quad 5.62942 \mathrm{e}-03 \quad 28060.70 \mathrm{c} \quad 2.09590 \mathrm{e}-03 \quad 28061.70 \mathrm{c} \quad 8.96301 \mathrm{e}-05$

$28062.70 \mathrm{c} \quad 2.80805 \mathrm{e}-04 \quad 28064.70 \mathrm{c} \quad 6.96915 \mathrm{e}-05$

$25055.70 \mathrm{c} \quad 1.46450 \mathrm{e}-03 \quad 14028.70 \mathrm{c} \quad 6.26555 \mathrm{e}-04 \quad 14029.70 \mathrm{c} \quad 3.17252 \mathrm{e}-05$

$14030.70 \mathrm{c} \quad 2.10595 \mathrm{e}-05 \quad 15031.70 \mathrm{c} \quad 4.00400 \mathrm{e}-05 \quad 6000.70 \mathrm{c} \quad 1.12390 \mathrm{e}-04$

$16032.70 \mathrm{c} \quad 1.48393 \mathrm{e}-05 \quad 16033.70 \mathrm{c} \quad 1.17128 \mathrm{e}-07 \quad 16034.70 \mathrm{c} \quad 6.57476 \mathrm{e}-07$

$16036.70 \mathrm{c} \quad 3.12340 \mathrm{E}-09 \quad 27059.70 \mathrm{c} \quad 1.74020 \mathrm{e}-04 \quad 42092.70 \mathrm{c} \quad 1.25428 \mathrm{e}-05$

$42094.70 \mathrm{c} \quad 7.81810 \mathrm{e}-06 \quad 42095.70 \mathrm{c} \quad 1.34556 \mathrm{e}-05 \quad 42096.70 \mathrm{c} \quad 1.40979 \mathrm{e}-05$

$42097.70 \mathrm{c} \quad 8.07166 \mathrm{e}-06 \quad 42098.70 \mathrm{c} \quad 2.03947 \mathrm{e}-05 \quad 42100.70 \mathrm{c} \quad 8.13928 \mathrm{e}-06$

$\mathrm{H} 2 \mathrm{O}$ - water

$1001.70 \mathrm{c} \quad 6.67360 \mathrm{e}-02 \quad 8016.70 \mathrm{c} \quad 3.33680 \mathrm{e}-02$

lwtr. $01 \mathrm{t}$

Al2O3 - Alumina 


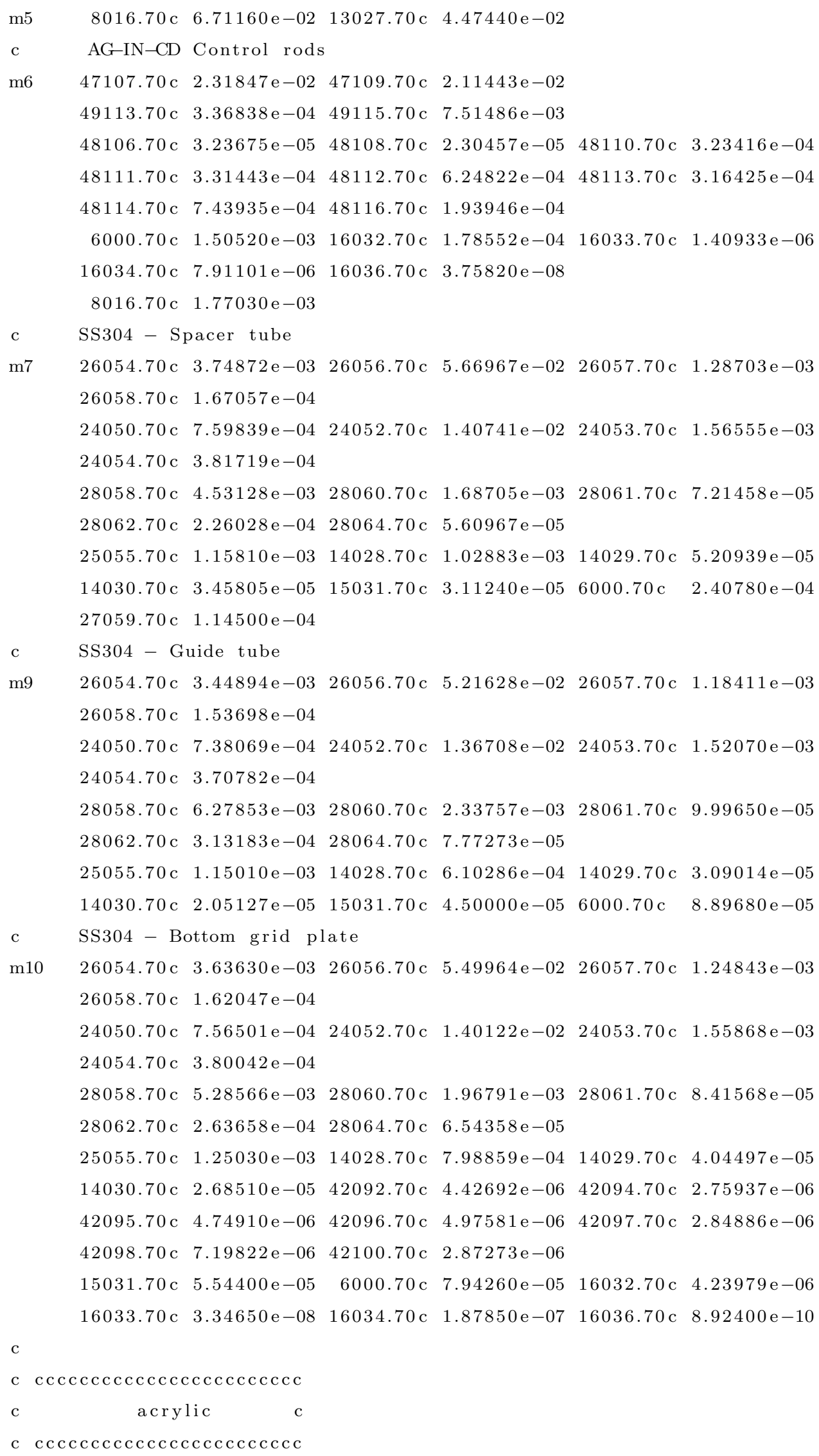




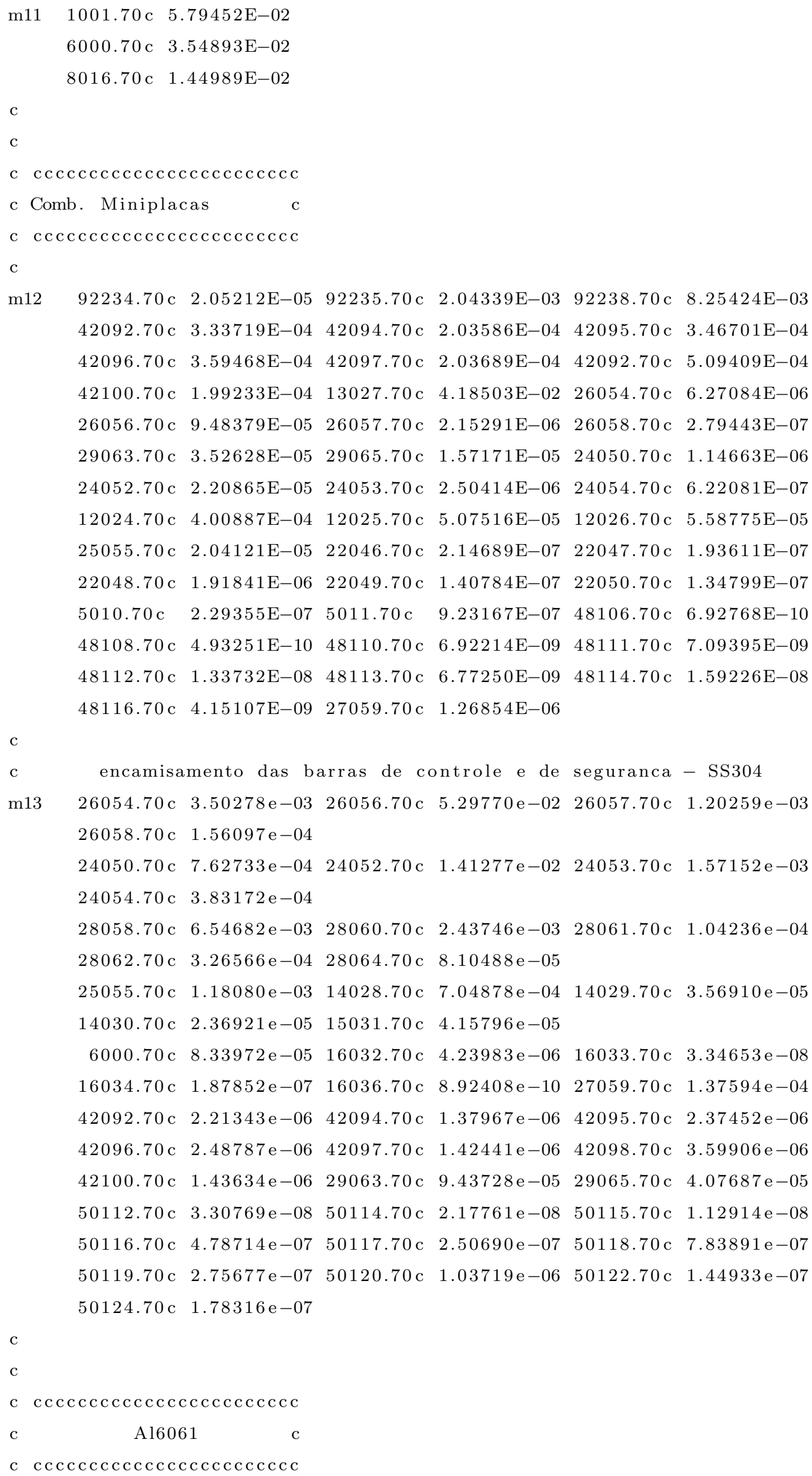




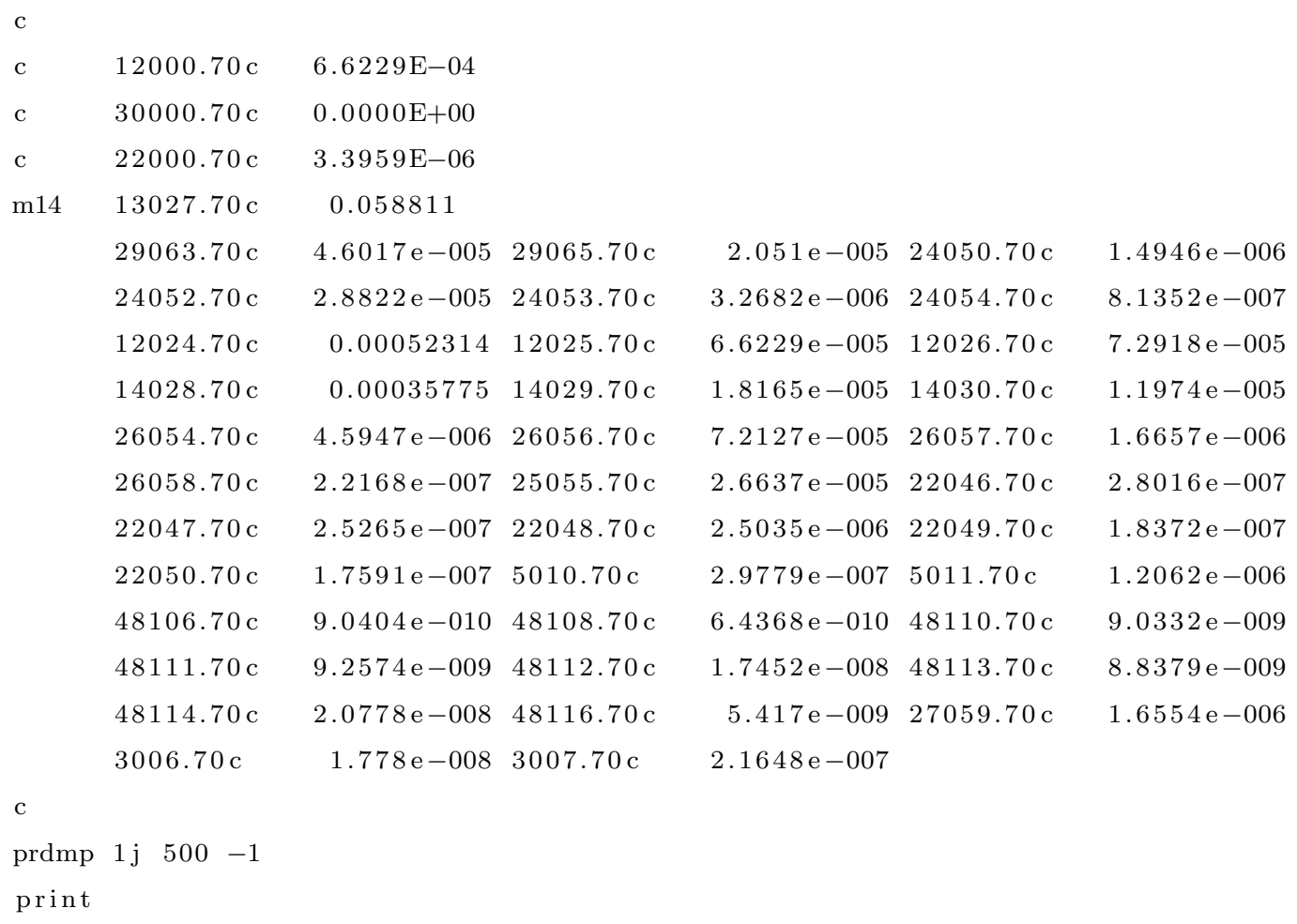


$\mathrm{D}$

\section{Dados De Entrada Do CITATION}

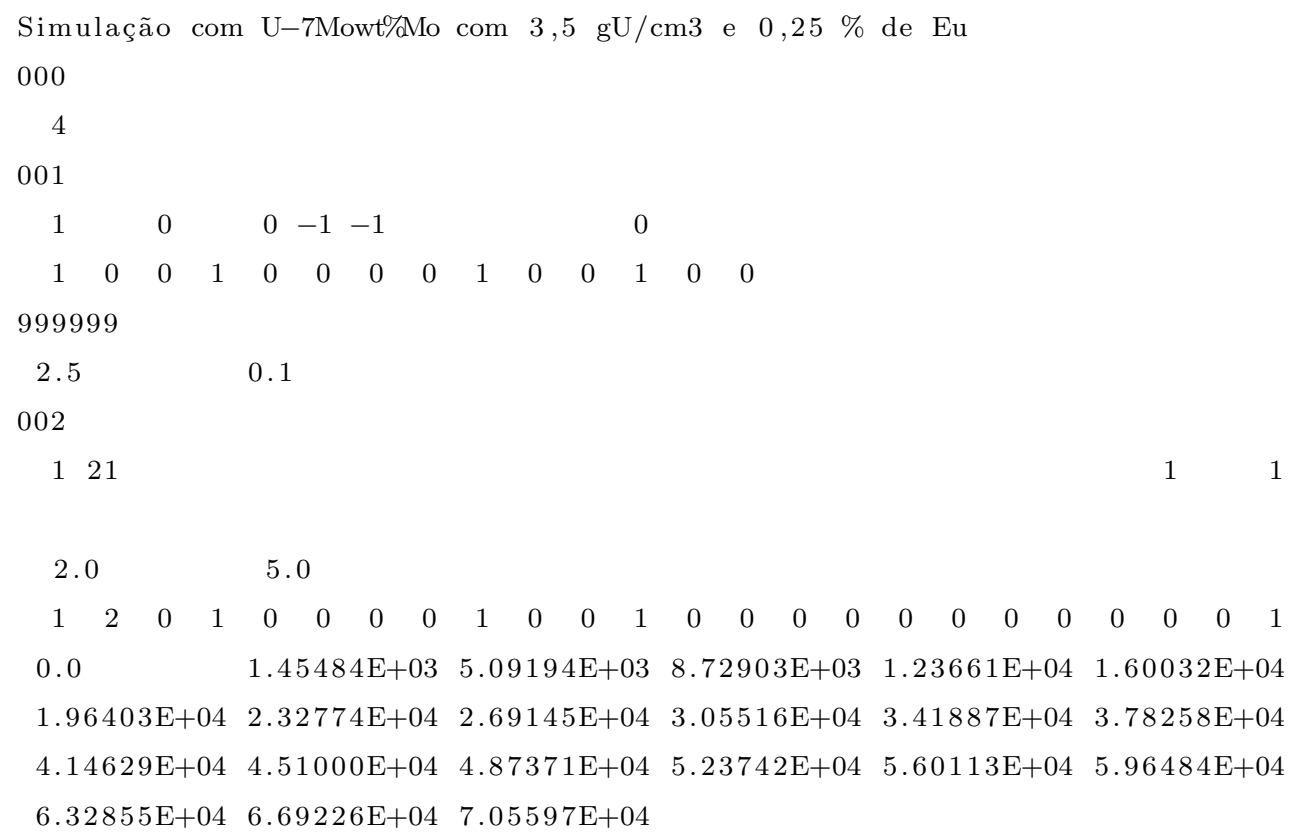




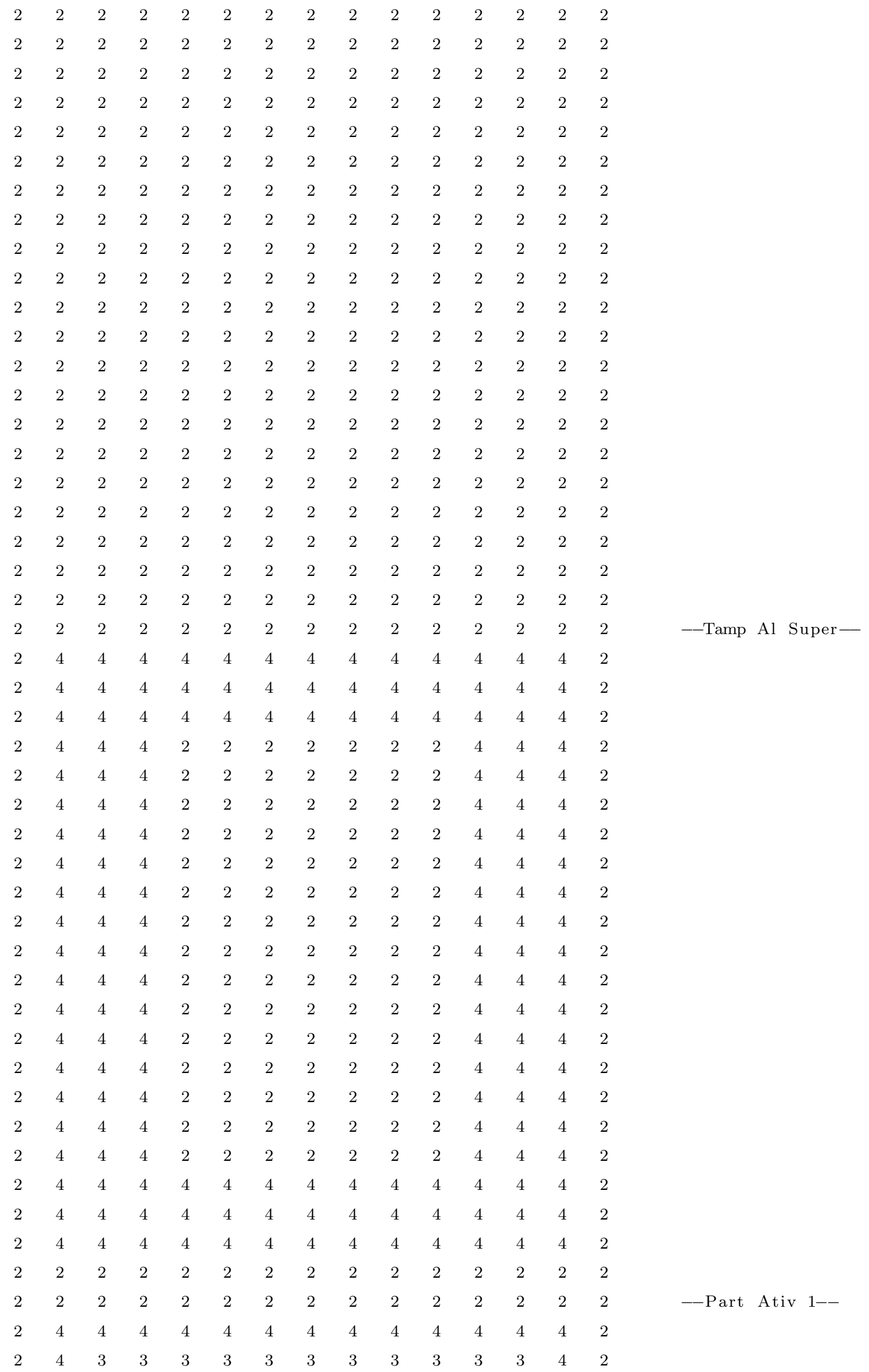




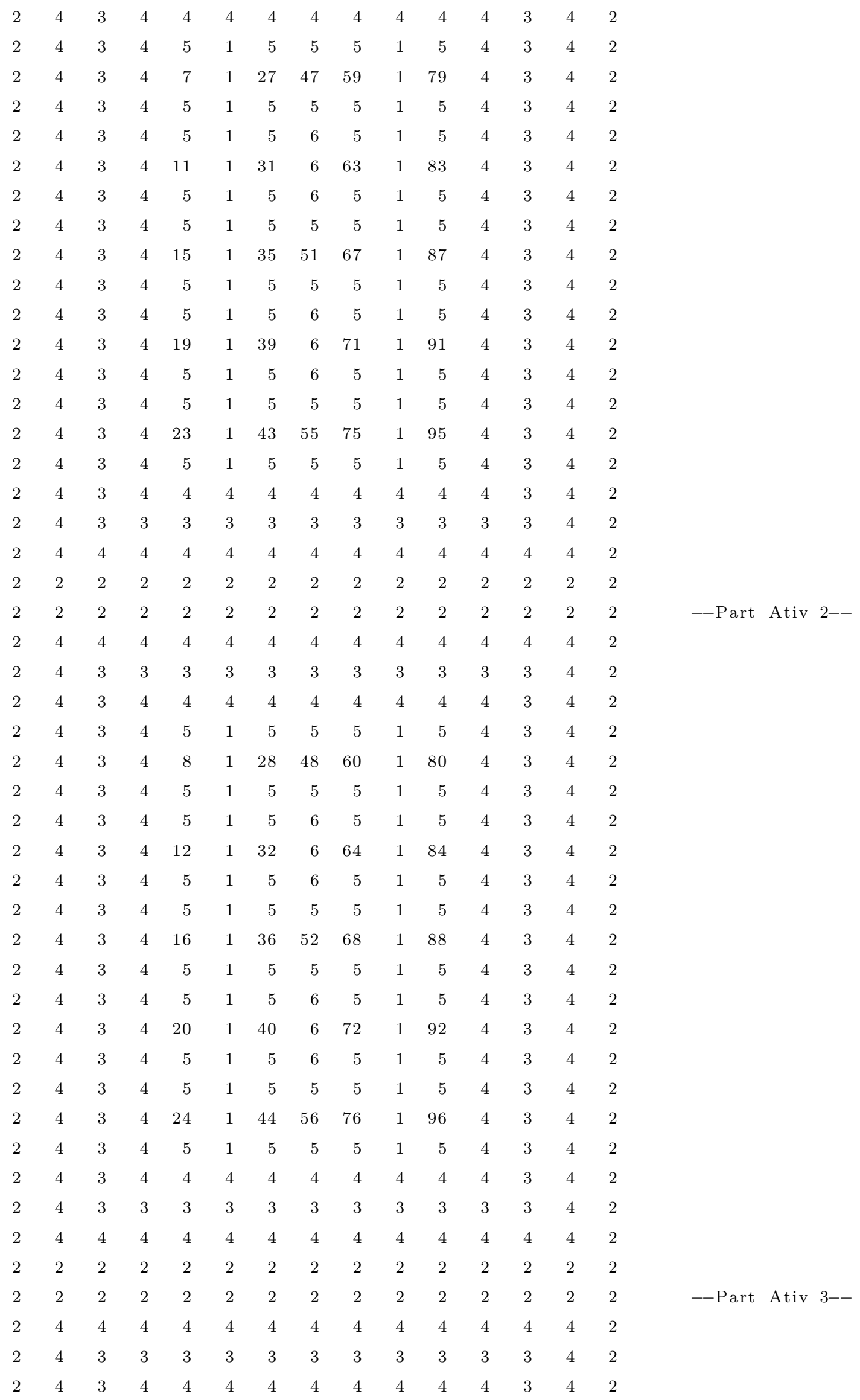




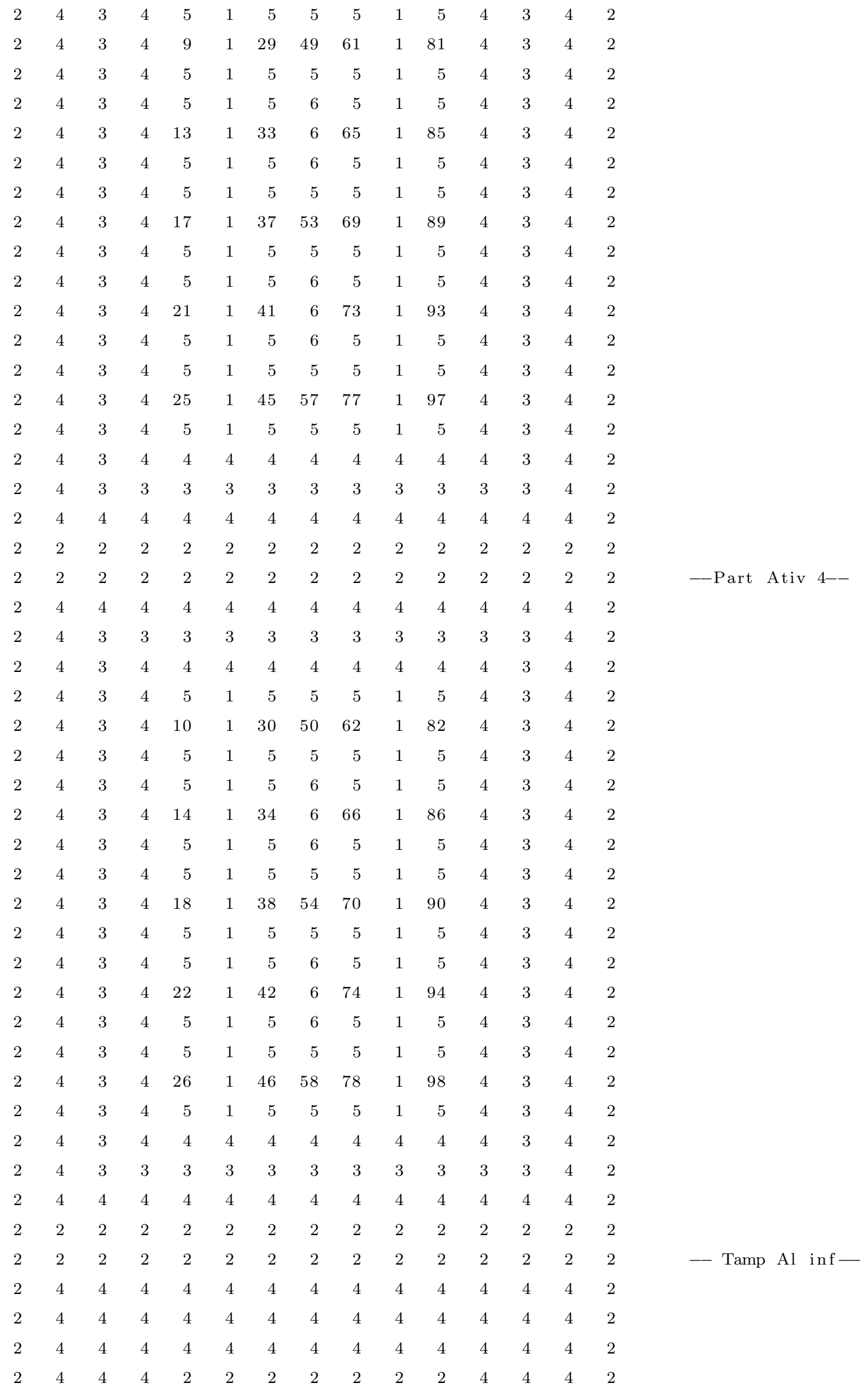




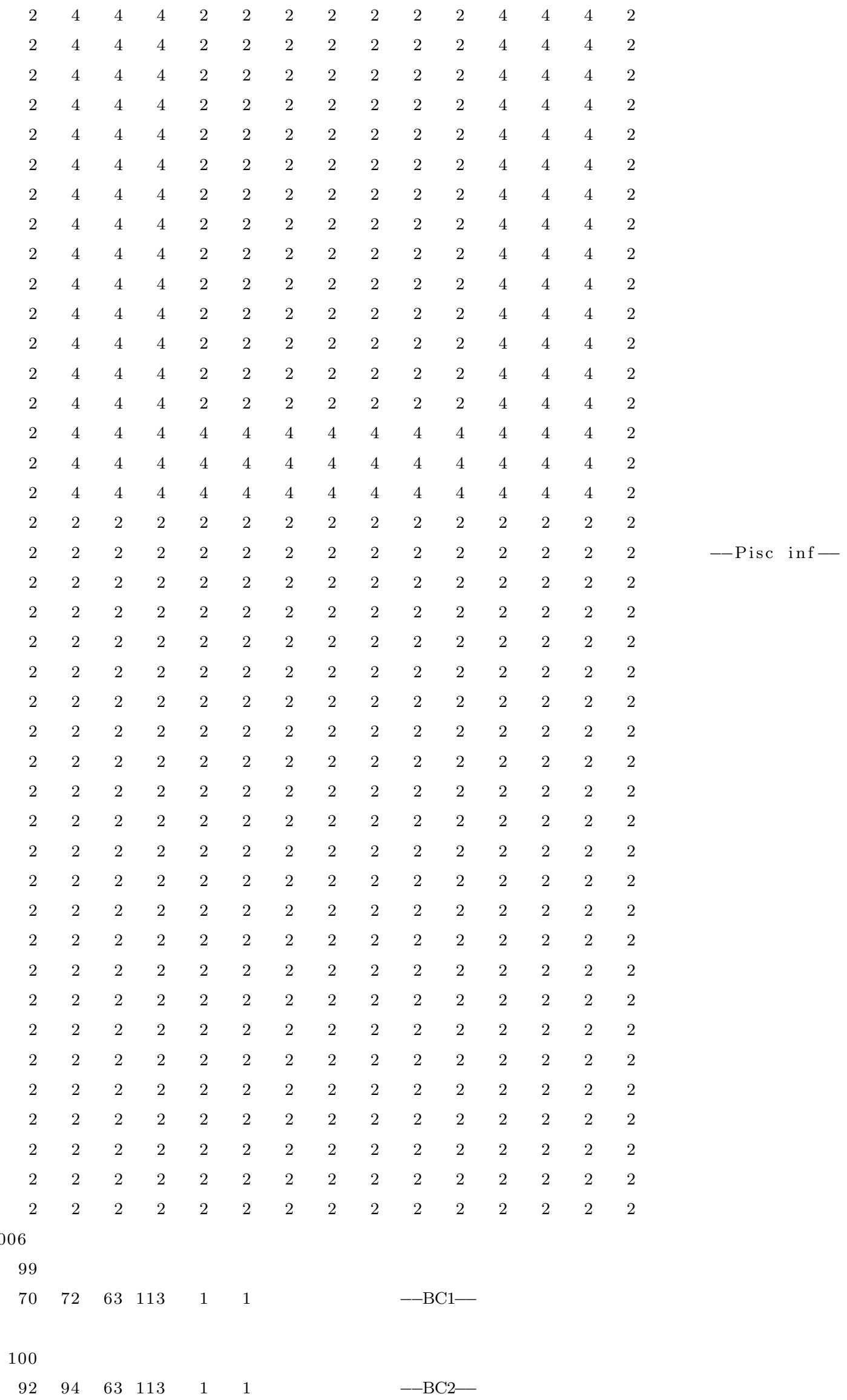




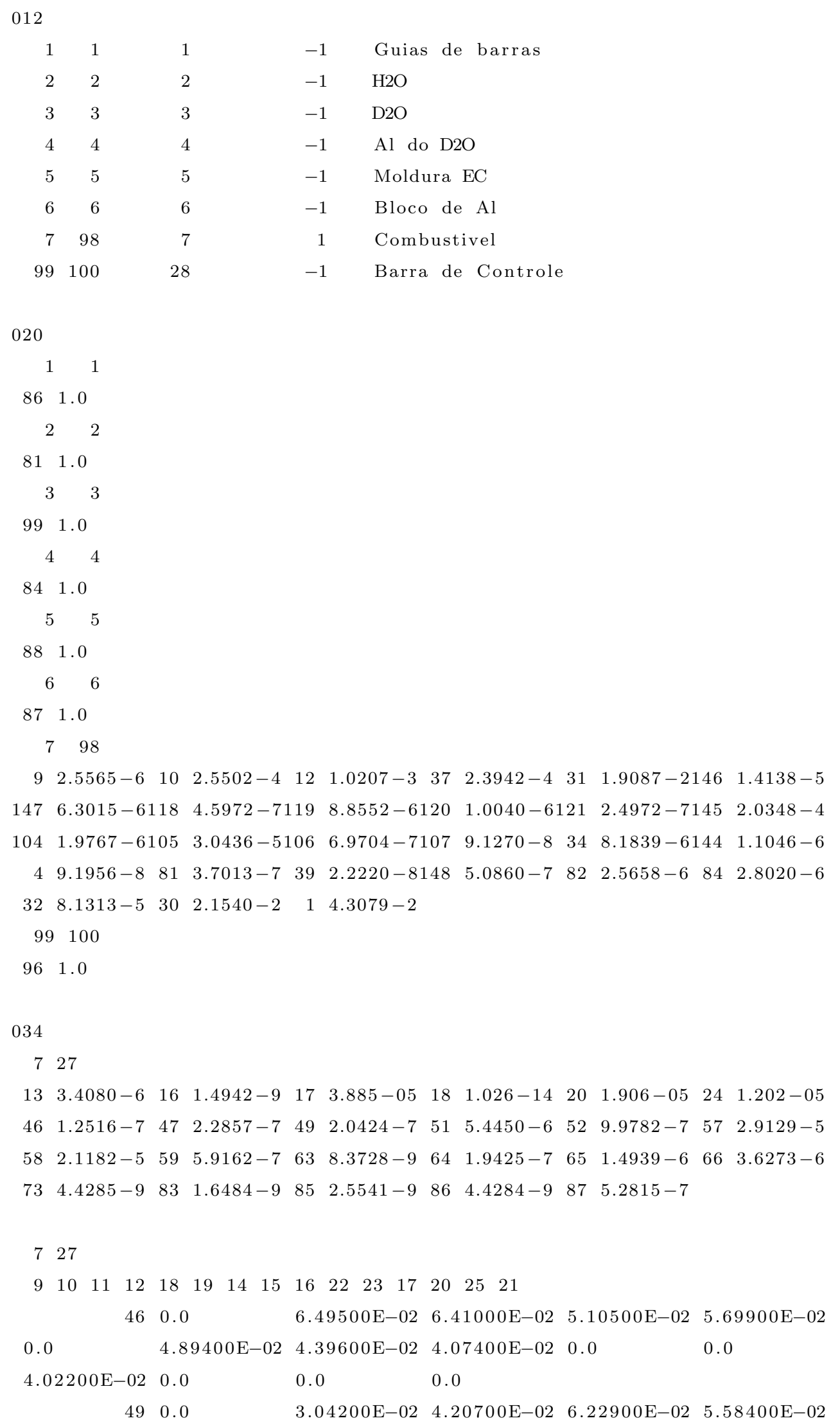




\begin{tabular}{|c|c|c|c|c|c|}
\hline 0.0 & $6.95000 \mathrm{E}-02$ & $6.71300 \mathrm{E}-02$ & $6.15100 \mathrm{E}-02$ & 0.0 & 0.0 \\
\hline $5.88300 \mathrm{E}-02$ & 0.0 & 0.0 & 0.0 & & \\
\hline 51 & 0.0 & $9.67000 \mathrm{E}-03$ & $2.47000 \mathrm{E}-02$ & $3.97500 \mathrm{E}-02$ & $3.17900 \mathrm{E}-02$ \\
\hline 0.0 & $5.40500 \mathrm{E}-02$ & $5.54900 \mathrm{E}-02$ & $6.14600 \mathrm{E}-02$ & 0.0 & 0.0 \\
\hline 0.0 & 0.0 & 0.0 & 0.0 & & \\
\hline 52 & 0.0 & $2.88300 \mathrm{E}-02$ & $3.03400 \mathrm{E}-02$ & $2.59400 \mathrm{E}-02$ & $3.69600 \mathrm{E}-02$ \\
\hline 0.0 & $3.86900 \mathrm{E}-02$ & $3.54400 \mathrm{E}-02$ & $2.84300 \mathrm{E}-02$ & 0.0 & 0.0 \\
\hline $2.75800 \mathrm{E}-02$ & 0.0 & 0.0 & 0.0 & & \\
\hline 57 & 0.0 & $6.29700 \mathrm{E}-02$ & $5.63100 \mathrm{E}-02$ & $6.83500 \mathrm{E}-02$ & $6.66000 \mathrm{E}-02$ \\
\hline 0.0 & $6.44900 \mathrm{E}-02$ & $6.74800 \mathrm{E}-02$ & $7.07000 \mathrm{E}-02$ & 0.0 & 0.0 \\
\hline $6.90000 \mathrm{E}-02$ & 0.0 & 0.0 & 0.0 & & \\
\hline 58 & 0.0 & $2.42000 \mathrm{E}-03$ & $1.58000 \mathrm{E}-03$ & $2.80000 \mathrm{E}-04$ & $8.83000 \mathrm{E}-03$ \\
\hline 0.0 & $1.15200 \mathrm{E}-02$ & $6.98000 \mathrm{E}-03$ & $2.31000 \mathrm{E}-03$ & 0.0 & 0.0 \\
\hline $2.64000 \mathrm{E}-03$ & 0.0 & 0.0 & 0.0 & & \\
\hline 59 & 0.0 & $5.93700 \mathrm{E}-02$ & $6.08500 \mathrm{E}-02$ & $4.55800 \mathrm{E}-02$ & $4.70300 \mathrm{E}-02$ \\
\hline 0.0 & $4.42800 \mathrm{E}-02$ & $4.72000 \mathrm{E}-02$ & $4.70400 \mathrm{E}-02$ & 0.0 & 0.0 \\
\hline $4.67800 \mathrm{E}-02$ & 0.0 & 0.0 & 0.0 & & \\
\hline 63 & 0.0 & $2.09611 \mathrm{E}-02$ & $2.34100 \mathrm{E}-02$ & $2.53100 \mathrm{E}-02$ & $2.21100 \mathrm{E}-02$ \\
\hline 0.0 & $2.04300 \mathrm{E}-02$ & $2.23300 \mathrm{E}-02$ & $2.36800 \mathrm{E}-02$ & 0.0 & 0.0 \\
\hline $2.41900 \mathrm{E}-02$ & 0.0 & 0.0 & 0.0 & & \\
\hline 66 & 0.0 & $1.06700 \mathrm{E}-02$ & $1.36900 \mathrm{E}-02$ & $1.61000 \mathrm{E}-02$ & $1.27500 \mathrm{E}-02$ \\
\hline 0.0 & $1.23900 \mathrm{E}-02$ & $1.36900 \mathrm{E}-02$ & $1.52400 \mathrm{E}-02$ & 0.0 & 0.0 \\
\hline $1.61500 \mathrm{E}-02$ & 0.0 & 0.0 & 0.0 & & \\
\hline 73 & 0.0 & $3.20480 \mathrm{E}-04$ & $5.54000 \mathrm{E}-03$ & $1.32800 \mathrm{E}-03$ & $7.15000 \mathrm{E}-02$ \\
\hline 0.0 & $1.65480 \mathrm{E}-03$ & $1.48600 \mathrm{E}-02$ & $2.41750 \mathrm{e}-03$ & 0.0 & 0.0 \\
\hline $2.20700 \mathrm{E}-02$ & 0.0 & 0.0 & 0.0 & & \\
\hline 75 & 1.0 & 1.0 & 1.0 & 1.0 & 1.0 \\
\hline 1.0 & 1.0 & 1.0 & 1.0 & 1.0 & 1.0 \\
\hline 1.0 & 1.0 & 1.0 & 1.0 & & \\
\hline
\end{tabular}

036

$\begin{array}{lll}7 & 27 & 16\end{array}$

$005+009+010+011-018+019$

$008+012-013+014+015+016+017-020+021$

$010+212-213+214+215-216+022+5231150-220+221$

$009+212-213+214+215-216+222-5248850+025$

$003-046-047+048$

$002-049+050$

$001+051$

$002-052+053$

$002-057+058$

$002-059+060$

$005+063+5644700-066+067$

$005+063+5655300-066+067$

$002-063+061$

$002-073+074$ 
$001+075$

$006+082+083+084+085+086+087$

999 


\section{Referências Bibliográficas}

/1/ WAUGH R. C. The Reaction and Growth of Uranium Dioxide-Aluminium Fuel Plates and Compacts, Oak Ridge, Tenn, Oak Ridge National Laboratory, 1959.(ORNL2701).

/2/ TISSIER, A. CERCA: Working Towards Better LEU Fuel Production, Nuclear Engineering International 36 (449): 50-1, 1991.

/3/ NAZARÉ S. Low Enrichment Dispersion Fuel For Research and Test Reactors,J. Nucl. Mater., vol. 121, 14-24 p., 1984.

/4/ SNELGROVE J. L. Qualification Status Of LEU Fuel, In: ARGONNE NATIONAL LABORATORY. Reduced Enrichment For Research Reactor: International Meeting on Held in Buenos Aires, Argentina, Sep. 28, Oct. 1, 1-18p., 1987.

/5/ SIMÕES A. V. Desempenho Sob Irradiação de Combustíveis a Dispersão de MTR, Dissertação de Mestrado., São Paulo: IPEN-USP., 1993.

/6/ OlIVEIRA F. B. V. Desenvolvimento De Um Combustivel De Alta Densidade A Base Da Liga Urânio -Molibdênio Com Alta Compatibilidade Em Altas Temperaturas, São Paulo: IPEN-USP, Tese de Doutorado, 328 p., 2008.

/7/ DURAZZO, M. et al. Fabrication of Powder from Ductile U-Mo Alloys for Use as Nuclear Dispersion. Materials Science Forum (Online), v. 727-728, p. 362-367, 
2012.

/8/ LOPES D.A. et al. PROCESSING WINDOW DESIGN FOR U ALLOYS, European Research Reactor - RRFM, Prague, 18 - 22 March, pp. $46-51$ (2012).

/9/ Cross Section Plotter. Disponível em: <http://atom.kaeri.re.kr>, Acessado em: 2015 .

/10/ ALMEIDA C. T. S. Desempenho Sob Irradiação De Elementos Combustíveis Do Tipo U-Mo, São Paulo: IPEN-USP, Dissertação de Mestrado, 195 p., 2005.

/11/ RYU H. J. et al. Interdiffusion In The Si-Rich Layer Of U-Mo/Al-Si Fuel, In 32nd International Meeting On Reduced Enrichment For Research And Test Reactors, Lisbon, Portugal, October 14-20, 2010.

/12/ RYU H, J. et al. The Effect Of Si-Rich Layer Coating On U-Mo Vs. Al Interdiffusion., Nuclear Engineering And Technology, vol. 43, 8 p., 2011.

/13/ GLAGOLENKO I. et al. Technical Report Irradiation Testing Of The RERTR Fuel Miniplates With Burnable Absorbers In The Advanced Test Reactor, Idaho National Laboratory (INL), 2010.

/14/ Storr G. J. Australia's new Research Reactor - OPAL, IGORR, Beijing, China, 2009.

/15/ The Jules Horowitz Reactor (JHR). General Description. Disponível em: <http://www-cadarache.cea.fr/rjh/general-description.html>. Acessado em: 12 January 2015 .

/16/ Barhein J, Rhotenstein W. and Taviv E. The HAMMER Code System Technion, Israel Institute of Technology, Haifa, Israel, NP-565, 1978. 
/17/ Greene N. M. et al. AMPX-II A Modular Code System for Generation Coupled Multigroup Neutron-Gamma Libraries from ENDF/B, ORNL-TM-3706, 1976.

/18/ England T. R., Wilson W. B. and Stamatelato. Fission Product Data for Thermal Reactors Part 2: Users Manual for EPRI-CINDER Code and Data, Los Alamos Scientific Laboratory of The Univerity of California, Los Alamos, New Mexico, December, 1976.

/19/ ANTUNES A. Um Estudo da Física de Sistemas Multiplicativos Subcríticos Acionados por Fontes e a Utilização de Códigos Determinísticos no Cálculo Destes Sistemas, São Paulo: IPEN-USP, Dissertação de Mestrado, 106 p., 2008.

/20/ Fowler T. B., Vondy D. R., Cunningham G. W. Nuclear Reactor Core Analysis Code: Citation, Oak Ride National Laboratory, Oak Ridge, Tennessee, USA, Rev. 2, July 1971. ORNL-TM- 2496.

/21/ Leppänen J. Serpent - A Continuous - Energy Monte Carlo Reactor Physics Burnup Calculation Code - User's Manual, March 6, 2013. Disponível em: $<$ http://montecarlo.vtt.fi/>, Acessado em: 03/2015.

/22/ X-5 Monte Carlo Team. MCNP - A General Monte Carlo N-Particle Transport Code, Version 5 Volume II: User's Guide, version 1.60, Los Alamos National Laboratory, Los Alamos, April 24, 2003.

/23/ RYU H. J., KIM Y. S., PARK J. M., CHAE H. T. and KIM C. K. Performance Evaluation of U-Mo/Al Dispersion Fuel By Considering A Fuel-Matrix Interaction, Nuclear Engineeringand Technology, vol. 40, 409-418 p., 2008.

/24/ Olivares L., Marin J., Barrera. M., Gutierrez C., and Lisboa, J. Dispersion Fuel Miniplates Based on Umo Powder Produced by Centrifugal Atomization, RERTR, 
Warsaw, Poland, October 14-17, 2012.

/25/ Champion G., Allenou J., Pasturel M. and Tougait O. A New Method of Produncing U(Mo) Particles for Material Testing Reactors (MTR), RRFM, Czech Republic, Prague, March 18-22, 2012.

/26/ Lamarsh J. R. Introduction to Nuclear Engineering, Polytechnic Institute of New York, $2^{\text {nd }}$ Edition, 1983.

/27/ Santos A. dos. et al. Isothermal Experiment Of The IPEN/MB-01 Reactor - Experimental Determination Of The Effective Delayed Neutron Parameters and Reactivities Of The IPEN/MB-01 Reactor, NEA/NSC/DOC/(2006)1, Light Water Moderated Reactor - LWR. IPEN(MB01)-LWR-RESR-001-CRIT-COEF-KIN. 